\title{
System-directed pairing of protein amino acids. Part I
}

\author{
Miloje M. Rakočević \\ University of Niš, Faculty of Sciences and Mathematics, Department of Chemistry, \\ Višegradska 33, 18000 Niš, Serbia
}

\begin{abstract}
The idea of this review paper is as follows. If it can be shown (and it can!) that the pairing of protein amino acids is system-directed (determined), then the hypothesis of a prebiotically determined genetic code (Rakočević, 2004a) gets its full meaning. The hypothesis is supported by the fact that all these pairings come to the fore primarily through classes and subclasses of amino acid molecules. What is, however, unexpected and even unbelievable from the point of view of current science is the fact that the quantities, i.e. number of atoms (in a direct or indirect relation to the number of nucleons), in these classes and subclasses, are determined by Gauss' number $51(51=3 \times 17)$, or Gauss' sequence: $51 \pm 10,51 \pm 20,51 \pm 30,51 \pm 40$ and $51 \pm$ 50; also by Dürer's number $34(34=2 \times 17)$, even more either by its double value, 68; or by Dürer's sequences: $34 \pm 10,34 \pm 5$ and $68 \pm 10,68 \pm 5$. Since the hypothesis refers to constituents - amino acids and nucleotides - it follows that in terms of the type and number of constituents, it makes no sense to talk about evolution of GC, but only about its generating. [Generated, not degenerated code!] It makes sense to talk about the evolution of the genetic code only from the "moment" when the resulting peptide and nucleotide chains enter into chemical reactions and interactions; although even then it can be said that this is just a second phase of GC generation.
\end{abstract}

Key words. Natural code, genetic code, chemical code, protein amino acids, nucleotides, genetic code Table, amino acids pairing.

1. Introduction. Why am I writing a paper about amino acid pairing within the genetic code? I try to give an argument once again for my hypothesis (Rakočević, 2004a, Section 7.1 , p. 231) ${ }^{1}$ that the genetic code (GC) was still prebiotic complete (Box 1); complete from the aspect of possessing its amino acid and nucleotide constituents: 20 AAs and 4 Py-Pu bases ${ }^{2}$ But where did I get the idea that pairing could be an argument? From a set of 20 amino acids, it is possible to get 190 pairs (a combination of the second class from a set of 20 elements, without repetition), so mostly a priori they give up the "futile job".

\footnotetext{
${ }^{1}$ In the following citations instead of "Rakočević", I will write abbreviated "MMR". I would also like to mention that this is the third version of the paper. The first two are posted on my site www.rakocevcode.rsm, both incomplete but sufficient to set out the basic essence. [The first is more in Serbian, and the second is combined, in Serbian and English.]

${ }^{2}$ We mean here the "Standard Genetic Code". All other "genetic codes" will be considered "deviant", as they are most often called in the literature (Budisa et al., 1999; Knight et al., 2001; Weaver, 2012), and as I explained in a previous paper (MMR, 2018a, Box 2); more precisely, we will consider that they represent only a "degree of freedom" in deviation from the standard one.
} 
However, it makes sense to search for the best 10 pairs from a chemical point of view, in the sense that every two in a pair most be similar, or near to be similar. ${ }^{3}$

2. Elaboration of amino acid pairing. If such a thing were possible, to find the best 10 pairings, that would be enough to question the views that the molecular evolution of GC continued even after the origin of life. Supposedly so, until GC became "frozen" at the level of 20 AAs and 4 Py-Pu bases, which is the prevailing opinion in current science (Box 2). We would have an "argument more" if it could be shown that this pairing takes place within strictly defined chemical system-arrangements (Box 3); such that in addition to being chemical, they are also formal organizational patterns. ${ }^{4}$

These are system-arrangements that follow from the chemical properties of AAs (MMR, 2018a,b; 2019a), but at the same time follow from the Periodic System of Numbers (PSN), given in the decimal number system (Figures 1-8 and their derivatives; Tables 1-5); Surveys 1-3 in relation to Surveys 4 to 10)..$^{5}$ These are: 1 . Orthogonal (OS), 2. Diagonal (DS), and 3. Angular system-arrangement (AS). ${ }^{6}$ What is surprising, however, is the fact that the key determinants of all three of these systems ultimately are the Gauss' number $(51)^{7}$ and its "distributions": $51 \pm 10,51 \pm 20,51 \pm 30,51 \pm 40,51 \pm 50$; and Dürer's number (34) and its double value (68). We have talked about the Gauss' number, as a part of the Gaussian algorithm, in several previous papers, especially in the papers (MMR, 2006, 2011b), while we are now talking about the Dürer's number as determinant of GC for the first time (Box 4$).^{8}$

\footnotetext{
${ }^{3}$ This search, in the act of writing this paper, is a posteriori search, because I have already published facts of this kind in various papers and/or monographs. But, such separate and "broken" facts can only partially testify, and we need one synthetic testimony here, and hence this synthetic a posteriori paper. In this first part of the paper, only the general platform of the whole paper is given, as a basis for the elaboration of this Part I and the Part II that will follows.

$4 " \ldots$ the existence of such a harmonic structure with unity of a determination with physical-chemical characteristics and atom and nucleon number at the same time appealed to Aristotle and to his idea of unity of form and essence. " (MMR, 2004a, p. 233).

${ }^{5}$ Note 1: All the above mentioned illustrations are given at the end of the text, in the Main Atlas. Additional illustrations are given in Atlases A, B, C, D, E, F. Note 2: The key argument for the fact that in natural codes "fits" decimal number system is given in (MMR, 2019a, Tab. A1, p. 29); also here in Tables A3-A7.

${ }^{6}$ When it comes to these three system-arrangements, whenever we write "system" for short, we mean "system-arrangement".

${ }^{7}$ On the relationship of one Gaussian number, "51", and his two numbers, "50, 51", as middle pair in the sequence: 1, 2, 3, ... 98, 99, 100, see in Footnote within Box 8.

${ }^{8}$ I have known about Magic square (4 x 4) since my high school days, albeit more as games than as scientific fact. However, during the GC research, I viewed that this Magic square has to do with the uniqueness of the number 4 and its half, the number 2. This uniqueness (being in a 1: 2 ratio) concerns not only to "the symmetry in the simplest case" (Marcus, 1989), but also to the uniqueness of a special kind (Box 5 and Figure 1.5). Unfortunately, I didn't know about Dürer's copperplate engraving (Figure C2). This was presented to me some 25 years ago by Prof. Aleksandar Petrović from the Faculty of Philology, University of Belgrade, for which I am more than grateful.
} 
Figure 1 shows the pathways on which all three system-arrangements are generated. First, we have the end column with the "cut" initial part of the "pillar" on the boundary of the first Boolean spatial triangle (red color). The lower part of Figure 2 shows how this string of numbers is reflected in a mirror, with the superposition of the number 22, and then how the binary sequence, "taken off" from the six-bit binary tree, is added; a sequence corresponding to the "Golden Path" sequence on the Farey tree (MMR, 1998a, Figures 1 and 2).

After mirroring, the sequence is obtained: $02,13,24,16,05$. When a mirror is placed behind this sequence, a series of numbers is obtained: 20, 31, 42, 61, 50. In the upper part of Figure 2 we see that the same sequence follows and from the chemistry of protein amino acids, given in one specific system-arrangement. And that purely chemical system was created by starting from the simplest amino acid, glycine (Table 1). The most similar amino acid, alanine, is added to it, and so on, all the way to the most diverse AA in the set of 20 protein AAs, to the heterocyclic (heteroaromatic) amino acid, histidine, as last, the twentieth.

Then we notice in Figure 1 the second way, which "removes" the second specific system-arrangement, the diagonal system (DS): with numbers as significant quantities, from 11 to 91; and in Figure 3 (in relation to Figures 1.1 and 1.2) we see how it appears when we take it from PSN and link it with a new specific chemical system-arrangement of AAs, with the CIPS (Cyclic Invariant Periodic System in Figure 4).

How this chemical arrangement is formed (in Figure 3) we find out by comparing this system with the arrangement of AAs, given in Table 2. There are 16 AAs of alanine stereochemical type arranged by chemically adequate pairs (Box 6, 7 and 8 in relation to Box 9), and hierarchically according to the number of atoms in the side chains of amino acid molecules within the first column. [On stereochemical types of AAs see in (Popov, 1989) and (Rakočević and Jokić, 1996).] Aliphatic AAs come first, as less complex, and then aromatic, as more complex.

On the left side of Table 2 for aliphatic AAs, another hierarchy was implemented, in three subsets of AAs: 1 pair, 2 pairs, 3 pairs. This was to show their chemical similarity / dissimilarity. The A-L are the only two purely hydrocarbon AAs, which have only carbon and hydrogen in the side chain. The next two pairs are amino acids that, in addition to carbon and hydrogen in the side chain, also have another element, the chalcogenic one an element from the sixth group of the Periodic System of the Elements (PSE), oxygen or sulfur.

Finally, the next three pairs of AAs make sense to go together for the following chemical reasons. First comes a pair of carboxyl AAs: D-E. [As part of the carboxyl group, they possess the chalcogen element oxygen.] Along with them is the pair N-Q, which are actually their amide derivatives. And, as these two amides also possess 
nitrogen, there is a (chemical) justification for joining them with the pair $K-R$, in which both AAs also possess nitrogen.

The two zigzag lines "respect" the presented chemical distinction of grouping pairs, in the sense that in addition to indicating a balance in chemical properties, they also indicate a balance in the number of atoms. [Balances in chemical properties are accompanied by balances in the number of particles; similar with "something" what we have in PSE; for example, the number "6" denotes the chemical properties of carbon, "7" represents the properties of is nitrogen, and "8" for oxygen.]

The right side of Table 2 shows, however, how this chemical distinction of grouping pairs is "not respected" due to the establishment of a new balance in the number of atoms. ${ }^{9}$ A new grouping of pairs is established: all two by two; the sets of four AAs are obtained. And these sets (quadruplets) appear as rows in the Diagonal Systemarrangement (DS), presented in Figure 3. Quadruplets are taken by consistent unambiguous logic, by the logic of "reading" the order of AAs by Gray Code, counterclockwise: STLA, DEMC, KRQN, FYWH.

To the four classes of AAs of the alanine stereochemical type thus obtained are joined by one of the four of AAs from the non-alanine stereochemical types (respectively, according to the hierarchy of the number of atoms in them). We get the "required" system-arrangement, which is at the same time the Gaussian system, when only numbers are looked at, and our system when chemistry is taken into account (Figure 3 in relation to Figures 4, 5 and 6 and their derivatives).

Finally, we present the third system-arrangement. In Figure 1 we see a series of numbers 26 - 16, 17, 18, given at an angle. By joining the numbers 16, 17 and 18, respectively, starting from the number 26 , we get a series of numbers: $26,42,49,77$. And this series of numbers, as the number of atoms in the bodies of 20 amino acid molecules follows also from the third system-arrangement (angular, AS), presented in Figure 7. Figure 7 shows that this third specific system-arrangement (angular, AS) is also determined by the Dürer's number, i.e. by multiples of his number. [The number of atoms in the first two columns is ( 1 x 68) and in the next two ( $2 \times 68)$.]

3. Working hypothesis. From the fact that the three presented system-arrangements [Orthogonal (OS), Diagonal (DS) and Angular (AS)] are simultaneously natural chemical systems, as well as systems contained in the Periodic Systems of numbers, it makes sense to investigate their interrelationship. For such an ad hoc research, we set up a working hypothesis, according to which in possible symmetrical structuring and restructuring of

\footnotetext{
${ }^{9}$ MMR, 2018a, p. 33: "The term (and notion) 'balancing' means the achieving a balance of the values of physical-chemical factors (measured by the appropriate parameters) between two subclasses of the constituents of genetic code, within the class as a whole. ... The term (and notion) 'nuancing' means a minimal change of values of the physical-chemical factors and quantities in establishing of the balances."
} 
these three system-arrangements, by intercrossing, the presented chemical pairings will, mutatis mutandis, be preserved, as well as determination by Gauss and Dürer numbers.

According to the logic contained in the working hypothesis, to prove it, it is sufficient to check the result of the intersection of three systems on the basis of "the symmetry in the simplest case" (Markus, 1989). And that means checking which amino acid pairs are obtained by crossing every two systems: the first and the second, the first and the third, and the second and the third; which AAs are the same, and which are different in the first and second decades, that is, in their two and two quintets.

But before searching for one such result, it should be said that in the act of setting the working hypothesis, we had a good hint of a favorable outcome. This is the "Cyclic Chemical Similarity Table" found in Table 1.1. It is derived from the "Chemical Similarity Table" (Table 1) as follows: the first two AAs from the first two (upper) quintets, G-N, are added to the first two AAs from the other two (lower) quintets, L-M, and so on. Finally, the first row (GNLM) thus obtained is repeated at the end (bottom), resulting in a cyclic system. And, what is surprising is the fact that this new systemarrangement corresponds to one unique arithmetic system through the identity of quantities 117, 118, 119, 120 (Table C7).

4. The results of comparing the three systems. Surveys 1, 2, and 3 give the results of the comparison of each two systems. The comparison is made from the aspect of the identity/difference of AAs in four amino acid quintets (four quadrants). The result of the comparison is such that it confirms the working hypothesis: Mostly the original pairings of AAs are preserved, as well as the determination by Gauss and / or Dürer numbers. In cases where new pairings occur (different from the original ones), they are such as to show new chemical aspects that were not seen before the system was compared.

What is particularly interesting, however, is the fact that in Survey 1 we have a change from the Gauss' number (51) by \pm 20 ; in Survey 2, the change from the Dürer number and / or its double value, by \pm 10 ; and in Survey 3, also from the Dürer number by \pm 5 . Surveys 4-7 show unique arithmetic systems in which the change for \pm 5 is a reality. [Survey 7.1 shows some "hidden" relationships in Survey 3.] Survey 8 gives the final result of the comparison of the three systems (OS, DS, AS), in the form of the change from Gauss' number 51 by \pm 20 in Survey 1; then change from the Dürer number 34 and its double value 68 by \pm 10 in Survey 2, and by \pm 5 in Survey 3 .

The uniqueness of the total result (the change in the number of atoms at the crossing of the three systems for $(5,10,20)$ corresponds to the numbers adjacent to the line $(26-$ $16,17,18)$ of the angular system in PSN in Figure 1; and also with the uniqueness of Plato's geometric progression" (Survey C4). ${ }^{10}$

\footnotetext{
${ }^{10}$ It makes sense to observe the geometric progression, with the quotient 2, which follows from the formula $\left[2^{\wedge} \mathrm{n}(\mathrm{n}=0,1,2,3, \ldots)\right]$, so that it is connected to some "zero point" in space (as in example: $\underline{\mathbf{0}} 5, \underline{\mathbf{1}} 0, \underline{\mathbf{2}} 0$, $\underline{4}, \ldots$, which we have in Survey 8).
} 
Survey 9 shows how the Fibonacci sequence is generated simultaneously in relation to (GZSP), to Multiplication Table (MT) and to the final result of crossing three amino acid system-arrangements; while Survey 10 shows "normal" generation of Fibonacci sequence in relation to GZSP, but then it is missing the relation with the result of the crossing of the three systems, as well as with MT. It is understood that GZSP can be realized via any other number system, but then both specific uniqueness, I and II, which are discussed here below, are missing.

5. The logic of uniqueness. From the results of the crossing of the three systemarrangements of AAs, it follows that the key determinants of the genetic code are indeed Gauss' number 51 and Dürer's number 34, as well as their double (sometimes multiple) multiplications. On the other hand, both numbers are products of number 17, triple and double products, respectively. In any number system, the number 17, as a prime number is the seventh in the series of all prime numbers, and therefore the relation between the value of that number and its ordinal number is expressed in the following form: 17-07. But, we have this kind of relationship, the neighborhood relationship in PSN, only in the decimal number system (Tables A3 and A4, in relation to the previous two A-atlas Tables: A1 and A2).

However, it makes sense to talk about the uniqueness of the number 17 even when its products are formed: $2 \times 17=34$ and $3 \times 17=51$. When we have these two numbers as determinants of the genetic code, in the way we presented in this paper, then it makes sense to look again at the results we obtained in Surveys 1 to 3 . In the first case, the change from the Gauss' number is \pm 20 ; the change from the Dürer's number is \pm 10 in the first case and \pm 5 in the second. This change again indicates the adequacy of the periodic number system given in the decimal number system. [Number 10 as $(2 \times 5)$ and number 5 as $(1 \times 5)$.] In other words, we have the ratio $q$ : $q / 2$, which is the ratio of ,the symmetry in the simplest case“ (Marcus, 1989).

The mentioned form of uniqueness of number 17, the form 07-17 (the neighborhood of angular line within PSN, Figure 1), leads us to the need to set a hypothesis (for further researches), according to which unique regularities also participate in determining the organization of natural codes, primarily chemical, genetic and speech-linguistic (De Saussure, 1985). Among other possible regularities, there is also the relationship between the subset of prime numbers and the set of a series of natural numbers. In support of this hypothesis, we cite the already discovered regularities: determination of PSE by the golden ratio and the Fibonacci sequence, analogous to the relation of the sequence of prime numbers and the series of all natural numbers (Trifonov and Dmitriev, 1981) (Box 11 ); as well as the determination of the genetic code by p-adic numbers (Dragovich et al., 2006-2021; Mišić, 2016).

6. Specific uniqueness (I). The uniqueness of the determination of the GC by Gauss' number and by the Dürer's number is also expressed in the connection of these 
uniqueness with the existence of the first and second "key point of difference of the number systems" within the Table of multiplication of number systems (Tables C2 and C3). The explanation goes like this. It is the fact that all three systems, which we discussed (OS, DS, AS) exist in the same PSN (Periodic System of Numbers); and that the third (AS) is precisely the one that results from the chemical differentiation of protein AAs into four types of diversity (Figure 8). It follows from these facts that it makes sense to look at the "environment" of its position within PSN, as indicated in Figure $1.3(15,25$ and 17, 27). ${ }^{11}$ For the environment $17-27$, we will only say here that it builds on the already discussed essence $07-17$. The novelty is $15-25$, whose uniqueness is presented in Tables C2 and C3.

From all of the said, and referring to W. Heisenberg (Heisenberg, 1969; Heisenberg, 1972), as we called the position of the chemical elements of life in PSE (CNOH) the "Island of life", the position of the angular system and its environment in PSN we can call as the "Mathematical island of life."12

7. Specific uniqueness (II). The chemical essence of the three systems found in PSN consists of 20 protein AAs. They all have the same head (amino acid functional group), and a hierarchically arranged diversity of the body (side chain), based on the principles of similarity and self-similarity, as is immediately obvious from reading their four types of diversity. That same head is almost represented by the molecule of the smallest of them, the glycine molecule, whose formula we have sketched here in Figure 4.1. This formula, on the other hand, is such that it contains the image of the " Island of life", precisely through the action of the principle of self-identity.

What do we mean by this? That there is no other organic molecule whose functional groups best reflect the chemical content of the "Island of life" (carbon, nitrogen, oxygen, hydrogen, $\mathrm{C}, \mathrm{N}, \mathrm{O}, \mathrm{H}$ ) (Box 15).

As the Glycine molecule contains 75 nucleons, we cannot help but wonder if the digitality of digits "7" and "5" is related to the mirroring we are talking about all the time, in this as well as in some previous papers? From Figure 2 (bottom right) we see that mirroring is in relation to the equation: $2+5=7$; the "actors" of mirroring are addends 2 and 5. If it would be shown that the presented mirroring (Figure 2) has anything to do with the "Island of life" (Fig. 4.1), especially with the quantity of glycine [("75") $\rightarrow(7=$

\footnotetext{
${ }^{11}$ Except in PSN, the uniqueness of 15 and 25 we have in Tables C2 and C3; for 17 in A-Atlas (Tables A1A5 and Tab. A7); and for 27 as the last multiple in Shcherbak's Table of multiples of the number 37 (Shcherbak, 1994, Table 1, p. 476).

${ }^{12}$ From the comparison of Figure 2 with Figure 1, it follows that it makes sense to call GC the image of the mirror image (MMR, 2019b). On the other hand, interpreting this abstract "Island of Life" in the spirit of the quoted quote from Heisenberg's account of the connection between quantum theory and Plato's philosophy (Box 14), it makes sense to say that GC as "Mirror Image" corresponds to Plato's notion "Shadow of Shadows". However, these questions, like some others, require additional discussion, which we will give as Discussion (II) in Part II of this paper.
} 
$5+2)$ ], then, in the mentioned operation, the actors are the sum and the larger addend, the number 7. In support of one such hypothesis (for further researches) is a specific uniqueness of the quantity "75", expressed in correspondence with the ratio 2:3 (Table C4 and Survey C3).

8. The pairing of AAs molecules. The original amino acid pairings are found in the "Gaussian system" in Figure 3. They follow from the original physicochemical relationships of 16 amino acids of the alanine stereochemical type (Table 2) and from the four non-alanine type of amino acids, which are simply hierarchically associated at the beginning of each of four rows. How these original pairings occur it is explained in detail in Box 8. We see the first possible new pairings right there, in the same Figure (Figure 3), "across" from the "Gaussian system" - in the "Dürer system". ${ }^{13}$

Several new pairings appear in the given "Dürer' system". They are formed by a simple "shear", for one, two or three steps, in relation to the "Gaussian system", as explained in the Legend to Figure 3. Shading shows which amino acids belong to the first and which to the second class (in relation to two classes of the aminoacyl-tRNA synthetases). In the first column of Figure 3, all AAs are unshaded; in the second one all are shaded except for one exception (T). We read unshaded versus shaded: DE, KR, FY, GV. Furthermore, we have the reverse state in the next two columns. In the third column all AAs are shaded, and in the fourth all are unshaded; all but one exception (C). And here we read pairs, going from right to left: NQ, AL, HW, PI.

We are now "hunting" exceptions to the original pairs, given in Box 8. The two hydroxide amino acids, ST, are still a pair, both belonging to the unshaded space, meaning that both belong to the second class (related to the enzymes synthetases). Hence, we inevitably have a new pairing: SC and TM. [As an incidental, "collateral damage", there is also a systemic cyclicity, through S-C pairing. $]^{14}$

How the "shear" occurred can be clearly seen by simultaneously observing the left and right sides in Figure 3, going from left to right. We see, in the illustration on the right, how the MC went above, one step higher; QN too. With these two steps up, the

\footnotetext{
${ }^{13}$ Some specific balancing and nuancing of AAs in the two classes thus obtained, I have presented in the paper (MMR, 1997a). From that work, the following are taken over and given here: Tab. F1, Tab. F2 and Box 9. Here we see how "the system chemistry" takes precedence over "the chemistry of the test tube" in generating of GC. By the logic of things, as with all other original pairs in the set of 16 AAs of the alanine stereochemical type (Table 2 in relation to Table 4), the smaller molecule $\mathrm{C}$ would be expected to be in class II, and the larger M in class I. However, this is not happening. In reality, both hydroxide AAs appear to be of lower rank (because oxygen is from the second period of PSE), and both thiol AAs appear to be of higher rank (because sulfur is from the third period).

${ }^{14}$ Here we see how "the system chemistry" takes precedence over "the chemistry of the test tube" in generating of GC. By the logic of things, as with all other original pairs in the set of 16 AAs of the alanine stereochemical type (Table 2 in relation to Table 4), the smaller molecule $\mathrm{C}$ would be expected to be in class II, and the larger M in class I. However, this is not happening. In reality, both hydroxide AAs appear to be of lower rank (because oxygen is from the second period of PSE), and both thiol AAs appear to be of higher rank (because sulfur is from the third period).
} 
"descent down" of LA inevitably followed. That is all there is to the change in the path from left to right illustration, so it is all over in the area of aliphatic AAs. In the area of aromatic AAs no change. In this "strait" of movement, the four amino acids from the three non-alanine stereochemical types "must go" down from the position of the vertical column, and become the lower, last row.

All these changes caused the organization of the whole system to move from the "Gaussian system" to the "Dürer' system", which is characterized by the relationships shown in Figure 3. On the right side it is shown that, within the rows, there is a realization of Dürer's sequence: 58-68-78. But within columns only the quantity 78 remained, although it was constituted sequencing in a new way: that what form the first and third rows, form also the first and fourth columns (78 atoms). Then, the quantity 68 follows from second and fifth row. Finally, we have a little less correspondence between the fourth row and the second column: in the fourth row it is 58 , and in the second column $58+2$.

Shear was not "invented" by chemistry. It is already in arithmetic systems. We find it in Table A4. In that Table we have a pairing in the set of natural numbers so that zeroth and first, second and third, fourth and fifth, etc. go together. [Here, zero appears as a natural number, although mathematics speaks of "a set of natural numbers, an extended zero". We take zero as a natural number not only because Mendeleev thinks so. The reason for "taking" zero as a natural number lies in the fact that this is inevitable if the set of natural numbers is viewed as a set of numbers generated from Boolean spaces. For example, if we look at a Boolean cube then the numbers associated with the vertices of the cube are classified as follows: four even numbers $(0,2,4,6)$ are "down" and four odd $(1,3,5,7$.$) are "up".]$

We look at Table A4 again. We see that only in the case of a decimal number system is a connection establlished with the Fibonacci sequence. This is significant because the Fibonacci sequence is in direct relation to the golden mean; and the golden mean follows from a specific pairing in the set of natural numbers. We find this specific pairing already in the Multiplication Table as: $(0,1),(1,2),(2,3),(3,4)$, etc. [(MMR, 2011b, Table 1.2, p. 822) and (Table $\mathrm{C} 1 \&$ Survey $\mathrm{C} 1$ here, in this paper). But we find also such an order in our work on the Generalized golden mean (MMR, 2004b, Table 1, p. 96); That paper also can be found in ArXiv (arXiv:math/0611095v4 [math.GM]).]

9. New pairing of AAs molecules. As said, we have the original pairings in the case of the separation of the alanine stereochemical type from the remaining three (glycine, proline and valine type). And, in the case of three system-arrangements (OS, DS, AS), all 20 protein AAs are together, in each of three systems. That is why it is necessary to look at possible new pairings within them.

We first look at a system arrangement with four types of diversity (Figure 8), which is directly related to the angular system arrangement (AS). We see that the original pairs 
that we have in the "Gaussian system" are preserved here (Figure 8 in relation with Figure 3). We read pairs from left to right: GP, AL, VI, CM, FY. So far, half of the system has been realized. We read the second half going from right to left: ST, DE, NQ, KR, HW. Such a classification is necessary, because this is the only way to observe the cyclical nature of the system.

As for pairing in the orthogonal system (OS) (Table 1), we have the following state of affairs. It is expected that a system-arrangement must occur in which the only two amino acids that possess structural isomerism (leucine and isoleucine) will be paired. And we really find that here $(\mathrm{L}, \mathrm{I})$. It is also understandable that the only two carboxylic amino acids (with a carboxyl group and in the "body" and not just in the "head") are found in pairs, each with its own amide derivative (DN, EQ). As new couples, a couple more GA and VP appear. Why VP, we explained in a previous paper (Rakočević and Jokić, 1996), and GA follows from both chemistry and logic: in a system in which AAs are ranked by similarity, glycine is certainly most similar to alanine. In everything else we have the original pairs, as in Box 8, or Figure 3.

Determination of GC by Gaussian number, i.e. Gaussian numbers, can be found in the GCT itself, if in the Table we read AAs in order as they come, by columns, with the validity of the principle "if anything, then everything". [For example, serine is counted in the result only at the first occurrence (only at the top of the second column, but not at the fourth).] ${ }^{15}$ The balancing and nuancing here is more than obvious; moreover, here the two turn into sophistication: the "gradation" of physical-chemical properties corresponds to the "seesaw" of quantity - the number of atoms - in columns and rows.

The "hidden" Gaussian pair 1-101 is also included inside the seesaw, via the following reason: there are 102 atoms in the two inner columns; in the two outer columns also 102. However, the number of atoms in the two outer columns can be read in another way: $101+1$. This is because the glycine amino acid is different from the remaining 19 . It is the only one that does not have mirror symmetry, and also, instead of hydrocarbon side array, has only a hydrogen array, represented by only one hydrogen atom. It follows that it makes sense in a set of 20 canonical AAs to put one against the other: a nonhydrocarbon and a hydrocarbon entity, using form 1-101.

In Figure 3.1. the "reduction" of the Table of the genetic code (GCT) from 23 to 20 amino acids is shown. We have the same in the following Figure 3.2. But there, in the columns, there is no change from Gaussian numbers 41 and 61 by \pm 6 atoms. There is a different distinction of molecules in question here. The principle "if anything, then everything" is manifested here in a new way and in a new meaning: "What applies to the

\footnotetext{
15 It has been shown that it makes sense (both formal and chemical) to read 20 AAs from the GCT if the columns are read for one step across the order (MMR, 2004a, Tables 7 and 8, p. 228).
} 
whole, applies to its distinct parts." The four amino acids in column "C" can be said to be encodings of both pyrimidine and purine codons; or encoded by (only) pyrimidine codons; finally, that they are encoded by (only) purine codons. In this third case, we see that there is correspondence with the third column, with column "A". If taken so that the amino acids of the second column are encoded by purine codons, then they can be joined by amino acids from the third column which are also encoded by purine codons. In this new set of amino acids, the number of atoms is exactly 61, while in the pyrimidine amino acids of the third column, that number is 41 . [We have this reduction to quantities 41 and 61 in Figure D6, but not with the same but with different AAs.]

Conversely from the procedure in Figures 3.1 and 3.2, in Figure 3.3, instead of reducing from 23 to 20 AAs we have progress from 23 to 24 AAs. [Correspondences: All 6 Tables in the E-Atlas, plus Table F6.] Quantity "88" is in nuanced balance with quantities "87" and "77" within this system-arrangement (Figure 3.3). But it inevitably corresponds to Dürer's sequence, "58-68-78", which we also find in the system arrangement, presented in Table E6, through the differences: 30, 20 and 10 . Correspondence with Table F6 goes through "filled states": 60, 70 and 90 in Table 3.3 versus $(40,40,40)$ and $[(1 \times 60),(2 \times 60)]$ in Table F6.

We now look separately Figure 3.3 The first and third columns, observed individually, each for itself, form a "group", in terms of physicochemical properties: all AAs in the first column are nonpolar, and all AAs in the third column are polar. But, through SPID ('Spontaneous Intelligent Design'), whose source is in the "Island of Life" of PSE, it is arranged so that these large differences are coded by the minimum difference in the number of atoms, by number 10. In this sense, the second and fourth columns, each for itself, do not form a group. For the fourth column, this has long been proven. [MMR, 1988 b, Section 4, $1^{\text {st }}$, first paragraph, p. 213: "It seems, though, that the first and the second group are influenced by the second base more than the third and the fourth group. (with $A$ and $G$ as the middle bases). The results of the experiments carried out by Michel Sjostrom and Svante Wold (1985) speak in favour of this implication. They investigated the differences between 20 natural amino acids, with 20 different parameters, and found that the amino acids encoded by guanine $(\mathrm{G})$ as the middle base, do not form a separate group."]

That the AAs in the second column are also "horns in a bag" is shown as follows. Proline is the only one in the set of 20 amino acids in which the head and the body are connected. The threonine is the only one in the set of 16 amino acids of the alanine stereochemical type in which in the $\mathrm{CH}_{2}$ group, located between the head and the body, one hydrogen atom is replaced by a $\mathrm{CH}_{3}$ group. In relation to these two "robust" molecules (proline and threonine), alanine as the first possible hydrocarbon derivative, and serine as the alanine's first possible oxidation derivative, inevitably "protrude". Only 
together, the second and fourth columns not only form a group, but by balancing the number of atoms join the other two "groups" $(87,88,77)$. All these examples correspond to the fact of the existence of "The cipher of the genetic code" (Similar in dissimilar versus dissimilar in similar) (MMR, 2018a), as well as our earlier explanations of the meaning of the existence of "intruders" that are duplicated. ["T. Jukes was right in saying that arginine is an "intruder" in the set of twenty amino acids.11 But that attitude applies to all three "markers", to all three "border stone" (L, S, R) in the distinctions shown. That is right, arginine is the most pronounced "horn in the bag"... As we can see, it is only with the discovery of amino acid arrangements with the duplication of two or more of AAs that the balancing and nuancing of the properties of AAs come to the full expression, what at the first glance, in a set of 20 AAs, is not easy to see. The doubling of AAs is analogous to "doubling" into a soldier's platoon. When the platoon commander notices that his three soldiers are "intruders" because they are strikingly protruding from their heights in comparison to the others, he requests from his superiors three more of the similars, to balance the heights."]

10. The pairing through the crossing. In Survey 1, the amino acid quintets of the diagonal system (DS, which follows from arrangement in Figure 3) and the orthogonal system (OS which follows from the arrangement in Table 1$)^{16}$ were compared (crossed). The Pairs that are new pairings relative to the original pairs (original as in Box 8 and Figure 3) are the same ones we found in the orthogonal system in Table 1: GA, LI, VP, QE, ND.

In Survey 2, the amino acid quintets of the angular system (AS from Figure 7) and the orthogonal system (OS from Table 1) were compared (crossed). And, in order to understand the chemical essence of pairing in Survey 2, it is necessary simultaneously to monitor pairing in Survey 3. First and foremost, we see that the VP pair, in addition to appearing in the original Orthogonal System (Table 1) and in Survey 1, appears in one "hidden" form in both of these crosses; in the crossing of AS with OS and DS with AS (Survey 2 and 3 , respectively). ${ }^{17}$

In Surv. 2 we have first dis-pairing and then pairing again. First, we have dis-pairing of the pairs existing in Survey 1: ST, WH, VP, QE, ND, CM, and the resulting singlets are paired again: $\mathrm{PQ}, \mathrm{SD}, \mathrm{VE}$. With the help of Surv. 3, in which there are "hardened singles" (C, M, H, W, which, in Surv. 3, have no one to pair with) we learn that only the first three pairs in Surv. 2 (PQ, SD, VE) are indeed pairs, while the remaining three pairs

\footnotetext{
${ }^{16}$ We call it orthogonal because it is "taken" from the last column of the PSN (Fig. 1), which is orthogonal to the base of the System. The taking method is shown in Figure 2.

${ }^{17}$ In order to understand the chemical essence of all these pairings, it is useful to keep in mind Figure 5, which shows the formulas of AAs.
} 
$(\mathrm{NH}, \mathrm{CT}, \mathrm{WM})$ are "quasi pairs", i.e. the pairs with a higher degree of chemical freedom. ${ }^{18}$

If all three changes are taken together (from Gaussian number 51 in Survey. 1; and from Dürer's number 34 and its double value 68 in Surveys 2 and 3), then the sequence is obtained: $05,10,20$, which represents the first three numbers of a specific geometric progressions with quotient 2; such progression as presented in Survey 8. If only changes from the Durer's number are taken into account, then the sequence is obtained: 05,10 , which corresponds to the first and second "key point of difference between number systems in the Multiplication Table", as shown in Tables C2 and C3.

To make it easier to understand, we read the above results once again from the first three Surveys, in reverse order $\left(3^{\text {rd }}, 2^{\text {nd }}, 1^{\text {st }}\right)$ and relate them to the mathematical regularities given in the last three Surveys, read also in reverse order $\left(10^{\text {th }}, 9^{\text {th }}, 8^{\text {th }}\right)$. After the reading, we find the following. In Survey 3 the change is by \pm 05 , and in Survey 2 by \pm 10 in relation to the Dürer's number, i.e. to double Dürer's number, respectively. And, that's all, from the aspect of determination by Dürer's number. By asking the question what is the total change, we find ourselves in the situation of generating a Fibonacci sequence (Surveys 10 and 9); and the first key point of difference between number systems in the Multiplication Table [as "3 x 5 = 15"] in decimal number system was also "played" at the same time (Table C2).

Returning from Survey 2 to Survey 1, includes determination by Gaussian number (51), with a change of \pm 20 . By asking the question - what is the total change in relation to both Dürer's and Gauss' number, respectively, the answer is, for: $\pm 05, \pm 10, \pm 20$, which puts us in the area of geometric progression with quotient 2 (Survey 8).

Such strictly deterministic results from the aspect of current science are not expected, but they certainly support our hypothesis (Box 1), with a simultaneous presentation of the sense, meaning and significance of SPID (Box 16). ${ }^{19}$

11. Discussion (I). ${ }^{20}$ Generating one-letter words from the four-letter alphabet is actually the state we have in the genetic code: U, C, A, G. Generating two-letter words from the two-letter binary alphabet $(0,1)$ creates Boolean logical square: 00, 01, 10, 11. It makes sense to associate the words thus obtained with four molecules, provided that these

\footnotetext{
${ }^{18}$ In this "higher degree of chemical freedom" we can easily find an explanation for the first two pairs. Thus in the NH pair both molecules possess nitrogen. In the CT pair, both molecules have a chalcogen chemical element: in the case of cysteine, sulfur, and in the case of threonine - oxygen. [If in a set of 20 canonical AAs there are only two pairs of chalcogen AAs, ST and CM, then their combinations are also pairs.] For the "quasi pair" WM we can only say that tryptophan is a derivative of phenylalanine (which has the first possible arene derivative in the side chain); and methionine is a cysteine derivative, where cysteine is the first possible thiol derivative of alanine.

${ }^{19}$ In addition, it is expected that these results of balanced and nuanced molecular system-arrangements through the pairing and classification of protein amino acids could be useful in bioinformatics, in the search and analysis of protein bases and their networks, especially in ontological approaches; such as they were originally conceived and realized (Ashburner et al. 2000).

${ }^{20}$ This is the first part of the Discussion, and the complete discussion will be given in Part II of this paper.
} 
molecules possess binarity in their characteristics; as in the genetic code: weaker / stronger chemical bond (uracil and adenine with two hydrogen bonds each; cytosine and guanine with three hydrogen bonds each); and, second characteristic: simpler / more complex molecule: two pyrimidine molecules, as single rings, are simpler than two purine molecules.

In the "practice" of the genetic code, it is the state of the first (out of a total of 24) permutations: 00 (U), 01 (C), 10 (A), 11 (G). First coordinate (of logical square): if Py then "0", if $\mathrm{Pu}$ then "1"; second coordinate: if two hydrogen bonds, then "0"; if three hydrogen bonds, then "1". [Cf. rules given by R. Swanson (1984) for the Codon ring (Fig. D1 in this paper).]

In addition to the hierarchy of nucleobases through the number of rings in the molecule and the number of hydrogen bonds, the chemical hierarchy, contained in the first permutation, through the subsets of pyrimidine and purine molecules, respectively, is also determined by functional groups. Thus, uracil is simpler than cysteine due to less diversity; it has two oxo groups, while cysteine is a more complex molecule by having one oxo and one amino group. On the other hand, adenine is a simpler molecule in that it has only an amino group, while glutamine has two functional groups, one amino and one oxo group. The stated binary properties of $\mathrm{Py}-\mathrm{Pu}$ molecules and the properties of their derivatives, constituents of RNA, are related to the number of atoms and nucleons in them (Survey B3).

The question is, could the chemistry of life be different from this one with two binary characteristics. The primordial "Island of life" (Fig. 4.1) refers not only to amino acid constituents of the genetic code, but also to nucleotide ones. It is known that the so-called aromatic compounds are more stable than aliphatic; and the main representatives of aromatics are arenes. Of all the arenas, the simplest is the one with six carbon atoms in the ring, benzene. The next, from the aspect of ring diversity, is a molecule with one different atom in the ring, and that is pyridine. [We say "the first", from the aspect of neighborhood, because nitrogen is a neighboring element to carbon in the Periodic System of the Elements (PSE).] But pyridine is one of the strongest organic bases; life would be "fried" before it came into being. It is an analogous situation we had at the "Island of life" with a stop at oxygen; a step further, the choice of fluorine would be deadly; in this case, too, life would be "fried" before it could be created.

Another possibility is that there are two nitrogen atoms in the ring, when a relatively weak base is formed, which we read from the constants of acidity and basicity (MMR, 1994a, Figure 1.1, p. 8). But pyrimidine is still a strong base. If, however, it is replaced with two of its derivatives, uracil and cytosine, the acidity-basicity of constituents becomes lower. In order to reach the above-mentioned logical square, it is necessary to 
derive pyrimidine in the other direction, in the direction of purine formation; but purine also with two derivatives: adenine and guanine.

The above discussion shows why the "choice" of four bases ( $2 \mathrm{Py}$ and $2 \mathrm{Pu}$ ) is a unique case, corresponding to the uniqueness of the "Island of life". [To the correspondence between these four bases should be added the correspondence with four aromatic canonical AAs, described in the Scenario of generating of the constituents of GC (MMR, 2018a, Section 2, p. 32).] The experiments in the synthesis of nucleobases in laboratory conditions, which correspond to syntheses in interstellar spaces should also be having in mind (Miller, 1953; Oro, 1961; Lazcano and Bada, 2004; Parker and Bada, 2011). And, also keep in mind the corresponding theoretical works on the genetic code (Yang, 2004; Glaser, et al, 2007; Castro-Chavez, 2010, 2011; Mišić, 2011; Negadi, 2011a, 2011b, 2015). ${ }^{21}$

The uniqueness of adenine as "HCN pentamer" requires additional comment. First of all, in connection with the formula of cyanide $\mathrm{HCN}$, in relation to the formulas of cyanic acid, HOCN, and isocyanic acid, HNCO, the main actors of chemical reactions in the prebiotic chemical "soup", according to the research of the astrobiologists cited above. Only now, when we know that hydrogen cannot be in the first, but only in the seventh group of PSE (MMR, 2018b), it makes sense to talk about the "Island of life" (from the aspect of the neighborhood of groups and elements in them). In this regard, the island of life should be understood as appearing in the basic form $(\mathrm{C}, \mathrm{N}, \mathrm{O}, \mathrm{H})$ and in the extended form $[(\mathrm{C}, \mathrm{N}, \mathrm{O}, \mathrm{H})+(\mathrm{P}, \mathrm{S})]$, giving an "island" of four elements, with the ability to build molecules of one atom each, and / or of only three less polar $(\mathrm{H}, \mathrm{C}, \mathrm{N}$ in relation to oxygen); in such a case we have a uniqueness of a special and specific form.

The astrobiologists quoted above suggest that the first of molecule which was the actor in chemical reactions within the prebiotic chemical "soup" is adenine, whose "HCN pentamer" synthesis is realized in compliance with the principle of economicity - "with less to get more": in pairing relation uracil-adenine, the one-ring uracil, built of four chemical elements $(\mathrm{C}, \mathrm{N}, \mathrm{O}, \mathrm{H})$, to connect with two-ring adenine, built of only three

\footnotetext{
${ }^{21}$ When I list authors among astrobiologists who do not prioritize astrobiological research, Castro-Chavez, Negadi and Yang, I do so because both groups of researchers, in addition to the physicochemical properties of the constituents of GC, also have important formal characteristics. Thus F. Castro-Chavez in his works presents the circular form of GC; T. Negadi and CM Yang present the fact that the genetic code is determined by the Fibonacci and / or Lucas sequence, from the aspect of the number of atoms and nucleons in the constituents. CM Yang points out that this determination also applies as a specialty; it also refers to the number of carbon atoms, when that number is taken as a subset of the set of the total number of atoms in amino acid molecules. As far as astrobiologists are concerned, for this occasion, it will be enough to list only one quote as follows. Glaser, et al, 2007: "The question whether the nucleobases can be synthesized in interstellar space is of fundamental significance in considerations of the origin of life. Adenine is formally the HCN pentamer, and experiments have demonstrated that adenine is formed under certain conditions by HCN pentamerization in gas, liquid, and condensed phases."
} 
elements $(\mathrm{C}, \mathrm{N}, \mathrm{H})$. In addition to the above aspect of the principle of economicity ("profit increase"), the second aspect of "cost minimization" (corresponding to William Ockham's logical principle "Entia non sunt multiplicanda praeter necessitatem") also applies: On the way from "RNA world"22 to "DNA world", for complementary pairing with thymine, which instead of uracil, appeared in DNA, not to introduce new purine, but to engage adenine in that "new world" as well. [Based on what has been said about glycine and adenine, it makes sense to talk about the glycine-adenine "Island of Life" (Figure 4.1), as an inevitable start of life anywhere in the universe, given the fact that genetic and chemical codes are prebiologically generated in parallel and in unity (MMR, 2018b; 2020b).]

The uniqueness of adenine also concerns the structure of the Universal Genetic Code Table (GCT). The starting point is that instead of the first permutation of bases alphabet in GCT (UCAG as in: Crick, 1966, 1968) it took the one that starts with adenine: ACGU (Damjanović, 1998; Rakočević, 2000a, 2002, 2004a; Damjanović and Rakočević, 2005, 2006). Column "A" in GCT is the most sophisticated in terms of adding codons to amino acids: Out of a total of 16 codons in column "A" two are "stop codons"; the remaining 14 codons are assigned to seven amino acids: each individual amino acid is assigned with two pyrimidine, or two purine codons, which is not the case in the remaining three columns.

The multi-meaning properties of GCT are manifested in the fact that in it, from the aspect of distinction in 64 codons, three codons have a "stop" meaning, and 61 an amino acid meaning (MMR, 2004a, Table 3, p. 224). From the aspect of distinction in 16 codon families, two readings are necessary: 23 of AAs (Crick, 1966, 1968; Rumer, 1966; Shcherbak, 1993, 1994; Rakočević, 2018a, Tab. 1A, p. 34); and also 24 of AAs (Damjanović, 1998; Rakočević, 2007a, Tab. 7 [Figure 3.3 and Table E1 in this paper]; Wohlin, 2015). As shown above, it makes sense to read 20 AAs, as many there are in reality, in the standard GC (MMR, 2004a, Tabs 7 and 8, p. 228; Figure 3.1 and 3.2 in this paper).

All of the above distinctions are related to the 24 permutations of the four-letter alphabet of $\mathrm{GC}^{23}$, especially the first, which we have said contains a key chemical

\footnotetext{
${ }^{22}$ MMR, 2004a, p. 133: "Setting the problem in this manner could mean justification of the hypothesis on independent preceding existence of one 'RNA World' (Gilbert, 1986; Orgel, 1986) ..."

${ }^{23}$ It is about the uniqueness of the four-letter alphabet which, per se, corresponds to the two-letter alphabet of the six-bit binary tree $(0,1)\left[4^{\wedge} 2=2^{\wedge} 4\right]$ and Dürer's "magic square" at the same time. [MMR, 2013b: ".... all these versus 1 letter of alphabet (as letter minimum), 2 letters as word root (nucleotide doublet), 3 letters as 3-letter word (codon) and 4 letters as letter maximum within alphabet. ... By this one can notice that all these self-similarities are possible only for 4-letter alphabet and 3-letter words".] [Additional Note (30.03.2021): For each permutation, it is possible to obtain three Table-arrangements: 16 codons in four columns, in each column the same letter in the first, second, or third codon position, respectively. Combinations of permutations also make sense; for example, with two permutations as in the Codon Path
} 
hierarchy [Hierarchical permutation]. Therefore, when using any other permutation, it is important to always present its relation to the first permutation. However, whenever we say "permutation" it always refers to a pair of permutations: the original and the mirror image, which boils down to reading the Genetic Code Table, GCT, from left to right, and, from right to left. ${ }^{24}$ Knowing the distinction into two simple i.e. the single-ring nucleotide and two complex ones, i.e. double-ring (in the set of four nucleotides that are constituents of GC), when classifying permutations it is necessary to take into account the distinction between two plus two letters in the alphabet; and it also makes sense to talk about significant pairs of pairs, as is the case with two pairs of amino-oxo permutation, [(UGCA / ACGU) - (CAUG / GUAC)], ${ }^{25}$ where in the first pair we have a sophisticated permutation in the position of the mirror image (ACGU) (Damjanović, 1998; Rakočević, 2000a, 2002, 2004a; Damjanović and Rakočević, 2005, 2006), and in the second pair $p$ adic permutation in the position of original before the mirror (CAUG) (Dragovich et al., $2006-2021){ }^{26}$

The presented pair of pairs is another good example for proving the validity of the idea of the existence of the cipher of the genetic code ("similarity in dissimilarity versus dissimilarity in similarity") (MMR, 2018a, in Abstract). The two presented permutations, from the aspect of complementarity through chemical functional groups, are similar; but the properties that follow from them are dissimilar: p-adic and non-p-adic. It is therefore the case of the existence of similar in dissimilar. However, there is also a difference in that what is similar (two similar permutations): one of these two permutations is the original (CAUG) in its pair, and the other is the mirror image (ACGU).

This "game" of similarities and dissimilarities, sophisticatedly develops further. Thus, the third column in GCT with the middle base "A" is really and especially sophisticated. All seven of its amino acids are similar to each other, precisely because they are encoded by similar codons (all 14 codons have a middle base "A"). In addition, all detachments

Cube (Swanson, 1984, Fig. 2), where AAs are separated into two classes with only one exception (Figure F1); or with three permutations as in Figure F3 (where AAs are separated into two classes without any exception); or with more permutations as in Figure F5.

${ }^{24}$ Figure F4 shows, in the upper part, four subsets in a set of 24 permutations of the Alphabet of GC. In the lower part, 12 pairs of these permutations are shown: the original and its mirror image, where the original is considered a permutation with a smaller ordinal number.

25 This is the only pair of pairs in the set of 24 permutations, from the aspect of matching amino-oxo functional groups, analogous to Rumer's system of nucleotide doublets in which amino-amino and oxo-oxo relations are established between the left (single meaning) and right (double meaning) octet of nucleotide doublets. [Cf. Rumer, 1966; MMR, 2018a, Tab. 2A and 2B, p. 34.]

${ }^{26}$ It is true that this is the only pair of pairs of the indicated species (amino-oxo): amino-amino and oxooxo relations occur both within each of the two autonomous pairs and between the pairs. However, observing the autonomous pair for itself, in the set of 24 permutations, we have one more amino-oxo pair, the sixth pair (Fig. F4). Whether it will also be able to participate in mating in one or both of the above pairs will be determined a posteriori, after the eventual discovery of the properties of AAs or codons, which properties, chemically and / or logically, allow. 
are polar, both from the aspect of hydropathy (Kyte and Doolittle, 1982) and from the aspect of cloister energy (Swanson, 1984).

However, Tables E2 and E3 show us that in this similarity there is a dissimilarity, from two aspects: from the aspect of molecule structure, and from the aspect of ordinal number of AAs on the scale $0-19$ in the quaternary number system: ${ }^{27}$ The difference on the scale is obvious; three amino acids $(\mathrm{E}, \mathrm{Q}, \mathrm{K})$ are located at the beginning of the scale, while the remaining four amino acids $(\mathrm{N}, \mathrm{H}, \mathrm{D}, \mathrm{Y})$ are located at the end of the scale. But the difference in chemical structure is also obvious: a subset of three amino acids is characterized by an increase in the number of methylene groups, while a subset of four amino acids has an emphasis on functional groups. ${ }^{28}$

In the set of illustrations given in the Atlases, the six Tables in the A-Atlas have a special purpose, so here we briefly analyze them, precisely from the aspect of their special purpose, which we are talking about here. The central number in the Gaussian scale is the number 51, which is "excluded" from the "labeling" of the number of atoms in amino acid molecules (Figures 3 and 5 in relation to Figures 1.1 and 1.2). However, the number of atoms in the indicated classes of AAs is such that it is in relation to the number $51(51 \pm 10,51 \pm 20,51 \pm 30,51 \pm 40,51 \pm 50)$. On the other hand, the basic Dürer's number is 34. The question is: is it a coincidence that Gauss's indirectly included number 51, and Dürer's directly included number 34 are the products of an another Gauss' number - the number 17 ? [ 3 x $17=51$ and 2 × $17=34] .{ }^{29}$ We cannot answer this question, but we can present at least some relevant facts.

In Table A1, the uniqueness of the number 204 in the set of even numbers is presented. At the same time, the uniqueness of the sequence 16-17-18 in the Periodic System of Numbers (Fig. 1) can be seen here. The distinction at $87+117=204$ corresponds to the state in the genetic code: 117 as the number of hydrogen atoms and 87 as the number of non-hydrogen atoms. In Table A2 it is shown that the sequence 16-1718 results into a series of numbers: $26,42,59,77$, which is at the same time the number

27 In Damjanović's original work (Damjanović, 1998, Figure 2, p. 7), as well as in our common work (Damjanović and Rakočević, 2005), the ordinal numbers of AAs are indeed expressed by numbers in the quaternary number system, and here we give them in decimal for better understanding.

28 The D-N pair differs from the E-Q pair only in that, where AAs in the E-Q par are derivatives of D-N pair respectively: there is an increase in their side chains by one methylene group. On the other hand, lysine in addition to having an amino functional group, has four more methylene groups, while tyrosine, in addition to having the hydroxyl group, does not have any methylene. Finally, histidine is an extreme, but on the other hand the stop signal (at the beginning of the scale) is an extreme of a special kind.

29 "Seventeen is a permutable prime and a supersingular prime. ... the third Fermat prime, as it is of the form $\left\{\left[2^{\wedge}\left(2^{\wedge} n\right)\right]+1\right\}$, specifically with $n=2$. Since 17 is a Fermat prime, regular heptadecagons can be constructed with a compass and unmarked ruler. This was proven by Carl Friedrich Gauss and ultimately led him to choose mathematics over philology for his studies." https://en.wikipedia.org/wiki/17_(number) [Cf. position of the number 16 in Figure C5 $(16+1=17)$.] 
of atoms in the system-arrangement presented in Figure 7. In other words, the uniqueness of the given sequence is seen again.

In the first two tables of the A-Atlas we observe only the state of affairs in the decimal number system, while in Table A3 we observe the relation of number systems to the base $q$. The situation of the last two digits on the scale is tested. Thus, we see that only in the decimal number system the last two digits ( 8 and 9), i.e. their sum, correspond to the uniqueness of the situation: the number 17 corresponds to the last two digits on the scale of the decimal number system, and no other.

In Table A4, the analysis of the relationship between number systems continues. It is noticed that only in the decimal number system, through the two final digits, 8 and 9, by multiplying and adding them, we get quantities that correspond to the Fibonacci sequence. In Table 5 we follow what happens if the Gaussian and Dürer's numbers are added (analysis consistent with additive number theory): instead of the Gaussian ( 3 x 17 $=51)$ and Durer's $(2 \times 17=34)$ calculations $(5 \times 17=85)$. It makes sense to connect the obtained result with the first possible three-digit number, with the number 100 . In the case of the decimal number system, it is "one hundred units", while in the case of the octal number system, it is "sixty-four units", etc. Again, we have a correspondence with the Fibonacci sequence.

The obtained regularities are more than interesting. If we generate from the first set of numbers another composed of those numbers that are doubled in "triangles", the differences between each of the two neighbors are the doubled values of the final digit in the sequence within the "triangle". We have a zeroth triangle: $[0,(1,1), 2]$, then comes the first $[3,(5,5), 8]$, the second $[13,(21,21), 34]$, etc., where it makes sense to stop, because the number 34 is actually the Dürer's number. We also see how the second order, the order of difference, generates a double value of the Dürer's number. And the sum of the numbers in the "triangle" is so large that it gives the middle number of the triangle (in a single amount). This rule applies in turn, except that it does not apply to the zeroth triangle. That is, it also applies to the zeroth triangle, provided that the initial number, the number zero $(0)$ is read as "zero factorial", in which case we get the number one. ${ }^{30}$ Then, in that "zero triangle" is the sum of the numbers is 5, which corresponds to the said rule. It follows from the stated facts that it makes sense to call the obtained Fibonacci sequence as "The combinatorial Fibonacci sequence".

If the presented systemic pairing of protein amino acids gets in connection with previous representations of the existence of analogies of genetic and chemical code (MMR, 2018b; the existence of cipher of genetic code (MMR, 2018a) and the existence of the system of protein amino acids, then it is more than clear that I am actually talking

${ }^{30}$ It is interesting that $\mathrm{Dj}$. Koruga read one of the two units in the zeroth triangle as "zero factorial" (Koruga et al., 1993, pp. 30 and 306). 
about constituents of genetic code as Molecular Self-Organized Systems (M-SOS). That is what I promised in the introduction: "I try to give an argument once again for my hypothesis that the genetic code (GC) was still prebiotic complete."

And in the act of setting the hypothesis (MMR, 2004a, p. 231) it is said that it "must be based on several key principles". Of the six principles, the first is the following: "The principle of systemic self-related ${ }^{31}$ and self-similar organization", citing, both directly and indirectly, almost half of the system-arrangements contained in the paper, which support this principle. Having in mind the title of the paper in question (MMR, 2004a, p. 221: "A harmonic structure of the genetic code"), and all the references in his favor, it wanted to say exactly what we have come to now: constituents of GC represent Molecular Self-Organized Systems (M-SOS).

That this is so, although I did not say it directly, I have already explained in (MMR, 2019a), presenting a system-arrangement "led" by glycine, and here we now find it in Table 1 and Figure 2. Only then did I refrain from saying that all of this stems from the fact that glycine dictates the generation of the "System" not from a "test tube", from its position in the PSE, from the "Island of Life".

Now everything has been said, a complete story about the island of life in PSE, and about the pairing of AAs which is dictated by that island (by SPID, spontaneous intelligent design, as I have said several times in the above cited papers). And, with all that said, here, within the Discussion, I add a few more sentences.

As the "Island of Life" consists of the first possible (simplest) atoms of non-metallic elements $(\mathrm{C}, \mathrm{N}, \mathrm{O}, \mathrm{H})$, of such properties that can build the simplest of their molecules methane (plus $\mathrm{C}=\mathrm{O}$ ), ammonia and water, respectively, for further generation of possible organic molecules are spontaneously available, in addition to the methane pattern, also functional groups: $\mathrm{NH} 2, \mathrm{OH}, \mathrm{CO}$. The only molecule that fits from the aspect of "the principle of systemic self-related and self-similar organization" is glycine.

To answer the question - what further - Miller's experiment should be called for. That what Miller could not determine by the analysis of the "amino acid soup" that he received, is that he had to receive glycine first. What is the next amino acid? There are two possible solutions: the only atomic group that, to some extent, resembles a substituted hydrogen atom in its structure is the methyl group, and thus alanine is formed. Another possibility, with a somewhat smaller coincidence in similarity, is the iso-propyl group, with two solutions - valine and proline. ${ }^{32}$ In the newly formed side chain of valine, there is a possibility of exactly another substitution of the hydrogen atom, when isoleucine is formed. Substitution of another hydrogen atom is possible both practically and theoretically, but the amino acid thus formed would be outside the self-related and self-similar organization of a self-organized system. Proline has no chance of even a

31 "Self-related" refers to the mapping of functional groups from the "head" to the "body" of an amino acid.

${ }^{32}$ On the parallel generation of valine and proline see in (Rakočević and Jokić, 1996). 
single substitution; as in the case of glycine (glycine stereochemical type), the "generation street" ends blindly (proline stereochemical type).

Compared to valine and proline, alanine is "privileged", although at first glance it seems not. The point is that one hydrogen atom of the alanine methyl group can be substituted with an iso-propyl group, when leucine is formed. This act establishes similarity, self-similarity and self-relationity with valine, although leucine belongs to the alanine type, and valine to the valine stereochemical type. With this substitution (generation of leucine), the first possible branched hydrocarbon, iso-butane, entered the "game" of generating protein AAs for the second time, while preserving similarity and self-similarity. [First time with iso-leucine formation.]

At the same time, the list of possible aliphatic hydrocarbons that could participate in the formation of protein AAs, while preserving the stated principles, is exhausted. And according to the SPID hypothesis, the full capacity of the Island of Life is expected to be realized. How? There are two solutions. The first solution is to start mapping the functional groups from the amino acid head into the body; the second solution: to enter the area of aromatic hydrocarbons, where the most stable arenes among them are waiting. The simplest, and at the same time the most stable, benzene is waiting. Unfortunately, it cannot be a candidate but its toluene derivative possessing a branching pattern of isobutane.

How functional groups are mapped from the head to the body, and how aromatic AAs are included, has already been told, which can be easily found by the interested reader. ${ }^{33}$ The only thing left for us to say is that we believe that we agree with the reader on the answer to one important question that cannot be ignored here: If the periodic system of chemical elements applies to the entire universe, then the Island of life in it also applies; wherever they have acquired the condition for the appearance of these functional chemical groups, a life like terrestrial will occur, with the same four stereochemical types of AAs, and the same four types of diversity, with the degree of freedom in choosing individual AAs, not greater than valid on our chosen one - Planet Earth.

12. Conclusion. The facts, principles and regularities, presented in this review paper provides (we hope) the evidences to support our ancient hypothesis (MMR, 2004a) that the genetic code, from the aspect of its constituents, was prebiotic complete. The reason for this is the fact that there is a unity of chemical and genetic code, in the sense that both, mutatis mutandis, follow from the same mathematical equations (MMR, 2018b, Survey 2a, 2b, 3a and 3b, p. 296), and that the molecular components of the genetic code follow from the specific position (the position of the "island of life" in PSE) of nonmetallic chemical elements, which make the said molecules: $\left[\left(\mathrm{C}^{\mathrm{IV}}, \mathrm{N}^{\mathrm{V}}, \mathrm{O}^{\mathrm{VI}}, \mathrm{H}^{\mathrm{VII}}\right)+\left(\mathrm{P}^{\mathrm{V}}\right.\right.$, $\left.\mathrm{S}^{\mathrm{VI}}\right)$ ].

\footnotetext{
${ }^{33}$ Scenario in (MMR, 2018a, Section 2) and New insights in (MMR, 2019b).
} 


\section{Acknowledgements}

I am grateful to Vladimir Ajdačić, Branko Dragovich, Djuro Koruga, Dejan Raković, Anja Jokić, Lidija Matija and Nataša Mišić for the support and helpful, stimulating discussions and benevolent critique, during a series of years through my scientific work.

Box 1. Hypothesis on a (prebiotic) complete Genetic code (MMR, 2004a, Section 7.1, pp. 231-232.)

"When we consider evident validity of the first three principles [valid for the said hypothesis], ${ }^{1}$ it would be hard to expect that any other kind of 'origin form of life', more exactly, life 'in the beginning' could have been built with less than $4 \mathrm{Pu}-\mathrm{Py}$ bases, and less than 20 of AAs and/or with different from these canon standard molecules. That is the reason we can consider only origin abiotic, and not by all means biotic evolution of genetic code.

A scenario might have developed like this. We can assume, that during the period of generation of first atmosphere on the earth, and/or somewhere in the Universe - in area of generating of carbonaceous meteorites - the simplest possible compounds (or near to simplest) of simplest possible non-metals ... also had been generated. At a later stage many nucleotide/amino-acid aggregations, similar to aggregations of Miller's type, or to not much different aggregations of Murcheson-meteorite's type, had been realized.

Each of that aggregations could (and must) have its own 'evolution', but only one could have been selected - the one that gained the characteristic of self-reproduction (by which, through trial, error and success it became EVERYTHING); all other, not selected, could not have any chance (by which, through trial, error and unsuccess, from the aspect of code origin, and consequently life itself, they became NOTHING). Selfreproduction, in fact, could have indicated only that genetic code had been established and that it is the code that provides that reproduction. If there would not be, this generated (not degenerated) genetic code afterwards or if it would have changed and became different, it would lose its characteristic of reproduction of already originated life." (MMR, 2004a, pp. 231-232.)

1 (1) "The principle of systemic self-related and self-similar organization. (The 'head' of an AA in relation to the first possible 'organic' molecule - methane; the functional groups within AAs side chains in relation to functional groups within the AA 'head', and between themselves; ... (2) Principle of 'Compromise' [not in any teleological mean ...] (3) Principle of coherency with simple arithmetical structures and regularities." 
Box 2. Excerpts from key works of the eminents of the genetic code science

F.H.C. Crick, The origin of the genetic code. J. Mol. Biol. (1968) 38, 367-379

Page 367: "The general features of the genetic code are described. It is considered that originally only a few amino acids were coded, but that most of the possible codons were fairly soon brought into use. In subsequent steps additional amino acids were substituted when they were able to confer a selective advantage, until eventually the code became frozen in its present form."

$*$

L. E. Orgel, Evolution of the genetic apparatus. J. Mol. Biol. (1968) 38, 381-393

Pages 381-382: "It is argued that the evolution of the genetic apparatus must have required the abiotic formation of macromolecules capable of residue-by-residue replication. This suggests that polynucleotides were present even in the most primitive ancestors of contemporary organisms. ... Although I believe that the organization of the most primitive forms of life had much in common with that which finally won out, I do not wish to imply too close a correspondence. Thus it seems unlikely that genetic code was adopted suddenly in its final form. Rather I believe that a crude correlation was established between certain polynucleotide sequences (codons) and certain available amino acids (or groups of amino acids) and that the whole system subsequently perfected itself by the bootstrap principle probably in a long evolutionary process. "

Thomas H. Jukes, Possibilities for the evolution of the Genetic Code from a preceding form. Nature, Vol. 246, November 2, 1973, 22-26

Page 22: "Analysis of the interaction between mRNA codons and tRNA anticodons suggests a model for the evolution of the genetic code. Modification of the nucleic acid following the anticodon is at present essential in both eukaryotes and prokaryotes to ensure fidelity of translation of codons starting with A, and the amino acids which could be coded for before the evolution of the modifying enzymes can be deduced."

Page 24: "I have suggested that arginine displaced ornithine during the evolution of protein synthesis."

Page 26: "The ten amino acids in the ancestral code would be adequate for the synthesis of proteins with reasonably versatile properties, except that the absence of serine is surprising. The list includes leucine and valine with hydrophobic side chains; the 'helix-breaker', proline; the two simple amino acids: alanine and glycine; histidine, which binds substrates and prosthetic groups; aspartic and glutamic acids, the acidic pair; the basic amino acid ornithine; and glutamine, which is somewhat hydrophilic. According to the model, serine entered the code with eight codons ... The expansion of the code to eighteen amino acids ... was preceded by modification of tRNA ..."

MMR, Additional note (30.03.2021): I do not cite these excerpts to criticize, but to pay tribute to main eminents of GC science. Without the citation of T. Jukes in the Introduction to my paper in Biosystems (MMR, 2018a) my paper would not make sense. Without his idea on the arginine as an "intruder" in the set of protein AAs, there would be no system-arrangement, presented here in Figure 6. On the other hand, when it comes to F. Crick, his idea of GC "frozen" at the level of 20 AAs, only now comes to full expression. And in order to understand it that way, it is necessary to replace only two terms. Instead of talking about the post-biogenic evolution of GC constituents, it is necessary to talk only about prebiotic generating of constituents. Only after the synthesis of polynucleotides and peptides, and their at least "a crude correlation", as Orgel says [in correlation with what Heisenberg says about nucleic acids (Box 14)] can we talk about the evolution of GC, although even then I would rather talk about the second phase of 
prebiotic GC generation. That is what I would now say, refer to myself say back then, when expressing my hypothesis (MMR, 2004a). Yes, but priority is important, and priority belongs to L. Orgel-.

\section{Box 3. Definition of natural code}

In previous papers on natural codes, I have given definitions of "natural code," as such; essentially different from the understanding of natural codes in current science, so I list them here (abbreviated) for easier understanding of the matter in question.

From MMR, 2018b (in Abstract): "Based on the significant mathematical expressions a new essence of coding formalism in natural codes is showed”; MMR, 2017b (in Abstract): „Based on the significant mathematical expressions it is showed a new essence of coding formalism in natural code as such: it cannot be reduced only to two alphabets (which are consequences, and not the cause); a natural code is such an essence that can be represented by an appropriate mathematical expression, which contains a sequence from the series of natural numbers within itself. ..." (DOI 10.31219/osf.io/mxecj);

MMR, 2011a: "In determination of the genetic code, except two inherent alphabets - twenty amino acids and four amino bases (two pyrimidines \& two purines) - is involved still one "hidden alphabet", the series of natural numbers, with all its regularities and laws" (arXiv:1107.1998v2 [q-bio.OT]).

Additional Note (30.03.2021): When it comes to "all its regularities and laws", I still think so. However, within all these "all", it is primarily about unique arithmetic and/or algebraic regularities and laws, which are mostly unknown to modern mathematics. The reason for this is that if they were found in mathematical research, they would be immediately recognized as irrelevant trivia, or as variations of the numerological "game".

\section{Box 4. Dürer's magic square}

"Dürer's magic square is a magic square with magic constant 34 used in an engraving entitled Melancholia I by Albrecht Dürer (The British Museum, Burton 1989, Gellert et al. 1989). The engraving shows a disorganized jumble of scientific equipment lying unused while an intellectual sits absorbed in thought. Dürer's magic square is located in the upper right-hand corner of the engraving. The numbers 15 and 14 appear in the middle of the bottom row, indicating the date of the engraving, 1514.

Dürer's magic square has the additional property that the sums in any of the four quadrants, as well as the sum of the middle four numbers, are all 34 (Hunter and Madachy 1975, p. 24). It is thus a gnomon magic square. In addition, any pair of numbers symmetrically placed about the center of the square sums to 17 , a property making the square even more magical."

[My Note (30.03.2021): Cf. B-Atlas and Figures C1 \& C2.]

https://mathworld.wolfram.com/DuerersMagicSquare.html 
Box 5. Genetic code as a derivative of chemical code

(I)

$$
\begin{aligned}
& \left(m^{1}, m^{2}, m^{3}\right) ;(\mathrm{m}=4) \\
& \left(n^{1}, n^{2}, n^{3}, \ldots, n^{6}\right) \\
& (n=2)
\end{aligned}
$$

$$
m^{n}=n^{m}=16(m=4)
$$$$
(n=2)
$$

(III) If $(m=4 ; n=3)$, then
" $m^{\wedge} n "=64$
...(3)

[" $m$ " as GC alphabet; " $n$ " as binary alphabet, valid for the GC binary tree.]

[" $m \wedge n$ ” as number of nucleotide doublets; " $n \wedge m^{\wedge}$ as number of four-codon families (16) in Table 5 as well as on the GC binary tree.]

Through designated exponentiations, from " $m$ " follow nucleotide singlets in Pyrimidine-Purine (Py-Pu) alphabet, nucleotide doublets in Rumer's Table as well as nucleotide triplets in Table 5; and from " $n$ " follow the number of branches on the GC binary tree ([8], Fig. 1), and corresponding GC Tables [3]. Further GC relations are given in Survey $2 \mathrm{a}$ and $2 \mathrm{~b}$.

Excerpt from (MMR, 2018b, Eq. 3, p. 293). These equations are just a continuation of Eq. 1 and Eq. 2 in the original paper, which want to show how the Genetic Code (GC) follows directly from the chemical code, i.e. from the Periodic System of the Elements (PSE). [Eq 1 and Eq 2 are given here again in Figure 1.5.]

Box 6. Four diversity types of protein amino acids (MMR, 2018b)

$$
\begin{aligned}
& {\left[\underset{2}{\operatorname{GP}}(27)+\underset{4}{\operatorname{ALVI}}(\mathbf{7 6})+\mathrm{CMFYWH}_{6}(\mathbf{1 2 8})+\underset{8}{\operatorname{STDENQKR}}(153)\right]} \\
& =204+180
\end{aligned}
$$

[Explanation of Eq. (4): Within four diversity types of 2-4-6-8 AAs there is the number of atoms as follows. Within four standard hydrocarbon AAs there are 76 atoms; in two non-standard are 27 atoms; in eight AAs with "mapping" functional groups from the head to the body there are 153 atoms; in the six AAs without the "mapping" are 128 atoms. And then a balance: in two inner groups (with $10 \mathrm{AAs}$ ) there are 204 atoms as in 20 AAs side chains. On the other hand, in two outer groups (also with $10 \mathrm{AAs}$ ) there are 180 atoms as in $20 \mathrm{AAs}$ heads. (Cf. Table 8 and corresponding illustrations, in: [9].] 
Box 7. Four stereochemical types of protein amino acids

"The

side chain of glycine $(-\mathrm{H})$ comes from the shortest possible hydrogen chain $(\mathrm{H}-\mathrm{H})$, and none of the other 19 amino acids has a hydrogen chain of this kind. The side chain of alanine $\left(-\mathrm{CH}_{3}\right)$, or, in relation to glycine, $\left(-\mathrm{CH}_{2}-\mathrm{H}\right)$, follows from the shortest possible noncyclic hydrocarbon chain $\left(\mathrm{CH}_{4}\right)$, and still 15 amino acids have the alanine-analogue side chain in the form $\left(-\mathrm{CH}_{2}-\mathrm{R}\right)$. The side chain of valine $\left(\mathrm{H}_{3} \mathrm{C}-\mathrm{CH}-\mathrm{CH}_{3}\right)$ follows from the shortest possible cyclic hydrocarbon, from cyclopropane, with a permanent openness and with a linkage to the "head" of the amino acid through only one vertex of the cyclopropane "triangle"; still only one amino acid, isoleucine, belongs to this type with the side chain $\mathrm{H}_{3} \mathrm{C}-\mathrm{CH}-\mathrm{CH}_{2}-$ $\mathrm{CH}_{3}$. The proline type (only with proline) follows from the same source (cyclopropane), but with a permanent non-openness and with a linkage to the "head" through two vertices of the cyclopropane "triangle".

"From the possible inductive effect (IE)

(IE) and/or electron density (ED), the following was clear to us: glycine must be a pair within itself (G-G) as an etalon of IE-ED for all other pairs of non-cyclic amino acids; proline must also be a pair within itself (P-P) as an etalon for cyclic amino acids; the pair V-I must be an etalon for the linkage of two subsystems: cyclic and non-cyclic.

(Rakočević \& Jokić, 1996, pp. 345-346) 


\section{Box 8. Original chemical pairing}

From Table 2 follows Figure 3. These two illustrations, taken together, are viewed (directly or indirectly) in relation to Figure 4. The main "scene" is Figure 3, with the "Gauss' system" on the left and the "Dürer's system" on the right. ${ }^{34}$ The Gauss' system on the left follows from the basic system-arrangement of 16 amino acids of the alanine stereochemical type, given in Table 2. In Table 2 we see how of those possible 190 pairs, 8 of the 10 best possible pairings emerge from the aspect of chemical properties of molecules. we see: there are only (and exactly) two hydrocarbon amino acids (AL) and they make up a hydrocarbon pair; there are only two amino acids with a hydroxyl group (ST) and they form a hydroxide pair; there are only two sulfur amino acids (CM) and they form a thiol pair; there are only two amino acids with a carboxyl group in the side chain (DE) and they form a carboxyl pair; there are exactly two carboxylic amino acid amides (NQ) and they form an amide pair; there are exactly two carbocyclic aromatic amino acids (FY) and they form a carbocyclic aromatic pair; finally, there are exactly two heterocyclic aromatic amino acids (HW) and they form a heterocyclic aromatic pair.

After transferring Table 2 to the system on the left side of Figure 3, we proceed to search for two more pairs of amino acids that do not belong to the alanine stereochemical type. In the far right column, just at the bottom, we find two amino acids $(\mathrm{V}, \mathrm{I})$, the only two AAs that belong to the valine stereochemical type. If they are the only ones, and if they belong to the same stereochemical type, then they are inevitably a pair - a valine pair of amino acids. As we can see, out of 20 AAs, there are only two (GP) left, at the top of the far right column of Figure 3. Having been left so lonely, these two AAs (GP) inevitably are a pair at least as in four types of diversity of AAs (Box 6).

\footnotetext{
34 "Gaussian system" because the number of atoms in AAs, by columns and rows, is expressed by Gaussian numbers: in Figure 3 as 51 $10,51 \pm 20,51 \pm 30,51 \pm 40$; and in Figure 3.1 as $\mathrm{G}=1$ and [(FLIMV) + (CWR)] $=101$, from which pair follows 51 \pm 50 . "Dürer system" because the number of atoms in AAs within rows, is expressed by Dürer's numbers: $68 \pm 0$ and $68 \pm 10$. The Dürer's column system contains, however, the same quantities as found in CIPS shown in Figure 3.2 and Figure 4. [CIPS: Cyclic Invariant Periodic System as the result of the determination of the GC binary tree by the Golden mean (MMR, 1998a).]
} 
Box 9. The physical-chemical and essence-formal pairing process in nucleotide component of GC

Table 2. The pu-pyr bases arrangement (ordering according to Watson-Crick's table)

\begin{tabular}{lrrrrc}
\hline & U & C & A & G & $\begin{array}{c}\text { In/out } \\
\text { pair's sum }\end{array}$ \\
\hline BV & 0 & 1 & 2 & 3 & $3 \pm 0$ \\
AN(I) & 12 & 13 & 15 & 16 & $28 \pm 0$ \\
AN(II) & 34 & 35 & 37 & 38 & $72 \pm 0$ \\
\hline
\end{tabular}

BV: Binary values $00,01,10,11$, i.e., binary numbers expressed in decimal numbering system [cf. the same numbers in Fig. 1 in Swanson (1984, p. 188) and in Shcherbak (1994, p. 476: "The four numbers 0, 1, 2, 3 are used instead of the base symbols $\left.\left.\mathrm{T}, \mathrm{C}, \mathrm{A}, \mathrm{G}^{n}\right)\right]$. AN(I): the total atom number within pu-pyr bases $\mathrm{U}, \mathrm{C}, \mathrm{A}, \mathrm{G}$ respectively; AN(II): the total atom number within pu-pyr nucleotides, UMP, CMP, AMP, GMP, respectively; In/Out pair's sum: the sum within the inner pair C-A and outer pair $\mathrm{U}-\mathrm{G}$. [Notice that the nucleon (barionic) number is also pair's depending; so, for the ione form the "barionic numbers are: $\mathrm{A}+\mathrm{T}=259$ and $\mathrm{G}+\mathrm{C}=259+1$ "; and, on the same page: "The product of both prime quantums, i.e., $037 \times 07$, is equal to 259 " (Shcherbak, 1994, p. 476)]. The zero minimum changes, \pm 0 , correspond to the same such changes in amino acid AN valid for the rows 1 and $1^{\prime}$ in Table 1.

(MMR, 1997a)

Box 10. Chemical pairings in the "primordial" Gaussian distribution

Figures 1.1 and 1.2 are observed in relation to Figure 3. Instead of the usual reading of the coordinate system, starting from the beginning to the end point, here in Figures 1.1 and 1.2 we read otherwise: from the beginning, going from left to right; and from the beginning, going from right to left. (This is the meaning of constructing Figure 1.2). Balancing and nuancing occurs from the aspect of the number of atoms, but correspondingly with that, balancing and nuancing in the physico-chemical properties of amino acid molecules. The meaning of balancing and nuancing is to reduce the "Gaussian normal distribution" (given in Figures 1.1 and 1.2) to a line, and thus brings it into a position of "symmetry in the simplest case" (Markus, 1989).

And the "Alignment calculus" goes like this: from the far right column of Figure 3, two lowerlevel amino acids $(\mathrm{GV}=11)^{35}$ are linked to the two left-hand end columns, which are higher levels (with 91 atoms): by balance is reduced to 102 atoms. From this physical alignment (number of atoms as mass) emerges a balance in chemical properties. For example: glycine is related to serine and threonine, only two aliphatic AAs, possessing a hydroxyl group; and it is also related to two carboxylic amino acids (DE); both times by similarity of molecules in polarity (sameness in polarity, difference in structure). On the other hand, the branching in valine is related to the branching in arginine (and thus with lysine its pair-member), despite the fact that

\footnotetext{
${ }^{35}$ Both AAs are of the non-Alanine stereochemical types ("G" from glycine stereochemical type and "V" from valine stereochemical type). They are lower in that they have 11 atoms versus 21 atoms, as many as possess the remaining two AAs $(\mathrm{PI}=21$ ) from non-alanine stereochemical types ("P" from proline stereochemical type and "I" from valine stereochemical type).
} 
valine is nonpolar and arginine and lysine are polar AAs (sameness in structure, difference in polarity). The branching of the atoms in alanine corresponds to the branching in phenylalanine, which (branching) is located at the "junction" point of the "head" and "body" in the phenylalanine molecule (sameness in structure, difference in functional group: methyl group in alanine belongs to aliphaticity and phenyl group to aromaticity). ${ }^{36}$

A step further in balancing and nuancing is to link two higher level amino acids from nonAlanine types $(\mathrm{PI}=21)$ with the next two columns going from left to right, which are lower levels (with 81 atoms). This physical bond is also accompanied by bonds in chemical properties. Here are some examples. Proline corresponds to methionine (methylene groups in proline versus methyl groups in methionine indicate similarity of structural pattern) ${ }^{37}$ Proline also corresponds to two amide AAs (sameness in polarity, difference in structure), and isoleucine to AL and HW. Isoleucine in relation to AL: the same chemical function (aliphatic), but different affiliation to stereochemical types (isoleucine in valine stereochemical type, and AL in alanine stereochemical type); Isoleucine in relation to HW: The branching pattern is possessed by all three AAs (similar in structure), but differ in polarity, isoleucine is nonpolar, while HW are polar AAs.

After this balancing and nuancing by columns, we test balancing and nuancing by rows. The quantities of atoms 31 and 71 (two outer rows) give also 102, as well as 41 with 61 (two inner rows). And, in parallel, there is a process of balancing in the properties: AL versus HW (similarity in branching patterns, differences in polarity).

It is analogous in the case of ST versus FY, only in the opposite direction. ${ }^{38}$ Finally, the comparison also refers to the interrelationship of two acids (DE) with two bases (KR). The polarity of all four confirms the similarity, but that similarity also contains a difference. There is a similarity in structure (aliphatic pattern plus branching pattern), but there is also a big difference: DE are the only two AAs in the set of twenty that have a carboxyl group in the side sequence.

\footnotetext{
${ }^{36}$ In all three examples, our idea from the previous paper (MMR, 2018a) about the cipher of the genetic code, which is expressed through "similarity in dissimilarity versus dissimilarity in similarity", is literally confirmed.

37 The correspondence with methionine is at the same time the correspondence with its pair-member cysteine. As proline is polar (follows from the hydropathy index, given in Table 3), and methionine and cysteine are nonpolar, the idea of the Cipher of GC is also attested here.

${ }^{38}$ Here, too, there is a similarity in the branching patterns, and differences in the polarity. But these differences must be considered separately for two and two of AAs. The original amino acid in pair FY is phenylalanine, and tyrosine is its derivative. In the ST pair, the original is serine, and threonine is its derivative. We are now comparing the polarities, of two originals and two derivatives. Everything is clear in the case of FS: the first is nonpolar and the second polar. However, in the case of YT: from the aspect of the hydropathy index the first is far more polar than the second $(-1.3$ versus -0.7$)$.
} 
Box 11. "Model of prime numbers" corresponding to electron configuration of atoms

\begin{abstract}
“Поэтому 'модель простых чисел' оказывается пригодной лишь для интерпетации системы $(\mathrm{n}+1)$ - групп. Ми выбрали в качестве верхней границы конечного множества натуралных чисел число 120. Этот выбор оказывается обоснованным, если мы примем во внимание, что закономерности построения реальной схеми формированиия электронных конфигурации атомов хорошо известны или с достаточной уверенностью прогнозируются вплоть до $\mathrm{Z}=$ 120. Существующие прогнозы относительно электроных конфигураций атомов с Z>120 приводят к выводу о весьма сложной и запутанной последовательности построения реальной схемы“ (Трифонов, Дмитриев, 1981, стр 221 - 253).

["Therefore, the 'prime number model' turns out to be suitable only for interpreting the system of $(\mathrm{n}+\mathrm{l})$ - groups. We chose the number 120 as the upper bound of the finite set of natural numbers. This choice turns out to be justified if we take into account that the regularities of constructing a real scheme for the formation of electron configurations of atoms are well known or predict with sufficient confidence just up to $\mathrm{Z}=120$. The existing forecasts for electron configurations of atoms with $Z>120$ lead to the conclusion about a very complex and confusing sequence for constructing a real scheme" (Trifonov and Dmitriev, 1981, pp. 221 - 253.)]."
\end{abstract}

Box 12. The "harmonization" of molecules diversity

From MMR, 2013b: "As we have shown, golden mean 'falls' [on the Binary tree of GC] between the 38th and 39th codon (38. CAA, 39. CAG), which code for glutamine (Q), a more complex of only two amide amino acids (AAs); two codons, adjacent to the codons (40.UGU, 41.UGC), which code for one of the only two sulfur AAs, cysteine (C). This 'harmonization' of diversity is increased by the harmonic mean, in position 42 on the sequence $0-63$. The harmonization extends further to 'stop' codon (42.UGA) and to codon (43.UGG) that codes for the most complex AA, tryptophan (W). (The '42' as ending position on the 'Golden route' - with Fibonacci numbers on the Farey tree, corresponding with six-bit GC binary tree [MMR, 1998a].) "

\{Additional Note (30.03.2021): The "stop" codon UGA (the most diverse in the set of 64 codons) is located at position 42 , which is $2 / 3$ of 63 , the last position on the 6-bit binary tree; in other words, it is the position of the harmonic mean.\}

From MMR, 2019a, footnote 10: "Except of direct relationship of $2 / 3$... with the golden mean ... there is an indirect relationship in the following sense. In the cases presented here: 4 AAs vs. 6 AAs. But this is at the same time the 3/2 ratio as: 6 AAs vs. 4 AAs, and it is known that $3 / 2$ represents 'the limit of the golden numbers' (Moore, 2004, p. 211: "Our concern here is the study of the sequence $\{\mathrm{gn}\}$ of 'golden numbers'. A computer analysis of this sequence of roots indicated that the odd-indexed subsequence of $\{\mathrm{gn}\}$ was monotonically increasing and convergent to $3 / 2$ from below, while the even-indexed subsequence was monotonically decreasing and convergent to $3 / 2$ from above")" 
Box 13. Information content of the genetic code ${ }^{39}$

\title{
On the information content of the genetic code
}

\author{
T. Alvager ${ }^{a}$, G. Graham ${ }^{b}$, R. Hilleke ${ }^{a}$, D. Hutchison ${ }^{b}$ and J. Westgard ${ }^{a}$ \\ -Physics Department, Indiana State University, Terre Haute, IN 47809 and "Mathematics and Computer Science \\ Department, Indiana State University, Terre Haute, IN 47809 (U.S.A.)
}

(Received April 15th, 1988)

(Revision received October 12th. 1988)

written as

$I=-\sum_{i}\left(i x_{i} / 64\right) \ln \left(i x_{i} / 64\right)$

This form of the information function allows now a computation of its value for various $x$-distributions.

\section{Numerical evaluation of the information function}

Before the properties of the information function can be obtained, it is necessary to study how simple changes in the degeneracy distribution of the genetic code can be described in the formalism introduced in the previous paragraph. The simplest change in a genetic code would be to take a codon that represents one amino acid and reassign it to another amino acid. This change does not affect the number of codons $\left(\sum_{i} i x_{i}\right.$ in Eqn (3)) degeneracy of the amino acid to which the codon is assigned (it becomes a $(j+1)$ degeneracy).

There are two further restrictions one can put on possible changes. The first is not to allow $i=1$ so that an amino acid is not lost by reassigning its only codon to another acid. The second is not to allow $i=j+1$ as this would not result in a change in the degeneracy distribution of the code. From a practical point of view it is also important to choose a relatively small value of $i_{\max }$. The number of all distributions in the set of 64 codons is 1741630 . Since all of the known natural codes have $i_{\max }=6$ and because of the large total number of distributions we will restrict our computations to that set of distributions with $i_{\max }=8$. This reduces the number of distribution possibilities to 116263 . This, of course, includes the known codes and at the same time places the calculations in a more extensive setting.

39 Alvager et al, 1989, Biosystems, 22, p. 191: „The number of all distributions in the set of 64 codons is 1741630. Since all of the known natural codes have $i_{\max }=6$ and because of the large total number of distributions we will restrict our computations to that set of distribution with $i_{\max }=8$. " [Note: Because authors respected the 'natural limitations' (as René Thom: Box 14, last paragraph), they got an adequate result; by the uniqueness of the 6-bit binary tree in GC (with $2 \wedge 6$ codons) and the matrix of $16 \times 16$ nucleotide doublets, a total of $2^{\wedge} 8$ pairs of pairs (cf. position of the number 16 in Figure C5), which all together represent an expected correspondence. Even more correspondence because Alvager's number 1741630 can be found in Homer's and Njegosh's distinctions (MMR, 2015b, Fig. 2, p. 10 (here: Box 13.2) and Fig. 3, p. 12 (here: Box 13.1).] 
Box 13.1. Correspondence of the structure of the Iliad and the Odyssey (over the number of verses) with the structure of GC

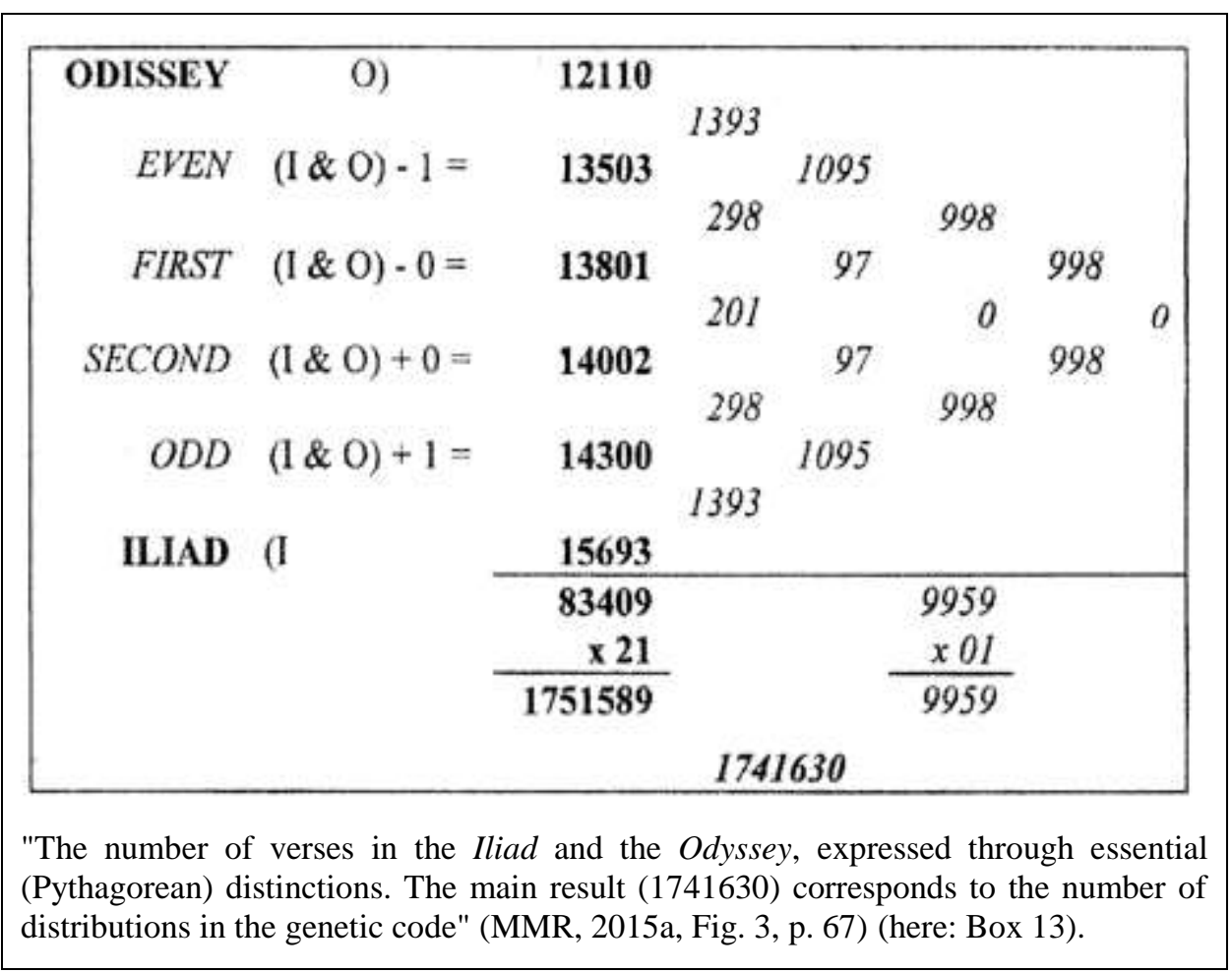


Box 13.2. Correspondence of the structure of the Iliad and the Odyssey (over the number of verses) with the structure of GC

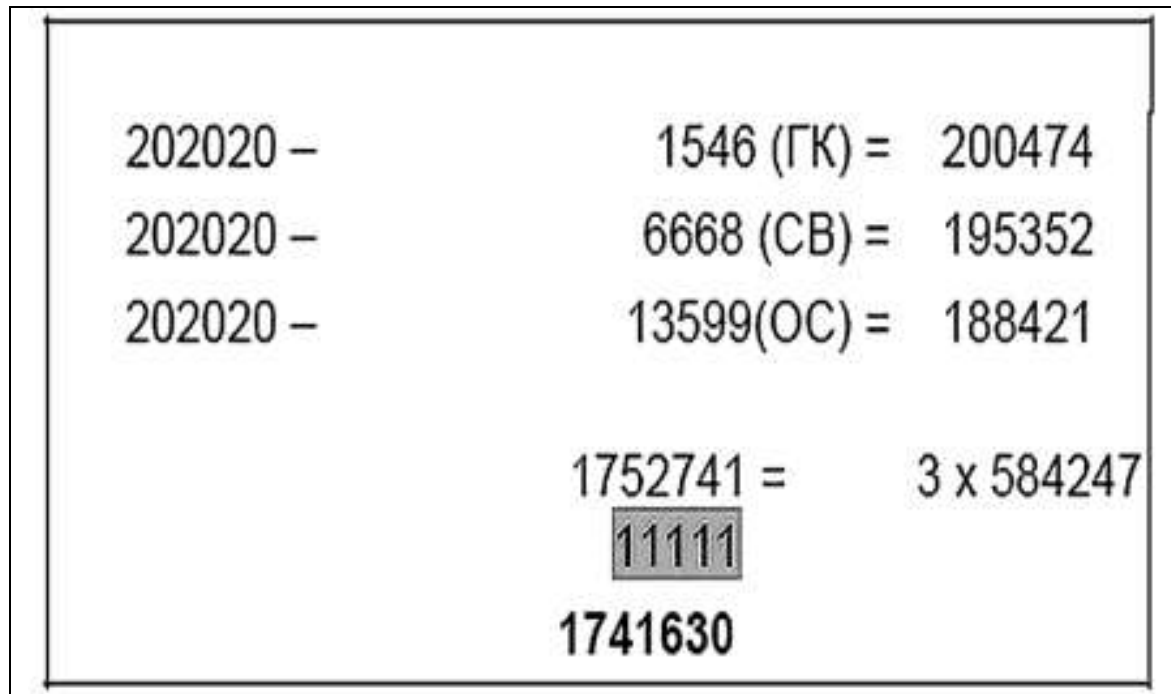

Number of verses in three of Njegošs works, in relation to the reference point 202020. [(202020) $)_{10}$ vs $(101010)_{2}$ on the six-bit binary tree.] [(MMR, 2003, p. 60): Njegoš's Primordial Logos (Његошев исконски логос), Volume II, p. 60) (in Serbian). Arithmetical algorithm for selection the number of verses for Glas kamenštaka (ГК), Svobodijada (CB) and Ogledalo srpsko (OC). Altogether, in correspondence with the number 1741630, which is found as a determinant of GC (Box 13). 
Box 13.3. Correspondence of the structure of Homer's Iliad and Njegoš's Mountain Wreath ${ }^{40}$

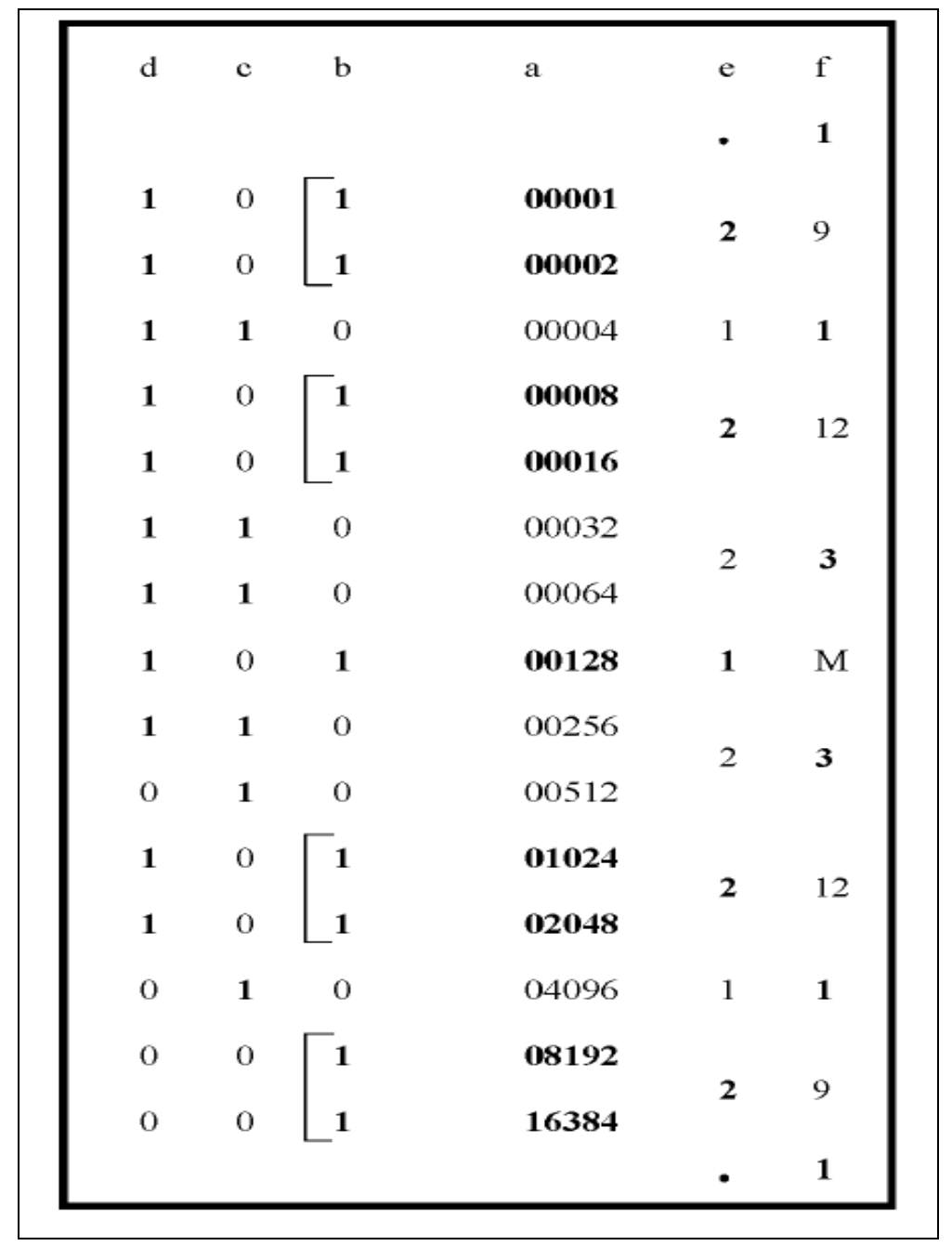

40 After (MMR, 1995, Fig. 9) or (MMR, 2015a, Fig. 4, p. 69): "The universal consciousness on the universal code of Nature: The Homer's and Njegoš's (Boolean) space sequence, $\mathrm{N}=2^{\mathrm{n}}$. (a) The binary sequence whose sum is $2^{15}-1=32767$; (b) Homer's choice: $27803_{10}=66233_{8}=110110010011011_{2}$ (the number of verses for Iliad plus Odyssey); (c) Njegoš's choice: $4964_{10}=11544_{8}=001001101100100_{2}$ (The Mountain Wreath: printed version 2819 verses plus 318 person-scenes, plus 116 pages for printing = 3253; manuscript version 1528 verses plus 150 person-scenes plus 033 pages $=1711$; all together - the total spaces of The Wreath: $3253+1711=4964)$; Homer's plus Njegoš's system: $66233_{8}+11544_{8}=77777_{8}$; (d) Homer's choice: $3583_{10}=6777_{8}=000110111111111_{2} \ldots$ (e) The number of Homer's yes-choice and nonchoice situations; (f) The (in literary science) known composition sequence of Iliad: from the middle point Mission to Achilles) 1 day full, 9 empty of events etc." [Add. Note: 6 vs 1 as (110/ 001); then: 2 vs 5 as (010 / 101); and: 3 vs 4 as (011 / 100). (MMR, 1995)] [Paul Dirac (in Nobel Lecture, December 12, 1933): "On this view the positron is just a mirror-image of the electron, having exactly the same mass and opposite charge."] http://www.ecpd.org.rs/pdf/2015/books/1995/1995_ecpd_consciousness.pdf 
Box 13.4. Number of verses in six chants of Njegoš's "The Ray of Microcosm" (Luča Mikrokozma) in relation to the Fibonacci sequence and the Golden mean

\begin{tabular}{|c|c|c|}
\hline a) & $\frac{a}{b}=\frac{a+b}{a}$ & \\
\hline б) & $\begin{array}{c}350: 210=1, \overline{666} \\
5: 3=1, \overline{666} \\
560: 350=1,6 \\
8: 5=1,6\end{array}$ & $(1-4)$ \\
\hline B) & $\begin{array}{l}510: 320=1,6 \\
8: 5=1,6 \\
830: 510=1,627 \\
13: 8=1,625\end{array}$ & $(5-2)$ \\
\hline r) & $\begin{array}{c}340: 280=1,2 \\
620: 340=1,8 \\
1,8: 1,2=1,5 \\
3: 2=1,5\end{array}$ & $(3-6)$ \\
\hline
\end{tabular}


Box 14. Werner Heisenberg (1969): "Der Teil und das Ganze: Gespräche im Umkreis der Atomphysik"

"They [symmetries] set forms that far-reaching determine later events. 'In the beginning there was symmetry', that is certainly more accurate than Democritus' thesis 'In the beginning there was a particle'. Elemental particles embody symmetries, they are their simplest representations, but they are only a consequence of symmetries ... Special geological and climatic conditions on our planet have enabled complicated carbon chemistry, which allows chain molecules in which information can be stored. Nucleic acid has proven to be a suitable repository of information for statements about the structure of living beings ... If on some planet of another stellar system the same climatic and geological conditions prevailed as on our Earth, and carbon chemistry led to the formation of nucleic acid chains there, we still could not assume that the same living beings were created there as at us. But it will be created by the same basic structure of nucleic acid. With this statement, I can't help but think of Goethe's natural science: he wanted to take all botany out of the proto-plant. According to him, the proto-plant is an object, but at the same time it represents the basic structure according to which all plants are built. In this Goethe sense, nucleic acid could be labeled as a proto-living being, because it is also, on the one hand, an object, and, on the other hand, represents the basic structure for the whole of biology. Speaking like this, we are, of course, already in the middle of Plato's philosophy. Elementary particles can be compared to regular bodies in Plato's Timaeus. They are proto-images, ideas of matter. Nucleic acid is the idea of a living being. These proto-images determine the whole further event". [(Heisenberg, 1969) (Hajzenberg, 1972, pp. 356-357). Translation from German into Serbian: Vera Stojić; from Serbian to English: MMR.]

Heisenberg's telling of "carbon chemistry" is, mutatis mutandis, the same as what I say about the Carbon world (Legend to Figure 4.1); his "chain molecules" of nucleic acids, that's the same thing Leslie Orgel says about peptide and nucleotide chains (Box 2).

Heisenberg's reference to the Bible and the classics of literature could satisfy Paul Feyerabend and his fierce critique of the alleged "chauvinism" of science. [Feyerabend, Against Method, 1993, Chapter 4.1: "There is no idea, however ancient and absurd, that is not capable of improving our knowledge. The whole history of thought is absorbed into science and is used for improving every single theory. Nor is political interference rejected. It may be needed to overcome the chauvinism of science that resists alternatives to the status quo ..." Footnote 56: "It is, therefore, important that the alternatives be set against each other and not be isolated or emasculated by some form of 'demythologization'. Unlike Tillich, Bultmann and their followers, we should regard the world-views of the Bible, the Gilgamesh epic, the Iliad, the Edda, as fully fledged alternative cosmologies which can be used to modify, and even to replace, the 'scientific' cosmologies of a given period."]

If these Heisenberg references are related to contemporary research on GC by T. Alvager et al. (Alvager et al., 1989) (Box 13), who strictly adhere to natural constraints, in calculations of the real and possible in distinctions within GC (answer to the question of the number of possible codon assignment to amino acids), then the strict mathematical requirements of René Thom were met; in addition, there is a chance to understand the correspondence between the structure of GC and the structure of those classical works of literature that are built exactly on the patterns of natural uniqueness (MMR, 1988-2017: works on the Bible and literature, in References).

[René Thom, 1990, p. 349-354, last paragraph on page 354: "I am sure mathematics undoubtedly 'informs' the world, as well as our own structure, but that is not the mathematics we know, the one that algebraists produce with the stubborn zeal of unlimited repetition of formal operations. On the contrary, in ... studying the natural limitations of formalism lies the mathematics of tomorrow." (Translation from French into Serbian: Vesna Polovina; from Serbian into English: MMR).] 


\section{Box 15. The "Island of Life" and "Glycine-Adenine-Life" (GAL)}

The facts we present in this paper on the existence of the "Island of Life" in PSE, in the space of the first (and simplest) non-metal elements, are a prerequisite for a possible deeper elaboration of the idea on life as such, anywhere in the Universe to exist, must be based on Glycine (From selection pressure" of the Periodic System results a "Glycine Life") (more exactly, "Glycine -Adenine - Life" (GAL). Support for this idea is the direct correspondence between the presented "island of life" and S. Miller's 1953 experiment, the 1958 repeated experiment, and the experiments of his student J.L. Bada, which he performed after the death of his teacher in 2007 (Lazcano and Bada, 2004; Parker and Bada, 2011). Already in S. Miller's experiment, in which he exposed a mixture of water, methane, ammonia and hydrogen, in a closed and sterilized assembly, to electric discharge, and obtained simple organic molecules, amino acids predominated: formic acid was obtained in the largest amount, followed is by the amino acid glycine; in third place is glycolic acid, precursor of glycine, and in fourth place is the amino acid alanine.

Glycine and alanine at the head of a "molecules series" of life actors is directly related to our orthogonal system-arrangement (Table 1), which through the process of mirroring leads to the final result of determination of GC by Gauss' and Dürer's number, as we have the opportunity to present to the scientific public today. In that first experiment, a smaller number of amino acids was obtained, but in later experiments, all canonical and many non-canonical AAs were obtained, but the main thing is that a racemic mixture of left and right AAs was always obtained. The fact that in reality only the left ones are on the scene, speaks of the influence of systemic chemistry in the selection of life molecules, from which it follows that it makes sense to speak only of systemic generation of genetic code, in inseparable unity with generation of chemical code.

As we can see, one another confirms: The experiments of S. Miller and co-workers confirm that the results obtained are a direct expression of the relationship in the "Island of Life"; On the other hand, learning about the existence of the "Island of Life" helps us to understand the experimental results of S. Miller and the aforementioned later researchers.

\section{Box 16. Chemical sense and meaning of the SPID (Spontaneous Intelligent Design)}

\section{Box 4}

The Spontaneous Intelligent Design.

Castro-Chavez, 2010, p. 718: 'We can conclude that the genetic code is an intelligent design that maximizes variation while minimizing hamful mutations"; Rakocevic, 2013a and 2015, p. 18: 'With insight into the results ... one is forced to propose a hypothesis (for further researches) that here, there really is a kind of intelligent design; not the original intelligent design, dealing with the question - intelligent design or evolution (Pullen, 2005), which is rightly criticized by F.S. Collins (2006). Here, there could be such an intelligent design, which we could call 'Spontaneous Intelligent Desigg' (SPID) that is consistent with that design which was presented by F. Castro-Chavez (2010), and is also in accordance with Darwinism. ... Actually, it can be expected that the hypothetical SPID, contained in the results ..., is in acoordance with an identical (or similar?) SPID, presented in the only diagram, in Darwin's book Origin of Species (Darwin, 1859), as we have shown through an analysis of that diagram in one of our books (Rakocervic, 1994; www. rakocevcode. Is). IIn the case of the statement that spontaneity and intelligent design are mutually opposite, one must ask the question: isn't it true that human intelligence is the result of a spontaneous evolutionary process?]"

The title of this Box is actually a hint of one of the aspects that will be contained in Discussion II within Part II of this paper. An integral part of the hint are Figures 4.1a, b, c, d, which we will briefly explain here. Both times, in this hint, as in Discussion II, we start from our hypothesis (MMR, 2018a, Box 4, p. 43) about the existence of "Spontaneous Intelligent Design" which follows directly from the Periodic System of the chemical Elements (PSE), i.e. from "Island of life", as interpreted in this paper. 
We first analyze the unique relationship of the binary and decimal system (Figure 1.4a). The target position, in the Periodic System of Numbers (PSN), is the three-digit occurrence position (Figure 1.4); more precisely, the appearance of the first three-digit pair of numbers (100/101). The result of their mirroring with superposition (analogous to the superposition of number 22 shown in Figure 2) is (300/301). The highlights are as follows:

1. The number of nucleons in 23 AAs, in their side chains, is 1443 , and the number of atoms in whole molecules, in 61 amino acids is 1143. The difference is $1443-1143=300$ (MMR, 2020b, Table 8 at the bottom $)^{41}$;

2. The number of nucleons in 23 AAs, in their side chains, is 1443 , and the number of atoms in whole molecules, in 61 amino acids is 1143 . The difference is $1443-1143=300$ (MMR, 2020b, Table 8 at the bottom $)^{42}$; then $(3666-1246=2 \times 1210)^{43}$, where the number 1210 is the second member of the second pair of friendly numbers $[1184,1210]$. [Determination by the first friendly pair $(220,284)$ we can find together with the "ordinary" pair $(204,300)$ in Fig. A2, and separated in Fig. A3.]. In Surv. 11 of the same paper (MMR, 2020b) stated that the group number for Beryllium is zeroth; virtual "zeroth group" from the aspect of non-reactivity, which is an analogy with noble gases. ${ }^{44}$ However, it is a real fact that $\mathrm{Be}$ is in group II of PSE. Hence, it makes sense to understand that the "Group number" of stable elements possessing stable isotopes is ambiguous (300 and 302). ${ }^{45}$

The number 204 we found as the number of atoms in a set of 20 standard protein AAs (in their side chains); number 300 as a determinant of the genetic and chemical code: first here in Fig. 1.4a; then in (MMR, 2020b, Surv. 12 and 13), where $1 / 2300$ represents the number of stable isotopes in the stable elements, and also 300 is the sum of the group numbers in the PSE in which the stable elements are found, as we said.

For Figures $4.1 \mathrm{~b}, \mathrm{c}$ it is obvious that there is no unique situation in them as we find in Figs. 4.1a, which, among other things, confirms Shcherbak's hypothesis about analogy with quantum physics (Shcherbak, 1993, 1994). On the other hand in Fig. 1.4d we see the uniqueness of both the decimal number system and the Gaussian sequence in it $\left[(1-101)_{\mathrm{q}}\right](\mathrm{q}=10)$, in the sense that a different GC with unit quantities at the end position of the atom number records is not possible. ${ }^{46}$

${ }^{41}$ It is important to say that the number 1443 is $1 / 6$ of the sum of the first four perfect numbers $(1443 \times 6=$ $8658=7770+0888$.

42 Notice that $3333-333=3000$, what is $10 \times 300$.

${ }^{43}$ Notice that $1246 \times 8=8658+1310$, where the number 8658 is the sum of first four perfect numbers; and the number 1310 corresponds to pairs 300/301 and 133/1113, from the aspect of the logic of "filling" the balance level. [Cf. filled balance level "333" in Surv. C10.]

${ }^{44}$ The first case ("group number" 300) follows from the answer to the question: "What is the 'Group number' in the set of stable multi-isotopic elements contained in even and odd groups, plus 'Group number' in the set of stable monoisotopic elements contained in odd groups; in the second case ("group number" 302), monoisotopic elements are taken into account from both, odd as well as even groups (Beryllium in the second group). This distinction is one of the examples of how SPID works, what its chemical sense is.

${ }^{45}$ In addition to the understanding given in the previous footnote, it is necessary to understand that here we are "dealing" with three three-digit numbers $(300,301,302)$ in relation to the first three three-digit numbers $(100,101,102)$; analogous to the appearance of the first three two-digit numbers in Fig. $1[(00,01,02)$ vs $(10,11,12)]$; in other words, both times in relation to the first Boolean triangle $(00,01,10)$ [or with record in decimal number system: $(0,1,2)]$, in Boolean space. Hence the meaning of mirroring in Figs 1.4a, b, c; and in Figs. 2.

${ }^{46}$ In the paper (MMR, 2020b) to which we refer here, there are two small errors (which do not affect the essence of things), as follows. In Surv. 12 writes that these are $s, p$ elements, but in fact they are $d, f$ elements. On the other hand, in Surv. 13. writes: $199+100=300$, instead of $199+101=300$. 


\section{References}

Alvager, T. et al. (1989) On the information content of the genetic code, BioSystems, 22, 189196.

Ashburner, Michael et al. (2000) Gene Ontology: tool for the unification of biology. The Gene Ontology Consortium, Nature Genetics, 25(1): 25-29. [PMC free article] [PubMed] [Google Scholar]

Attardi, G. (1985) Animal mitochondrial DNA: an extreme example of genetic economy. Int. Rev. Cytol. 93, 93-145.

Barrell, B.G., Bankier, A.T., Drouin, J. (1979) A different genetic code in human mitochondria. Nature 282, 189-194.

Budisa, N., Moroder, L., Huber, R. (1999) Review: structure and evolution of the genetic code viewed from the perspective of the experimentally expanded amino acid repertoire in vivo. CMLS 55, 1626-1635.

Castro-Chavez, F. (2010) The rules of variation: amino acid exchange according to the rotating circular genetic code. J. Theor. Biol. 264, 711-721.

Castro-Chavez, F. (2011) The Quantum Workings of the Rotating 64-Grid Genetic Code, Neuroquantology, 9(4), 728-746.

Crick, C. H. F. (1966) The Genetic Code. Cold Spring Harbor Symp. Quant. Biol., 31, published in: The chemical basis of life - an introduction to molecular and cell biology, Scientific American, 1973, 192-198.

Crick, C.H. F. (1968) The Origin of the Genetic Code. J. Mol. Biol. 38, 367-379.

Damjanović, M. Z. (1998) Logic core of genetic code, Proceedings (Glasnik) of the Section of Natural Sciences on Montenegrin Academy of Sciences and Arts (CANU), 12, 5-8.

Damjanović, M. Z., Rakočević, M. M. (2005) Genetic code: an alternative model of translation, Ann. N. Y. Acad. Sci. 1048, 517-523.

Damjanović, M. Z., Rakočević, M. M. (2006) Genetic Code: A new understanding of codon amino acid assignment, arXiv:qbio/0611033v1 [q-bio.OT] (an extended version of paper published in Ann. N.Y. Acad. Sci. 1048: 517-523 (2005)); published also in: Proceedings (Glasnik) of the Section of Natural Sciences of Montenegrin Academy of Sciences and art (CANU), No 17 (2006).

Darwin, Ch (1859) On the Origin of Species, John Murray, London.

De Saussure, Ferdinand (1985) Cours de linguistique generale, Payot, Paris.

De Sosir, Ferdinand (1989) Opšta lingvistika, Nolit, Beograd.

Dragovich, B., Dragovich, A. (2006) P-Adic Model of DNA Sequence and Genetic Code. arXiv:q-bio/0607018v1 [q-bio.GN].

Dragovich B, Dragovich A.Y. (2009) A p-adic model of DNA sequence and genetic code. P-Adic Numbers, Ultra-metric Analysis, and Applications, 2009 Mar 1;1(1):34-41.

Dragovich, B., Dragovich, A. (2010) P-adic modeling of the genome and the genetic code. Comput. J. 53 (4), 432-441; arXiv:0707.3043 [q-bio.OT].

Dragovich, B., Khrennikov, A.Yu., Mišić, N.Ž., (2017) Ultrametrics in the genetic code and the genome. Appl. Math. Comput. 309, 350-358; arXiv:1704.04194 [q-bio.OT]. 
Dragovich B, Misic N.Z. (2019) p-Adic hierarchical properties of the genetic code. Biosystems, Nov 1;185:104017.

Dragovich, Branko., Khrennikov., Andrei Yu., Kozyrev, Sergei V., Mišić., Nataša Ž. (2021) pAdic mathematics and theoretical biology, BioSystems, 199, 104288.

Dürer, Albrecht (2020) All solutions of Dürer's 'supermagic' square (sum 34) in Wikipedia https://s-media-cache-ak0.pinimg.com/236x/f5/ae/73/f5ae73c73b41779a4c41b251bba0d9d3.jpg

Eigen, M., Schuster, P. (1979) The Hypercycle, a Principle of Natural Self-Organization, Springer-Verlag, Berlin.

Feyerabend, Paul (1987) Protiv metode - skica jedne anarhističke teorije, Veselin Masleša, Sarajevo.

Feyerabend, Paul (1993) Against Method - Outline of an Anarchistic Theory of Knowledge, 3rd edition, Verso, London. https://theanarchistlibrary.org/library/paul-feyerabend-against-method.lt.pdf

Gilbert, W. (1986) The RNA world. Nature 319, 618.

Glaser, R., Hodgen, B., Farrelly, D., McKee, E. (2007) Adenine Synthesis in Interstellar Space: Mechanisms of Prebiotic Pyrimidine-Ring Formation of Monocyclic HCN-Pentamers, Astrobiology, Volume: 7 Issue 3: July 13, 2007. http://doi.org/10.1089/ast.2006.0112

Heisenberg, Werner (1969) Der Teil und das Ganze: Gespräche im Umkreis der Atomphysik, Piper \& Co. Verlag, München.

Hajzenberg, Verner (1972) Fizika i metafizika, Nolit, Beograd. (Prevela Vera Stojić)

Jukes, Thomas H. (1973) Possibilities for the evolution of the Genetic Code from a preceding form. Nature, Vol. 246, 22-26.

Kedrov, B.M. (1977) Predictions of Mendeleev in Atomism - Unknown Elements, Atomizdat, Moscow.

Knight, R.D., Stephene, F.J., Landweber, L.F. (2001) Rewiring the keyboard: evolvability of the genetic code. Genetics - Nat. Rev. 2, 49-58.

Konopel'chenko, B.G., Rumer, Yu.B. (1975) Klassifikaciya kodonov v geneticheskom kode. Dokl. Akad. Nauk. SSSR 223, 471-474.

Koruga, D.L. (1992) Neuromolecular computing. Nanobiology 1, 5-24.

Koruga, Dj. et al. (1993) Fullerene C60 History, Physics, Nanobiology, Nanotechnology, NorthHolland, Amsterdam, 1993.

Kyte, J., Doolittle, R.F. (1982) A simple method for displaying the hydropathic character of a protein, J. Mol. Biol. 157, 105-132.

Kuhn, Th.S. (1970) The Structure of Scientific Revolution, 2nd Edit., The University of Chicago Press, Chicago.

Lazcano, A., Bada, J.L. (2004) The 1953 Stanley L. Miller Experiment: Fifty Years of Prebiotic Organic Chemistry, Origins of Life and Evolution of Biospheres, 33 (3), 235-242.

Marcus, S. (1989). Symmetry in the simplest case: the real line. Computers Math. Applic.17, 103115.

Mendel, G. (1866) Versuche über Pflanzenhybriden. Verhandl. Des Naturvorschenden Vereins in Brunn, IV. 
Mendeleev, D. I. (1869) On the Relationship of the Properties of the Elements to their Atomic Weights, Zeitschrift für Chemie, 12, 405-406. [Reprinted in David M. Knight, ed., Classical Scientific Papers - Chemistry, Second Series, 1970.]

Менделеев, Д.И. (1958) Периодическая закон, Изд-во АН СССР, 1958, с. 1-839.

Miller, Stanley L. (1953) Production of Amino Acids Under Possible Primitive Earth Conditions, Science, 117 (3046), 528.

Miller, Stanley L. (1987) Which organic compounds could have occurred on the prebiotic earth? Cold Spring Harb. Symp. Quant. Biol. 1987, 52, 17-27. [PubMed] [Google Scholar]

Mišić, N.Ž. (2011) Nested numeric/geometric/arithmetic properties of shCherbak's prime quantum 037 as a base of (biological) coding/computing, Neuroquantology 9(4), 702-715.

Mišić, N.Ž. (2016) Standard genetic code: $p$-adic modelling, nucleon balances, and selfsimilarity. Facta Univ.: Phys. Chem. Tech. 14, 275-298. http://dx.doi.org/10.2298/FUPCT1603275M

Moore, G.A. (1994) The limit of the Golden Numbers is 3/2. The Fibonacci Quartely, June-July, 211-217.

Négadi, Tidjani (2011a) The multiple structure of the genetic code, in one and small number, January 2011, NeuroQuantology, 9(4).

Négadi, Tidjani (2011b) On Rakočević's Amino Acid Biosynthetic Precursors Relations, NeuroQuantology, December 2011, Vol 9, Issue 4, 772-784.

Négadi, Tidjani (2015) Mathematical Model for the Genetic Code(s) Based on Fibonacci Numbers and their q-Analogues or arXiv:1510.01278v1 [q-bio.OT]

Orgel, L. E. (1968) Evolution of the genetic apparatus, J. Mol. Biol. 38, 381-393.

Orgel, L.E. (1986) Mini review: RNA catalysis and the origin of life. J. Theor. Biol. 123, 127149.

Oró, Joan (1961) Mechanism of synthesis of adenine from hydrogen cyanide under possible primitive Earth conditions. Nature 191, 1193-1194.

Papović, R., Rakočević, M. (1988) Interdependence of Genetic and Ecological-Physiological Factors, XIX Congres of Union of Yugoslav Physiological (UYPS) with international participation, 20 - 24. XI 1988, Belgrade.

Parker, E.T., Bada, J.L. (2011) Primordial synthesis of amines and amino acids in a 1958 Miller H2S-rich spark discharge experiment, PNAS.

Plato (1888) Timaeus of Plato, edited with Introduction and Notes by R.D. Archer-Hind, M.A., fellow of Trinity College, Cambridge. London, New York: Macmillan and CO.

Platon (1970) Timaeus. Texte préparé et traduit par Albert Rivaud: Platon, Ouevers completes, tome X, Paris, 1970.

Popov, E.M. (1989) Strukturnaya organizaciya belkov, Nauka, Moskva. [Евгений Митрофанович Попов: "Структурная организациия белков", Москва: Наука, 1989.]

Rakočević, M. M. (1986a). Primena teorije sistema u tumačenju evolucije proteina, XXVIII Savetovanje hemičara SR Srbije, 16 - 18. januar 1986.

Rakočević, M. M. (1986b) Jedan novi aspekt tumačenja evolucionog procesa - eksponencijalni karakter evolucije proteina, Arhiv bioloških nauka, 37 (1-4), 1 - 10. 
Rakočević, M. M. (1988a) Theree-dimensional Model of the Genetic Code, Acta Biol. Med. Exp. $13,109-116$.

Rakočević, M. M. (1988b) Geni, molekuli, jezik, Naučna knjiga, Beograd. (www.rakocevcode.rs)

Rakočević, M. M. (1988c) The optimal for the Amino Acid Code, 6th Congress of the Federation of European Societies of Plant Physiology (FESPP), 4 - 10. IX. 1988, Split, Yugoslavia.

Rakočević, M. M. (1988d) The New Matrix of the Genetic Code, XIV Congress of Union Yugoslav Physiological Societes (UYPS) with international participation, 20 - 24. IX 1988, Belgrade, Yugoslavia.

Rakočević, M.M. (1990) Information-topological concept of the amino acid code, in: Proceedings (Zbornik radova) of Faculty of Science (former: Faculty of Philosophy), Chemistry Section, 1, 1990, pp. 3-23.

Rakočević, M.M. (1991) The coherence of the chemical and genetic code, in: Proceedings (Zbornik radova) of Faculty of Science (former: Faculty of Philosophy), Chemistry Section, 2, 1991, 1-29, Niš.

Rakočević, M.M. (1993) U Bibliji rečeni prirodni kod, Srpski književni glasnik, 2, 130 - 142, Naučna knjiga, Beograd.

Rakočević, M.M. (1994a) Logic of the Genetic Code, Naučna knjiga, Beograd. www.rakocevcode.rs)

Rakočević, M.M. (1994b) Does universal consciousness exist? (Emerging Logic of the Periodic System of Elements, Genetic Code and Human Consciousness), Toward A Scientific Basis for Consciousness, An Interdisciplinary Conference, The University of Arizona, Tucson, April 1214, 1994. Program and Abstracts, p. 123, Poster Presentations, No 62. [Abstract of this work can be found in the Proceedings of my papers, in: (MMR, 2017a).]

Rakočević, M.M. (1995) The universal consciousness and the universal code, "Consciousness Scientific Challenge for the 21st Century", Symposium, May 29 - 30, 1995, ECPD, European Centre for Peace and Development of the United Nations University for Peace, Belgrade. Second Edition in 1996. [This Symposium was a "replica in small" of the Conference of the University of Arizona in Tucson (MMR, 1994b). All illustrations from this paper were contained in my poster at the Tucson Conference. An extended version of the paper can be found in the Proceedings of my papers, in: (MMR, 2017a)]

http://www.ecpd.org.rs/pdf/2015/books/1995/1995 ecpd consciousness.pdf

Rakočević, M.M. (1997a) Two classes of the amino acyl-tRNA synthetases in correspondence with the Codon path cube, Bull. Math. Biol. Vol. 59, No. 4, pp. 645-648.

Rakočević, M.M. (1997b) Genetic Code as a Unique System, Studentski kulturni centar -Niš http://www.rakocevcode.rs

Rakočević, M.M. (1997c) The universal consciousness as a universal comprehension of the universal code, in: Brain and Consciousness Proceedings of the First Annual ECPD International Symposium on Scientific Bases of Consciousness 22-23 September 1997, Belgrade, Yugoslavia http://www.ecpd.org.rs/pdf/2015/books/1997/1997_ECPD_Symposium.pdf (Also in Collection of works: MMR, 2017a).

Rakočević, M.M. (1998a) The genetic code as a Golden mean determined system, Biosystems, 46, 283-291.

Rakočević, M.M., (1998b) Whole-number relations between protein amino acids and their biosynthetic precursors. J. Theor. Biol. 191, 463-465. 
Rakočević, M.M. (1998c) Harmonija periodnog Sistema hemijskih elemenata, Flogiston, 7, 169183. [Harmony of PSE.]

Rakočević, M.M. (2000a) The factors of the classification of protein amino acids, Proceedings (Glasnik) of the Section of Natural Sciences on Montenegrin Academy of Sciences and arts (CANU), 13, 273-294; (Available also at: arXiv:q-bio/0611004v1 [q-bio.BM])

Rakočević, M. M. (2000b) Njegošev iskonski logos (Njegosh's primordial logos), I, Interpress, Belgrade, (in Serbian only).

Rakočević, M.M. (2002) Genetic code: Alphanumerical regularities within a codon determined amino acid order, Proceedings (Glasnik) of the Section of Natural Sciences on Montenegrin Academy of Sciences and arts (CANU), 14, 183-197.

Rakočević, M. M. (2003) Njegošev iskonski logos (Njegosh's primordial logos), II, Interpress, Belgrade (in Serbian only).

Rakočević, M.M. (2004a) A harmonic structure of the genetic code. J. Theor. Biol. 229, 221-234.

Rakočević, M. M. (2004b) Further generalization of Golden mean in relation to Euler's "divine" equation, FME Transactions (Faculty of Mechanical Engineering, Belgrade, Serbia), 32, 95-98. https://www.mas.bg.ac.rs/_media/istrazivanje/fme/vol32/2/fme_vol_32_no_2_-

_rakocevic.pdf; arXiv:math/0611095v4 [math.GM]; http://www.rakocevcode.rs

Rakočević, M.M. (2006) Genetic Code as a Harmonic System. arXiv:q-bio/0610044v1 [qbio.OT].

Rakočević, M.M. (2007a) A New Genetic Code Table. arXiv:q-bio/0703012 [q-bio.GN].

Rakočević, M.M. (2007b) About Tesla's and Njegoš's general coherence, in: Tesla - Visions, work, life, Faculty of Mechanical Engineering, Belgrade, Serbia (in Serbian): О Теслином и Његошевом согласију општем, у: Тесла - визије, дело, живот, Машински факултет, Београд, Србија.

Rakočević, M. M. (2008) Genetic Code: Four-Codon and Non-Four-Codon Degeneracy. Appendix in second version, 20 Sep 2019. arXiv:0802.1056v2 [q-bio.BM].

Rakočević, M. M. (2009) Genetic code: The unity of the stereochemical determinism and pure chance, arXiv:0904.1161v1 [q-bio.BM], 2009.

Rakočević, M.M. (2011a) Genetic Code: Four Diversity Types of Protein Amino Acids. arXiv:1107.1998v2 [q-bio.OT].

Rakočević, M.M. (2011b) Genetic code as a coherent system, NeuroQuantology, 9 (4), 821-841. http://www.rakocevcode.rs

Rakočević M.M. (2011c) The universal code as a reality of holism, Round Table Knowledge Federation Dialog Belgrade 2011: Partial vs Holistic Oriented Approaches, Sept. 25/ Symposium of Quantum-Informational Medicine QIM 2011, Belgrade, 23-25, September, 2011.

Rakočević, M.M., (2013a) Harmonic mean as a determinant of the Genetic Code. arXiv:1305.5103v4 [q-bio.OT].

Rakočević, M.M. (2013b) Golden and harmonic mean in the genetic code. In: Proceedings of the $2^{\text {nd }}$ International Conference "Theoretical Approaches to Bioinformation Systems" (TABIS.2013), September, 17-22, 2013, Belgrade, Serbia. (Also in OSF Preprints DOI 10.31219/osf.io/2pfe7) http://www.tabis2013.ipb.ac.rs/tabis2013.pdf 
Rakočević, M.M. (2015a) Njegoš’s Po(i)etics (in Serbian with summary in English for all chapters of universal poetic structures, in: Njegoševa po(i)etika, p. 128. Pitura, Beograd. http://www.rakocevcode.rs

Rakočević, M.M. (2015b) Po(i)etics of universal poetic structures, in: Njegoševa po(i)etika, p. 128. Pitura, Beograd. http://www.rakocevcode.rs [key word "Njegosh"]

Rakočević, M.M. (2015c) Universal poetic structures - Njegosh's work in relation to the works of Homer and Dante, Serbian literary magazine, 2015. year, pp. 137-148. (Publisher: The Serbian Writers Assotiation, Francuska 7, Belgrade, Serbia.)

Rakočević, M.M. (2017a) Harmony of genetic code (Vol. 2) OSF Preprints DOI 10.31219/osf.io/89uah [(Vol. 1 on: DOI 10.31219/osf.io/c38rg ) (Vol 1 contains articles published in arXiv; it is better to find them there, because they are not updated here from the aspect of new versions)

Rakočević, M.M. (2017b) Analogies of Genetic and Chemical Code (an expanded version), OSF Preprints DOI 10.31219/osf.io/mxecj

Rakočević, M.M., (2017c) Enigma of Darwin Diagram. OSF Preprint DOI 10.31219/osf.io/qzg69

Rakočević, M.M., (2017d) Genetic code: Chemical Distinctions of Protein Amino Acids, OSF Preprints DOI 10.31219/osf.io/86rjt

Rakočević, M.M. (2017e) Golden and Harmonic Mean in the Genetic Code [OSF Preprint DOI 10.31219/osf.io/2pfe7]

Rakočević, M.M., (2017f) Tesla's Hidden Holism, Second International Congress Nikola Tesla Disruptive innovation, Sava Center, Belgrade, 2-4 June 2017, Invited lectures, Session 1, June 2 [OSF Preprint DOI 10.31219/osf.io/c4dws ] [www.rakocevcode.rs ]

Rakočević, M.M. (2018a) The Cipher of the Genetic Code, BioSystems 171 (2018) 31-47.

Rakočević, M. M. (2018b) Analogies of Genetic and Chemical Code, Polyhedron, 153, 292-298.

Rakočević, M. M. (2019a) Protein amino acids as a complete (periodic) system, Chemia Naissensis, Vol 2, Issue 1, pp. 1-43.

Rakočević, M. M., (2019b) Genetic code as an image of the mirror image. Part I, OSF Preprint DOI $10.31219 /$ osf.io/xht $4 \mathrm{c}$

Rakočević, M. M. (2020a) A note on the system chemistry, OSF Preprint DOI $\underline{10.31219 / \text { osf.io/z7bm3 }}$

Rakočević, M. M. (2020b) Analogies of genetic and chemical code. Supplement 1, OSF Preprints DOI 10.31219/osf.io/34c8n

Rakočević, M. M. (2020c) Essays on natural codes: probably and improbably (I) OSF Preprint DOI 10.31219/osf.io/c47yf

Rakočević, M.M., Jokić, A. (1996) Four stereochemical types of protein amino acids: synchronic determination with chem. characteristics, atom and nucleon number. J.Theor. Biol. 183, 345-349.

Ravas, Aleksandra (2018) Carl Friedrich Gauss and the formula for the sum of the first $n$ natural numbers (in Serbian). Presentation from the 14th Serbian Mathematical Congress (SMAK), held from 16 to 19 May 2018. year, at the Faculty of Science and Mathematics in Kragujevac, Serbia. http://elib.mi.sanu.ac.rs/files/journals/nm/259/nmn259p41-53.pdf 
Rumer, Yu.B. (1966) O sistematizacii kodonov v geneticheskom kode, Dokl. Akad. Nauk. SSSR 167, 1393-1394.

Shcherbak, V. I. (1993) Twenty Canonical Amino Acids of the Genetic Code: The Arithmetical Regularities. Part I. J. Theor. Biol. 162, 399-401.

Shcherbak, V. I. (1994) Sixty-four Triplets and 20 Canonical Amino Acids of the Genetic Code: The Arithmetical Regularities. Part II. J. Theor. Biol. 166, 475-477.

Sjoestroem, M., Wold, S. (1985) A multivariate study of the relationship between the genetic code and the physical-chemical properties of amino acids. J. Mol Evol, 22 (3) 272-7.

Sukhodolets, V.V. (1985) A sense of the genetic code: reconstruction of the prebiological evolution stage, Genetika, XXI, 10, 1589-1599 (in Russian).

Swanson, R. (1984) A unifying concept for the amino acid code. Bull. Math. Biol. 46, 187-207.

Thom, René (1979) La genèse de la présentation de l'espace selon Piaget, in: Théories du langage, Théories de l'apprentissage. Le débat entre Jean Piaget et Noam Chomsky, Éditions du Seuil, Paris, 1979.

Thom, René (1990) Geneza prezentacije prostora prema Pijažeu, u: Teorije jezika, teorije učenja, Izdavačka knjižarnica Zorana Stojanovića, Sremski Karlovci, Srbija.

Trifonov D.N, redaktor (1981) Uchenie o periodichnosti - istoriya i sovremenost'. (Nauka, Moskva).

Trifonov, D.N., Dmitriev I.S. (1981) O kolichestvenoy interpretacii periodičeskoy sistemy; in: Uchenie o periodichnosti - istoriya i sovremenost'; redactor D.N. Trifonov (Nauka, Moskva), pp. 221-253.

Van Nostrand (1983) Scientific Encyclopedia, $6^{\text {th }}$ Ed., New York.

Verkhovod, A.B. (1994) Alphanumerical divisions of the universal genetic code: new divisions reveal new balances, J. Theor. Biol. 170, 327-330.

Weaver, R.F. (2012) Molecular Biology, fifth international edition. McGraw-Hill, New York.

Wohlin, Åsa (2015) Numeral series hidden in the distribution of atomic mass of amino acids to codon domains in the genetic code, J. Theor. Biol., 369, 95-109.

Yang, Chi Ming (2004) On the 28-gon symmetry inherent in the genetic code intertwined with aminoacyl-tRNA synthetases-The Lucas series, Bulletin of Mathematical Biology volume 66, pages1241-1257. 


\section{ATLAS OF ILLUSTRATIONS}

\section{Main Atlas: Figures}

\begin{tabular}{|c|c|c|c|c|c|c|c|c|c|c|c|}
\hline$(-2)$ & $\begin{array}{l}\cdots \\
\ldots\end{array}$ & & & & & & & & & $\ldots$ & -22 \\
\hline$(-1)$ & -21 & -20 & -19 & -18 & -17 & -16 & -15 & -14 & -13 & -12 & -11 \\
\hline (0) & -10 & -09 & -08 & -07 & -06 & -05 & -04 & -03 & -02 & -01 & 00 \\
\hline (1) & 01 & 02 & 03 & 04 & $\overline{-05}$ & 06 & 07 & 08 & 09 & 10 & 11 \\
\hline (2) & 12 & 13 & & & $16^{-}$ & -17 & -18 & 19 & 20 & 21 & 22 \\
\hline (3) & 23 & 24 & 25 & $26^{\prime}$ & 27 & 28 & 29 & 30 & 31 & 32 & 33 \\
\hline (4) & 34 & 35 & 36 & (37) & 38 & 39 & 40 & 41 & 42 & 43 & 44 \\
\hline (5) & 45 & 46 & 47 & 48 & 49 & 50 & $\underline{51}$ & 52 & 53 & 54 & 55 \\
\hline (6) & 56 & 57 & 58 & 59 & 60 & 61 & $\overline{62}$ & 63 & 64 & 65 & 66 \\
\hline (7) & 67 & 68 & 69 & 70 & 71 & 72 & 73 & 74 & 75 & 76 & 77 \\
\hline (8) & 78 & 79 & 80 & 81 & 82 & 83 & 84 & 85 & 86 & 87 & 88 \\
\hline (9) & 89 & 90 & 91 & 92 & 93 & 94 & 95 & 96 & 97 & 98 & 99 \\
\hline (A) & $\mathrm{AO}$ & $\mathrm{A} 1$ & $\mathrm{~A} 2$ & A3 & $\overline{A 4}$ & A5 & $\mathrm{A} 6$ & A7 & $A 8$ & A9 & $\mathrm{AA}$ \\
\hline (B) & B1 & B2 & B3 & B4 & B5 & B6 & B7 & B8 & B9 & $\mathrm{BA}$ & $\mathrm{BB}$ \\
\hline
\end{tabular}

Figure 1. Periodic Number System (PSN) in the decimal number system. From (MMR, 2019a, Fig. A1, p. 28) (https://www.pmf.ni.ac.rs/chemianaissensis/) This PSN was originally called "The Table of minimal adding (TMA)" in [MMR, 2011b, Tab. 4, p. 826: "The Table of minimal adding in decimal numbering system. A specific arrangement of natural numbers in decimal numbering system, going from 01 to 11 and so on, with Shcherbak's 'simulation' analogs $(13,25,37,49 \ldots)$ within the first diagonal."] The definite name "Periodic System of Numbers" I have used in several previous papers, especially in (MMR, 2019a, Fig. A1, p. 28). From one work to another, the variations are only in the emphasis of certain significant places (shadows, etc.). Thus, three significant places are highlighted and marked here, from which we "take" three systemarrangements, which are shown to correspond to some chemical system-arrangements. The first place is in connection with the first Boolean spatial "triangle"; on the right side it is written twice and marked in red: 0-1-2. This "triangle" was actually taken together with its mirror image, with the superposition of number 2, as shown in the lower part of Fig. 2, on the left. Another significant place is: 26-16-17-18; and the third - the second diagonal, marked by shading (11-91). \{Additional Note (30.03.2021): The terms "first diagonal" and "second diagonal" are optional. 


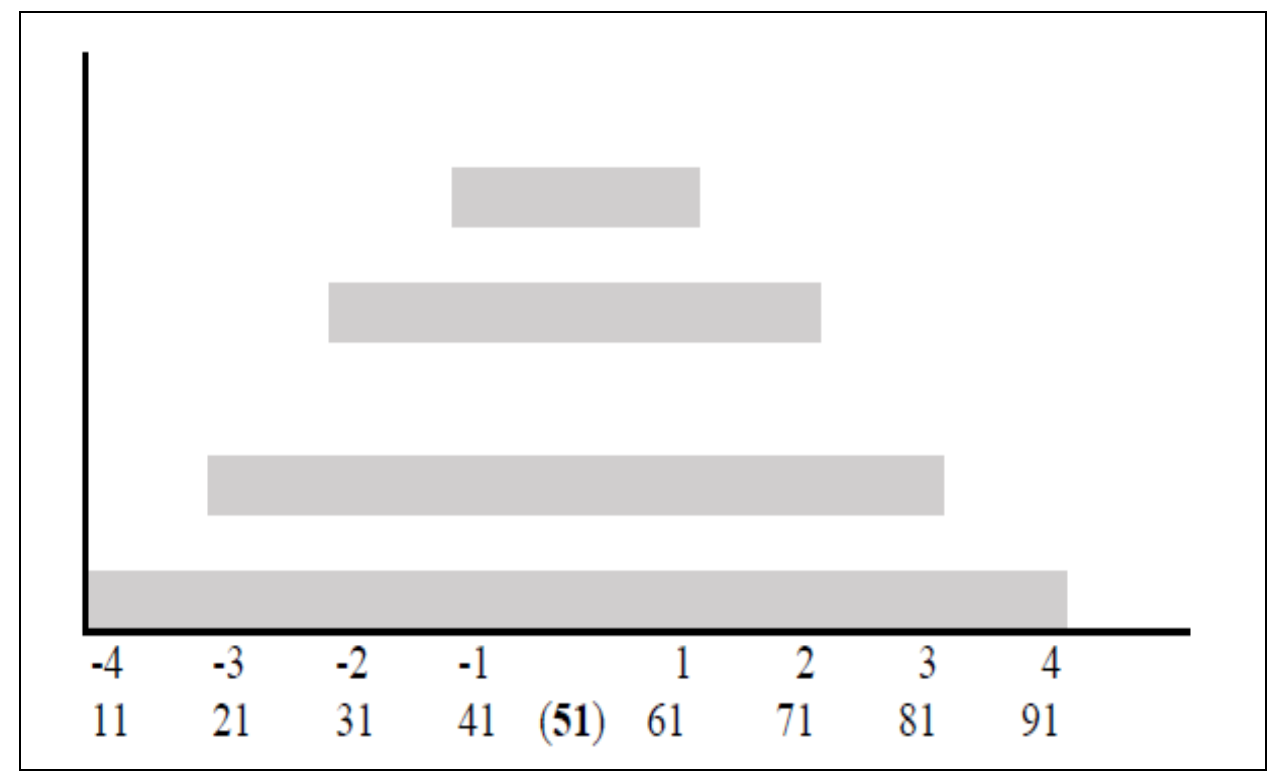

Figure 1.1. Gaussian addition procedure and Gauss' numbers: $51 \pm 10,51 \pm 20,51 \pm 30$, $51 \pm 40$ (Fig. 3 and Box 10). It is about a quarter of the number of atoms in 20 protein AAs (in their side chains: $204=4 \times 51)(51=3 \times 17)$. The uniqueness of both numbers (17 and 204) is presented in Tables A1-A4 within A-Atlas.

[Note 1: According to a well-known anecdote (Ravas, 2018), "Little Gauss" calculated the sum for the first $n$ numbers, where $\mathrm{n}=100$. Here, however, $n=101$. With a generalization of the procedure, we have either a central pair, i.e. a doublet [in case: (50, 51)] when $n$ is an even number, or we have a central singlet (in this case of 51). But what is important here is to keep in mind the center of the series of natural numbers which are summed. In such a case, both situations belong to Gauss: a pair of numbers $(50,51)$ and a singlet, 51. Especially since this illustration, as well as the following (Figure 1.2), shows that this is a primordial "germ" of normal distribution that Gauss will discover in his mature scientific age.]

[Note 2: The reason more that the numbers 100 and 101 are taken in unity is the fact that they are not only neighbors in the Periodic System of Numbers (PSN, Figures 1.3 and 1.4), but there is the first appearance of three-digit numbers; and when the decimal number is written with zeros and units it inevitably corresponds to a binary number system. (Indirectly and with octal number system, because $10-2=8$.) (Cf. Tables C5 and C5.1).] 


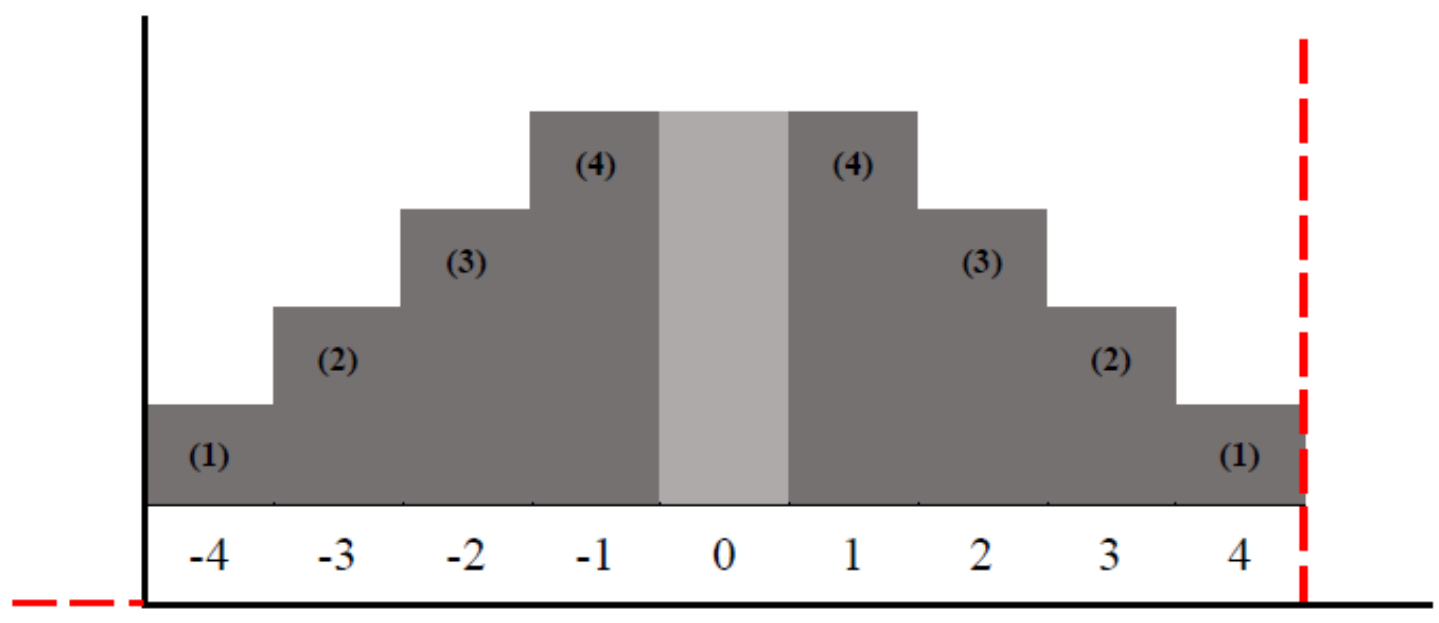

Figure 1.2. Gaussian addition procedure and Gaussian number as $51 \pm 10,51 \pm 20,51 \pm$ $30,51 \pm 40$ (broader graphic exploration: the correspondence with the scale in Figure 1.1). Two beginnings of the coordinate system are indicated, from left to right and from right to left. On the ordinate are given the distances from the starting point, and on the abscissa is given the distance from the central - zero point (above which the "mirror" is given).

[Note: Comparing this system-arrangement with the arrangement in Figure 1.1, we see that the quantity "51" has a value of zero, which is the reality in GC (Figure 3).] 


\begin{tabular}{|c|c|c|c|c|c|c|c|c|c|c|c|}
\hline & & & & & & & & & & & 20 \\
\hline & -21 & -20 & -19 & -18 & -17 & -16 & -15 & -14 & -13 & -12 & -11 \\
\hline (0) & -10 & -09 & -08 & -07 & -06 & -05 & -04 & -03 & -02 & -01 & 00 \\
\hline (1) & 01 & 02 & 03 & 04 & 05 & 06 & 07 & 08 & 09 & 10 & 11 \\
\hline (2) & 12 & 13 & 14 & 15 & 16 & -47 & -18 & 19 & 20 & 21 & 22 \\
\hline (3) & 23 & 24 & 25 & 26 & 27 & 28 & 29 & 30 & 31 & 32 & 33 \\
\hline (4) & 34 & 35 & 36 & 37 & 38 & 39 & 40 & 41 & 42 & 43 & 44 \\
\hline (5) & 45 & 46 & 47 & 48 & 49 & 50 & 51 & 52 & 53 & 54 & 55 \\
\hline (6) & 56 & 57 & 58 & 59 & 60 & 61 & 62 & 63 & 64 & 65 & 66 \\
\hline (7) & 67 & 68 & 69 & 70 & 71 & 72 & 73 & 74 & 75 & 76 & 77 \\
\hline (8) & 78 & 79 & 80 & 81 & 82 & 83 & 84 & 85 & 86 & 87 & 88 \\
\hline (9) & 89 & 90 & 91 & 92 & 93 & 94 & 95 & 96 & 97 & 98 & 99 \\
\hline (A) & $\mathrm{AO}$ & $\mathrm{A} 1$ & A2 & A3 & A4 & A5 & A6 & A7 & A8 & A9 & AA \\
\hline (B) & B1 & B2 & B3 & B4 & B5 & B6 & B7 & B8 & B9 & BA & BB \\
\hline
\end{tabular}

Figure 1.3. Periodic Number System (PSN) in the decimal number system. Everything is the same as in Figure 1, except that the choice of positions (shading) is different, corresponding to the chemical system-arrangement in Figure 6.2 [First row there: $(1+22$ vs $11+2)$ ]. The red box indicates a significant sequence: Shcherbak's Prime quantum 037 (Shcherbak, 1994); quantity 26 as the starting column in a system-arrangement in Figure 7; and number 15 as the first key point of symmetry in the Multiplication Table of the decimal number system; the number 25 as the second key point in the said Table. (Cf. Tables $\mathrm{C} 2$ and $\mathrm{C} 3$ ). 


\begin{tabular}{|c|c|c|c|c|c|c|c|c|c|c|c|}
\hline & & $\begin{array}{r}00- \\
10 \\
100-1\end{array}$ & $\begin{array}{r}11-2 \\
0-10 \\
1 / 1 \\
\quad(1\end{array}$ & $\begin{array}{l}/ 22 \\
/ 10 \\
1-10 \\
0101\end{array}$ & $\begin{array}{l}11-00 \\
-100 \\
0 \rightarrow( \\
)_{2}=(4\end{array}$ & $\begin{array}{l}\rightarrow 00-1 \\
\rightarrow(100-10 \\
100-101-1 \\
5)_{8}=(37)\end{array}$ & $\begin{array}{l}-22-1 \\
-100 \\
0)_{2}=\end{array}$ & $\begin{array}{l}1-00 \\
10\end{array}$ & $8=($ & $300)_{1}$ & \\
\hline \multirow{12}{*}{00} & & & & & & & & & & 00 & 01 \\
\hline & 01 & 02 & 03 & 04 & 05 & $06 \quad 07$ & 08 & 09 & 10 & 11 & \\
\hline & 12 & 13 & 14 & 15 & 16 & $-17^{---18}$ & 19 & 20 & 21 & 22 & \\
\hline & 23 & 24 & 25 & $26^{\prime}$ & 27 & $28 \quad 29$ & 30 & 31 & 32 & 33 & \\
\hline & 34 & 35 & 36 & 37 & 38 & 39 & 41 & 42 & 43 & 44 & \\
\hline & 45 & 46 & 47 & 48 & 49 & 50 & 52 & 53 & 54 & 55 & \\
\hline & 56 & 57 & 58 & 59 & 60 & 62 & 63 & 64 & 65 & 66 & \\
\hline & 67 & 68 & 69 & 70 & 71 & 72 & 74 & 75 & 76 & 77 & \\
\hline & 78 & 79 & 80 & 81 & 82 & 83 & 85 & 86 & 87 & 88 & \\
\hline & 89 & 90 & 91 & 92 & 93 & 94 & 96 & 97 & 98 & 99 & \\
\hline & 100 & 101 & 102 & 103 & 104 & 105 & 107 & 108 & 109 & 110 & \\
\hline & 111 & 112 & 113 & 114 & 115 & $116 \quad 117$ & 118 & 119 & 120 & 121 & \\
\hline
\end{tabular}

Figure 1.4. Cyclic Periodic System of numbers in decimal number system, without indicating the position of negative numbers. The system is cyclic because $(00,01)$ are at the beginning and end. [Analogous to Mendeleev's PS in two ways: 1. The zero group of chemical elements, the so-called noble gases, is found both at the beginning and at the end [Table 13 in (Kedrov, 1977); 2. The elements of the first group ( $\mathrm{Cu}, \mathrm{Ag}, \mathrm{Au})$ are indicated also at the end of the PSE (Kedrov, 1977, p. 128, copy XII). [This confused many authors who felt that Mendeleev was hesitant here as to whether these elements were in the first or eighth group.] This cyclicity is also analogous to the specific systemarrangement of GC in which the first row of AAs also appears at the end (Table 1.1). In this way the diagonal is extended by pair 01 and $101(01+100=102)$, corresponding to the Gauss' pair 01 and 100. Above the PSN (quite above) two mirroring are indicated in the range of double digits and triple digits; both corresponding to quantitative relationships in GC. 


\begin{tabular}{|c|c|c|}
\hline $\begin{array}{l}(10|11| 10)_{2} \rightarrow(46)_{10} \\
10+11+10=(31)_{10}\end{array}$ & $\underline{0} 15$ & $\underline{0} 14$ \\
\hline $\begin{array}{l}(100|101| 100)_{2} \rightarrow(300)_{10} \\
100+101+100=(301)_{10}\end{array}$ & $\underline{001}$ & \\
\hline $\begin{array}{l}(110|111| 110)_{2} \rightarrow(446)_{10} \\
(110+111+110)_{10}=(331)_{10}\end{array}$ & $\underline{1} 15$ & 686 \\
\hline $\begin{array}{l}(1000|1001| 1000)_{2} \rightarrow(2200)_{10} \\
(1000+1001+1000)_{10}=(3001)_{10}\end{array}$ & 801 & 516 \\
\hline $\begin{array}{l}(1010|1011| 1010)_{2} \rightarrow(2746)_{10} \\
(1010+1011+1010)_{10}=(3031)_{10}\end{array}$ & 285 & 270 \\
\hline $\begin{array}{l}(1100|1101| 1100)_{2} \rightarrow(2746)_{10} \\
(1100+1101+1100)_{10}=(3301)_{10} \\
\ldots\end{array}$ & 555 & \\
\hline
\end{tabular}

Figure 1.4a. Unique connection of binary and decimal number system. Explanation in Box 16. 


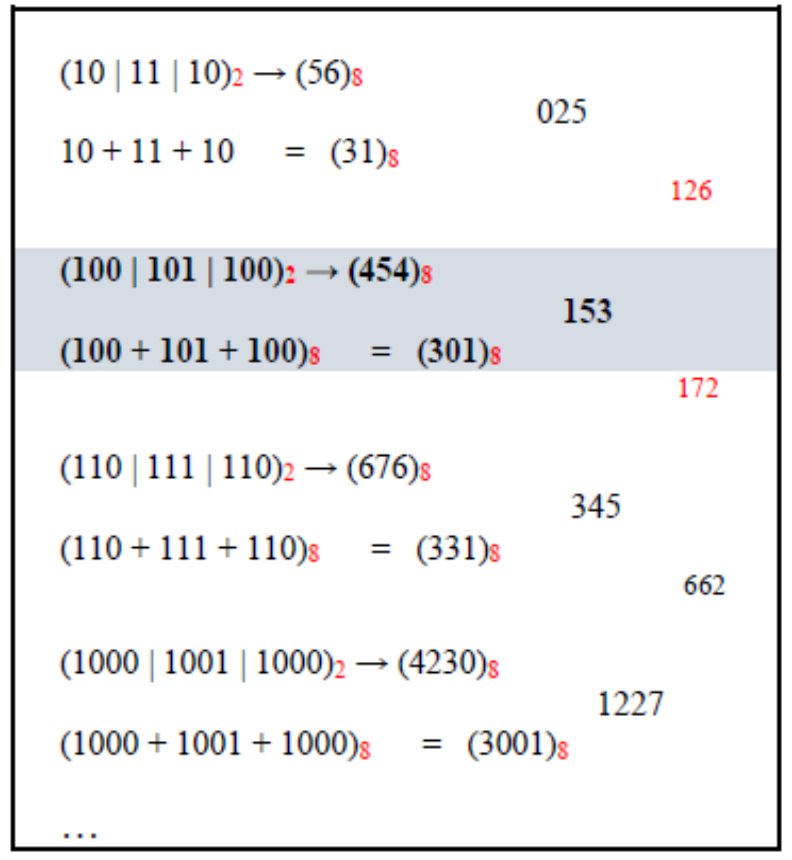

Figure 1.4b. Unique connection of binary and octal number system.

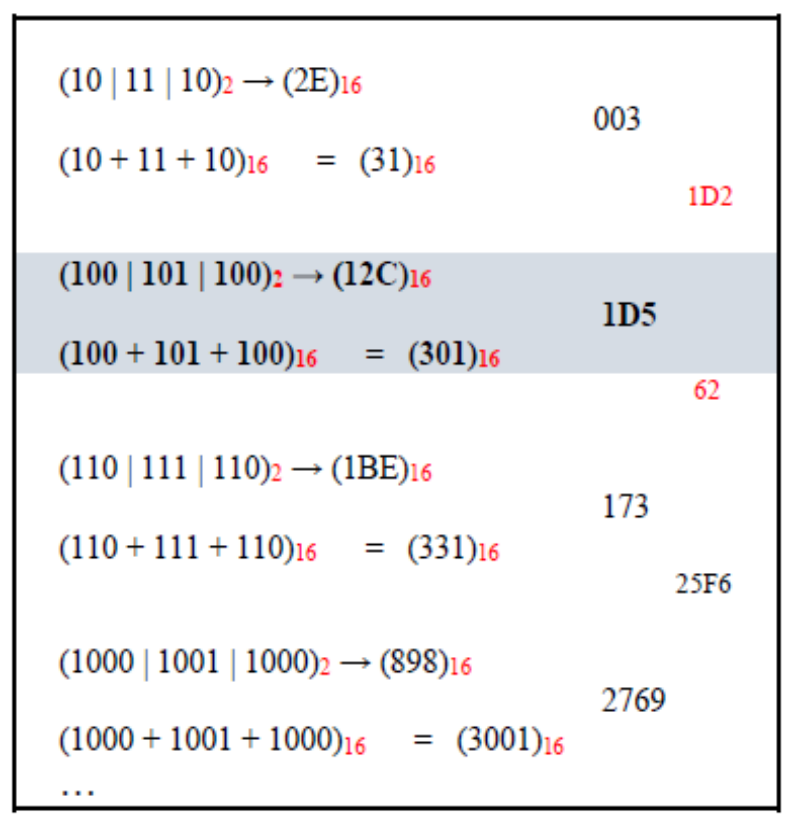

Figure 1.4c. Unique connection of binary and hexadecimal number system. 


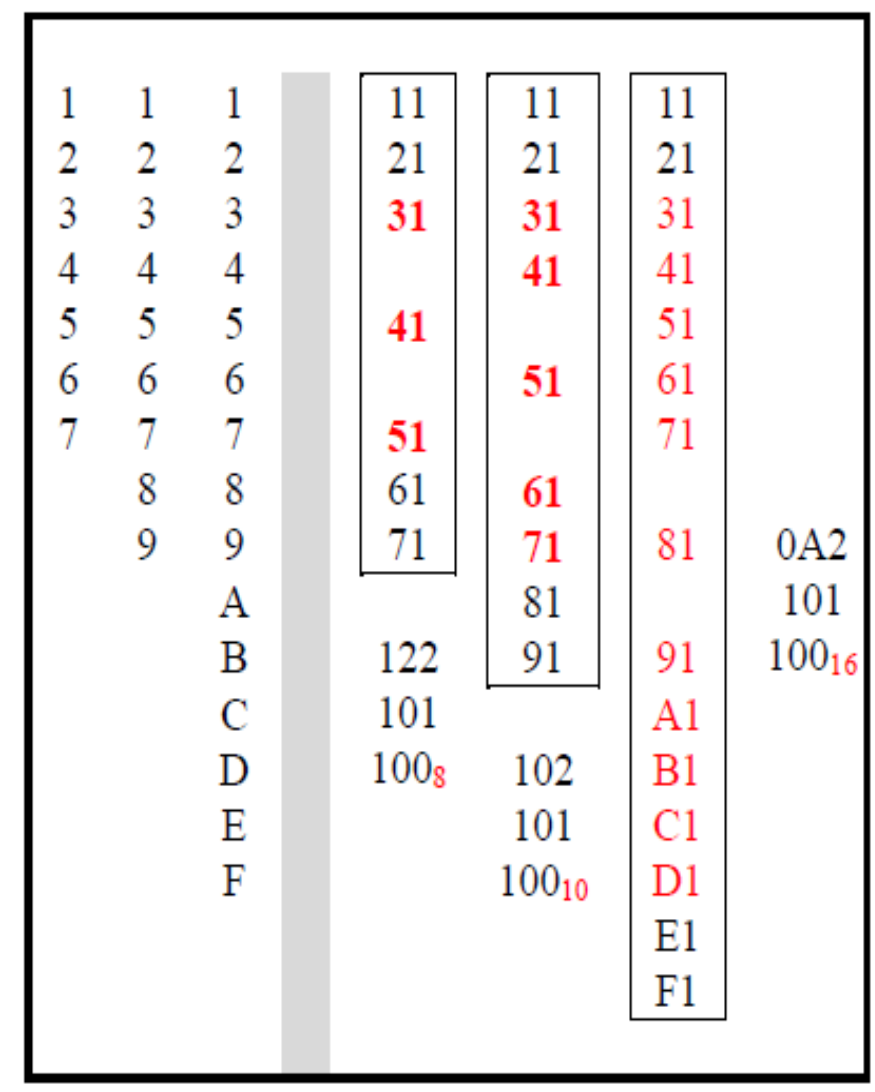

Figure 1.4d. Number systems in relation to the diagonal system (DS) within Figure 1 and Figure 1.4. [Cf. Fig. 3.] 


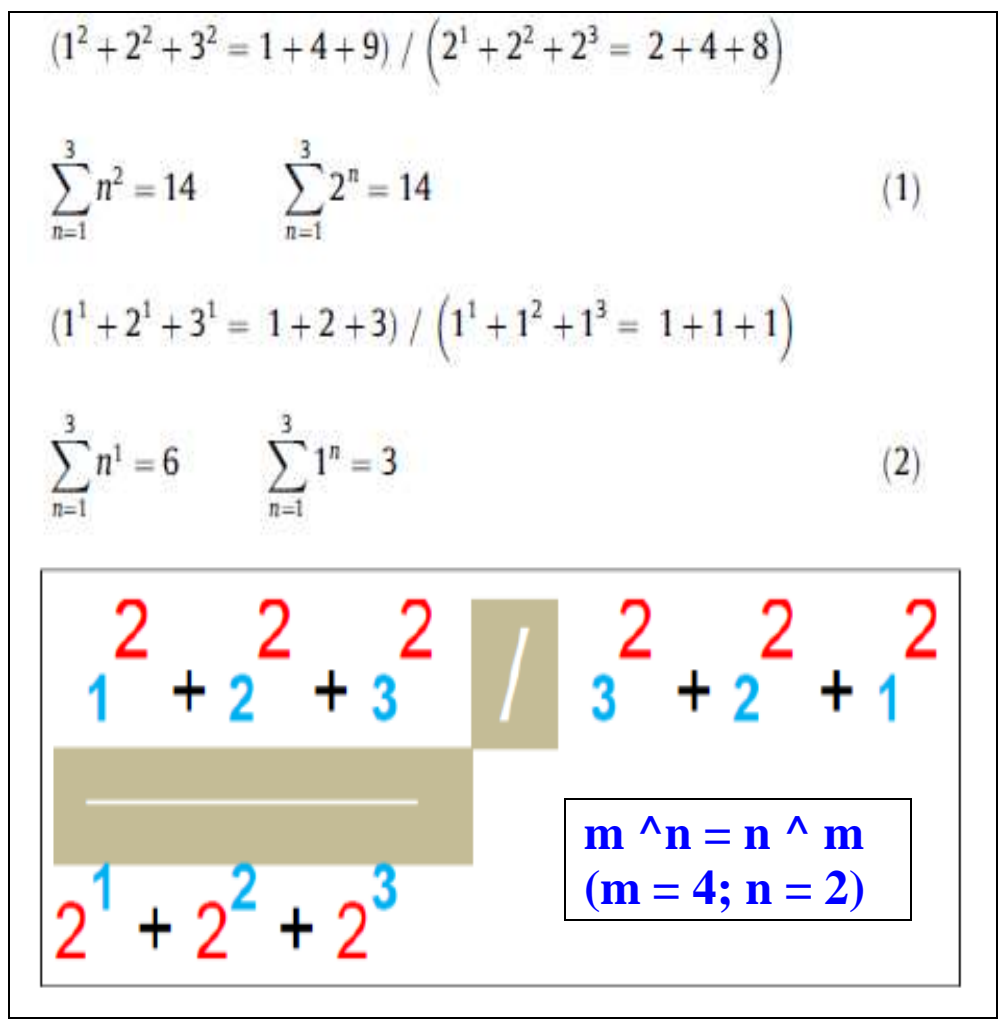

Figure 1.5. The mirroring of the Formula of Periodic system of chemical elements (Chemical Code). The upper part is taken from (MMR, 2018b) and it represents the two previous steps in relation to the third, given here in Box 5. The lower part presents one "hidden" double mirror, plus the message: the uniqueness of one (squaring number four) can to repeat the three associated, which by this and such association present a new uniqueness.

[Note: Squaring the number four represents the realization of a large square with 16 small squares. The first 16 numbers from a series of natural numbers can be placed in these small squares, in various ways. The best way (corresponding to the principle of selfsimilarity) will be the one that provides the maximal number of the same results, as we find in the so-called Dürer's magic square (Box 4 and Figures B1 and B1.1).] 


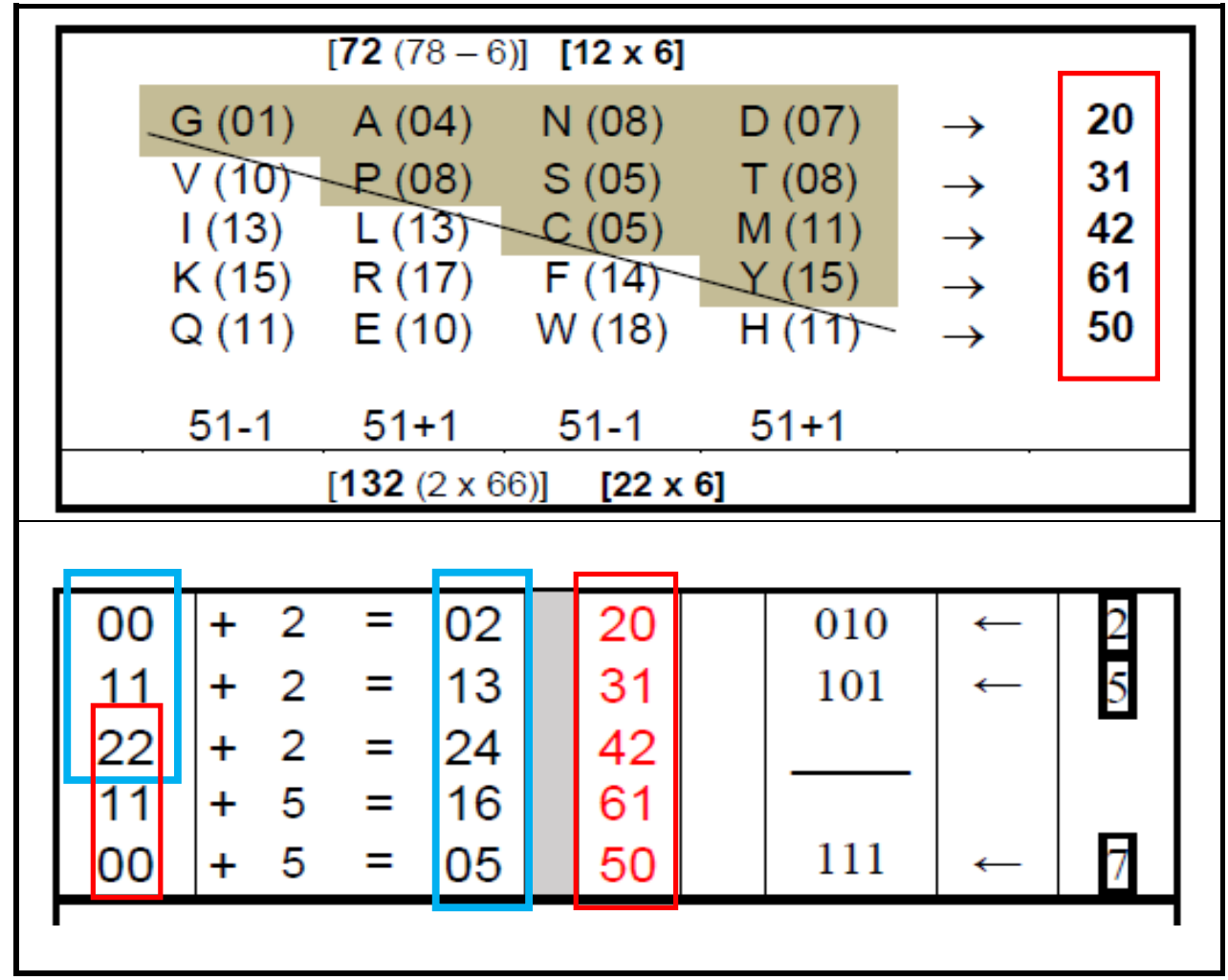

Figure 2. The illustration above follows from AAs arrangements sorted by chemical similarity; originally in (MMR, 2019a, Table 2); here as in Table 1. The illustration below shows why GC (observed in the form of its amino acid component) is a mirror image. It is shown the "double" Boolean triangle (00-11-22) together with its mirror image (00-11-22 / 22-11-00), created by superimposing two 22 into one, i.e. by mapping the two 22 into one: $22 \& 22 \rightarrow 22$. To the resulting mirrored "narcissus", to its vertices, the numbers 2 and 5 "taken off" from the six-bit binary tree are added. At the lower part (on the right), the binary "path" on the six-bit binary tree is shown, where the biggest change occurs (in each subsequent step, the numbers 0 and 1 are replaced). 


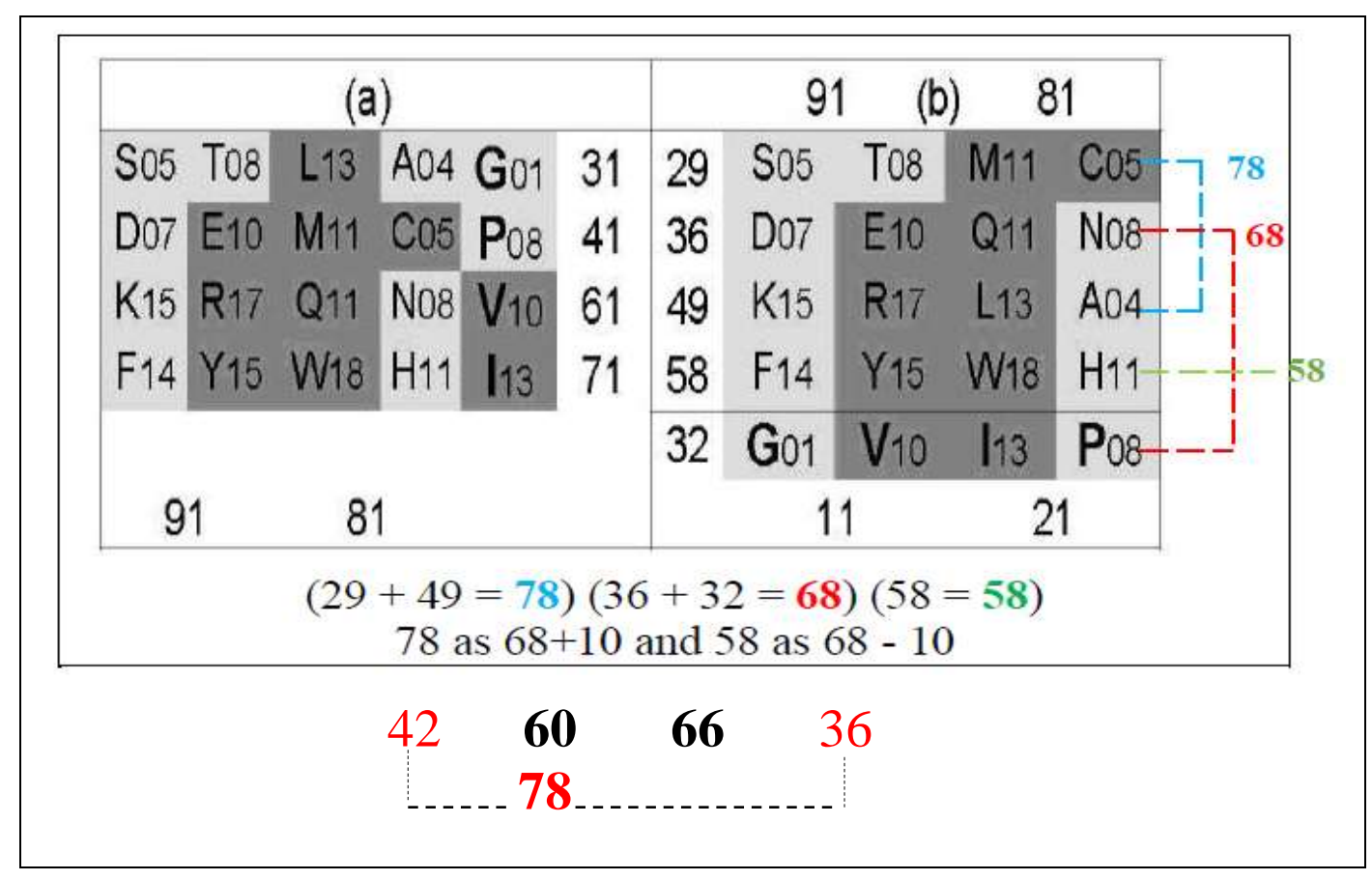

Figure 3. From (MMR, 2011b, Fig. 9, p. 834): The distribution of amino acids according to Gauss' algorithm. (a) the distribution of amino acids has been derived from right side of Table 2, by presenting two pairs here in one row as the 'pair of pairs'. In the beginning of each row obtained in this way one non-alanine stereochemical type amino acid has been associated, by the increasing molecule mass (GPVI). Atom number (in amino acid side chains) in the rows and columns, generated in this way, corresponds, one hundred per cent, to the quantums from the first row of Gauss' algorithm of adding numbers from 1 to 101. [The first row of "Gauss' algorithm" as in Figure A1; or as here in Figure 1, as a diagonal: 11, 21, $31,41,-, 61,71,81,91$.$] Dark tones: Class I of amino acids handled by class I of enzymes$ aminoacyl-tRNA synthetases; light tones: Class II. Going from (a) to (b) it is obviously that chemically related groups of AAs have been 'taken off' by 0,1 and 2 steps, respectively. By zero 'steps' in aromatics; by one step in chalcogen AAs (M, C in relation to S, T) and carboxylic (carboxylic AAs D \& E in relation with their amides $\mathrm{N} \& \mathrm{Q}$ ); by two steps in source aliphatic AAs: A, L \& K, R. The distribution in (b) is the same as in (a) but 'leveling' has been conducted here according to the chemical properties of molecules, so there is no more the taken off process. (Analogies with an arithmetical 'taken of' process see in Table A4, in first to last column.) Non-alanine stereochemical type amino acids have been added to the beginning of columns, instead to the beginning of rows. Shading is the same as in (a).

\{Additional Note 1 (30.03.2021): "Gauss' algorithm" because at the time when I first presented this system-arrangement (MMR, 2006), I did not know that it could be "downloaded" from the Periodic System of Numbers (PSN). It doesn't change anything, it remains Gauss's algorithm, regardless of the fact that he was only eight or nine years old (Ravas, 2018) when he saw it; especially since this algorithm corresponds to one of the greatest mathematical discoveries of the mature Gauss as a scientist - Gaussian normal distribution (Figure A1) \} 
\{Additional Note 2 (30.03.2021): Independent of the "Gauss' algorithm" it is immediately obvious that the number of atoms in the classes of AAs corresponds to the second diagonal of PSN, shown in Figure 1\}

\{Additional Note 3 (30.03.2021): Quantities 58-68-78 are discussed in the legends of the illustrations that follow. Going from the left system to the right: "shear" for one step [DEMC into DEQN] is analogous to "shear" which we find in the set of natural numbers, as a kind of a specific uniqueness [Table A4 (55-55; 89-89 etc.)]. At the very bottom: The distribution of amino acids in columns (in the right arrangement) as in determination of AAs on the binary tree of GC (MMR, 1998a, Fig 1): 60, 66, 78 (Figure 4 in this paper).

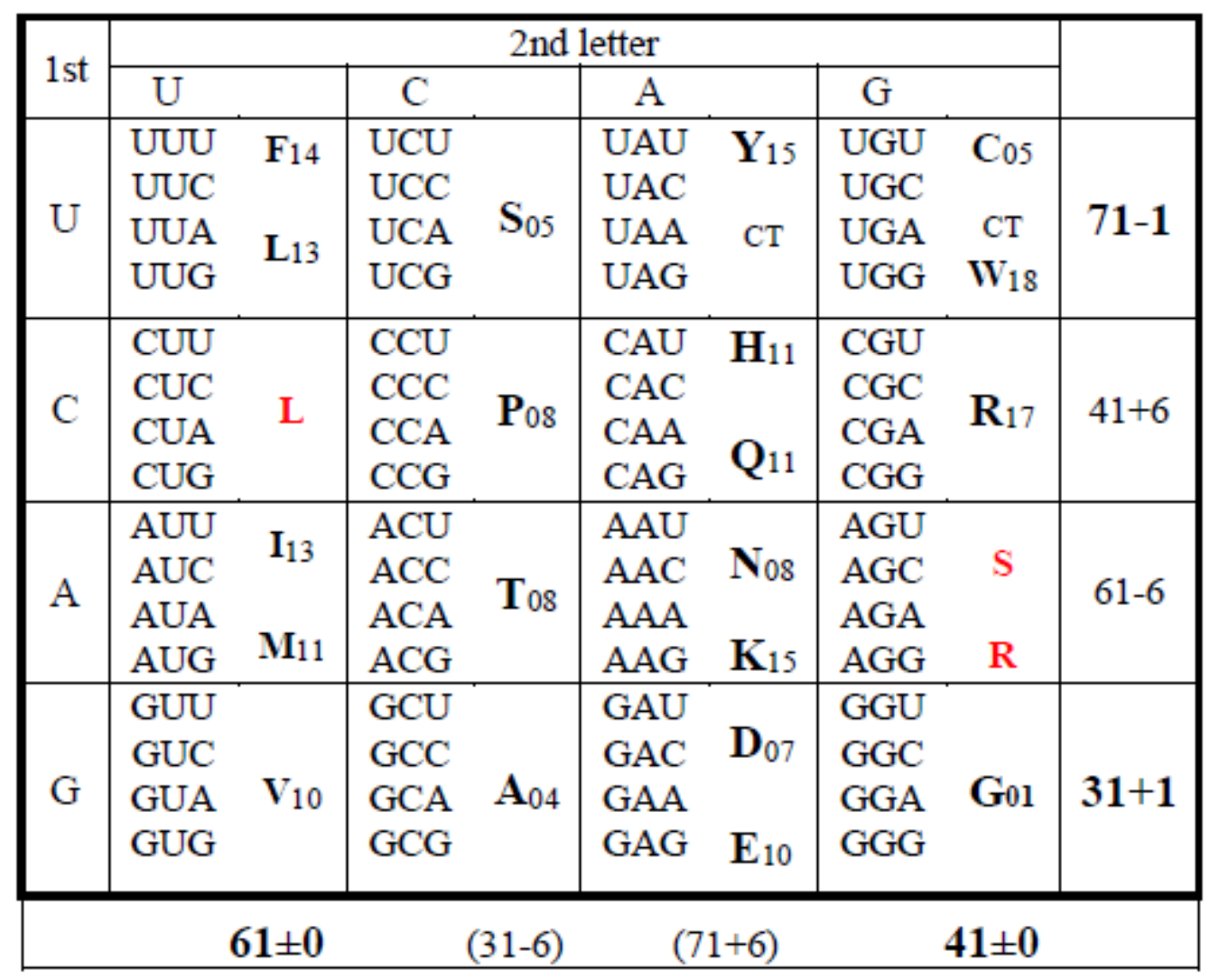

Figure 3.1. The standard GCT. According to the "if anything, then everything" principle [my modification of the biological principle "all, or nothing"], each amino acid (AA) is "read" only once, and in that way the state in a set of 20 protein AAs is seen and considered. [Another such a way of reading - odd columns versus even columns - I showed in one of the previous papers (MMR, 2004a, Tabs 7 and 8, p. 228).] The index gives the number of atoms in the side chains of AAs (including proline), relational to the standard functional amino acid group $\left[\mathrm{H}_{2} \mathrm{~N}-\mathrm{CH}-\mathrm{COOH}\right]$. The relation with the Gaussian algorithm is immediately obvious (Fig. 3 in relation to Tab. A1). [Cf. Fig. D6.] 


\begin{tabular}{|c|c|c|c|c|c|c|c|c|}
\hline $\begin{array}{l}\text { UUU } \\
\text { UUC } \\
\text { UUA } \\
\text { UUG }\end{array}$ & $\mathbf{L}$ & $\begin{array}{l}\text { UCU } \\
\text { UCC } \\
\text { UCA } \\
\text { UCG }\end{array}$ & $\mathbf{S}$ & $\begin{array}{l}\text { UAU } \\
\text { UAC } \\
\text { UAA } \\
\text { UAG }\end{array}$ & $\mathrm{CT}$ & $\begin{array}{l}\text { UGU } \\
\text { UGC } \\
\text { UGA } \\
\text { UGG }\end{array}$ & $\begin{array}{l}\text { C } \\
\text { CT } \\
\text { W }\end{array}$ & $71-1$ \\
\hline $\begin{array}{l}\text { CUU } \\
\text { CUC } \\
\text { CUA } \\
\text { CUG }\end{array}$ & & $\begin{array}{l}\mathrm{CCU} \\
\mathrm{CCC} \\
\mathrm{CCA} \\
\mathrm{CCG}\end{array}$ & $\mathbf{P}$ & $\begin{array}{l}\text { CAU } \\
\text { CAC } \\
\text { CAA } \\
\text { CAG }\end{array}$ & H & $\begin{array}{l}\text { CGU } \\
\text { CGC } \\
\text { CGA } \\
\text { CGG }\end{array}$ & $\mathbf{R}$ & $41+6$ \\
\hline $\begin{array}{l}\text { AUU } \\
\text { AUC } \\
\text { AUA } \\
\text { AUG }\end{array}$ & M & $\begin{array}{l}\text { ACU } \\
\text { ACC } \\
\text { ACA } \\
\text { ACG }\end{array}$ & $\mathbf{T}$ & $\begin{array}{l}\text { AAU } \\
\text { AAC } \\
\text { AAA } \\
\text { AAG }\end{array}$ & $\mathbf{K}$ & $\begin{array}{l}\text { AGU } \\
\text { AGC } \\
\text { AGA } \\
\text { AGG }\end{array}$ & & $61-6$ \\
\hline $\begin{array}{l}\text { GUU } \\
\text { GUC } \\
\text { GUA } \\
\text { GUG }\end{array}$ & V & $\begin{array}{l}\text { GCU } \\
\text { GCC } \\
\text { GCA } \\
\text { GCG }\end{array}$ & $\mathbf{A}$ & $\begin{array}{l}\text { GAU } \\
\text { GAC } \\
\text { GAA } \\
\text { GAG }\end{array}$ & D & $\begin{array}{l}\text { GGU } \\
\text { GGC } \\
\text { GGA } \\
\text { GGG }\end{array}$ & G & $31+1$ \\
\hline & 61 & \multicolumn{4}{|c|}{$\begin{array}{lll}61 & / & 41\end{array}$} & & 41 & 204 \\
\hline
\end{tabular}

Figure 3.2. The standard GCT in which 20 AAs are read. Red color: coding with purine codons, and blue with pyrimidine. [Cf. Table E3.] 


\begin{tabular}{|c|c|c|c|c|c|c|c|}
\hline $\begin{array}{l}\text { UUU } \\
\text { UUC } \\
\text { UUA } \\
\text { UUG }\end{array}$ & $\mathbf{L}$ & $\begin{array}{l}\text { UCU } \\
\text { UCC } \\
\text { UCA } \\
\text { UCG }\end{array}$ & $\begin{array}{l}\text { UAU } \\
\text { UAC } \\
\text { UAA } \\
\text { UAG }\end{array}$ & $\mathbf{Y}$ & $\begin{array}{l}\text { UGU } \\
\text { UGC } \\
\text { UGA } \\
\text { UGG }\end{array}$ & $\begin{array}{l}\text { C } \\
\text { CT } \\
\text { W }\end{array}$ & 70 \\
\hline $\begin{array}{l}\text { CUU } \\
\text { CUC } \\
\text { CUA } \\
\text { CUG }\end{array}$ & $\mathbf{L}$ & $\begin{array}{l}\mathrm{CCU} \\
\mathrm{CCC} \\
\mathrm{CCA} \\
\mathrm{CCG}\end{array}$ & $\begin{array}{l}\text { CAU } \\
\text { CAC } \\
\text { CAA } \\
\text { CAG }\end{array}$ & $\begin{array}{l}\mathbf{H} \\
\mathrm{Q}\end{array}$ & $\begin{array}{l}\text { CGU } \\
\text { CGC } \\
\text { CGA } \\
\text { CGG }\end{array}$ & $\mathbf{R}$ & 60 \\
\hline $\begin{array}{l}\text { AUU } \\
\text { AUC } \\
\text { AUA } \\
\text { AUG }\end{array}$ & $\begin{array}{c}\text { I } \\
\text { M }\end{array}$ & $\begin{array}{l}\mathrm{ACU} \\
\mathrm{ACC} \\
\mathrm{ACA} \\
\mathrm{ACG}\end{array}$ & $\begin{array}{l}\text { AAU } \\
\text { AAC } \\
\text { AAA } \\
\text { AAG }\end{array}$ & $\mathbf{K}$ & $\begin{array}{l}\text { AGU } \\
\text { AGC } \\
\text { AGA } \\
\text { AGG }\end{array}$ & $\begin{array}{l}\mathbf{S} \\
\mathbf{R}\end{array}$ & 90 \\
\hline $\begin{array}{l}\text { GUU } \\
\text { GUC } \\
\text { GUA } \\
\text { GUG } \\
\end{array}$ & V & $\begin{array}{l}\text { GCU } \\
\text { GCC } \\
\text { GCA } \\
\text { GCG } \\
\end{array}$ & $\begin{array}{l}\text { GAU } \\
\text { GAC } \\
\text { GAA } \\
\text { GAG } \\
\end{array}$ & D & $\begin{array}{l}\text { GGU } \\
\text { GGC } \\
\text { GGA } \\
\text { GGG }\end{array}$ & G & 032 \\
\hline 87 & & 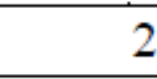 & & 77 & & 63 & 220 \\
\hline 87 & & $=63+2$ & & 77 & & & \\
\hline
\end{tabular}

Figure 3.3. The standard GCT with four duplicate AAs (L, I, S, R). It can be used to test the question - whether balancing and nuancing in the number of atoms really follow balancing and nuancing in physical and chemical properties. [Rakočević and Jokić, 1996, p. 345: "Shcherbak $(1993,1994)$ and Verkhovod (1994) have shown that the structural and functional distinction of protein amino acid molecules is followed by a strict balanced proportionality of nucleon number. ... We show ... that the presented law of balanced proportionality of nucleon number, as well as of atom number corresponds with the structural and functional distinctions, present in the four stereochemical types of protein amino acids, as well as in six types of their precursors within the biosynthesis pats. "] 


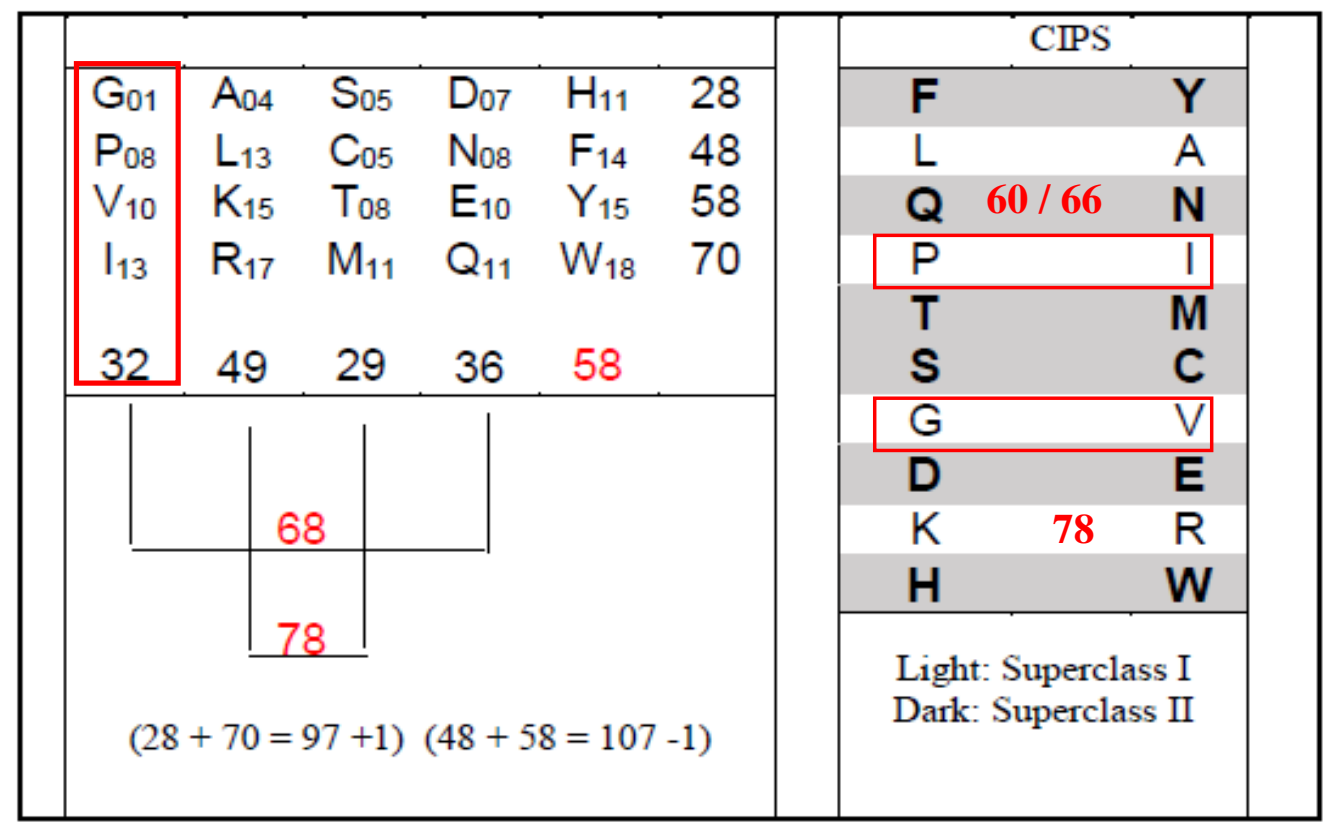

Figure 4. From (MMR, 2011b, Figure 6, p. 832) (here: illustration on the right): "The Cyclic Invariant Periodic System (CIPS) of canonical AAs. [protein AAs] ... In the middle position there are chalcogen AAs ( $\mathrm{S}, \mathrm{T} \& \mathrm{C}, \mathrm{M})$; follow - in next "cycle" - the AAs of non-alanine stereochemical types $(\mathrm{G}, \mathrm{P} \& \mathrm{~V}, \mathrm{I})$, then two double acidic AAs with two their amide derivatives $(\mathrm{D}, \mathrm{E} \& \mathrm{~N}, \mathrm{Q})$, the two original aliphatic AAs with two amine derivatives (A, L \& K, R); and, finely, four aromatic AAs (F, Y \& H, W) - two up and two down. The said five classes belong to two superclasses: primary superclass in light [white] areas and secondary superclass in dark areas. Notice, that each amino acid position in this CIPS is strictly determined and none can be changed."

\{Additional Note 1 (30.03.2021): About quantities 60-66-78 everything has already been said in the original paper (MMR, 1998, p. 289): „Within seven 'golden' amino acids (side chains) there are 60 atoms; within their seven complements there are $[60+(1 \times 6)]$ and within six noncomplements there are $\{[60+(1 \times 6)]+(2 \times 6)\}$ of atoms. .. Notice that the differences are $1 \times 6$, $2 \times 6$ and $3 \times 6$ which means realization of minimum change principle and continuity principle at the same time." \}

\{Additional Note 2 (30.03.2021): Now one can cf. classes and superclasses in left illustration: the quatities $97 / 107$ correspond to quantities $87 / 117 ; 117$ as the number of hydrogen atoms in 20 AAs, within their side chains; 87 as the number of non-hydrogen atoms. The quantities $58-68-78$ as $68 \pm 10$.

\{Additional Note 3 (30.03.2021): The chemical elements that make up the amino acid molecules in CIPS are contained in an "Island of life", within the PSE, as shown in Figure 4.1.\} 


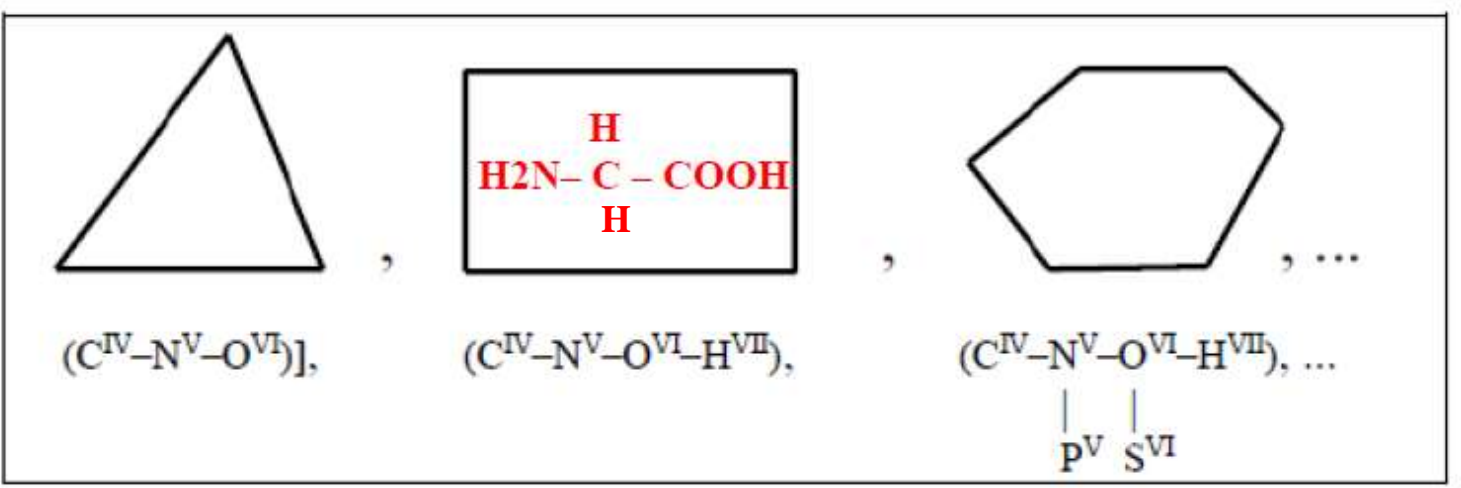

Box 2

The deviant genetic codes.

At that very first time (from 1966 until 1979) the Genetic Code Table was considered to be the Table of a universal genetic code. However, later with the discovery of alternative genetic codes, the Table was renamed in GCT of standard genetic code. The universality of the genetic code was first challenged in 1979, when mammalian mitochondria were found to use a code that deviated somewhat from the "universal" (Bamell et al., 1979; Attardi, 1985). Our opinion about "deviant codes" we have expressed in one of the previous works (Rakročevic, 2004), and we still think the same today, that they represent only a "degree of freedom" in deviation from the standard one. [Kright et al., 2001, p. 49: 'The genetic code ewolved in two distinct phases. First, the 'canonical' ode emerged before the last universal ancestor, subsequently, this code diverged in numerous nuclear and organelle lineages"; Weaver, 2012, pp. 568-569: These deviant codes are still closely related to the standard one from which they probably evolved'.]

Figure 4.1. Above: Polygonal line of topological circle (corresponding to the "Island of life" in PSE constituted by the elements that make up a Carbon world i.e. an Organic world). With the knowledge that hydrogen cannot be in the first group of PSE (MMR, 2018b), "Island of life" becomes evident. The chemical logic corresponding to the atomic polygonal line is as follows: $\left[\left(\mathrm{C}^{\mathrm{IV}}-\mathrm{N}^{\mathrm{V}}-\mathrm{O}^{\mathrm{VI}}\right)\right],\left(\mathrm{C}^{\mathrm{IV}}-\mathrm{N}^{\mathrm{V}}-\mathrm{O}^{\mathrm{VI}}-\mathrm{H}^{\mathrm{VII}}\right),\left(\mathrm{C}^{\mathrm{IV}}-\mathrm{N}^{\mathrm{V}}-\mathrm{P}^{\mathrm{V}}-\mathrm{O}^{\mathrm{VI}}-\right.$ $\left.\mathrm{S}^{\mathrm{VI}}-\mathrm{H}^{\mathrm{VII}}\right)$. Down: from (MMR, 2018a).

Additional explanation: With just one glance at PSE (Periodic System of chemical Elements) it is immediately obvious that, outside of the "Island of Life", there are no nonmetallic elements that could participate in the building of life. Potential candidates could be arsenic and selenium, although they are not non-metals, they are amphoter elements. As we know, selenium is indeed involved in some organisms instead of sulfur (selenocysteine). Of course, there is a possibility for other deviant genetic codes, in which lysine would be replaced not only by pyrrolizine, but also perhaps by some other amino acid; or that the sulfur in the amino acid is bound differently than it is in methionine, and the like. 


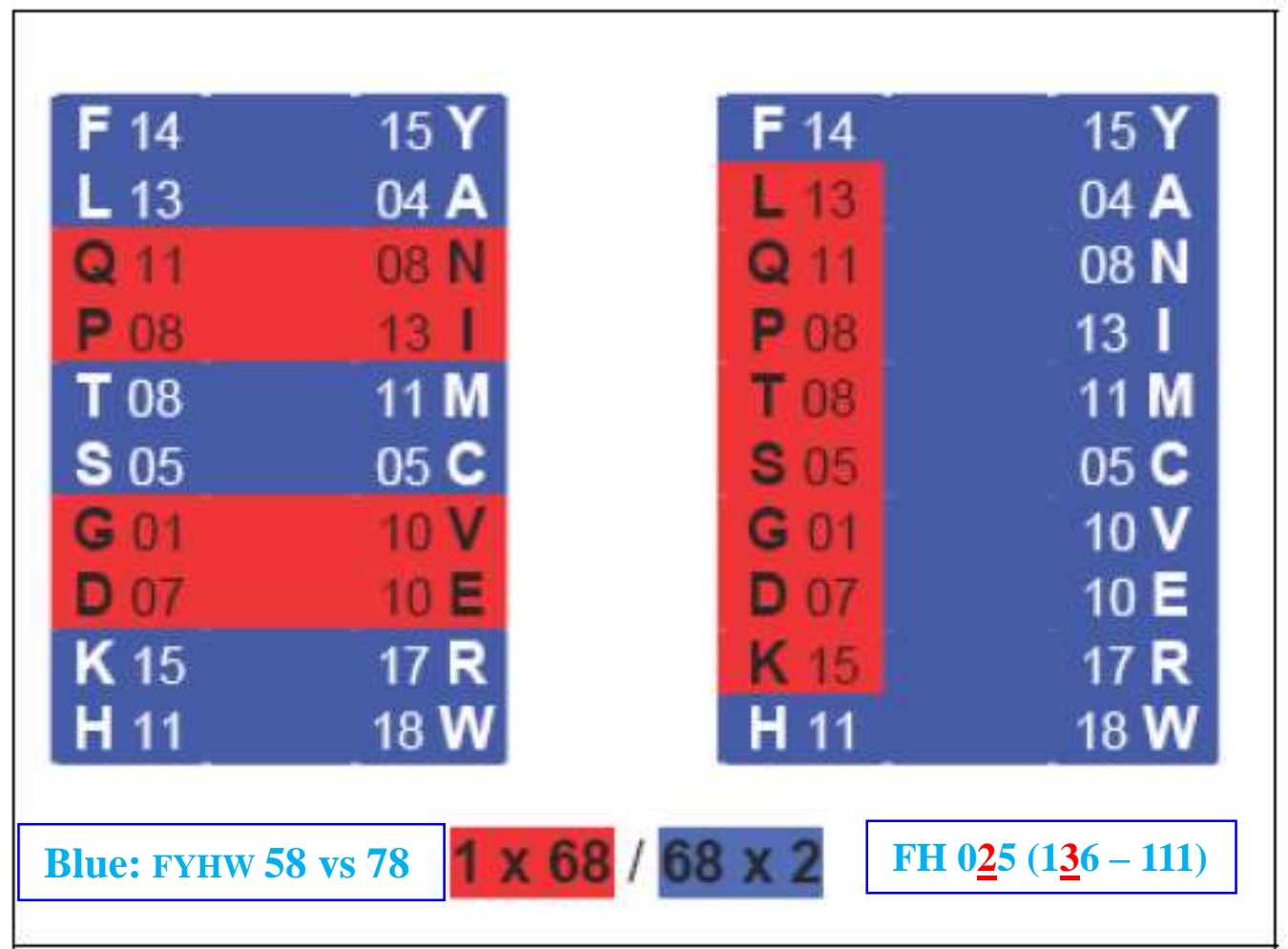

Figure 4.2. From (MMR, 2009a, Table B.2): "The number of amino acid molecules in proportion 2:3 and the number of atoms within side chains 1:2. On the right: the quantum "1 x 68" make the aliphatic "golden" AAs, without F, plus two smaller aliphatic non-complements (D \& K); and the quantum "2 x 68" of all others. On the left: the quantum " 1 x 68" make four AAs (G, P and V, I) of nonalanine stereochemical type (larger diversity!) plus two and two AAs - two double acidic $(\mathrm{D}, \mathrm{E})$ and only two amides $(\mathrm{N}, \mathrm{Q})$, what means a very specific diversity; and the quantum "2 x 68" all other AAs. arXiv:0903.4110v1 [qbio.BM].

\{Additional Note (30.03.2021): Original paper about "Golden" AAs, their complements and non-complements in (MMR, 1998a). 


\begin{tabular}{|cccc|c|}
\hline H 11 & W 18 & $\rightarrow$ & 29 & \multirow{2}{*}{ K 15} \\
K 07 & R 17 & $\rightarrow$ & 32 & 78 \\
N 08 & Q 11 & $\rightarrow$ & 17 & \\
P 08 & I 13 & $\rightarrow$ & 19 & \\
A 04 & L 13 & $\rightarrow$ & 17 & 68 \\
G 01 & V 10 & $\rightarrow$ & 11 & \\
\hline S 05 & C 05 & $\rightarrow$ & 10 & \\
T 08 & M 11 & $\rightarrow$ & 19 & 58 \\
F 14 & Y 15 & $\rightarrow$ & 29 & \\
\hline Odd 35 & 62 & & 097 & $4 \times 34$ \\
11 & 01 & & 10 & $2 \times 34$ \\
Even 46 & 61 & & 107 & \\
\hline
\end{tabular}

Figure 4.3. Relationships within the CIPS (Cyclic Invariant Periodic System), the systemarrangement as in Figs 3, 4 and 7, with further nuancing and balancing of quantities 58-68-78. Thus, we have first aromatic AAs (FY HW 58); then go together non-alanine (GP VI 32) and dicarboxylic (from alanine type) with their derivatives (DN EQ 36) $[32+36=68]$; And, finally aliphatic (AL KR 49) with chalcogen AAs (ST CM 29) [49 + $29=78]$.

\begin{tabular}{|c|c|c|c|c|}
\hline 5 & $\mathrm{~F}$ & 91 & $107 \mathrm{Y}$ & $\mathbf{w}=$ white $; \mathbf{d}=$ dark \\
\hline 4 & L & 57 & $15 \mathrm{~A}$ & $244+421=665$ \\
\hline 3 & Q & 72 & $58 \mathrm{~N}$ & $\mathbf{w} 244+\mathbf{d} 448=686+6$ \\
\hline 2 & $\mathrm{P}$ & 41 & 57 & r $142+1421=569-6$ \\
\hline $\mathbf{1}$ & $\mathrm{T}$ & 45 & $75 \mathrm{M}$ & $386 \quad 665 \quad(133 \times 5)$ \\
\hline 1 & $\mathrm{~S}$ & 31 & 47 & $665-386=(31 \times 9)$ \\
\hline 2 & G & 01 & 43 & $386=496-110$ \\
\hline 3 & D & 59 & 73 & \\
\hline 4 & $\mathrm{~K}$ & 72 & $100 \mathrm{R}$ & $\mathbf{r}=$ red; $\mathbf{l}=$ light \\
\hline 5 & $\mathrm{H}$ & 81 & $130 \mathrm{~W}$ & \\
\hline
\end{tabular}

Figure 4.4. Relationships within CIPS, corresponding to nucleon number distinctions (in AA side array) through the AAs classes. On the right side, it can be seen that the number of nucleons in the classes of AAs is such that the form of number-digits confirms the effect of the principles of similarity and self-similarity. [Analogies with quantum physics were first noticed by $\mathrm{V}$. Shcherbak (1994).] Correspondence with differences in the quantities of protons (hydrogen and non-hydrogen protons), with the number of protons, in relation to the system-arrangement of $\mathrm{V}$. Sukhodolets' presented in Figure 4.5. [686 vs 569] \{Note: Number 496 is the third perfect number, and number 110 is a half of the first friendly number. The sum of the numbers from 1 to 31 is 496.$\}$ 


\begin{tabular}{|c|c|c|}
\hline \multicolumn{3}{|l|}{ The number of $\mathrm{H}$ atoms (in brackets) and nucleons } \\
\hline \begin{tabular}{|l|l|l|l|l|l|l}
$\mathrm{G}(01) 01$ & $A(03) 15$ & $S(03) 31$ & $D(03) 59$ & $C(03) 47$
\end{tabular} & (13) 153 & \\
\hline 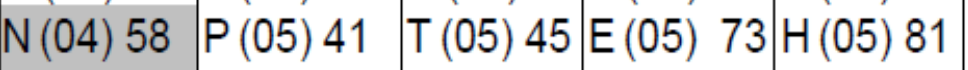 & (24) 298 & $(\mathbf{5 9} / 58)$ \\
\hline 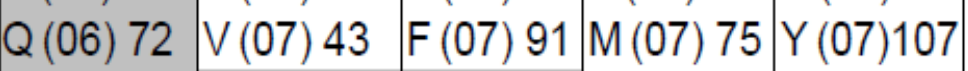 & (34) 388 & $569 / 686$ \\
\hline W (08)130|R (10) 100|K (10) $72 \mid$ I (09) $57 \mid \mathrm{L}(09) 57$ & (46) 416 & \\
\hline \multicolumn{2}{|l|}{$\begin{array}{l}569 \text { as neutron number and } 686 \text { as proton number! } \\
569-59=627-117 \\
686-58=628\end{array}$} & \\
\hline
\end{tabular}

Figure 4.5. From (MMR, 2011b, Table 7, p. 830): “The Sukhodolets' system of amino acids in a $4 \times 5$ arrangement. The Sukhodolets' Table, with a minimal modification (Sukhodolets, 1985): the system of 4 x 5 AAs. The shadow space: AAs with even number of hydrogen atoms $(4,6,8,10)$; the non-shadow space: AAs with odd number of hydrogen atoms $(1,3,7,9,11)$. In brackets: number of hydrogen atoms and out of brackets the number of nucleons. Nucleon number through a specific "simulation": 569 within two outer rows, as the number of neutrons, 569, in all 20 AAs - within their side chains; and 686 nucleons within two inner rows, as the number of protons, 686, in all 20 AAs - within their side chains. [The "simulation" as a holistic information within a part about the whole? (Rakočević, 2011c)] Within 20 side chains of amino acid molecules there are 569 neutrons as well as 569 non-hydrogen protons. Within 20 side chains of amino acid molecules there are 117 hydrogen protons, what means 117 hydrogen atoms at the same time $(117=59+58)$." 


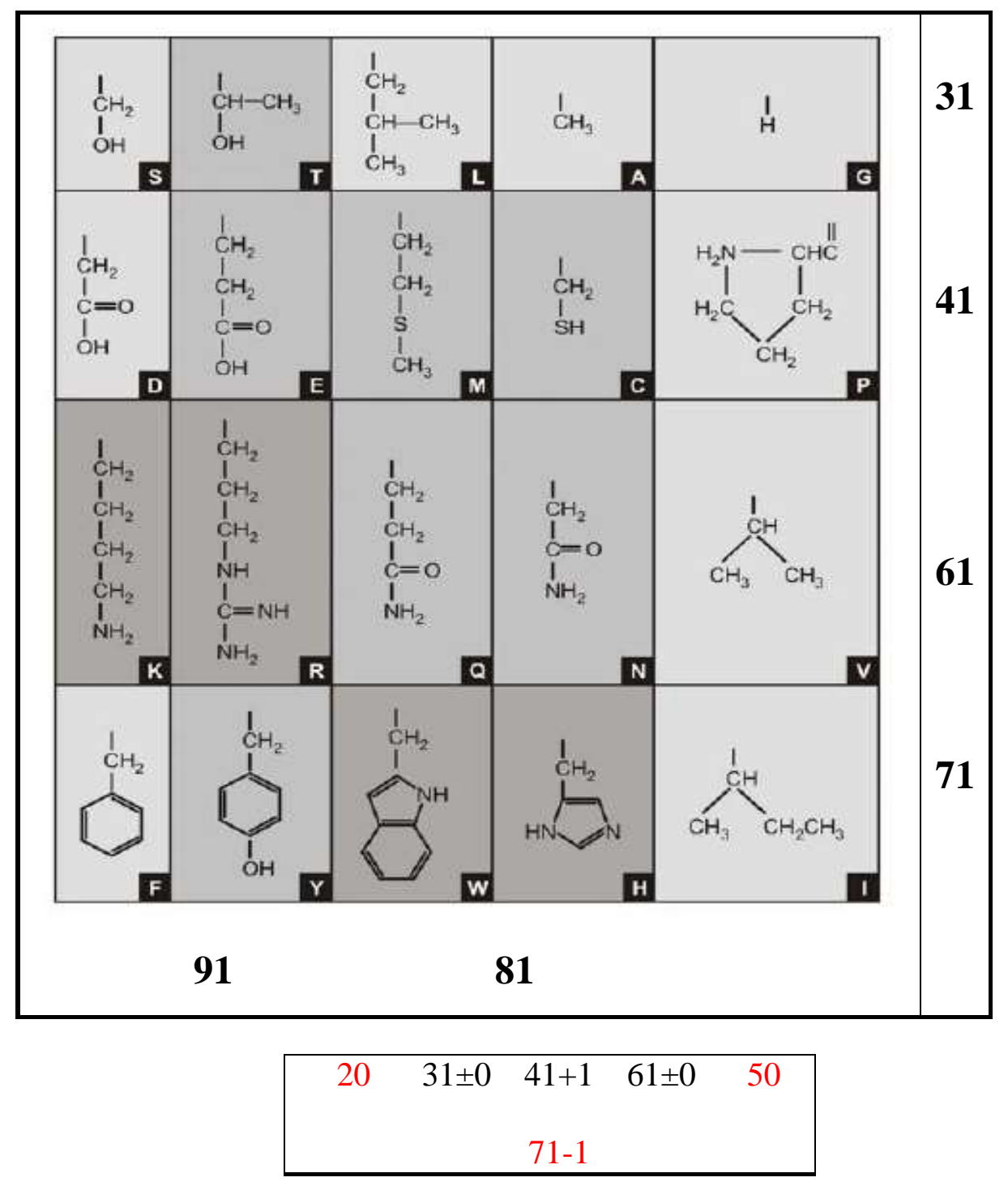

Figure 5. From (MMR, 2006, Fig. 1.2, p. 6) and from (MMR, 2011b, Fig. 10, p. 835) (www.rakocevcode.rs): The structure of amino acid molecules. The simplest amino acid is glycine $(\mathrm{G})$ whose side chain is only one atom of hydrogen. It is followed by alanine (A) whose side chain is only one $\mathrm{CH}_{3}$ group, which is the smallest hydrocarbon group. There are total of 16 amino acids of alanine stereochemical type with one $\mathrm{CH}_{2}$ group between the "body" and the "head". The glycine type contains glycine $(\mathrm{G})$ only; valine type contains valine and isoleucine $(\mathrm{V}$, I). The last stereochemical type is proline type with proline $(\mathrm{P})$ which represents the inversion of valine in the sense that the "triangle" of three $\mathrm{CH}_{2}$ groups for the "head" is not bound by the basis, therefore not only with one but with two $\mathrm{CH}_{2}$ groups (Popov, 1989; Rakočević \& Jokić, 1996). Light tones $[(\mathrm{G}, \mathrm{P}, \mathrm{V}, \mathrm{I})$ (32 atoms)] \& [(A, L, S, D, F) (43 atoms)]: invariant AAs; most dark tones $[(\mathrm{K}, \mathrm{R}, \mathrm{W}, \mathrm{H})(61$ atoms]: most variant AAs; less dark tones [(T, E, M, C, Q, N, Y) (68 atoms)]: less variant AAs. Notice a further possibility for splitting: 1. two aliphatic AAs [(K, R) (32 atoms)], 2. two aromatic AAs [(W, H) (29 atoms)], 3. chalcogen AAs plus aromatic hydroxide derivative [(MC, TY) (39 atoms), and 4. dicarboxylic amino acid plus two amides [(E, Q, N) (29 atoms). A specific calculation: less variant AAs, all aliphatic but one (Y), plus two 
more variant (aromatic: W, H), equals $68+29=97$ atoms; invariant AAs, all aliphatic but one (F) plus two more variant (aliphatic: K, R), equals $75+32=107$ atoms; if so, then: $107-97=$ 10; $107+97=204$. [Additional calculations: $32+43=75 ; 61+68=129$ (cf. Tab. C6.]

\{Additional Note 1 (30.03.2021): For AAs of the alanine stereochemical type (first four columns) the distinctions were made only on the basis of the structure of "body" i.e. side chain, without taking into account the head, i.e. the amino acid functional group. When we say "invariant amino acid", it means that in this type of structure there is nothing simpler than the given AA. Invariant, therefore, are only A, L, S, D, F (alanine as the first possible hydrocarbon derivative; leucine as the first possible branched derivative; serine as the first possible hydroxide derivative; aspartic acid as the first possible carboxylic derivative; and phenylalanine as the first possible of arenes hydrocarbon derivatives. In the case of AAs of non-alanine stereochemical types we have a different situation. There is no distinction possible with head exclusion. [AAs of non-alanine types do not have a $\mathrm{CH}_{2}$ group between the head and the body, as is the case with 16 AAs of alanine stereochemical type. (In several papers I have explained that threonine is specific: one hydrogen atom in the $\mathrm{CH}_{2}$ group is substituted by a methyl group.)] In AAs of the non-alanine type (last column) the body is directly attached to the head, and in all four AAs in the question is the first possible case. So in glycine the smallest possible atom (hydrogen atom) binds to the head of AA; proline is the first possible case of cyclicity in the set of protein AAs; valine is the first possible case with binding of isopropyl group (semi-cyclic group); isoleucine is the first possible derivative of valine, possessed by the isopropyl group).

\{Additional Note 2 (30.03.2021): This distinction with the possession, or non-possession, of a "barrier" between head and body was the reason why in my first pre-print paper in arXiv, the AAs of non-alanine-type I called as "contact" AAs, and of alanine type as "non-contact" AAs (MMR, 2006, Remark 1, pp. 8-9).

\{Additional Note 3(30.03.2021): If would be only one more AA in the valine stereochemical type, formed by one hydrogen atom being substituted by a methyl group in the side chain of the isoleucine, the principle of self-similarity would cease to apply. [This would be the same situation as if there were a side chain with an n-ethyl, n-propyl, or n-butyl group within the alanine type, as I explained in the scenario of generating genetic code constituents (MMR, 2018a, Section 2, p. 32)].\}

\{Additional Note 4 (30.03.2021): The case of glycine is additionally unique, in a set of unique AAs of non-alanine stereochemical types. It is about the fact that it has two identical hydrogen atoms in the molecule; and this is the reason that glycine is the only AA in the set of protein AAs that does not have optical isomerism, i.e. enantiomerism. Hence the ambivalence: both of these atoms can be considered to belong to both the head and the body. On the other hand, this compactness of this molecule makes it the only organic molecule that best reflects the structure of a unique non-metallic island (" Island of life") in the Periodic system of the chemical elements (PSE).

\{Additional Note 5 (30.03.2021): At the very bottom: Correspondence with the number of atoms in the system-arrangement in Figure 2, with changes for \pm 0 and \pm 1 in relation to Gauss' sequence.

\{Additional Note 6 (30.03.2021): The reader is asked to correct a mistake in the proline formula: one hydrogen atom is bound to a nitrogen atom, not two.\} 


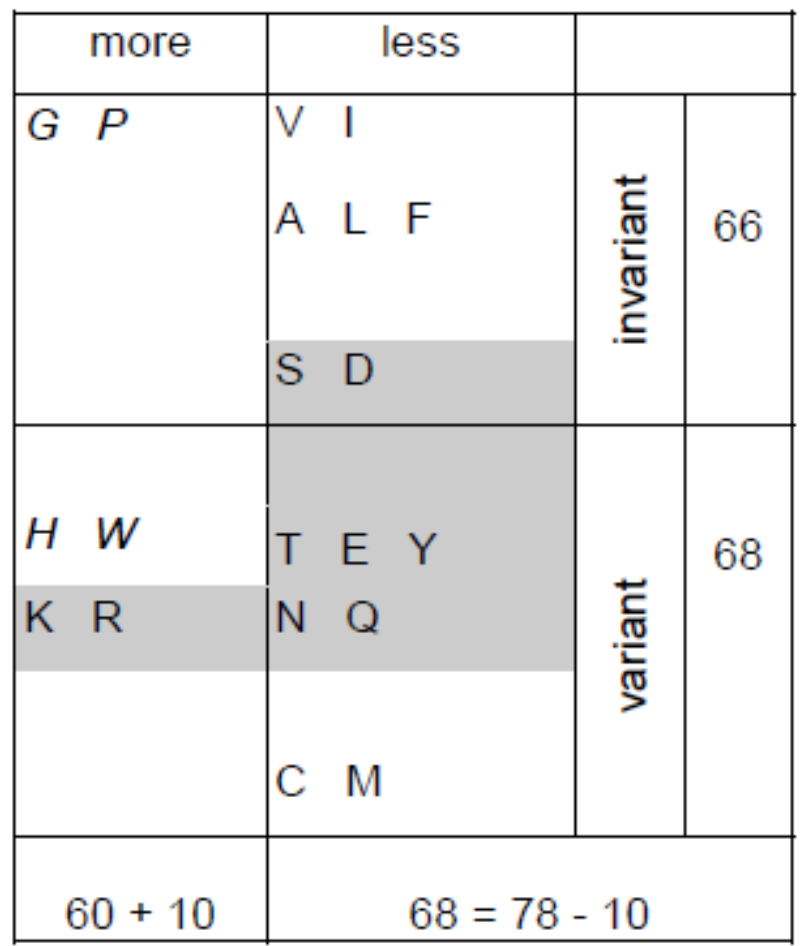

Figure 5.1. From (MMR, 2011b, Fig. 11, p. 835): This Figure shows that the splitting of AAs into two classes - variant and invariant - is not only a formality (the result of Gauss' algorithm), or just a matter of chemical structure of molecules, but also the matter of amino acid functions (polarity). In column "more" (more variant and more invariant) there are six AAs, two polar (KR) and four semi-polar (GP and HW). In column "less" (less variant and less invariant) there are 14 AAs, seven polar and seven non-polar. If, however, do not look at the number of molecules than at the number of atomic associations then they are seven polar and six non-polar. The AAs leucine (L) and isoleucine (I) are one and the same atom association through the structural isomery. Thus, the amino acid molecule patterns expressed in this Figure appear to be 4-9-6, what means: 4 semi-polar, 9 polar and 6 non-polar. [As a noteworthy is the fact that the pattern 4-9-6 corresponds to the third perfect number 496.]

\{Additional Note 1 (30.03.2021): About relations between polarity of AAs and their positions within GCT see in (MMR, 2018a, Equ. 5-8, p. 45)

\{Additional Note 2(30.03.2021): From Table 3 we see that lysine (K) and arginine (R) are polar in both parameters: hydropathy and cloister energy. On the other hand glycine $(\mathrm{G})$ and tryptophan (W) are polar in hydropathy and non-polar in cloister energy. The histidine $(\mathrm{H})$ is polar in hydropathy, but neutral in cloister energy. The proline $(\mathrm{P})$ is a special case: it is polar from the aspect of hydropathy, and non-polar from the aspect of polar requirement (Woese et al., 1966; Konopel'chenko and Rumer, 1975; Rakočević, 2004a).\}

\{Additional Note 3 (30.03.2021): If a set of invariant AAs is paired - each with each - and compared with each other in terms of invariance, glycine will always be the "winner" as the possessor of the simplest non-cyclic side chain, and proline as the possessor of the simplest cyclic side chain. Hence their special position in this system-arrangement. 


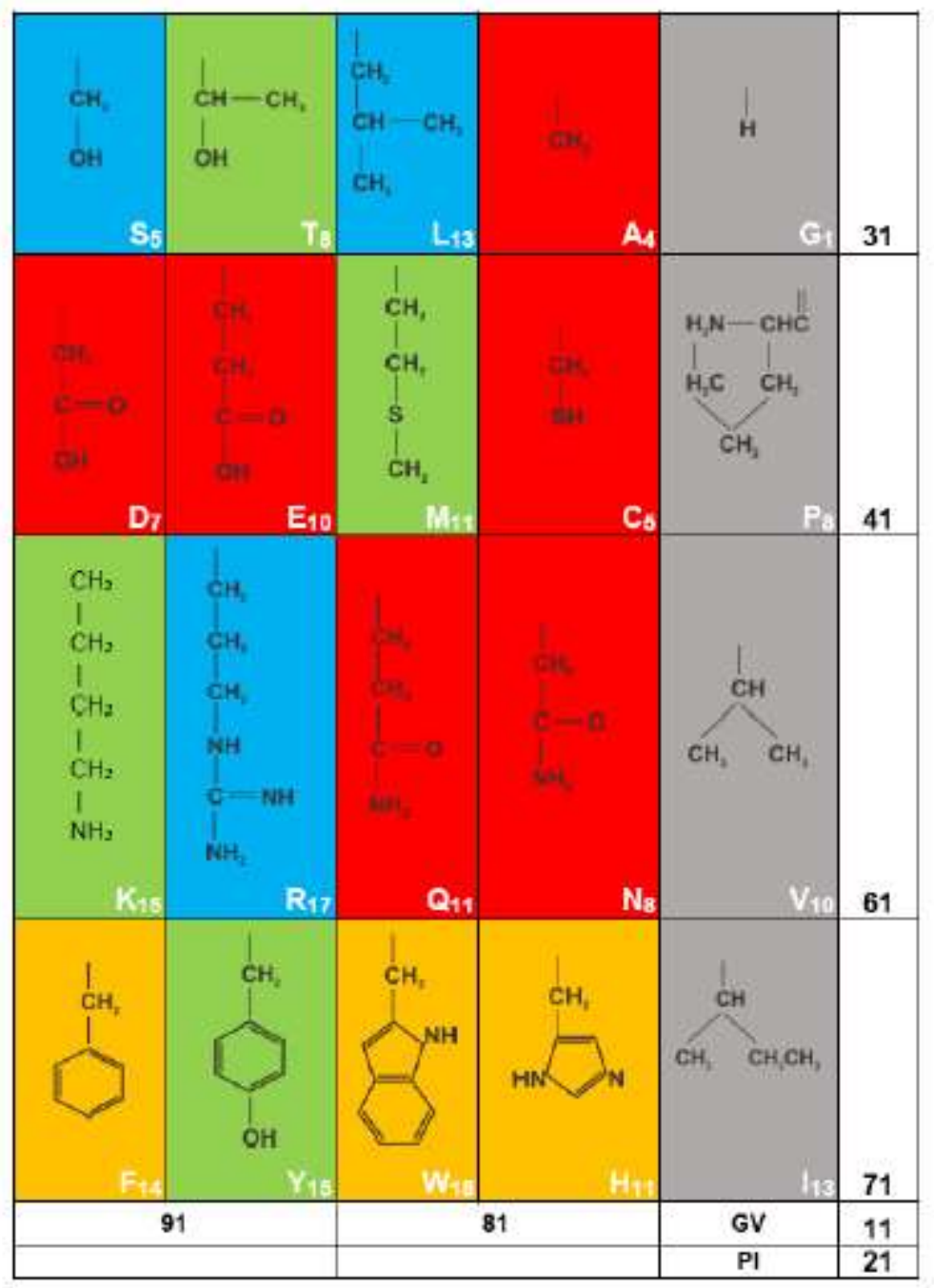

Figure 6. From (MMR, 2020a, Fig. 1, p. 4) (DOI 10.31219/osf.io/z7bm3): „The chemical system of the Genetic code: $6+3$ native AAs, 3+4 non-native AAs, altogether 16 AAs of alanine stereo-chemical type plus 4 AAs of non-alanine stereo-chemical type. Natives: red plus orange; non-natives ("intruders") blue plus green AAs and four AAs as a second class with gray color."

\{Additional Note (30.03.2021): The distinctions follow the head-to-body relationships in amino acid molecules as explained in the mentioned original paper. 
Green KYTM $299+$ Blue LSR $188=\mathbf{4 8 7}$

$\operatorname{Red} \mathrm{AC} 62+[\mathrm{DE} 132+\mathrm{NQ} 130=262]=324=18 \times 18$

Orange FWH $302(302+324=\mathbf{6 2 6}[\mathbf{6 2 6}+\mathbf{4 8 7}=1111+2$

Green KYTM $299-$ Blue LSR $188=111$
Red (AC DE NQ) 324 - Orange $(\mathrm{FWH}) 302=22$
$(299+324)-(188+302)=111+22$

Figure 6.1. From (MMR, 2020a, Tab. 1, p. 6): Distinctions of AAs through chemical properties and number of nucleons in distinctive classes given in Figure 6 (without of AAs of nonalanine stereochemical types, in gray color). The correspondence with the arithmetic system given in the following Figure 6.2 is more than obvious.

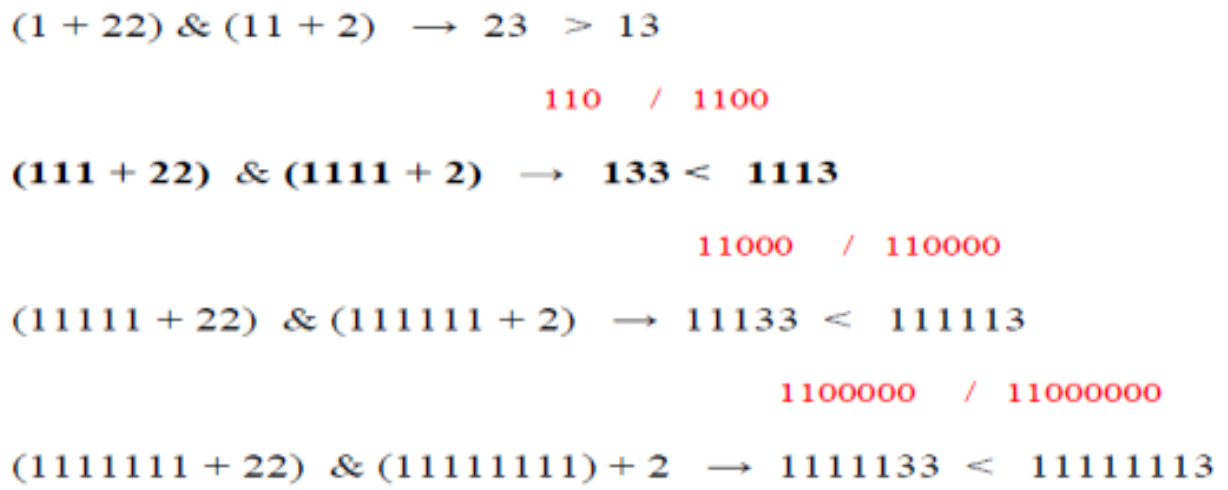

Figure 6.2. From (MMR, 2020a, Tab. 2, p. 6): Relations of the first two numbers with the first possible (double) Boolean space triangle in PSN (Figure 1.1) by generating a series of odd and even numbers (as sets of units).

\{Additional Note (30.03.2021): The first case corresponds to the chemical code, as shown in (MMR, 2018b, Survey 3a, p. 296); and the second one with the genetic code, as shown in the previous Fig. 6.1.\} 


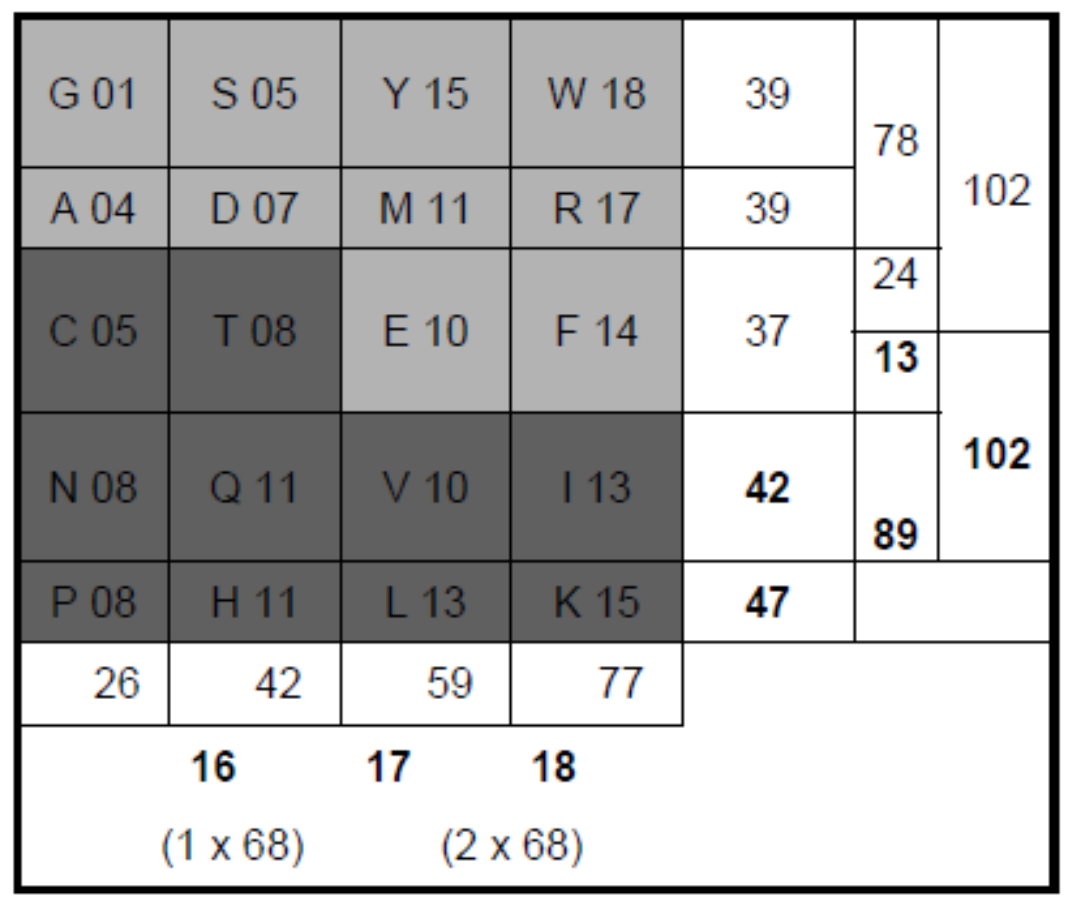

Figure 7. This Figure follows from (MMR, 2011b, Fig. 3, p. 828): "A specific classification and systematization of amino acids which follow from four diversity types ... In the shadow space there are 20 AAs with atom number in molecules side chains. Within first two and last two columns: 1 × 68 and $2 \times 68$ atoms, respectively. Within two inner and two outer columns: $102 \pm 1$ atoms. Regarding at the rows: there are 78 atoms within first two and $78+11=89$ within last two rows; within first half of the middle row 13 , and within the second one $13+11$ atoms. Within two halves of shadow spaces (light and dark) there is also a specific balance: $102 \pm 00$ atoms. All amino acid sequences are of the growing series from the aspect of number of atoms; all but one, in which Q-11 precedes V-10, because different stereochemical types have been distinguished: NQ belongs to alanine but V-I to valine type." 


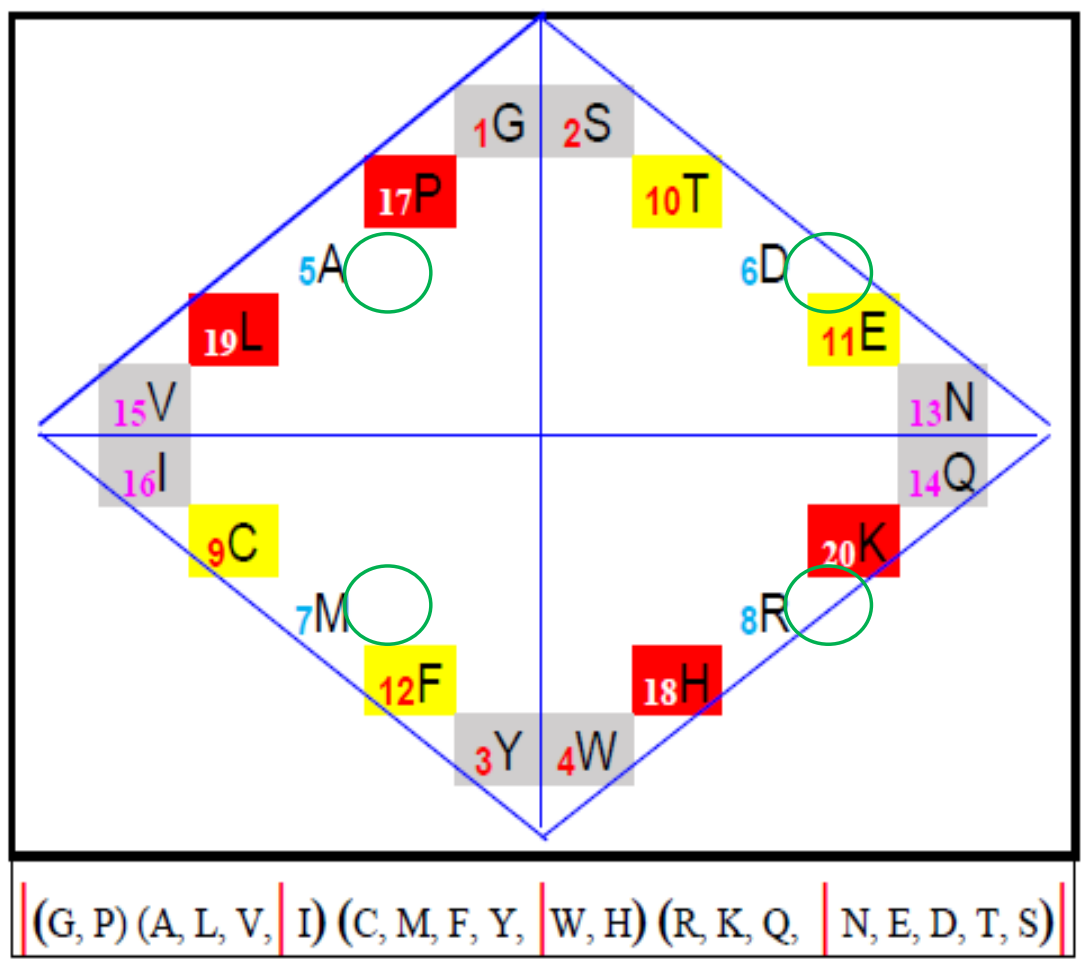

Figure 8. This figure follows from (MMR, 2011b, Fig. 2, p. 822): "Four diversity types of protein amino acids in a linear arrangement in form of the sequence 2-4-6-8; then in a circular arrangement, in form of the sequence 5-5-5-5. From this last sequence it is possible a new arrangement in form of the sequence 4-4-4-4-4 as in system presented in Figure 7." 


\section{Main Atlas: Tables}

Table 1. Chemical similarity Table

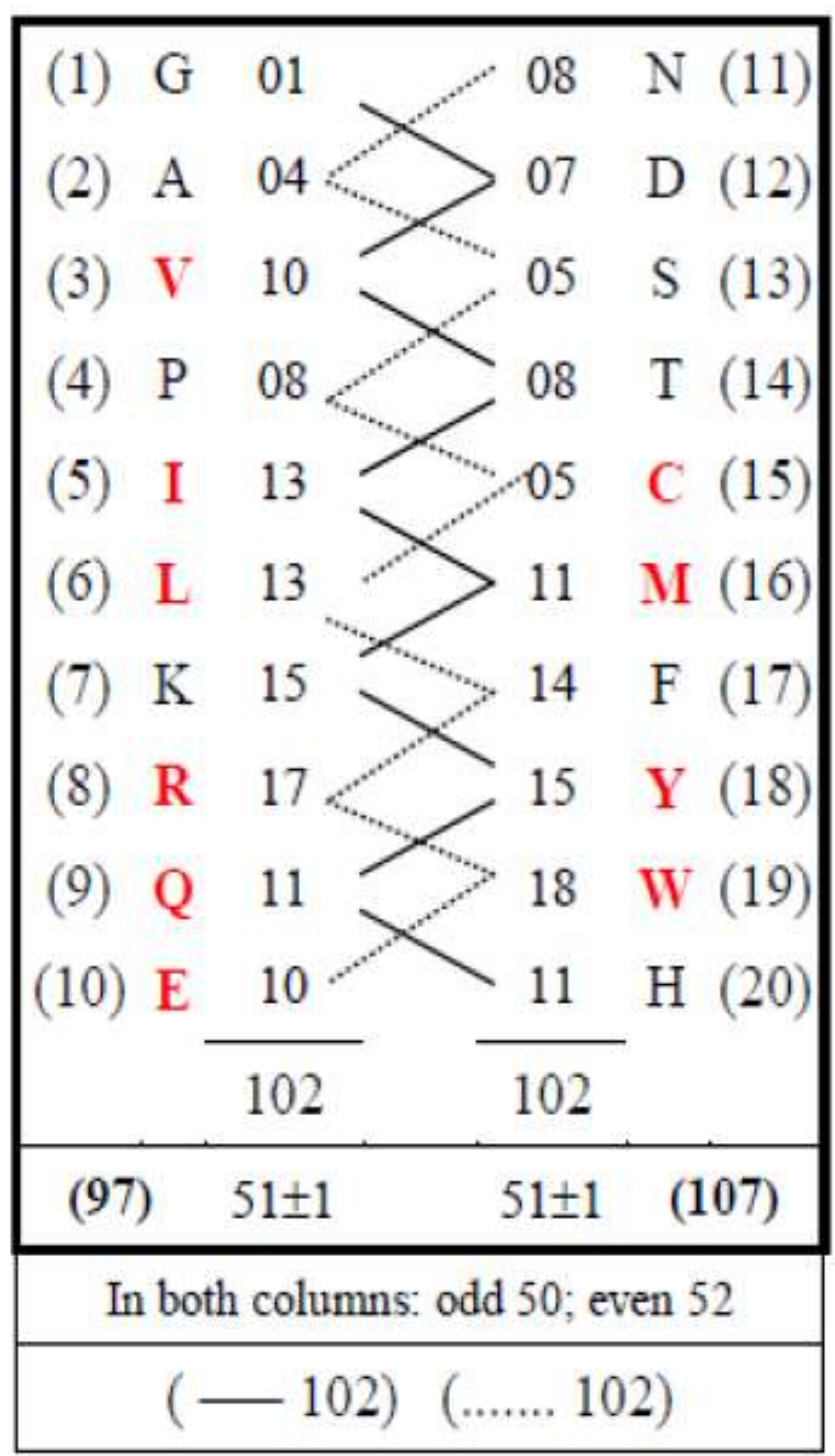

From MMR, 2019a (Table 2, p. 14): “The 20 protein AAs are arranged into two decades in accordance to ordinal amino acid number, 1-10 and 11-20; the numbers presented outer: the ordinal numbers 1-20; the numbers presented inner: the number of atoms within side chain of the responding amino acid. In red color AAs handled by class I aminoacyl-tRNA synthetases. In both columns: odd 50 and even positions 52 atoms. Within two decades there are 102 atoms in each; in both zigzag lines also 102 and 102 atoms. First four plus six last equals 97/107 respectively $[(\mathrm{GAVP})+(\mathrm{CMFYWH})=97][(\mathrm{NDST})+(\mathrm{ILKRQE})=107]$ $[\mathrm{VILRQE}=74][\mathrm{CMFYWH}=74][\mathrm{GAPK}=28 ; \mathrm{NDST}=28][\mathrm{FH}=25][\mathrm{CMYW}=49][74+49=123]$ $[28+28+25=81] . "$ 
Table 1.1. Cyclic Chemical Similarity Table

\begin{tabular}{|c|c|c|c|c|c|}
\hline \multicolumn{4}{|c|}{119} & \multirow{3}{*}{$\begin{array}{l}\text { (33) } \\
(40)\end{array}$} & \\
\hline G 01 & N 08 & L 13 & M 11 & & \multirow{3}{*}{12} \\
\hline A 04 & D 07 & $\mathrm{~K} 15$ & F 14 & & \\
\hline V 10 & S 05 & R 17 & Y 15 & \multirow{2}{*}{$\begin{array}{l}\text { (47) } \\
(45)\end{array}$} & \\
\hline P 08 & T 08 & Q 11 & $\mathrm{~W} 18$ & & \multirow{3}{*}{117} \\
\hline I 13 & C 05 & E 10 & H 11 & (39) & \\
\hline G 01 & $\mathrm{~N} 08$ & L 13 & M 11 & (33) & \\
\hline $24 / 13$ & $18 / 23$ & $40 / 39$ & $37 / 43$ & $118 / 119$ & \\
\hline \multirow[t]{2}{*}{ (37) } & (41) & (79) & $(80)$ & $117 / \mathbf{1 2 0}$ & \\
\hline & & 118 & & & \\
\hline
\end{tabular}

From MMR, 2017d (Table 4, p. 13): "The first row is repeated at the bottom, and thus one cyclic system is obtained. There are 117 atoms in two outer columns; at even positions 118, at odd 119; in two inner columns 120 atoms. On the other hand, in the lower half of the Table there are 117 atoms ones more; in the lower diagonally "wrapped" area 118, and in the upper 119; in the upper half of Table 120 atoms. The repeated four AAs at the bottom of the Table make to achieve a diagonal balance with a difference of only one atom; moreover, to establish a sequence from the series of natural numbers: 117, $118,119,120 . "$

\{Additional Note (30.03.2021): This system-arrangement is created by taking pairs of AAs of the first and second quintet of pairs in Table 1, respectively. For correspondence with the analog arithmetic system-arrangement see Table C7.\} 
Table 2. Amino acids of alanine stereochemical type

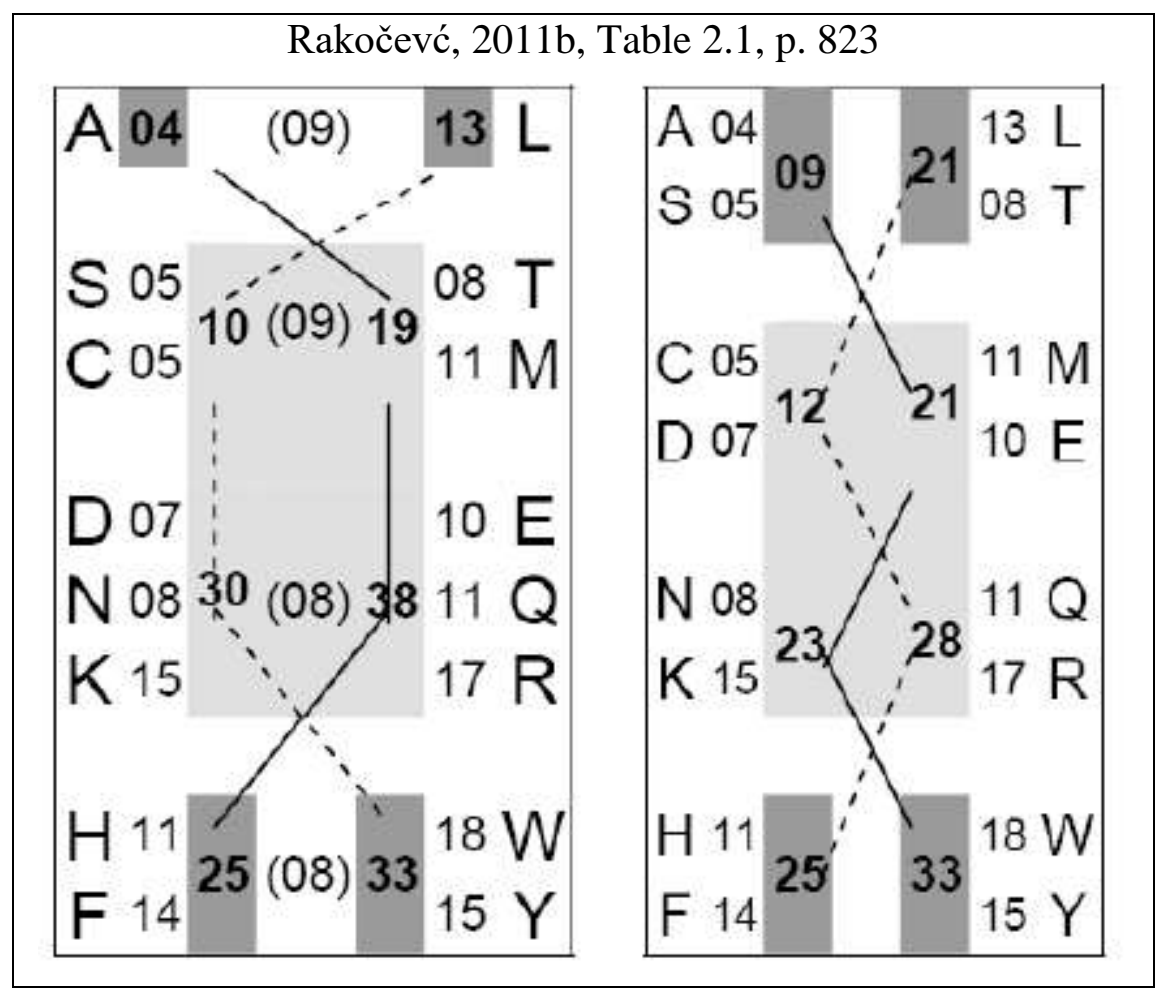

From MMR, 2011 (Table 2.1, p. 823): "The atom number within 8 pairs of alanine stereochemical type of AAs. On the full line, as well as on the dotted one, there are 86 atoms; the differences 8 and $9(9-8=1)$ express "the minimum change relation among the amino acids" (Swanson, 1984, p 191). The order follows from the atom number hierarchy. ... Notice that within outer class of AAs $(\mathrm{AL}+\mathrm{FY}+\mathrm{HW})$ there are $[(4+33=$ $37)+(13+25=38)=75]$ of atoms; and within inner class $(10+38=48)$ and $(19+30=$ 49). Then $48+49=97$ atoms] On the other hand 75 atoms plus 32 atoms in four AAs of non-alanine stereochemical types gives 107 atoms. Altogether $97+107=204$ atoms within 20 AAs side chains."

\{Additional Note (30.03.2021): The uniqueness of the number 204 is shown by the illustrations in the A-Atlas.\} 
Table 3. Distribution of pairs of 16 AAs of alanine and 4 AAs of non-alanine stereochemical types

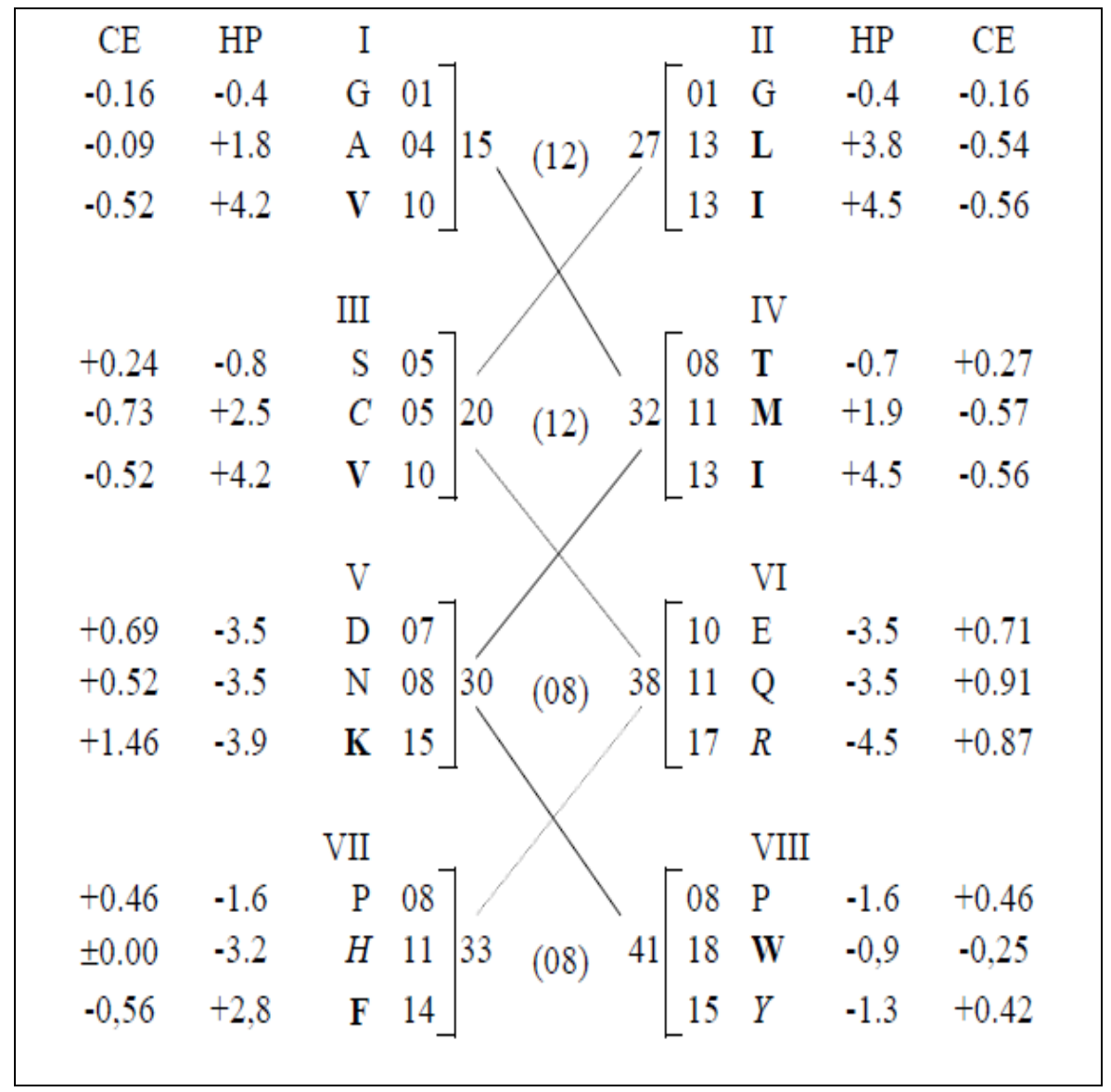

From (MMR, 1997b, Survey 7, p. 102): “On the full line, as well as on the dotted line, there are 118 atoms; HP: hydropathy index on a number unnamed scale (Keyte, Doolittle, 1982); CE: cloister energy in kcal/mol (Swanson, 1984)" 
Table 4. Two classes of AAs, handled by two classes of enzymes aminoacyl-tRNA synthetases

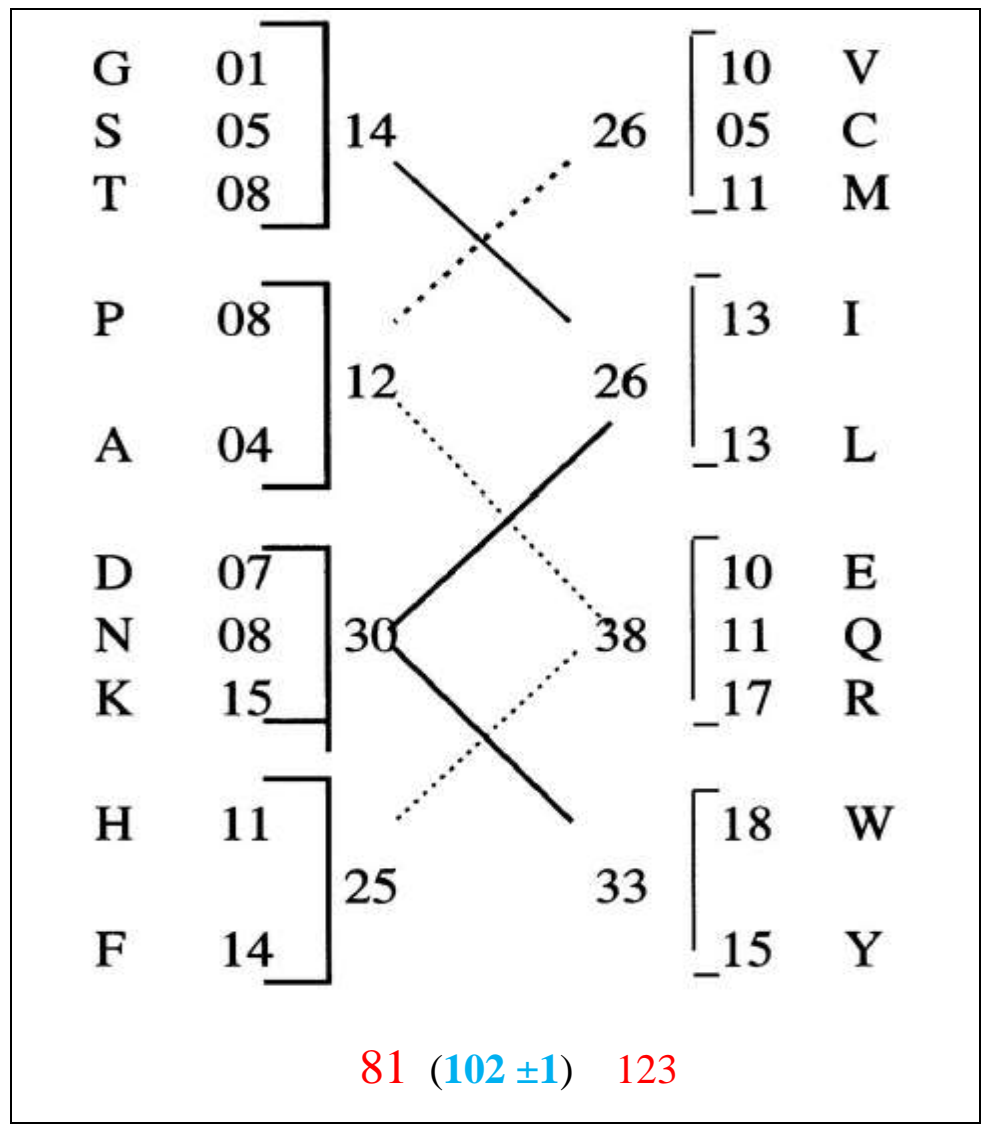

From MMR, 1998a, Survey 4, p. 290): “Atom number balance directed by two classes of enzymes aminoacyl-tRNA synthetases. This system follows from the systems given in Surveys 2-3 [MMR, 1998a, pp. 289-290]. On the first (full) zigzag line there are 102+1 whereas on the second (dotted) line 102-1 atoms. Arithmetic mean for both: $102 \pm 1$. Class II handles the smaller amino acids within the pairs (on the left), whereas the larger (on the right) are handled by class I aminoacyl-tRNA synthetases." 
Table 5. The crossing of CIPS from Figure 4 and two classes of AAs from Table 4

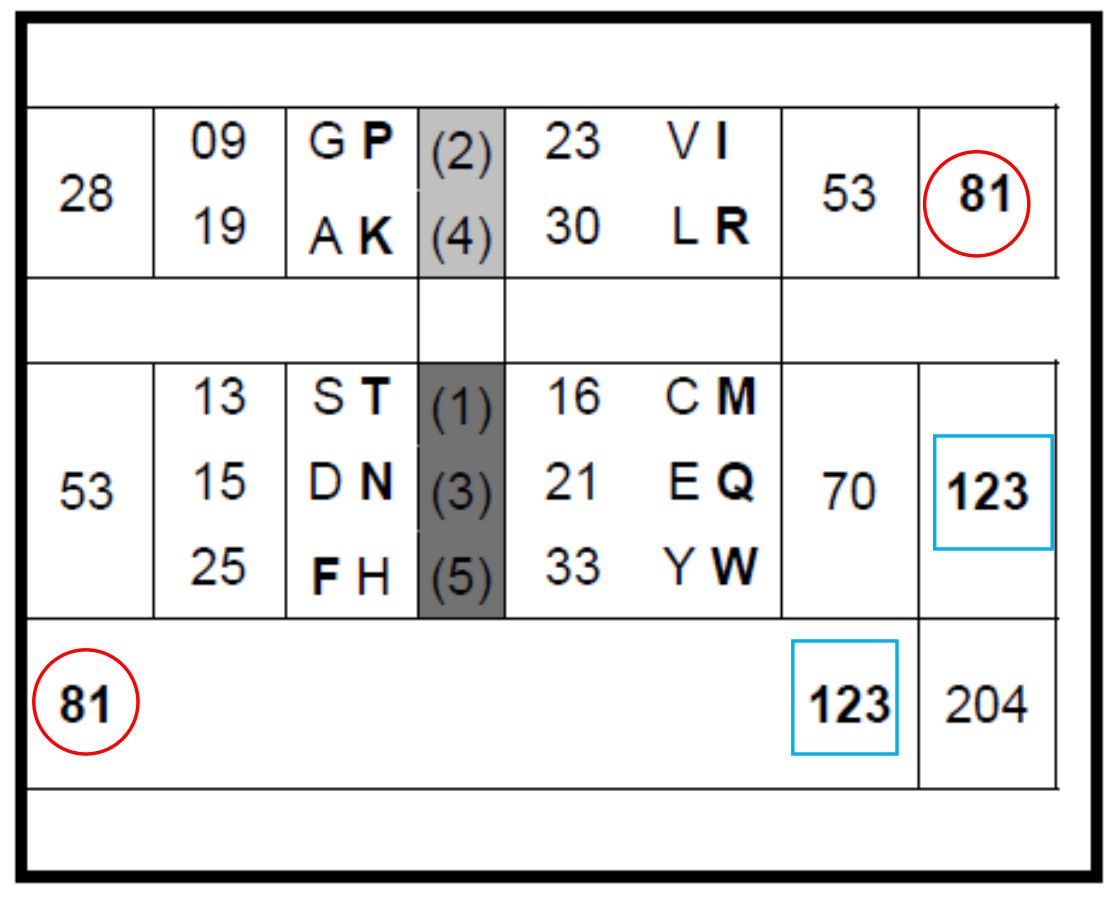

From MMR, 2011b, p. 833: "The amino acid arrangement in accordance to the principle: 'a little' and 'full' in relation to 'small' and 'large'. So, on the left there are AAs (81 atoms) from the left side of Figure 8 (class II, with smaller molecules within the pairs); and on the right there are AAs (123 atoms) from the right side of Figure 8 (class I, with larger molecules within the pairs). At the same time very up there are AAs from primary superclass (81 atoms), just aliphatic and nonpolar (A, V, L, I) and 'a little' polar (G, P, K, R) (hydrogen and nitrogen are less polar than oxygen!); in the other hand, except aromatic and sulfur AAs, down are AAs from secondary superclass (the row with 123 atoms), also aliphatic, but 'full' polar."

\{Additional Note (30.03.2021): It is expected that these classifications of protein amino acids could be useful in bioinformatics, in the search and analysis of protein bases and their networks, especially in ontological approaches (Ashburner et al. 2000). 
Survey 2. The comparing four quintets of AAs in AS and OS

\begin{tabular}{|c|c|c|}
\hline AS & \begin{tabular}{lll}
\multicolumn{4}{c}{$(\mathrm{I}) \mathrm{a}$} \\
$\mathrm{GA}$ & $\mathrm{NP}$ & $\mathrm{C} \rightarrow 26$ \\
$\mathrm{SD}$ & $\mathrm{QH}$ & $\mathrm{T} \rightarrow 42$ \\
& & \\
& & $(1 \times 68)$
\end{tabular} & 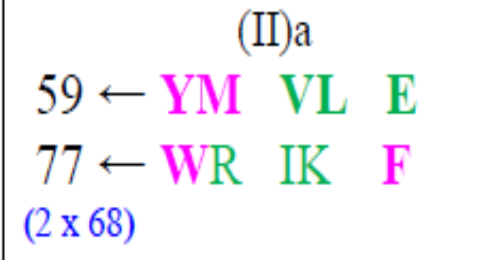 \\
\hline OS & \begin{tabular}{lll}
\multicolumn{4}{c}{$(\mathrm{I}) \mathrm{b}$} \\
$\mathrm{GA}$ & $\mathrm{VP}$ & $\mathrm{I} \rightarrow 36$ \\
$\mathrm{QE}$ & $\mathrm{KR}$ & $\mathrm{L} \rightarrow 66$ \\
& &
\end{tabular} & 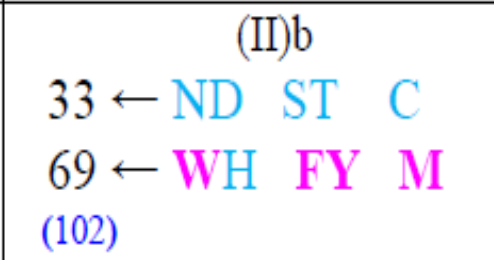 \\
\hline \multicolumn{3}{|c|}{$\begin{array}{c}\left(\mathrm{G}_{1} \mathrm{~A}_{4} \mathrm{P}_{8} \mathrm{Q}_{11}=34-10\right) ;\left(\mathrm{S}_{5} \mathrm{D}_{7} \mathrm{~N}_{8} \mathrm{H}_{11} \mathrm{C}_{5} \mathrm{~T}_{8}=34+10\right) ; \\
\left(\mathrm{V}_{10} \mathrm{E}_{10} \mathrm{~K}_{15} \mathrm{R}_{17} \mathrm{I}_{13} \mathrm{~L}_{13}=68+10\right) ;\left(\mathrm{F}_{14} \mathrm{Y}_{15} \mathrm{~W}_{18} \mathrm{M}_{11}=68-10\right)\end{array}$} \\
\hline \multicolumn{3}{|c|}{$[34 \pm 10] \quad[68 \pm 10]$} \\
\hline \multicolumn{3}{|c|}{$\begin{array}{c}\text { I (GP })_{27} \text {, II (ALVI) } 76 \text {, III }(\mathrm{CM} \mathrm{FY} \mathrm{WH)})_{128} \text {, IV }(\text { RK QN ED TS })_{153} \\
{[\text { I } 27+\text { IV } 153=180][\text { II } 76+\text { III } 128=\mathbf{2 0 4}]}\end{array}$} \\
\hline
\end{tabular}

The comparison procedure is the same as in Survey 1, except that the Angular system (AS) is compared with the OS (Orthogonal system-arrangement). As we see the main results of the AS and OS crossing is $34 \pm 10$ and $68 \pm 10$. 
Survey 3. The comparing four quintets of AAs in DS and AS

\begin{tabular}{|c|c|c|}
\hline DS & 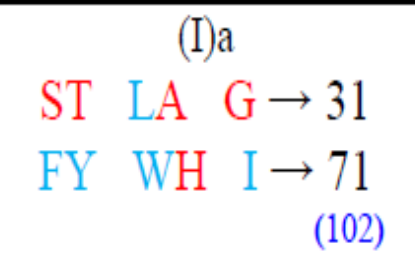 & $\begin{array}{l}\text { (II)a } \\
41 \leftarrow \mathrm{DE} \quad \mathrm{MC} \quad \mathrm{P} \\
61 \leftarrow \mathrm{KR} \quad \mathrm{QN} \quad \mathrm{V} \\
(102)\end{array}$ \\
\hline AS & 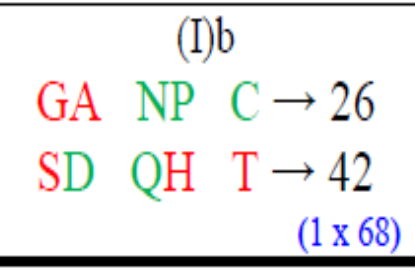 & 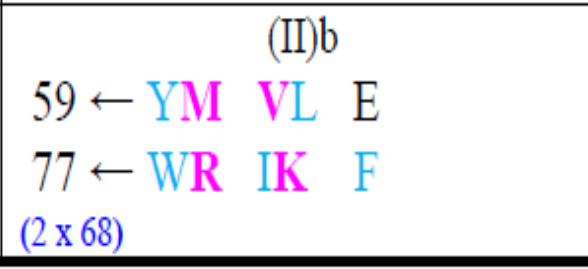 \\
\hline \multicolumn{3}{|c|}{$\begin{array}{c}\left(\mathrm{G}_{1} \mathrm{~A}_{4} \mathrm{~S}_{5} \mathrm{~T}_{8} \mathrm{H}_{11}=29\right)[34-5] ;\left(\mathrm{L}_{13} \mathrm{I}_{13} \mathrm{~F}_{14} \mathrm{Y}_{15} \mathrm{~W}_{18}=73[68+5]\right) \\
\left(\mathrm{N}_{8} \mathrm{P}_{8} \mathrm{D}_{7} \mathrm{Q}_{11} \mathrm{C}_{5}=39[34+5]\right) ;\left(\mathrm{K}_{15} \mathrm{R}_{17} \mathrm{~V}_{10} \mathrm{E}_{10} \mathrm{M}_{11}=63[68-5]\right) \\
{[34 \pm 5][68 \pm 5]}\end{array}$} \\
\hline \multicolumn{3}{|c|}{ 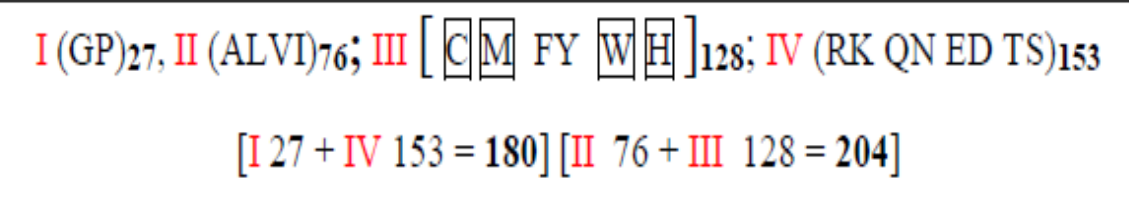 } \\
\hline
\end{tabular}

The comparison procedure is the same as in Survey 1 and 2, except that the Angular system (AS) is compared with the DS (Diagonal system-arrangement in Figure 1). As we see the main results of the DS and AS crossing is $34 \pm 5$ and $68 \pm 5$. 
Survey 4. The unique arithmetical system related to atom number within four quintets of OS in Surveys 1 and 2 (I)

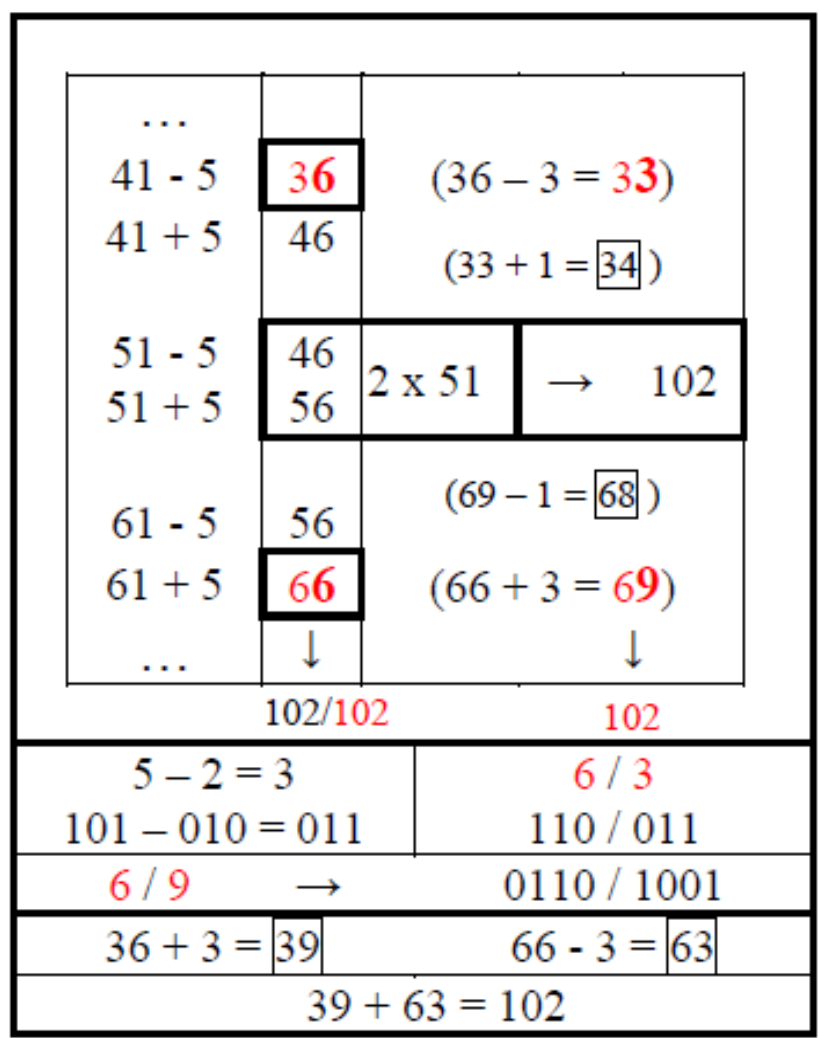

Among other things, we notice the uniqueness of the results 36, 33; 66, 69 in OS in Survey 1 and 2, with a binary basis in the same way as we have that basis in result 20,31, 42, 50, 61 in Figure 2. We also notice Dürer's number 34 (and its double value) with changes for +1 (as $68+1)$ and for -2 (as $68-2)$. [Cf. result $(20,31,42,50,61)$ in Figure 2 with Gauss' sequence in Figure 3 and Figure 5.] 
Survey 5. The unique arithmetical system related to atom number within four quintets of OS in Surveys 1 and 2 (II)

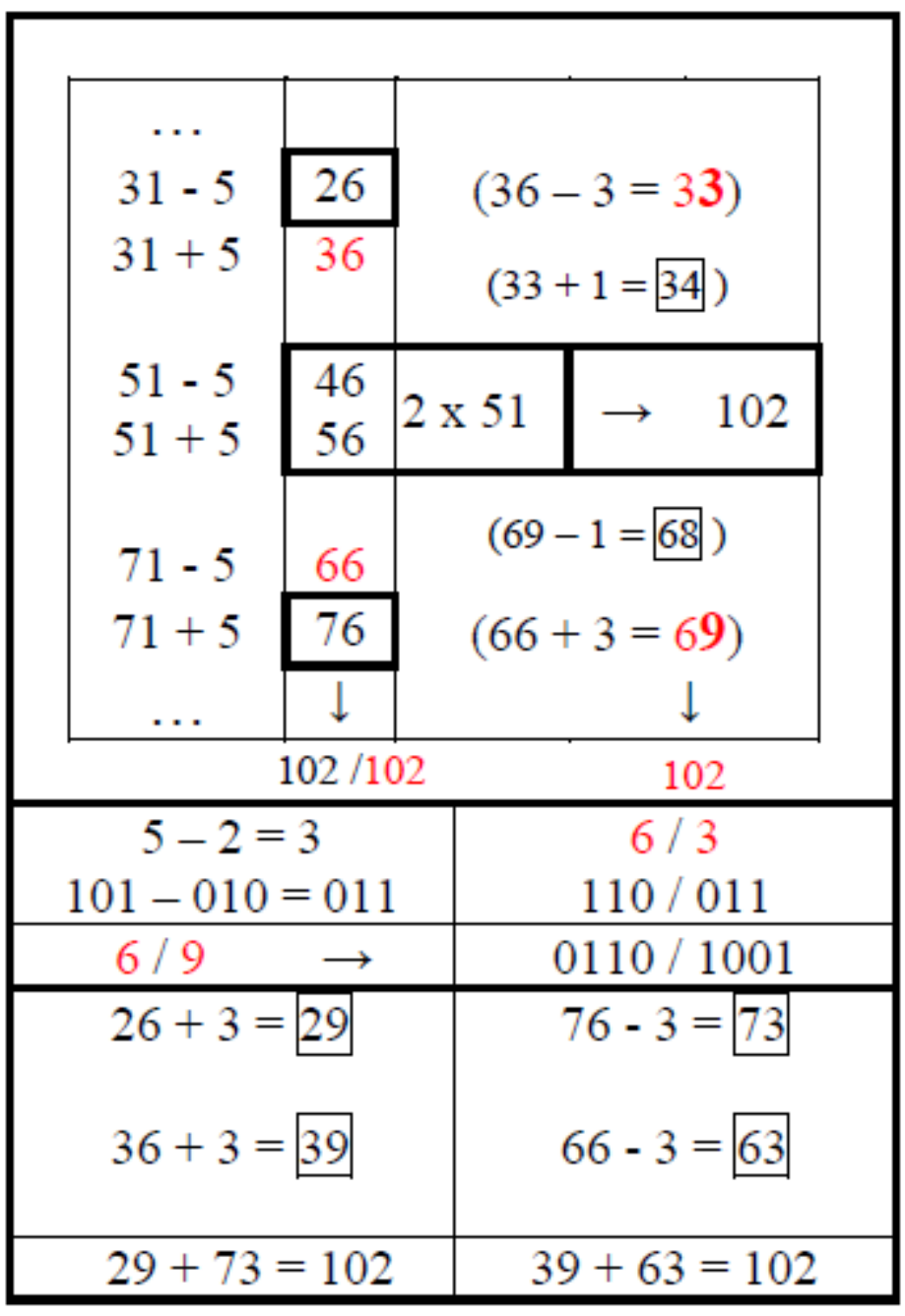


Survey 6. The unique arithmetical system related to result of comparing DS and AS in Survey 3 (I)

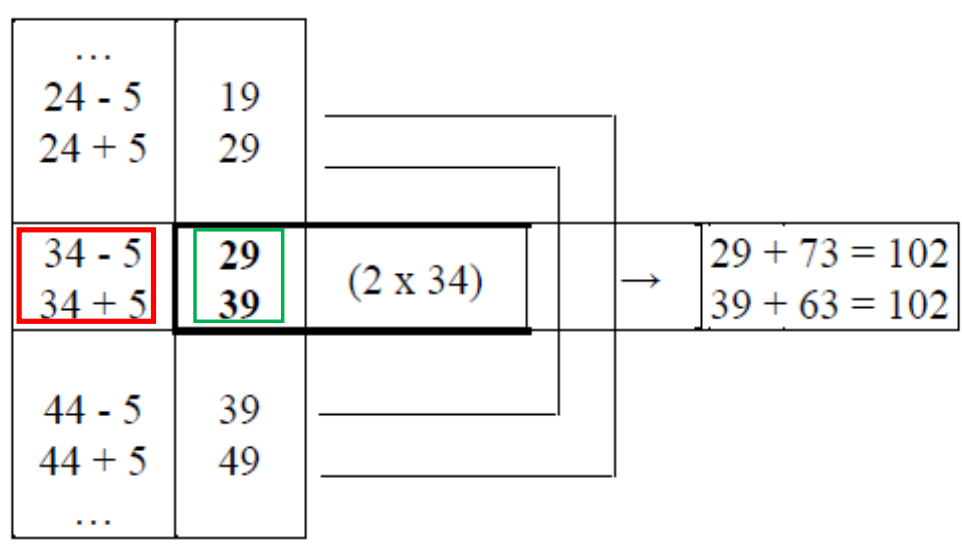

Survey 6.1. The unique arithmetical system related to result of comparing DS and AS in Survey 3 (II)

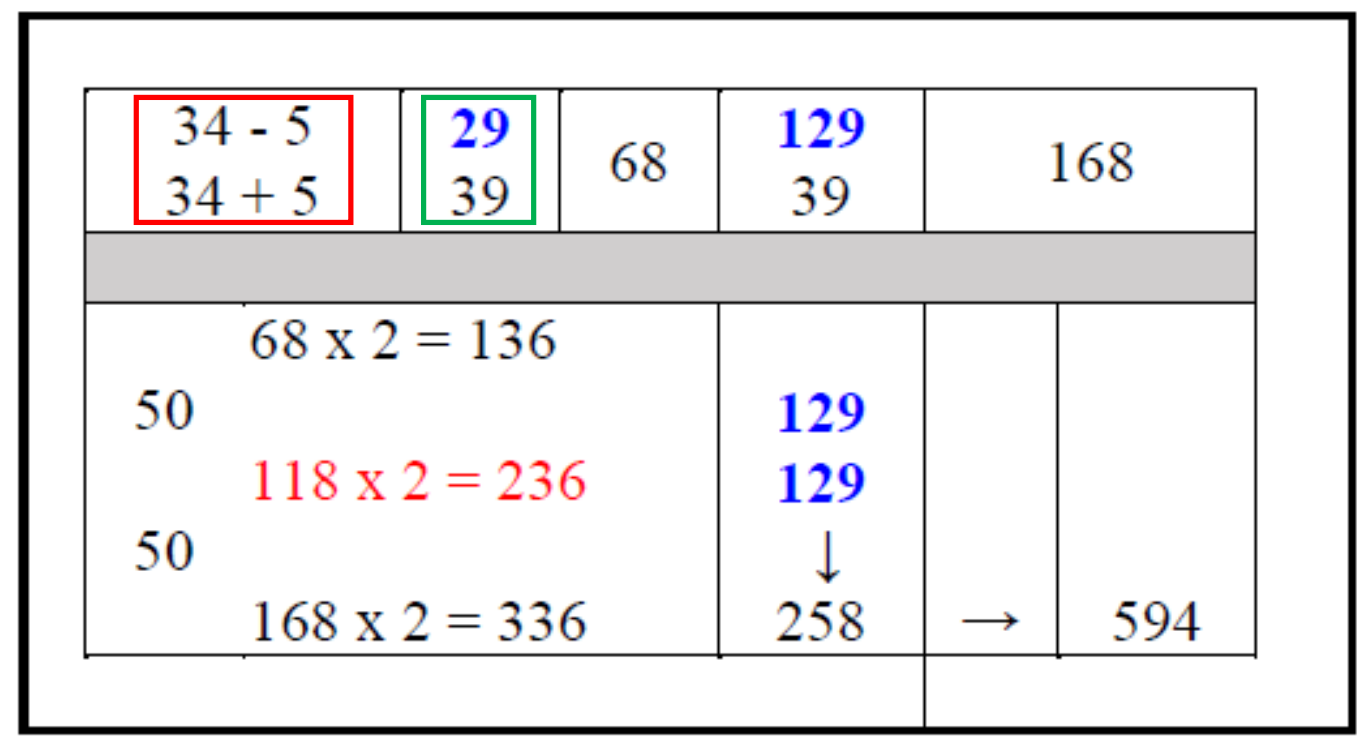

Significant quantities: The 129 (a half of 258) as in Table C6. In equation $(297-39=$ 258), the 297 is a half of $594(336+258)$, the total number of atoms within 61 amino acid molecules (within their side chains) in GCT. The 236 as total number of atoms within 24 amino acid molecules in system-arrangement presented in Table 3 . The 336 as $(297+39)$. 
Survey 7. The unique arithmetical system related to result of comparing DS and AS in Survey 3 (III)

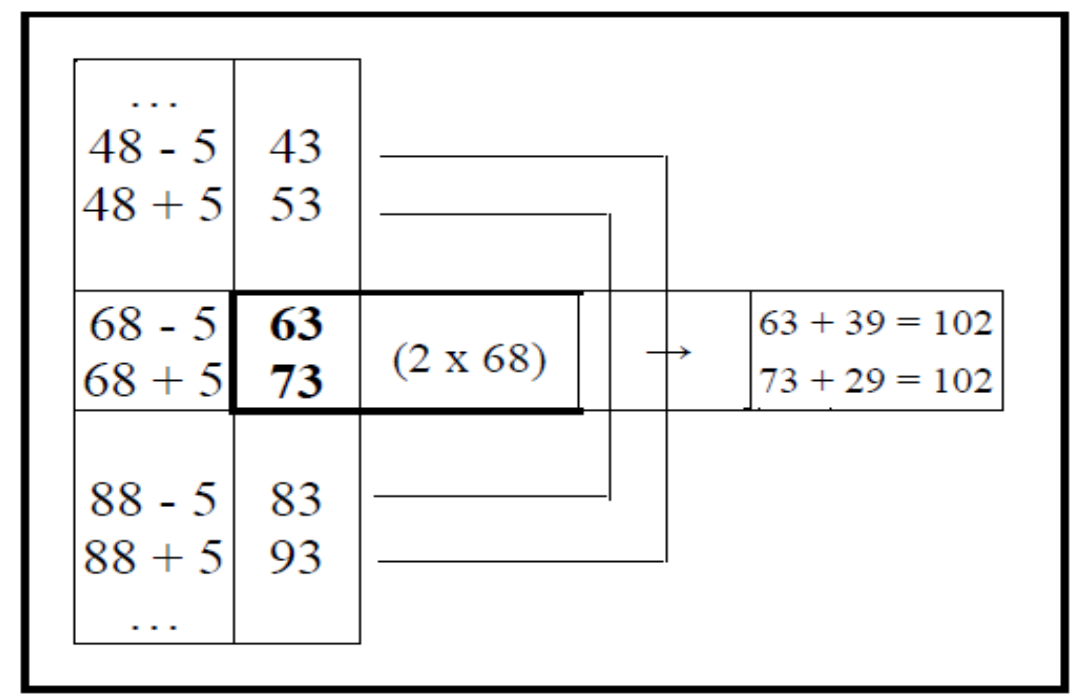

Survey 8. The unique arithmetical system related to result of comparing DS OS and AS system-arrangements

\begin{tabular}{|c|c|c|c|c|c|c|c|}
\hline $\mathrm{q}$ & & & & & & & \\
\hline 8 & $\frac{\underline{\mathbf{0}}^{4}}{(4)}$ & $\frac{1^{\mathbf{1}}}{(8)}$ & $\frac{\underline{\mathbf{2}}}{(16)}$ & $\frac{\mathbf{4}}{(32)}$ & $\frac{\mathbf{1 0}}{(64)}$ & $\frac{\mathbf{2 0}}{(128)}$ & $\ldots$ \\
\hline $\begin{array}{l}10 \\
\ldots\end{array}$ & $\frac{\mathbf{0} 5}{(5)}$ & $\frac{1}{(10)}$ & $\begin{array}{l}\frac{\mathbf{2}}{2} 0 \\
(20)\end{array}$ & $\frac{\mathbf{4}}{(40)}$ & $\frac{\mathbf{8}}{(80)}$ & $\frac{\mathbf{1 6}}{(160)}$ & $\cdots$ \\
\hline 16 & $\frac{\underline{\mathbf{0}} 8}{(8)}$ & $\frac{1}{(16)}$ & $\frac{\underline{\mathbf{2}}}{(32)}$ & $\frac{4}{(64)}$ & $\frac{\underline{\mathbf{8}}^{0}}{(128)}$ & $\frac{\mathbf{1 0}}{(256)}$ & $\ldots$ \\
\hline
\end{tabular}

DS, OS and AS system-arrangements: in Surv. 1 change in the number of atoms by \pm 20 , in Survey 2 for \pm 10 and in Surv. 3 for \pm 05 . For each $q$ we have a geometric progression with quotient 2 , with zero at the beginning (underlined numbers). Only in the decimal number system, the second order units (20) are in the middle, and in the octal it is not but (14) 8 (Tab. C1.1), which is (12) 10 units in the decimal system. 
Survey 9. Generating the Fibonacci sequence in relation to two key points of the Multiplication Table in the decimal number system

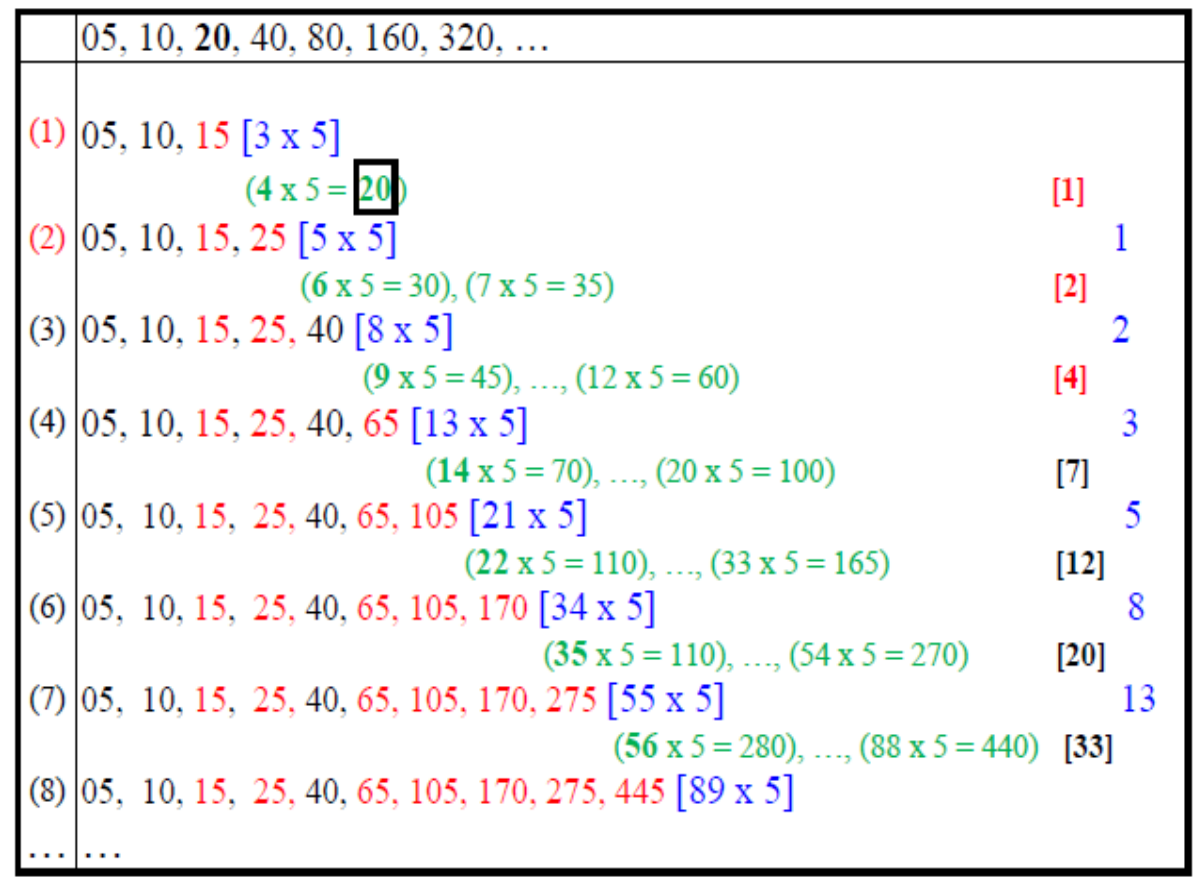

It starts from the half of the scale (as the whole unit in the decimal number system), from the number 5. [With the half of the unit also starts in Generalized Golden Mean (MMR, 2004b).] We see that the two key points [(3 x 5) and (5 x 5)] events in the first two steps. (Key points in Tabs. C2 and C3.) 
Survey 10. Generating the Fibonacci sequence outside the relation with two key points of the Multiplication Table in the decimal number system

\begin{tabular}{|c|c|c|}
\hline & $0,1,2,4,8,16,32, \ldots$ & \\
\hline (1) & $0,1,1[1 \times 1]$ & \\
\hline (2) & $0,1,1,2[2 \times 1]$ & \\
\hline (3) & $0,1,1,2,3[3 \times 1]$ & \\
\hline & $(4 \times 1=04$ & [1] \\
\hline (4) & $\begin{aligned} & 0,1,1,2,3,5 {[5 \times 1] } \\
&(6 \times 1=6) .(7 \times 1=7)\end{aligned}$ & 1 \\
\hline (5) & $0,1,1,2,3,5,8[8 \times 1]$ & 2 \\
\hline (6) & $\begin{array}{r}0,1,1,2,3,5,8,13[13 \times 1] \\
(14 \times 1=14), \ldots(20 \times 1=20)\end{array}$ & 3 \\
\hline $\begin{array}{l}\text { (7) } \\
\text { (8) }\end{array}$ & $\begin{array}{l}0,1,1,2,3,5,8,13,21[21 \times 1] \\
\quad(22 \times 1=22), \ldots,(33 \times 1=33) \\
0,1,1,2,3,5,8,13,21,34[34 \times 1]\end{array}$ & {$[12]^{5}$} \\
\hline & $\ldots$ & \\
\hline
\end{tabular}

The Fibonacci sequence is generated in relation to a geometric progression with quotient $2[2 \wedge \mathrm{n}(\mathrm{n}=0,1,2,3, \ldots)]$, "tied" to the zero point "somewhere" in space-time. 


\begin{tabular}{|c|c|c|c|c|c|c|}
\hline 00 & 02 & 04 & 06 & 08 & 10 & 12 \\
\hline 11 & 13 & 15 & 17 & 19 & 21 & 23 \\
\hline 22 & 24 & 26 & 28 & 30 & 32 & 34 \\
\hline 11 & 16 & 21 & 26 & 31 & 36 & 41 \\
\hline 00 & 05 & 10 & 15 & 20 & 25 & 30 \\
\hline 44 & 60 & 76 & 92 & 108 & 124 & 140 \\
\hline & 12 & 14 & 16 & 18 & 20 & 22 \\
\hline & 23 & 25 & 27 & 29 & 31 & 33 \\
\hline & 34 & 36 & 38 & 40 & 42 & 44 \\
\hline & 41 & 46 & 51 & 56 & 61 & 66 \\
\hline & 30 & 35 & 40 & 45 & 50 & 55 \\
\hline & 140 & 156 & 172 & 188 & 204 & 220 \\
\hline & 22 & 24 & 26 & 28 & 30 & 132 \\
\hline & 33 & 35 & 37 & 39 & 41 & 43 \\
\hline & 44 & 46 & 48 & 50 & 52 & 54 \\
\hline & 66 & 71 & 76 & 81 & 86 & 91 \\
\hline & 55 & 60 & 65 & 70 & 75 & 80 \\
\hline & 220 & 236 & 252 & 268 & 284 & 300 \\
\hline & 32 & 34 & 36 & 38 & 40 & 42 \\
\hline & 43 & 45 & 47 & 49 & 51 & 53 \\
\hline & 54 & 56 & 58 & 60 & 62 & 64 \\
\hline & 91 & 96 & 101 & 106 & 111 & 116 \\
\hline & 80 & 85 & 90 & 95 & 100 & 105 \\
\hline & 300 & 316 & 332 & 348 & 364 & 380 \\
\hline & $\ldots$ & & & & & \\
\hline
\end{tabular}

Figure A2. From (MMR, 2019a, Table A3, p. 30): "The source of PAAS mirror symmetry [PAAS = Protein Amino Acids System]. The arrangement represents the Table of distinct 2-5 adding (TDA) with starting column 00- 11-22-11-00 which follows from PSN (Periodic system of numbers: Figure 1) in decimal number system by overlapping the real sequence of doubled the first possible triangle in Boolean space (0-1-2) with its mirror image through compression and superposition at the point "22"). In the 10th step we have a realization of the sequence (20-31-42$61-50)$, the same with the number of atoms in five AAs classes $(20,31,42,61,50)$ as it is here presented: all five results in the 10th step are mirror image of the first step." [Cf. result 300 in Fig. 1.4 and in its derivatives.]

\{Additional Note 1 (30.03.2021): If patterns $(2,2,2)$ and $(5,5)$ are added to the start record of numbers $(00,11,22,11,00)$, then in the $10^{\text {th }}$ step the pattern "204" is obtained, which corresponds to the number of atoms in 20 protein AAs (in their side chains), and in $11^{\text {th }}$ step the first member of the first friendly pair of numbers, the number "220". On the other hand, in the $15^{\text {th }}$ step we get "284" which pattern corresponds to the second member of the first friendly pair 
of numbers, while in the $16^{\text {th }}$ step we get 300 , an important determinant of the genetic and chemical code, as we have shown in several times (cf. footnotes 44 and 45). \}

\{Additional Note 2 (30.03.2021): Order of sums of number quintets, from zeroth to tenth: $\left(0^{\text {th }}\right.$. $44),\left(1^{\text {st }} \cdot 60\right),\left(2^{\text {nd }} \cdot 76\right),\left(3^{\text {rd }} \cdot 92\right),\left(4^{\text {th }} \cdot 108\right),\left(5^{\text {th }} \cdot 124\right),\left(6^{\text {th }} \cdot 140\right),\left(7^{\text {th }} \cdot 156\right),\left(8^{\text {th }} \cdot 172\right),\left(9^{\text {th }} \cdot 188\right)$, $\left(10^{\text {th }} .204\right)$. The vertical line $\left[\left(10^{\text {th }} .204\right),\left(15^{\text {th }} .284\right)\right]$ is in correspondence with the key determinant of the Multiplication Table: Legend of Table C2: "...with $2 \times 5$, at the end of the scale; ... with $\mathbf{3} \times \mathbf{5}=\mathbf{1 5}$ we 'come down' from the scale." In this, as in any other analog line, the difference between the lower and upper sum of the quintet is $80(284-204=80)$. This number is in the relation to "the symmetry in the simplest case" (Marcus, 1989) with a significant diagonal: the diagonal from zeroth point 44 to the significant point $204(204-44=2 \times 80)$. [Notice that this regularity applies only to significant point 204, which corresponds to the number of atoms in 20 protein AAs (cf. Fig. 2)].\}

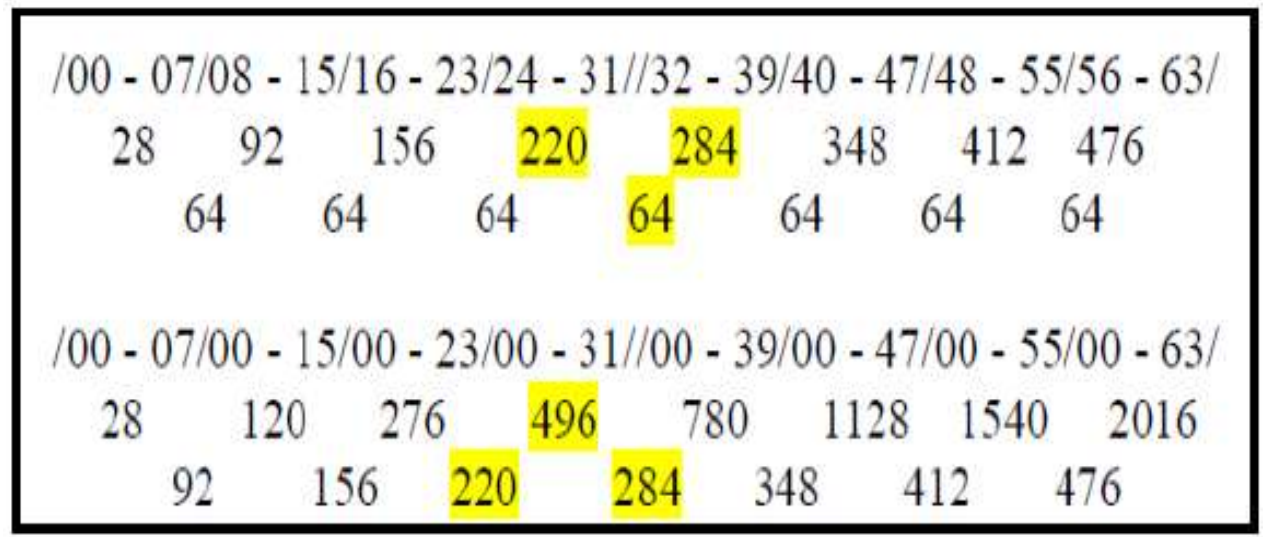

Figure A3. From (MMR, 2019a, Survey B2, p. 35): "The Survey follows from (Rakočević, 1997b, Figure 7, p. 60): "The determinations on the six-bit binary tree. "The determination of the series of the numbers 0-63. When we look closely into the structure of the sequence $0-63$ of the series of the natural numbers we come to the obvious and self-evident explanation of the reason why the genetic code must be six-bit code, no matter if it is the manifestation in the form of the Gray Code model (Swanson, 1984, p 188), or it is in the form of the Binary tree (Rakočević, 1994, p 38). There must be 8 codons, i.e. amino acid classes. The structure of the sequence 0-63 is strictly determined by third perfect number (496) and the sum consisted of the first pair of the friendly numbers $(220+284)$. Along with this, the specific Boolean square is being made and it is the restrictive factor, in a sense that it is not possible to 'go on' any further - not ahead, not back: (0) $220+284=504$; (1) $156+348=504$; (2) $92+412=504$; (3) $28+476=504$. The key distinctions within the genetic code are obviously self-evident: entity 64 as a series of continuity (correspondent with 64 codons); entity 20 from 496 (III PN)-476=20 (correspondent with 20 amino acids) etc." " 
Table A1. Unique number positions in the arranged set of natural numbers (I)

\begin{tabular}{|c|lc|}
\hline$\ldots$ & & \\
198 & $(14+184=198) ;[13+14+15=1 / 4(204-30)$ & {$[114+84=198]$} \\
200 & $(15+185=200) ;[14+15+16=1 / 4(200-20)$ & {$[115+85=200]$} \\
202 & $(16+186=202) ;[15+16+17]=1 / 4(202-10)$ & {$[116+86=202]$} \\
$\mathbf{2 0 4}$ & $(17+187=\mathbf{2 0 4}) ;[16+17+18]=1 / 4(\mathbf{2 0 4} \pm \underline{00})$ & {$[117+87=204]$} \\
206 & $(18+188=206) ;[17+18+19=1 / 4(206+10)$ & {$[118+88=206]$} \\
208 & $(19+189=208)[18+19+20=1 / 4(208+20)$ & {$[119+89=208]$} \\
210 & $(20+190=210)[19+20+21=1 / 4(210+30)$ & {$[120+90=210]$} \\
$\ldots$ & & \\
\hline
\end{tabular}

Explanation for all six Tables (A-Atlas): in the Discussion 
Table A2. Unique number positions in the arranged set of natural numbers (II)

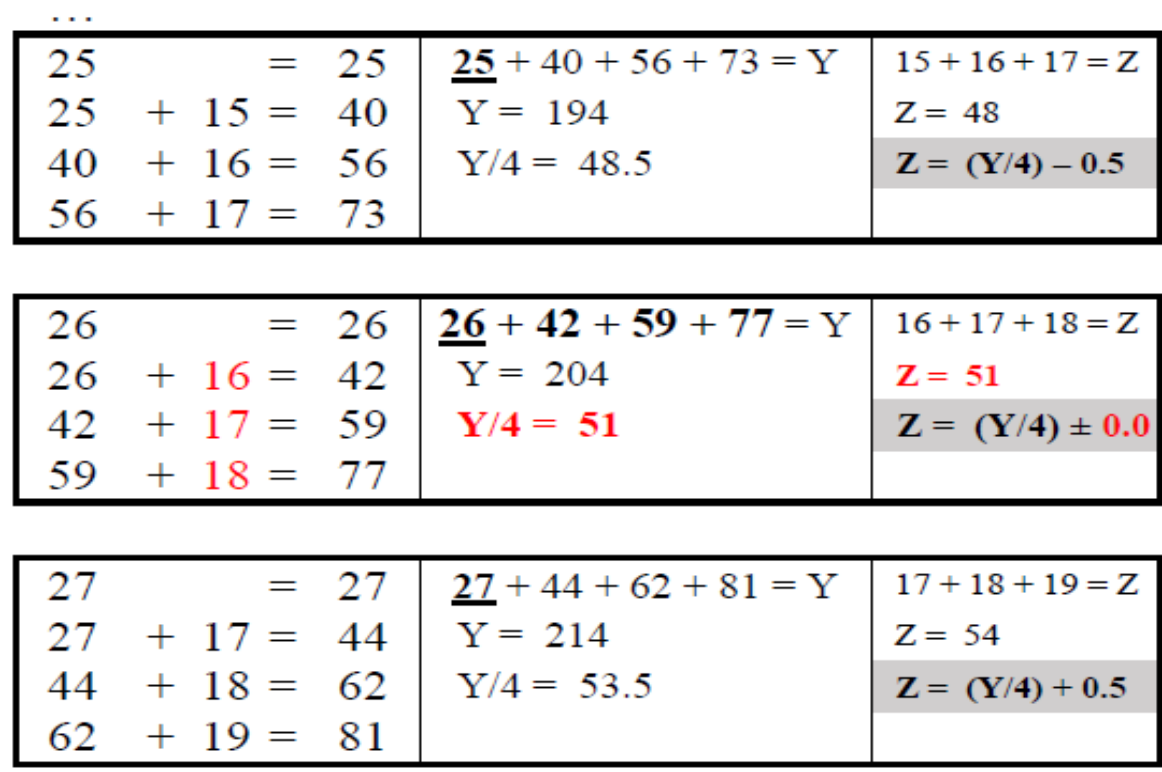


Table A3. Unique number positions in the arranged set of natural numbers (III)

\begin{tabular}{|c|c|c|c|c|c|}
\hline$q$ & & & & $q$ & $(17)_{10}$ \\
\hline 2 & $0 \times 1=00$ & $0+1=01$ & $00+01=01$ & 2 & 10001 \\
4 & $2 \times 3=12$ & $2+3=11$ & $12+11=23$ & & 101 \\
6 & $4 \times 5=32$ & $4+5=13$ & $32+13=45$ & 6 & 25 \\
8 & $6 \times 7=52$ & $6+7=15$ & $52+15=67$ & 8 & 21 \\
& & & & & \\
10 & $8 \times 9=72$ & $8+9=17$ & $72+17=89$ & 10 & 17 \\
12 & & & & & \\
14 & $\mathrm{~A} \times \mathrm{B}=92$ & $\mathrm{~A}+\mathrm{B}=19$ & $92+19=\mathrm{AB}$ & 12 & 15 \\
16 & $\mathrm{E} \times \mathrm{F}=\mathrm{D} 2$ & $\mathrm{C}+\mathrm{D}=1 \mathrm{~B}$ & $\mathrm{~B} 2+1 \mathrm{~B}=\mathrm{CD}$ & 14 & 13 \\
$\ldots$ & & & & & \\
& & & & & \\
& & & & \\
\hline
\end{tabular}


Table A4. Unique number positions in the arranged set of natural numbers: Correspondence with the Fibonacci series (I)

\begin{tabular}{|c|c|c|c|c|c|}
\hline$q$ & & & & $(\mathrm{n})_{10}$ & \\
\hline$\underline{\mathbf{0 2}}$ & $(0 \times 1=00)$ & \pm & $(0+1=01)$ & $01 /-01$ & $00 / 02$ \\
$\mathbf{6}$ & $(2 \times 3=12)$ & \pm & $(2+3=11)$ & $11 / 01$ & $12 / 10$ \\
6 & $(4 \times 5=32)$ & \pm & $(4+5=13)$ & $29 / 11$ & $40 / 18$ \\
8 & $(6 \times 7=52)$ & \pm & $(6+7=15)$ & $55 / 29$ & $84 / 26$ \\
10 & $(8 \times 9=72)$ & \pm & $(8+9=17)$ & $89 / 55$ & $144 / 34$ \\
12 & $(\mathrm{~A} \times \mathrm{B}=92)$ & \pm & $(\mathrm{A}+\mathrm{B}=19)$ & $131 / 89$ & $220 / 42$ \\
14 & $(\mathrm{C} \times \mathrm{D}=\mathrm{B} 2)$ & \pm & $(\mathrm{C}+\mathrm{D}=1 \mathrm{~B})$ & $181 / 131$ & $312 / 50$ \\
16 & $(\mathrm{E} \times \mathrm{F}=\mathrm{D} 2)$ & \pm & $(\mathrm{E}+\mathrm{F}=1 \mathrm{D})$ & $239 / 181$ & $420 / 58$ \\
18 & $(\mathrm{G} \times \mathrm{H}=\mathrm{F} 2)$ & \pm & $(\mathrm{G}+\mathrm{H}=1 \mathrm{~F})$ & $305 / 239$ & $544 / 66$ \\
$\underline{\mathbf{2 0}}$ & $(\mathrm{I} \times \mathrm{J}=\mathrm{H} 2)$ & \pm & $(\mathrm{I}+\mathrm{J}=1 \mathrm{H})$ & $379 / 305$ & $684 / 74$ \\
$\ldots$ & & & & & \\
\hline
\end{tabular}

Table A5. Unique number positions in the arranged set of natural numbers: Correspondence with the Fibonacci series (II)

\begin{tabular}{|c|c|c|}
\hline $\mathrm{q}$ & $\mathrm{q}=10$ \\
\hline 2 & $(0+1=01) ;(1 \times 1=01) ;(1 \times 3=11) ;(01+11)=100)$ & $04_{10}$ \\
4 & $(2+3=11) ;(2 \times 11=22) ;(2 \times 3=12) ;(22+12)=100)$ & $16_{10}$ \\
6 & $(4+5=13) ;(3 \times 13=43) ;(3 \times 3=13) ;(43+13)=100)$ & $36_{10}$ \\
8 & $(6+7=15) ;(4 \times 15=64) ;(4 \times 3=14) ;(64+14)=100)$ & $64_{10}$ \\
10 & $(8+9=17) ;(5 \times \mathbf{1 7}=\mathbf{8 5}) ;(\mathbf{5} \times \mathbf{3}=15) ;(85+15)=100)$ & $100_{10}$ \\
12 & $(\mathrm{~A}+\mathrm{B}=19) ;(6 \times 19=\mathrm{A} 6) ;(6 \times 3=16) ;(\mathrm{A} 6+16)=100)$ & $126_{10}$ \\
\hline$\ldots$ & & \\
\hline
\end{tabular}


Table A6. The modified Fibonacci series (The combinatorial Fibonacci series)

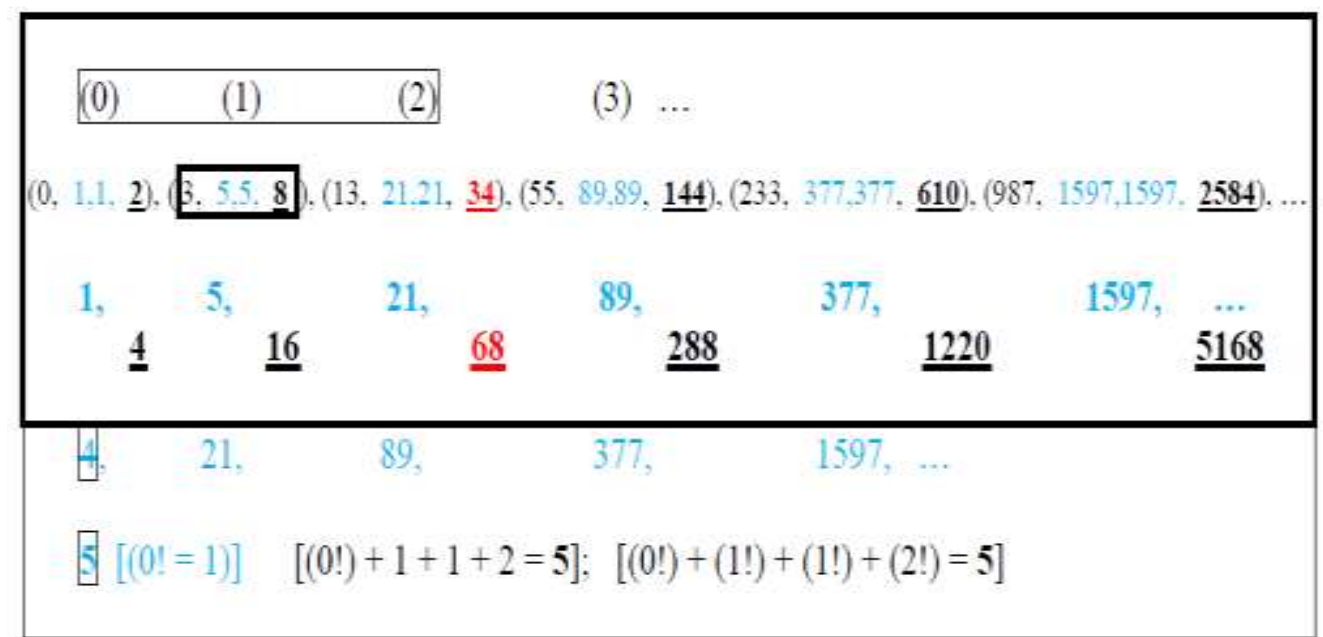

Explanation in the Discussion. 


\section{B - Atlas}

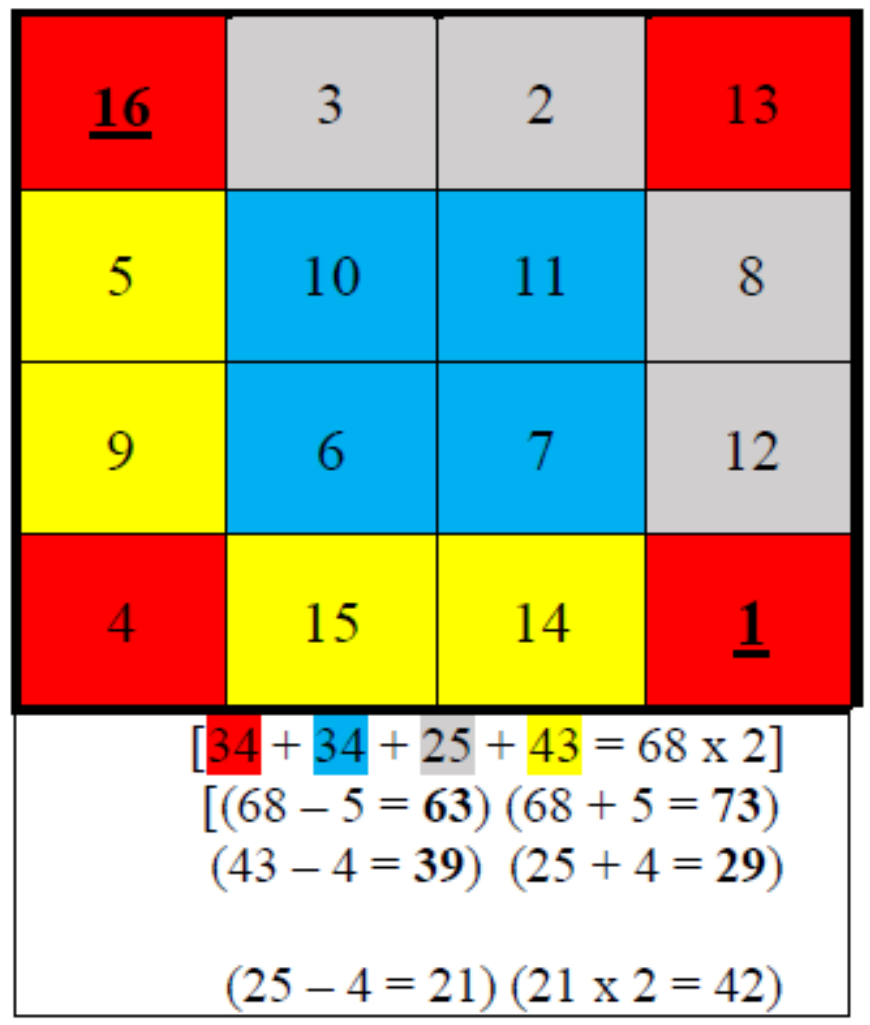

Figure B1. Dürer's magic square: $1 \rightarrow 16$. Colors as in the Table of GC in Fig. B2. Calculations: 25 as $24+1$ and 43 as 44-1; and in GC we have 24/44 (Survey 2). Correspondences: Quantities 29-39 and 63-73 in Surveys 3, 5, 6 and 7; quantities 39 and 63 in Surv. 4. 


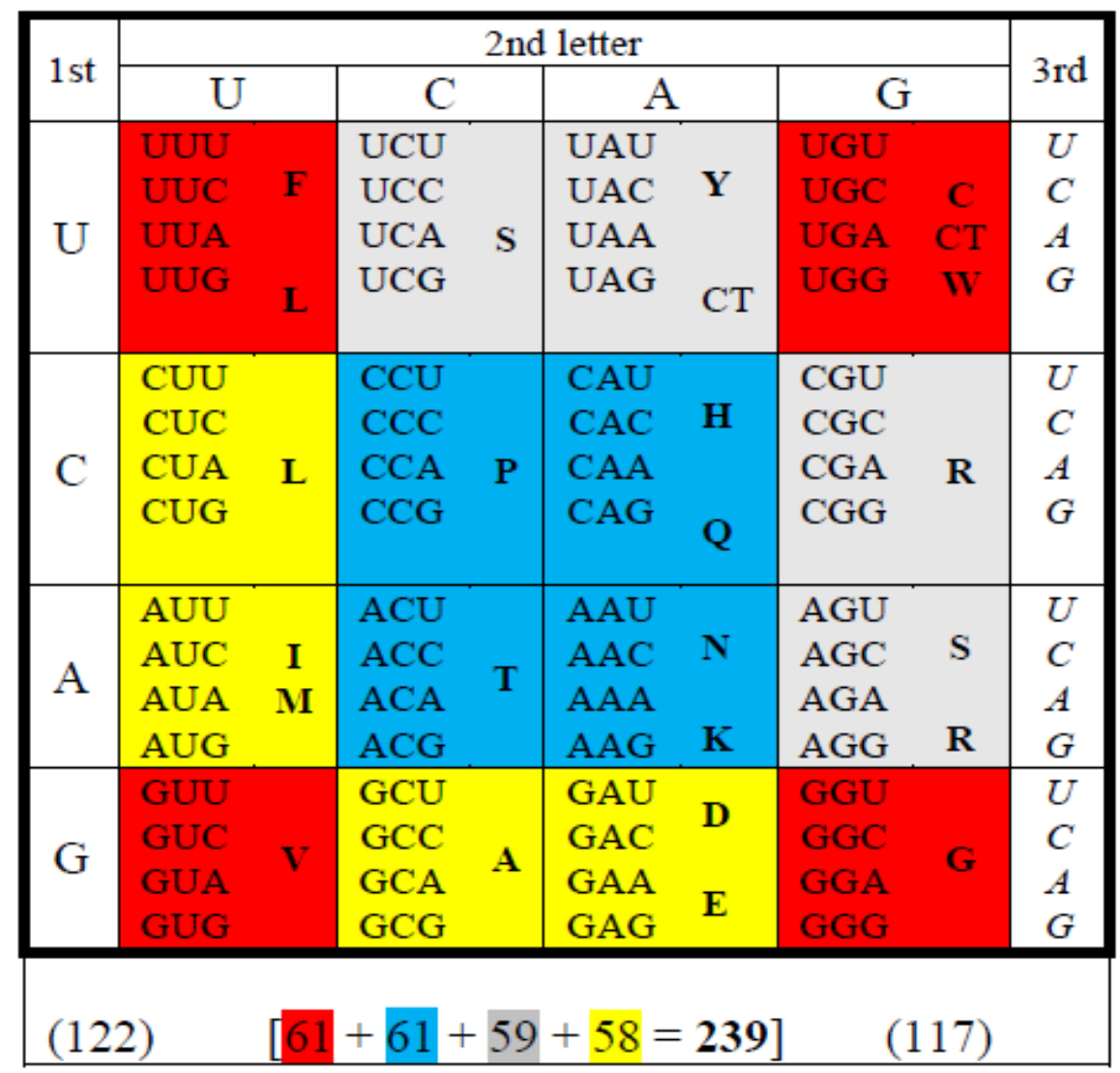

Figure B2. Genetic code Table in relation to Dürer's magic square. The correspondences: The 122 as $87+35[\mathrm{~L} 13+\mathrm{S} 05+\mathrm{R} 17=35]$. The 117 as number of hydrogen atoms in 20 AAs (within their side chains); the 87 as number of non-hydrogen atoms in 20 AAs. 


\begin{tabular}{|c|c|c|c|c|c|c|c|c|c|}
\hline \multirow{2}{*}{$\begin{array}{l}\text { 1st } \\
\text { lett. }\end{array}$} & \multicolumn{8}{|c|}{ 2nd letter } & \multirow{2}{*}{$\begin{array}{l}\text { 3rd } \\
\text { letter }\end{array}$} \\
\hline & \multicolumn{2}{|l|}{$U$} & \multicolumn{2}{|l|}{ C } & \multicolumn{2}{|l|}{$A$} & \multicolumn{2}{|l|}{$G$} & \\
\hline \multirow{4}{*}{$U$} & UUU & & UCU & \multirow{4}{*}{$\mathrm{S}$} & UAU & & UGU & & $U$ \\
\hline & UUC & $\mathbf{F}$ & UCC & & UAC & $\mathbf{Y}$ & UGC & C & C \\
\hline & UUA & & UCA & & UAA & & UGA & & $A$ \\
\hline & UUG & L & UCG & & UAG & CT & UGG & w & G \\
\hline \multirow{4}{*}{$C$} & CUU & \multirow{4}{*}{ L } & $\mathrm{CCU}$ & \multirow{4}{*}{$\mathbf{P}$} & CAU & & CGU & \multirow{4}{*}{$\mathbf{R}$} & $U$ \\
\hline & CUC & & $\mathrm{CCC}$ & & CAC & H & CGC & & $C$ \\
\hline & CUA & & $\mathrm{CCA}$ & & CAA & & CGA & & A \\
\hline & CUG & & CCG & & CAG & Q & CGG & & $G$ \\
\hline \multirow{4}{*}{ A } & AUU & & $\mathrm{ACU}$ & \multirow{4}{*}{$\mathrm{T}$} & $\mathrm{AAU}$ & & $\mathrm{AGU}$ & & $U$ \\
\hline & AUC & I & $\mathrm{ACC}$ & & AAC & N & $\mathrm{AGC}$ & S & C \\
\hline & AUA & & $\mathrm{ACA}$ & & AAA & & AGA & & $A$ \\
\hline & AUG & M & $\mathrm{ACG}$ & & $\mathrm{AAG}$ & K & $\mathrm{AGG}$ & $\mathbf{R}$ & G \\
\hline \multirow{4}{*}{ G } & GUU & \multirow{4}{*}{ V } & $\mathrm{GCU}$ & \multirow{4}{*}{ A } & GAU & & GGU & \multirow{4}{*}{ G } & $U$ \\
\hline & GUC & & $\mathrm{GCC}$ & & GAC & D & $\mathrm{GGC}$ & & C \\
\hline & GUA & & GCA & & GAA & & GGA & & $A$ \\
\hline & GUG & & GCG & & GAG & $\mathbf{E}$ & $\mathrm{GGG}$ & & G \\
\hline
\end{tabular}

Figure B3. Significant distinction of codons in GCT (28: 36) analogous to the distinction of the number of atoms in nucleotide molecules as in Survey B3. There is correspondence with Figure B2; correspondence in the number of atoms in amino acid molecules, distributed within the colored fields, as shown in Survey B1. 


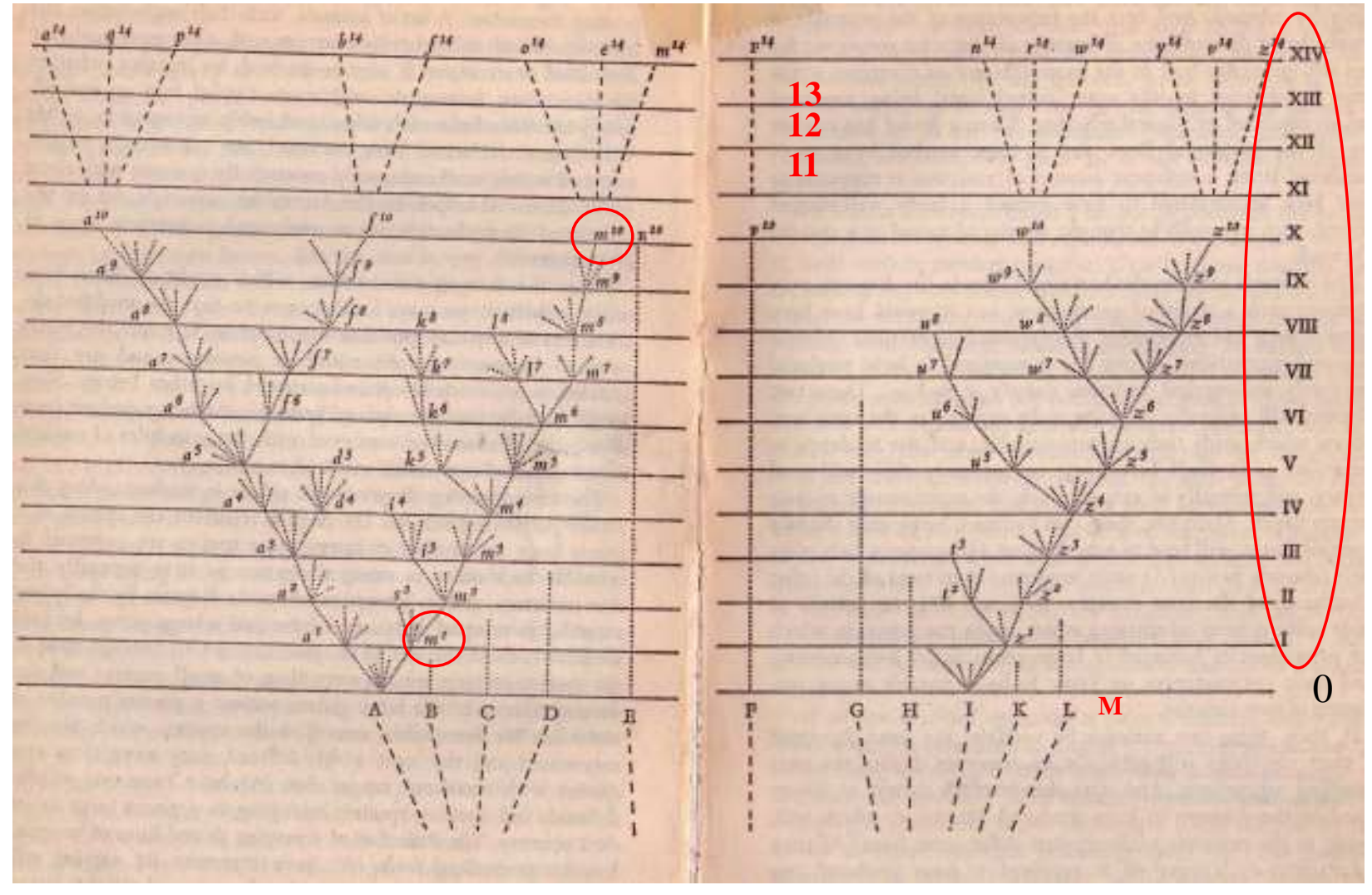

Figure B4. Darwin's diagram (the only illustration in his book The Origin of Species). At the top is a hidden correspondence with the "Arithmetic Logical Square" (cf. Tab. B5 and B6). Total number of levels: 14 plus zeroth level, which is an analogy with 14 groups plus zeroth group in Mendeleev's System in Table B1 (MMR, 2017c). 
Table B1. Mendeleev's manuscript Table of the Periodic system of long periods (Kedrov, 1977, p. 188)

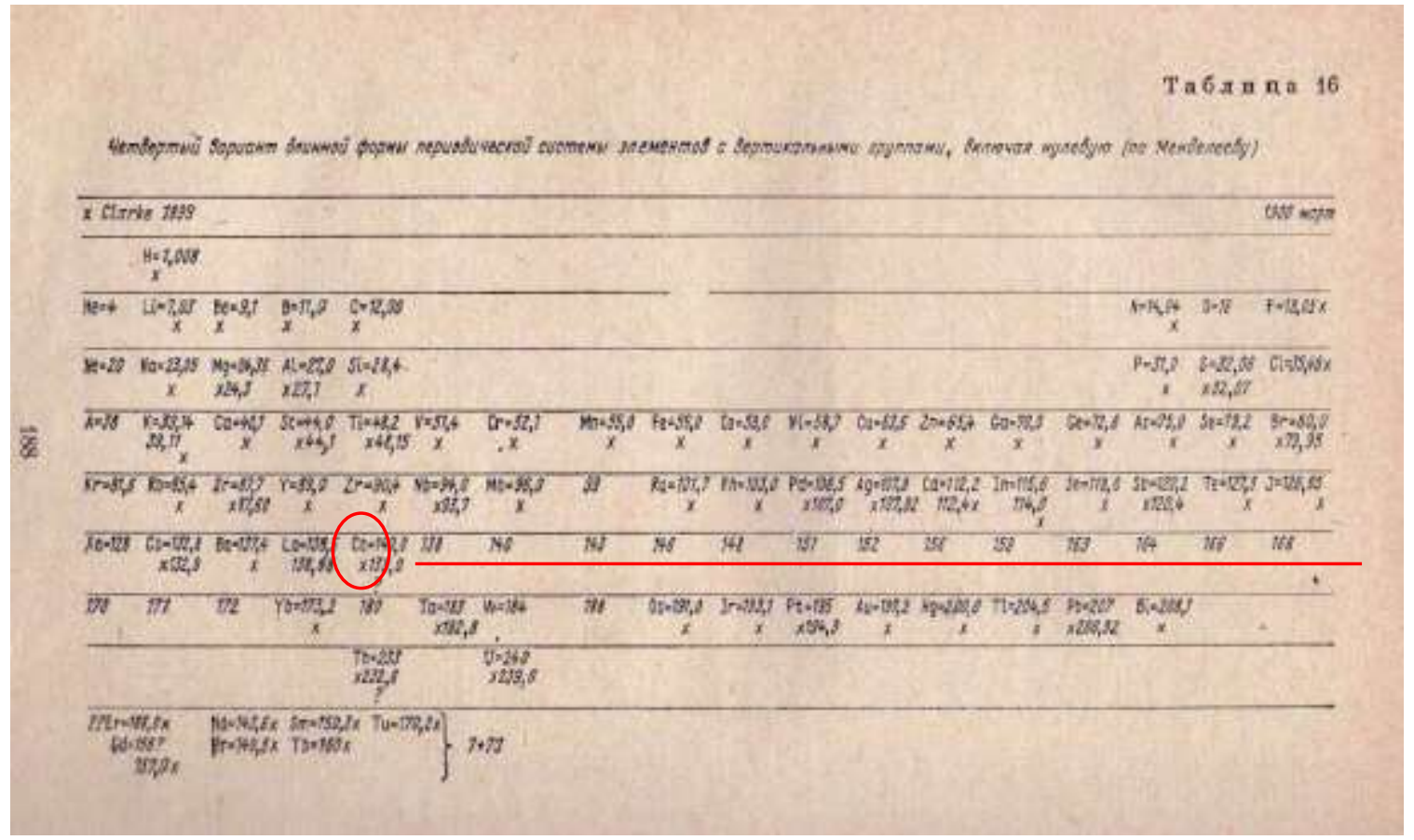

From (Kedrov, 1977, p. 188): For 14 lanthanides Mendeleev predicted 14 groups, for 14 elements, although two were not discovered during his lifetime. Total number of groups: 14 plus zeroth group, which is an analogy with 14 levels plus zeroth level on the Darwin diagram (Fig. B4) (Cf. the text in: MMR, 2018b, Preliminaries, first paragraph.) 
Table B2. Mendeleev's three-dimensional periodic system

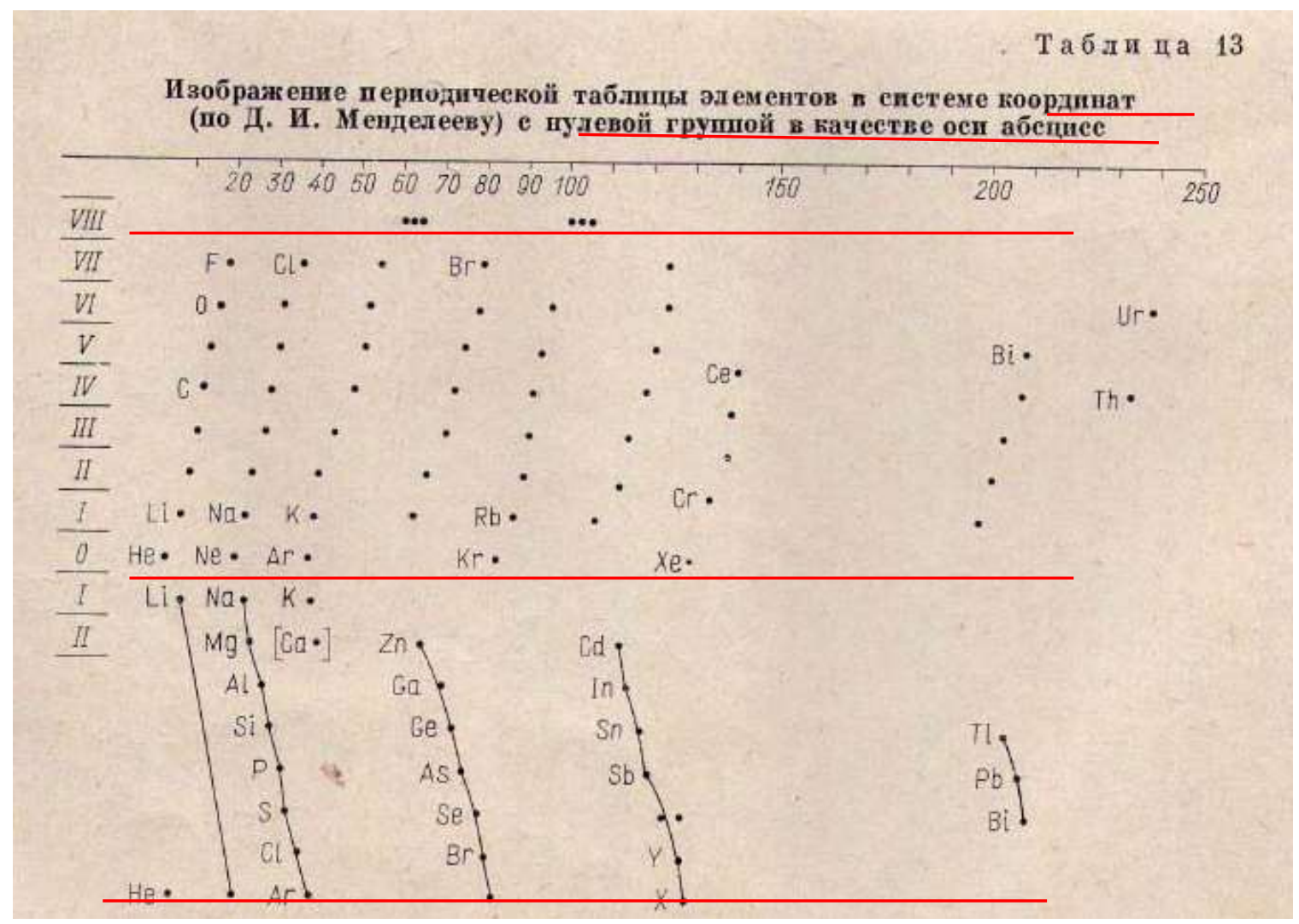

From (Kedrov, 1977, p. 183): Noble gases are found in both the zeroth and eighth group. Thus Mendeleev indicates the cyclicity, valid for the Periodic system of short periods. 
Table B3. Mendeleev's periodic system: position of elements within groups and rows

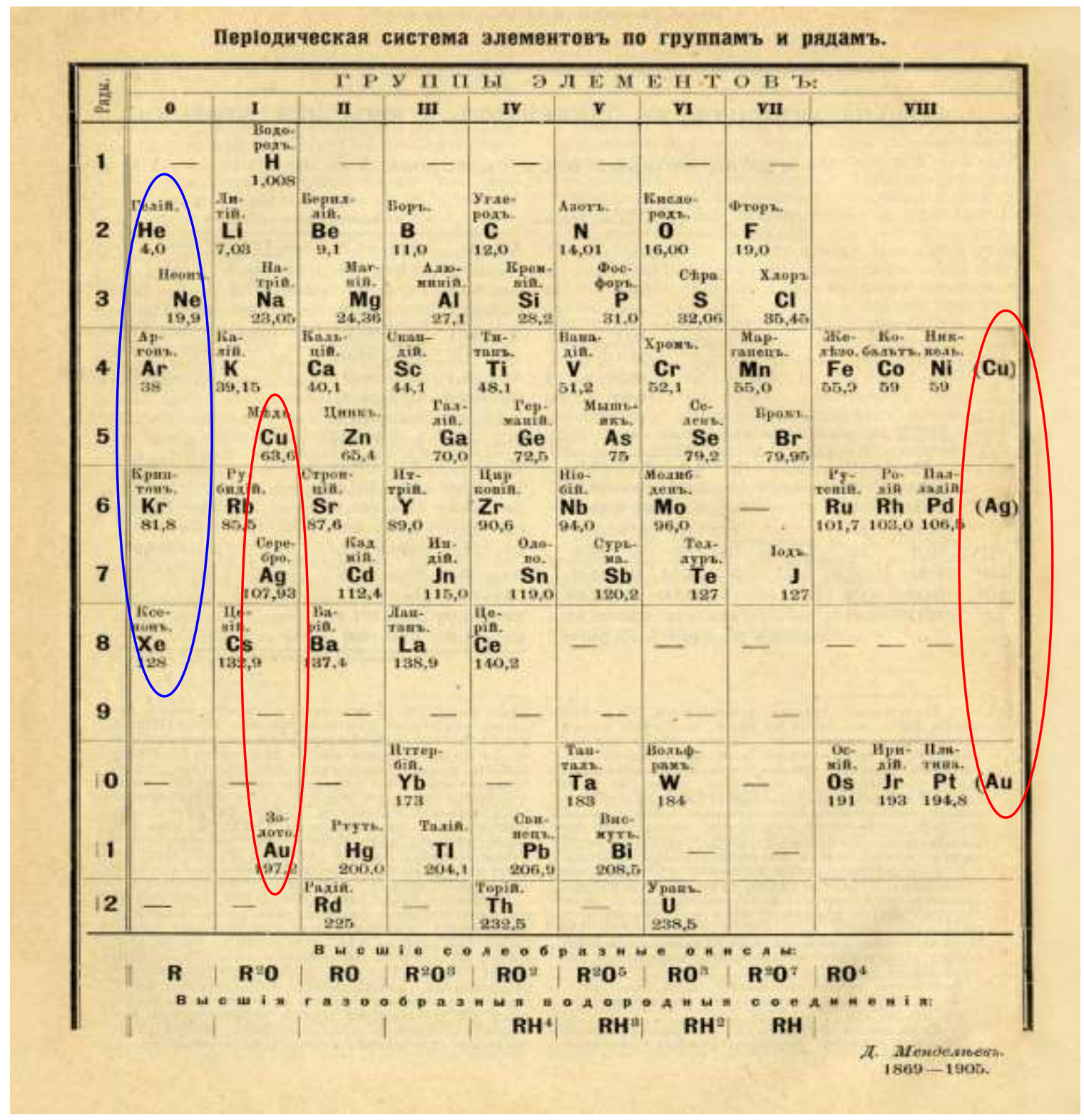

Mendeleev's PSE from VIII edition of Osnovi himii. Compared to the previous illustration (Table B2), a dilemma is noticeable: is cyclicality established through zeroth, or through the first group? 
Table B4. Prediction of the Table of long periods expressed in the Table of short periods

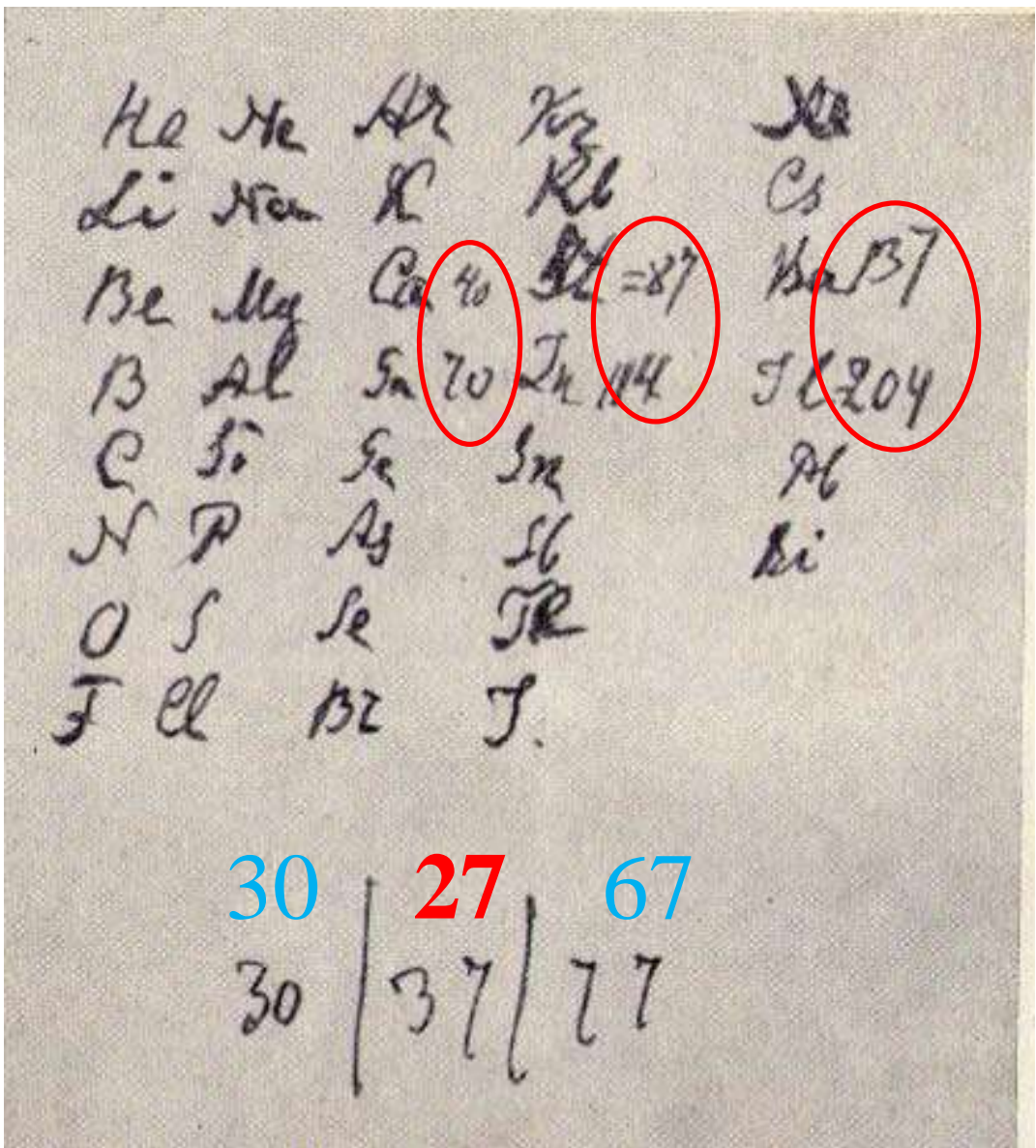

Mendeleev's "errors" as predictions (correspondence with Shcherbak's system in Table B4.1) (Kedrov, 1977, p. 128, photocopy X)

Table B4.1. Shcherbak's system of multiples of number 037 as determinant of nucleon number within Genetic code constituents (Amino acids) (Shcherbak, 1994, Tab. 1)

\begin{tabular}{rrrrrrrrrrrr}
\hline 0 & 1 & 2 & 3 & 4 & 5 & 6 & 7 & 8 & 9 \\
\cline { 4 - 8 } $\mathbf{0 0 0}$ & 037 & 074 & $\mathbf{1 1 1}$ & 148 & 185 & $\mathbf{2 2 2}$ & 259 & 296 & $\mathbf{3 3 3}$ \\
& 10 & 11 & 12 & 13 & 14 & 15 & 16 & 17 & 18 \\
& $\mathbf{3 7 0}$ & 407 & $\mathbf{4 4 4}$ & 481 & 518 & $\mathbf{5 5 5}$ & 592 & 629 & $\mathbf{6 6 6}$ \\
& 19 & 20 & 21 & 22 & 23 & 24 & 25 & 26 & 27 \\
& 703 & 740 & $\mathbf{7 7 7}$ & 814 & 851 & $\mathbf{8 8 8}$ & 925 & 962 & $\mathbf{9 9 9}$ \\
\hline
\end{tabular}

Nucleon number in the set of 23 AAs: $(1110+1110=2220) ;(333+592=925)(1110+333=1443)$ [Shcherbak, 1994, Fig. 1, p. 475] On "genesis" of 1443 from perfect numbers, see legend to Surv. C9. 
Table B5. Arithmetical "logical square"

\begin{tabular}{|c|c|c|c|}
\hline 0 & $\begin{array}{l}11 \times 1=11 \\
11 \times 2=22 \\
11 \times 3=33\end{array}$ & $\begin{array}{l}11 \times 1=11 \\
11 \times 2=22 \\
11 \times 3=33\end{array}$ & $11^{2}=121$ \\
\hline 1 & $\begin{array}{l}12 \times 1=12 \\
12 \times 2=24 \\
12 \times 3=36\end{array}$ & $\begin{array}{l}21 \times 1=21 \\
21 \times 2=42 \\
21 \times 3=63\end{array}$ & $\begin{array}{l}12^{2}=144 \\
21^{2}=441\end{array}$ \\
\hline 2 & $\begin{array}{l}13 \times 1=13 \\
13 \times 2=26 \\
13 \times 3=39\end{array}$ & $\begin{array}{l}31 \times 1=31 \\
31 \times 2=62 \\
31 \times 3=93\end{array}$ & $\begin{array}{l}13^{2}=169 \\
31^{2}=\overline{961}\end{array}$ \\
\hline 3 & $\begin{array}{l}14 \times 1=14 \\
14 \times 2=28 \\
14 \times 3=?\end{array}$ & $\begin{array}{l}41 \times 1=41 \\
41 \times 2=82 \\
41 \times 3=?\end{array}$ & $14^{2}=196$ \\
\hline
\end{tabular}

Logical square of symmetric inversion within decimal number system. Full cyclicity and symmetry is realized only with the numbers 12/21 and 13/31 within the set of two-digit natural numbers (MMR, 1994, p. 235). 
Table B6. Arithmetical "logical square" in the structure of the poem

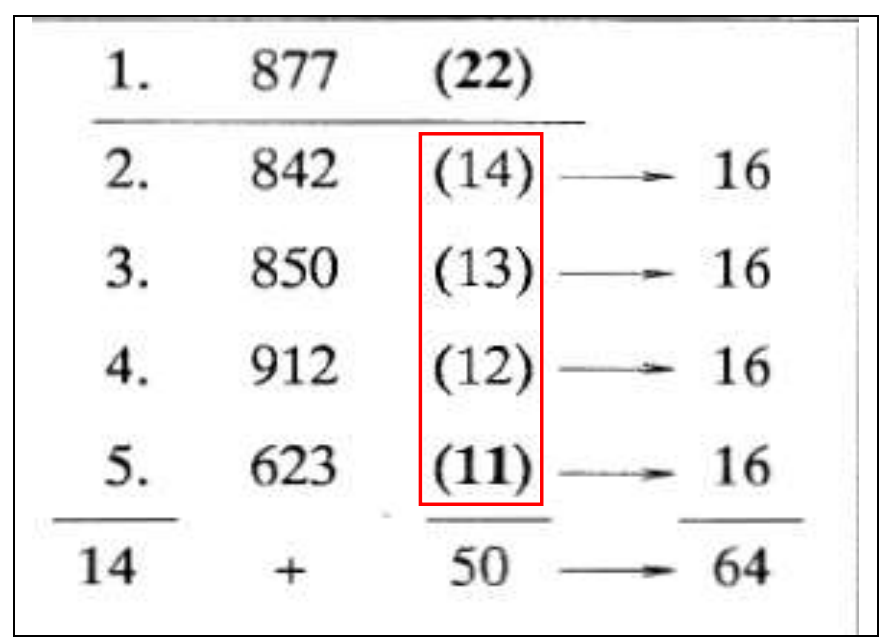

Number of verses in five acts of the False Emperor Śćepan Mali. Within the sum of digits "hides" the arithmetical "logical square" (corresponding to Tab. B5) (MMR, 2015a, Fig. 2a, p. 108). 
Table B7. The structure of the Divine Comedy in relation to the structure of GC

Dante Alighieri, La Divina Commedia

(An example from "Inferno"), number of verses:

VIII 130 (4). IX 133 (7). X 136 XII 139 (13)

$134,257,37_{10}, 49_{13}, 5 \mathrm{~B}_{16}, 6 \mathrm{D}_{19}, \ldots$

Dante Alighieri, La Divina Commedia ("Inferno", Canto IX, 61-63)

O voi ch'avete li 'ntelletti sani, Mirate la dottrina che s'asconde Sotto 'l velame de li versi strani. *

O you who have healthy thoughts, Look at the doctrine that is hidden Under the veil of the strange verses.

The number of verses in the 100 poems of the Divine Comedy corresponds to one essential finding in the genetic code. [Shcherbak, 1994, p. 475: "In the close vicinity of the decimal system, for example, some number systems ... (Quantum 134 = 7), $7\left(25_{7}=\right.$ 19), $10(37)_{10}, 13\left(49_{13}=61\right)$, etc, have the same periodic features for three-digit numbers"] (as in Table B4.1) 
Survey B1. Atom number distinctions in Tables B2 and B3

Display related to Figure $\mathrm{B} 2$
$\left(\mathrm{~S}_{5} \mathrm{Y}_{15} \mathrm{R}_{17} \mathrm{~S}_{5} \mathrm{R}_{17}\right) 59+\left(\mathrm{L}_{13} \mathrm{I}_{13} \mathrm{M}_{11} \mathrm{~A}_{4} \mathrm{D}_{7} \mathrm{E}_{10}\right) 58=117$
$\left(\mathrm{~F}_{14} \mathrm{~L}_{13} \mathrm{C}_{5} \mathrm{~W}_{18} \mathrm{~V}_{10} \mathrm{G}_{1}\right)$
$121+\left(\mathrm{P}_{8} \mathrm{~T}_{8} \mathrm{H}_{11} \mathrm{Q}_{11} \mathrm{~N}_{8} \mathrm{~K}_{15}\right) 61=122$
$122=87+35$
Display related to Figure $\mathrm{B} 3$
$\left(\mathrm{~F}_{14} \mathrm{~L}_{13} \mathrm{~L}_{13} \mathrm{I}_{13} \mathrm{M}_{11} \mathrm{~V}_{10}\right) 74+\left(\mathrm{S}_{5} \mathrm{Y}_{15} \mathrm{C}_{5} \mathrm{~W}_{18}\right) 43=117$
$\left(\mathrm{P}_{8} \mathrm{H}_{11} \mathrm{Q}_{11} \mathrm{R}_{17}\right)$
$47+\left(\mathrm{T}_{8} \mathrm{~N}_{8} \mathrm{~K}_{15} \mathrm{~S}_{5} \mathrm{R}_{17}\right) 53+\left(\mathrm{A}_{4} \mathrm{D}_{7} \mathrm{E}_{10} \mathrm{G}_{1}\right)$
$122=122$
$122=87+35$

Survey B2. Result 122 and 117 in Surv. B1 in relation to Dürer's number 68

$$
\begin{gathered}
{[(68-7)(68-7)](7 \times 7=49)(68+49=117)[61+61=122]} \\
61 \quad 61 \quad 49[(68=58+10)(49=59-10)] \\
{[117+122=239]} \\
07,17,117 / 232,222,122[222 \pm 10](222=6 \times 037)
\end{gathered}
$$

The sum of $[(-7)+(-7)]$ in relation to product $(7 \times 7)$ is observed by analogy with the results in Table C5.3. The number 68 is recognized as Dürer's double number ( 2 x 34). Number 293 is the number of atoms in 23 amino acids (within their side chains) in GCT. 
Survey B3. Distinctions of Py-Pu bases and nucleotides

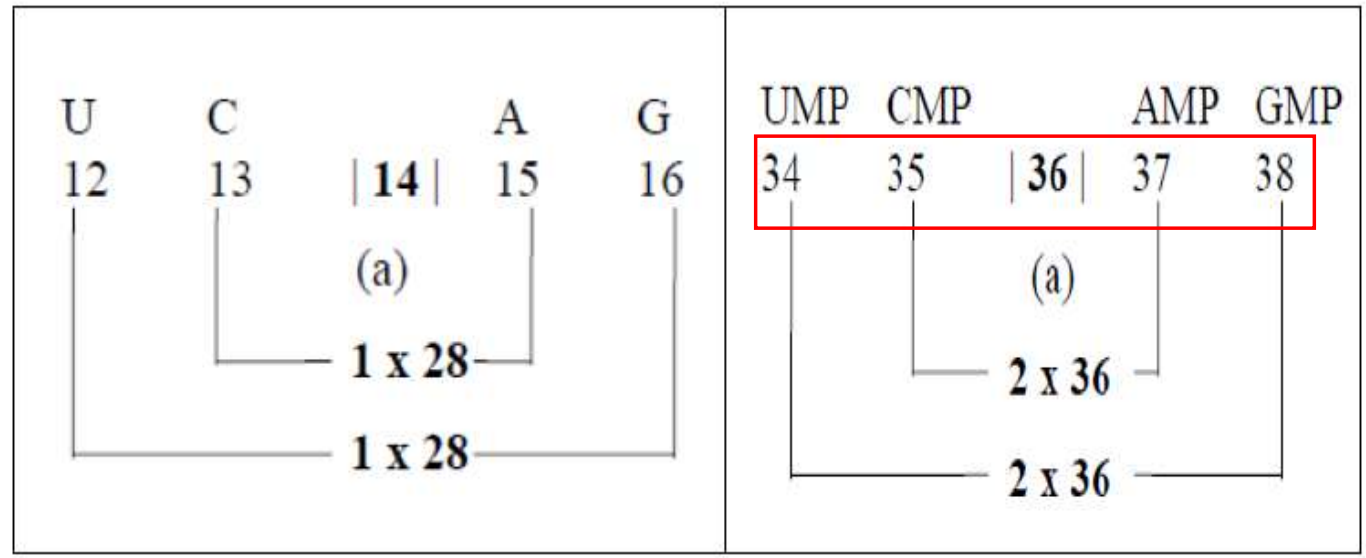

From (MMR, 1997b, pp. 62-63, Equ. 25-29). Distinctions as [(1 x 28):(2 x 36)] point to an analogy with the uniqueness of the relationship in the system-arrangement in Figure B3. The number 34 at the beginning of the sequence of the number of atoms is also recognized as a relation with the Dürer's number. 
Survey B4. Unique number positions represented in GC (I)

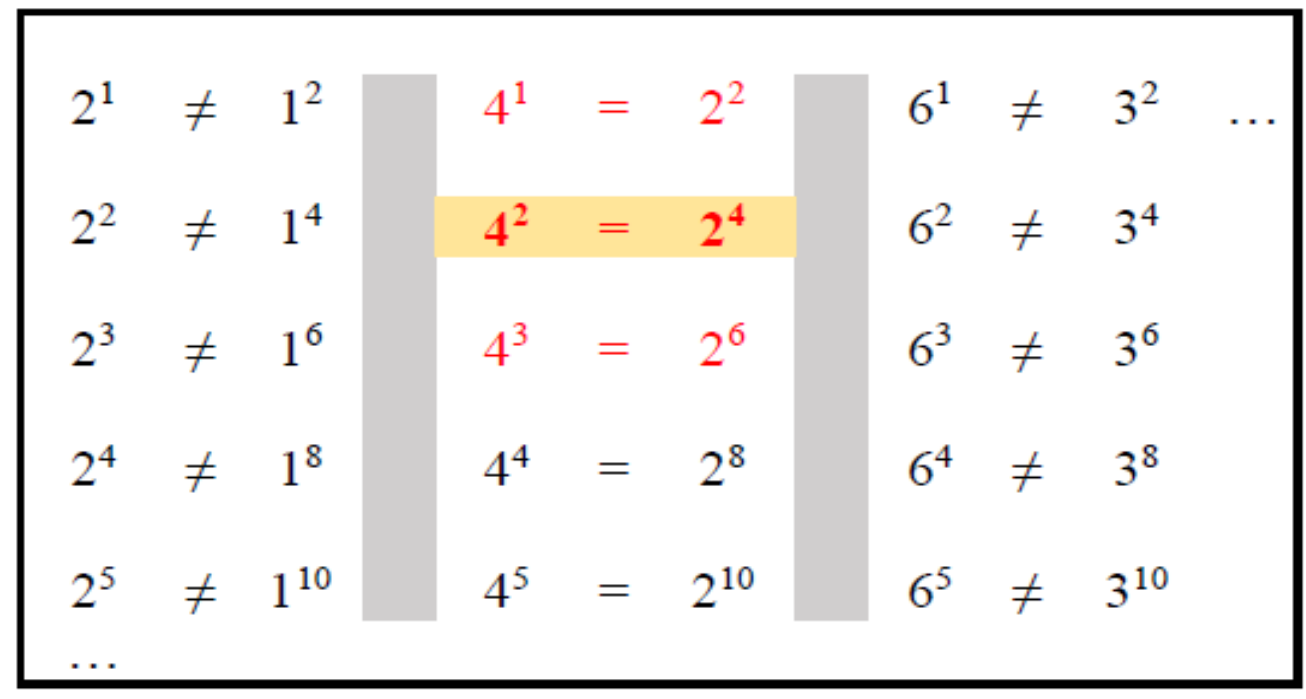

The first three equations in the central region [plus the equation $\left(2^{\wedge} 3=8\right)$ in Surv. B5] are the basic determinants of GC. There is a four-letter alphabet (U, C, A, G), but at the same time two-letter alphabet: $(\mathrm{Py}, \mathrm{Pu})$, or $(\mathrm{Y}, \mathrm{R})$ [pyrimidine, purine], according to the adopted ways of marking. The 16 nucleotide doublets are generated from the four-letter alphabet (U, C, A, G). The same doublets are also generated from the two-letter alphabet $(0,1)$, where "0" means Py, and "1" means Pu, in the Gray code model (Swanson, 1984, Fig. 1, p. 188) and/or on the binary tree of GC (MMR, 1994a, Fig. 2.2, p. 38; MMR, 1998a, Fig. 1, p. 284). From the presented four-letter and/or two-letter alphabet, 64 codons are generated in the Gray code model and/or on the binary tree. The insight into the facts that confirm the matching of GC to the three mentioned equations, as well as classify they into eight codon classes (and their AAs), in accordance with the four Py-Pu distinctions (MMR, 2004a, Tab. 3a), I first presented in tabular form (MMR, 1988b, Tab. 29, p. 122). I repeated the same Table in the following paper (MMR, 1994a, Tab. 2.2, p. 40). The Table was then taken over by $\mathrm{Dj}$. Koruga (1992, Tab. 3), on which occasion he not only commented on it, but also provided it with mathematical apparatus (the third equation here, and the first equation from B5). Finally, it remains for me to complete the system, as given here and in Surv. B5. [Koruga, 1992, p. 17: "Preliminary results ... show that it is possible that the binary characteristic of the genetic code is the factor which determines the number of amino acids which can be coded with the 61 codons (Swanson, 1984; Rakočević, 1988). In Table 3 we see the relationships between triplets of the genetic code and the binary genetic code and their eight repetitive structures."] 
Survey B5. Unique number positions represented in GC (II)

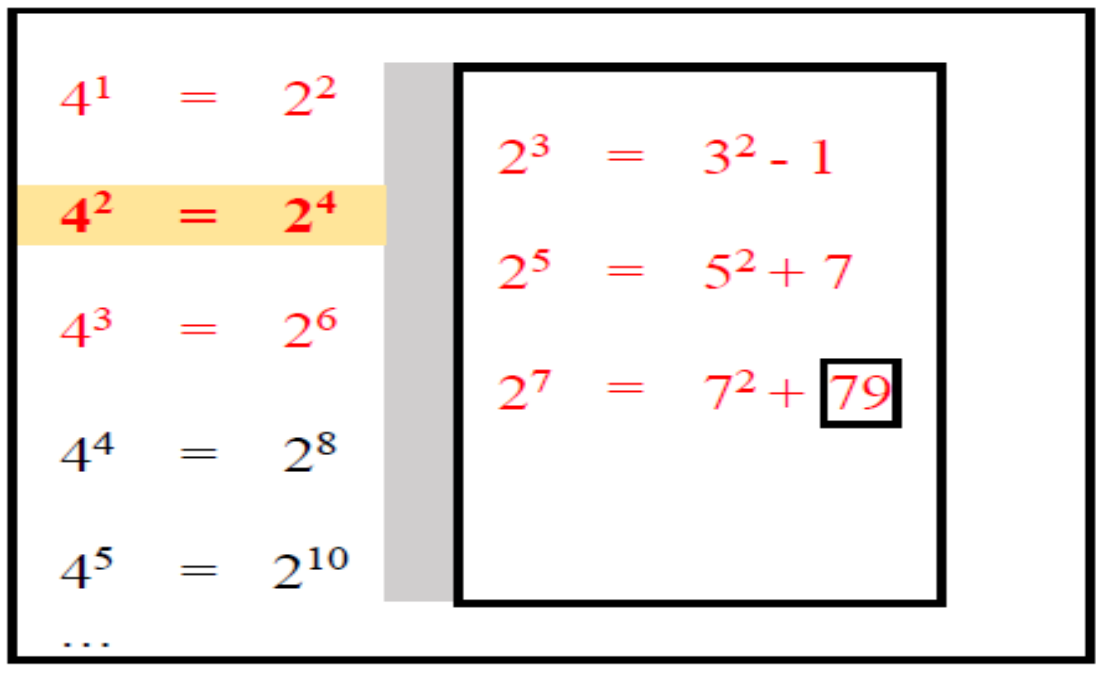

Note: The first row on the right illustration corresponds to the middle ninth Cantor set, valid for GC (cf. Fig. D2.1).

Survey B6. The uniqueness of numbers 39 and 79

\begin{tabular}{|l|l|}
\hline$\ldots$ & \\
$1 \times 38=76$ & $2 \times 78=156$ \\
$1 \rightarrow 38=(760 \times 1)-19$ & $1 \rightarrow 78=(1560 \times 2)-38$ \\
$2 \times 39=78$ & $2 \times 79=158$ \\
$1 \rightarrow 39=(780 \times 1) \pm 0$ & $1 \rightarrow 79=(1580 \times 2) \pm 0$ \\
$2 \times 40=80$ & $2 \times 80=160$ \\
$1 \rightarrow 40=(800 \times 1)+20$ & $1 \rightarrow 80=(1600 \times 2)+40$ \\
$\ldots$
\end{tabular}

The golden mean of 6-bit binary tree, valid for GC, is between numbers 38 and 39 (MMR, 1998a), and 7-bit probably valid for chemical code, between 78 and 79 (MMR, 1998c). [In PSE at position 78 is $\mathrm{Pt}$, and at position 79 is $\mathrm{Au}$, the element most resistant to chemical influences.] 
Display B1. Subtitle page of the book (Popov, 1989)

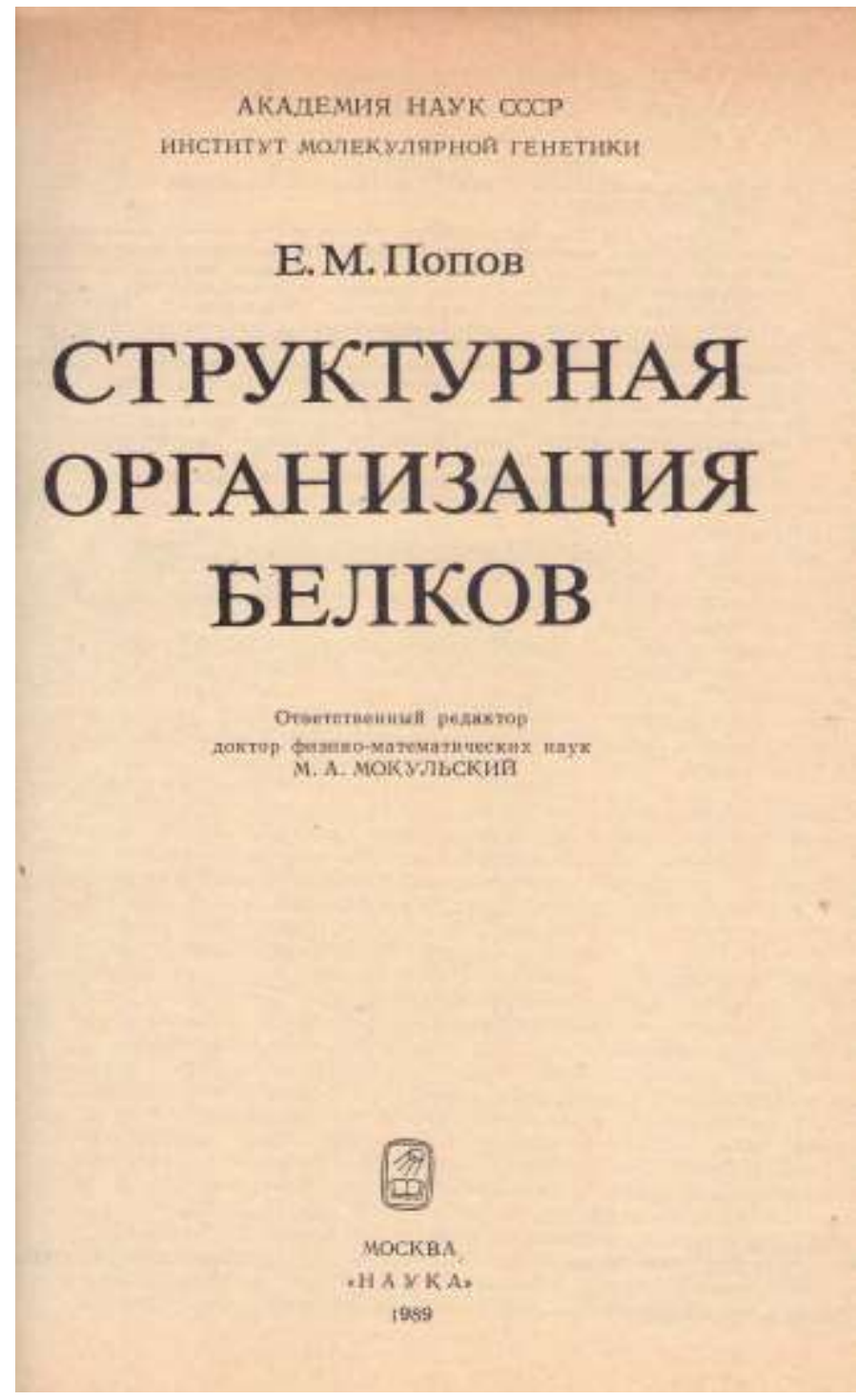

Евгений Митрофанович Попов: "Структурная организация белков" (Evgeny Mitrofanovich Popov: "Structural organization of proteins") (Popov, 1989). 


\section{Display B2. Conformational states of amino acid side chains in proteins, I}

(Popov, 1989, p. 79)

\section{КОНФОРМАЦИОННЫЕ СОСТОЯНИЯ АМИНОКИСЛОТНЫХ ОСТАТКОВ В БЕЛКАХ}

Ответ на поставленный вопрос требует сравнения ставших теперь известньми оптнмальных конформация метнламидов $\mathrm{N}$-ацетнл- $\alpha$-аминокислот $\mathrm{c}$ конформационными состояниями ауннокислотных остатков в нативных трехмерных структурах белков. Первые определяются лишь ближними взанмодействиями, а вторые - суммарным эффектом ближних, срелних и дальних взанмодействий, Сопоставдене должно выявить меру всздействия блнжних взанмодействий на реализующцеся в белках конформацнонные состояния и оценить роль зтнх нзаямодействий в структурной организании макроволекул. В соответствин с постулируемой в нашей теории (см. гл. II; (16-18]) согласованности всех вндов внутримолекулярных невалентных взанмодействай наблюдаемые в трехмерных структурах белков конформационые состоннин остатков должны входнть в набор ииякоянергетических оптимальных форм метнламидов $\mathrm{N}$-ацетил- $\alpha$-аминокислот. Т олько в этом случае представнтя прининтапьиая возможность сделать следующий шаг в сторону решения на основе рассматрниаемого подхода задачи структурной ортанизаини белков. Нелесообразно рассмотреть в отдельности гео метрню основных н 6 оковых цепей остатков.

\section{OCHOBIHBH ЦЕПИ}

По характеру нлияния боковой пепи (R) на конформаниониуо свободу ос-

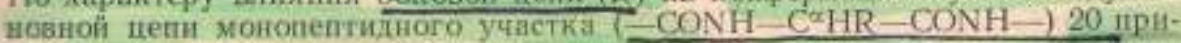

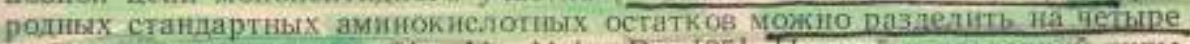
стереохиманеских типа: Gly, Ala, Val и. Pro [35]. Первый и последний типы

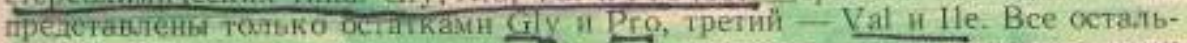

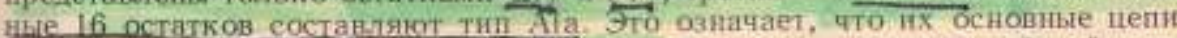

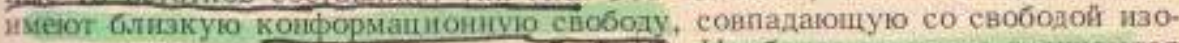
анрованного остатка Ala (cм. рис, 7, 0: Tठ̈), Нанбодее серьезно отличаются потеншнальные поверхиости Gly и Pro; различия же межлу поверхностями остатков типа Ala и Val сравнительно невелики, и в последунцем изложенин этн 18 остатков мы будем рассынтривать вместе.

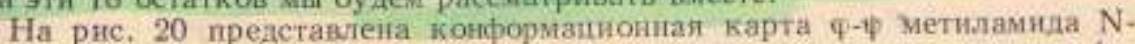
ацетил- $L$-аланина с нанесенными на нее конформацнонными точками ( $\varphi$, ф) всех остатков (за нсклюненнем Gly и Pro) миоглобнна $(1,5 \mathrm{~s})$, $\alpha$-химот. рипсина $(2,0 \mathrm{~A})$, белка хрусталика тлаза $(1,9 \hat{A})$, лизоцима $(1,5 \mathrm{~A})$, нейтротоксина $(1,8 \hat{\mathrm{A}})$, рубредоксина $(1,2 \hat{\mathrm{A}})$, панкреатического трипсинового ингибитора $(1,5 \mathrm{~A})$ и феррицитохрома $c(2,0 \AA)$. Всего на карту нанесено около 900 конформанионных точек. Белки выбраны пронзвольно; требовалось лншь, чтобы их крнсталлографические структуры были расшифрованы с хорошим разрешеннем (у выбранных белков оно указано в скобках).

Копформашионные карты метнламида $\mathrm{N}$-ацетил- $L$-аланина, приведенные на рис, 10 и 20, несколько отличаются между собой. Карта на рис. 20 построена с учетом только невалентных н торсионных взанмодействий, так как водородные связи $\mathrm{N}-\mathrm{H} . . \mathrm{O} \quad \mathrm{C}$ тита $3 \rightarrow-1$ у монопептндов в водной ереде очень слабы н практически не влияют на характер потенцнальной поверхности; то же можно сказать и об электростатических взанмодействиях атомов основной цеги в условиях полярного окружения. Более существенным оказалось то обстоятельство, что контуры конформационной карты рис. 20 были получены при минимизации энергии по валентным углам. Это, правда, 
Display B3. Conformational states of amino acid side chains in proteins, II (Popov, 1989, p. 88)

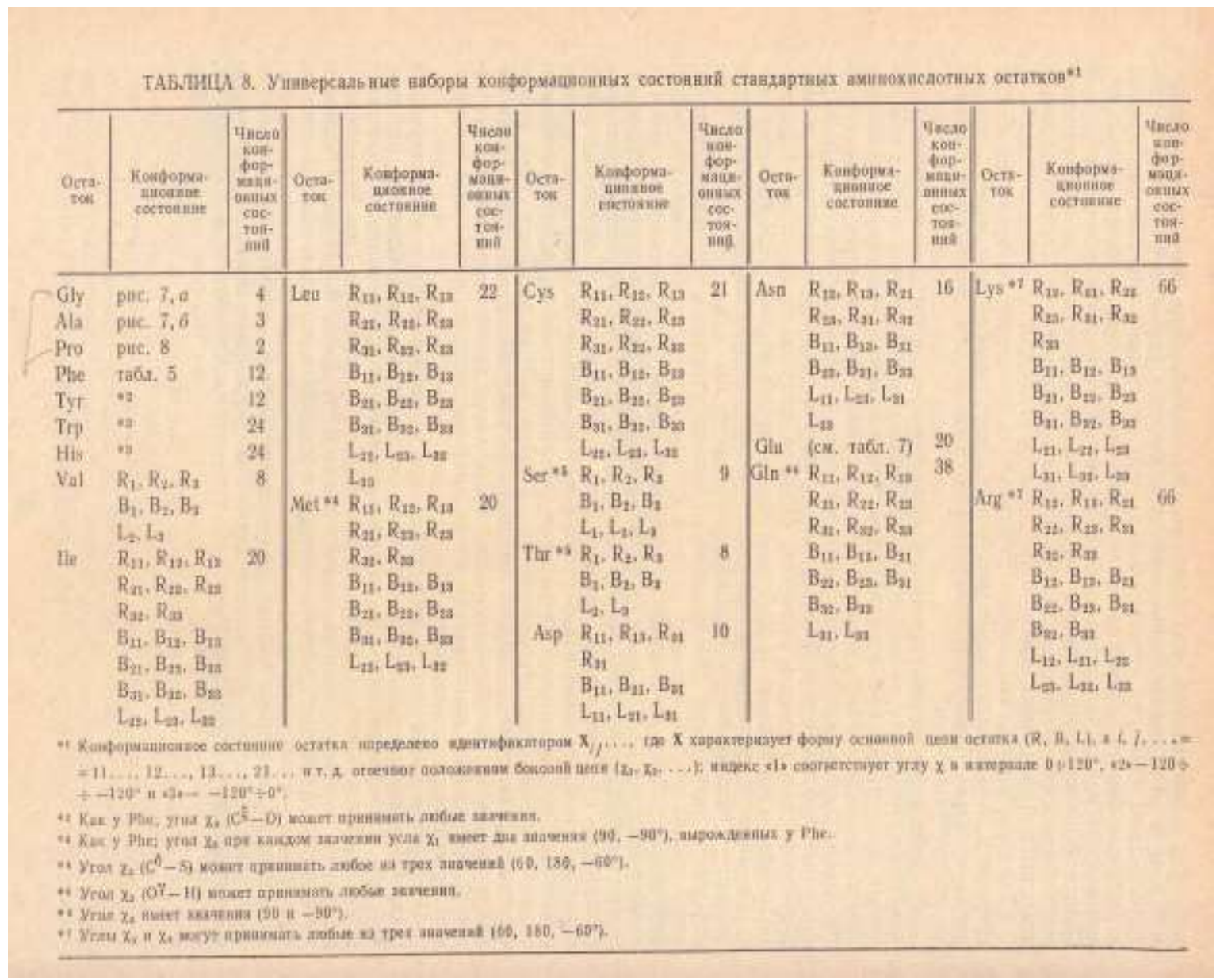


Display B4. The title page of the book (Koruga et al, 1993)

\section{FULLERENE}

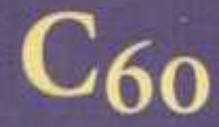

HISTORY, PHYSICS, NANOBIOLOGY, NANOTECHNOLOGY

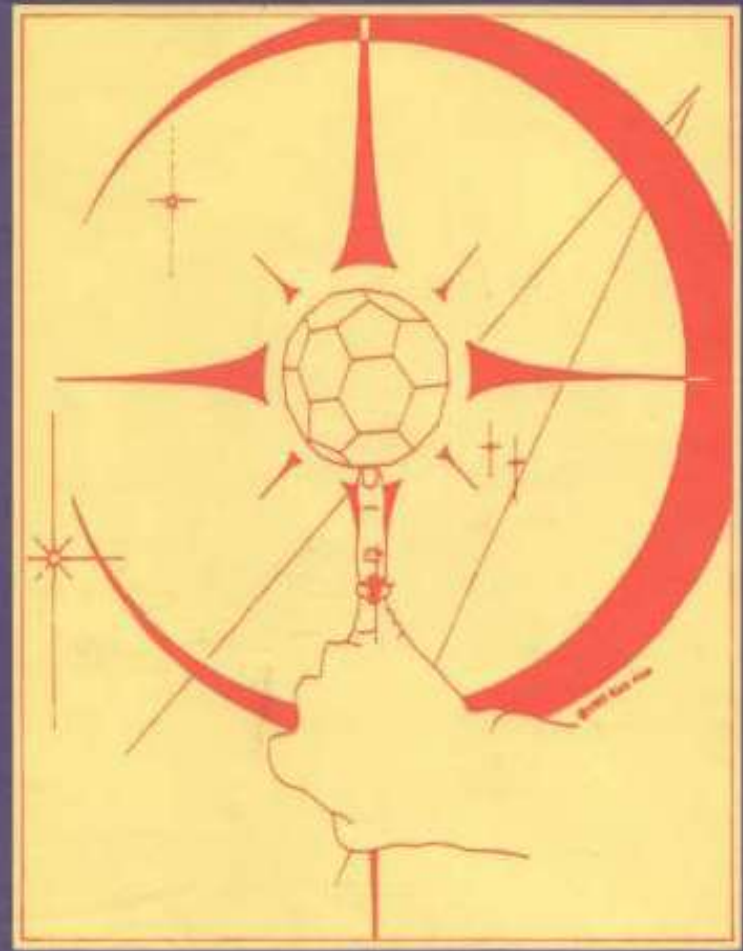

Djuro Koruga

Stuart Hameroff

James Withers

Raoulf Loutfy

Malur Sundareshan 
Display B5. The subtitle page of the book (Koruga et al, 1993)

\section{FULLERENE $\mathrm{C}_{60}$}

HISTORY, PHYSICS, NANOBIOLOGY, NANOTECHNOLOGY

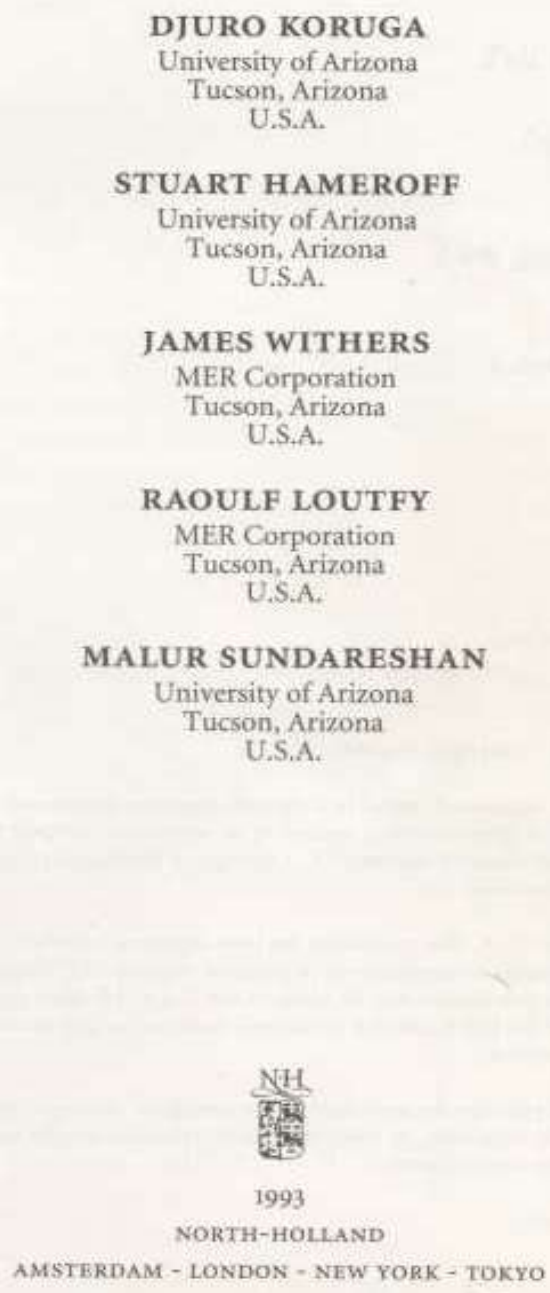




\section{Display B6. Excerpt from the book (Koruga et al, 1993) On the Fibonacci numbers and the zero factorial}

Fibonacci numbers: number sequence having as base $[0,0\} \mid$ that generates numbers according to the rule that the addition of two adjacent numbers gives the next succeeding number: $0+0 !=1,0 !+1=2,1+2=3,2+3=5 \ldots$ forming a sequence $1,2,3,5,8,13,21,34$, 55... The ratios between two successive numbers form the sequence $1 / 2,2 / 3,3 / 5 \ldots$ converging to $0.61803 \ldots=\phi_{1}$, while the sequence $2 / 1,3 / 2,5 / 3 \ldots$, converges to $1.61803 \ldots=\Phi_{\text {, }}$ where $\Phi-\phi=1$ and $1 / \phi=\Phi$. Since $\phi=1 / 2(\sqrt{5} \cdot 1)$ and $\Phi=1 / 2(\sqrt{5}+1)$, one of their major characteristic is the icosahedral and dodecahedral symmetry. There are four Fibonacci numbers: $\phi, \phi,-\phi,-\Phi$, two are real values $\Phi=1 / 2(\sqrt{5}+1), \phi=1 / 2(\sqrt{5}-1)$ while the other two numbers are complex $-\Phi=h(F \sqrt{5}+1),-\phi=1 / 2(i 2 \sqrt{5}-1)$.

We observe that for $n=0$, the zero-th term contains a zero factorial, the right factorial $\left.{ }_{n},\right]^{\prime \prime}$ and the left factorial $, 0,0^{\prime \prime}$, which can be denoted as $\langle(9)\rangle$. This is transformed expression 2.17 , because in the formula we have a zero factorial and velocity $v^{\circ}$, (recall

The zero factorial (it used to be written as 0 ! which is actually the right zero factorial) is a great enigma of mathematics, and its physical interpretation is still more problematic. The value of the zero factorial is a unity, which is very strange. However, if this were not so the "world of mathematics", as we know it today, would collapse as a ${ }_{\theta}$ house of cards". In other words, the equality of the zero factorial to 1 is ,artificial", although why is 0 ! $=1$ nobody knows for sure. The factorial is related to the gamma function, which was introduced into mathematics by Leonhard Euler (1707-1783). For example, factorial of number 5 is $5 !=1 \times 2 \times 3 \times 4 \times 5=120$, and it represents the right factorial. Our renowned mathematician Đuro Kurepa (1907-1993) introduced the concept of the left factorial $(! n)$ and proposed the hypothesis that the greatest common divisor of numbers $n !$ and In is number 2 (Kurepa, 1974), 
Display B7. Excerpt from the book (Koruga et al, 1993, p. 30)

During the spring of 1991, by pure chance, Professor Miloje Rakočevic of the University of Niš, came to the MMRC carrying a bundle of papers with his calculations and proofs that master authors like Göethe, Tolstoy ... Njegoš wrote masterpieces based on the principles of the Golden Mean. At that time I was teaching Golden Mean properties of microtubules in my course, Bioautomatic Control, and intensively working on the symmetry of $\mathrm{C}_{60}$. Knowing that the Golden Mean is the basis of 5-fold symmetry and the $\mathrm{C}_{60}$ molecule, and as a connoisseur of poetry and prose, I was interested in his ideas. At first skeptical about the possibility of applying the Golden Mean to literature, I began to realize as the interview progressed that Professor Rakočević may have uncovered something, but I had to have time to verify.

We agreed to meet again in two or three days time. During those couple of days, I reread "Ray of the Microcosmos" be Petar Petrović Njegoš (one of the greatest Yugoslav poets, prince of Montenegro, philosopher and bishop; born 1813, died 1851), one of the examples Professor Rakočević had spoken of as having been written in accord with the Golden Mean. My surprise was complete. The poem, "Rays of the Microcosmos," about Man and his relation to his God (Creator), his destiny, was really written according to the Golden Mean. I experienced both shock and joy. Was it then possible that masterpieces by Göethe, Shakespeare, Tolstoy, Njegoš and others were written in accord with the Golden Mean, and were they masterpieces because they were written according to the Golden Mean? When again I met with Professor Rakočević, we decided to organize a scientific symposium about the works of Njegoš in order to present these ideas to a wider audience. I asked one of my

\section{research associates ..."}

[From (MMR, 2003, pp. 84-85) (in Serbian): "The monograph from which this quote originates... Professor Koruga wrote together with four Americans. It is the first written monograph, in the world in general, on a new type of carbon molecules, denoted by fullerenes, in honor of the architect Fuller, who found the same type of symmetry characteristic of these molecules in architectural structures... Three researchers (RF Curl, RE Smalley and HW Kroto), who discovered this new class of molecules in 1984, received the Nobel Prize in Chemistry in 1996. Writing about the unique logic that applies, on the one hand, to fullerene, and, on the other hand, to architectural structures, Koruga, with his associates, introduces the term 'Njegos's scenario'. This means that the same (universal) logic that is in the organization of fullerene and architectural structures is also in the organization of the structure and composition of the Ray of the Microcosm."] [Cf. MMR, 1994b; 1995.] 
\{Additional Note 1 (30.03.2021): The idea of Prof. Koruga that one of the two units at the beginning of the Fibonacci sequence can be considered in the sense of "zero factorial (0!)" have to do with "Njegoš's scenario". When I presented to him the structure of the Ray of the Microcosm (six poems, without Dedication, in honor of Njegošs teacher, poet and philosopher, Simo Milutinović Sarajlija, in which there are 200 verses), given in relation to the Golden mean and the Fibonacci sequence (from 1 to 13), Prof. Koruga immediately had an idea of the position of Dedication: It is (in one virtual reality) "placed" in the only empty place, in the 28th stanza of the third poem, in the place of the 280th verse which does not exist. ${ }^{47}$ Thus, according to Prof. Koruga, Njegoš "played" also the beginning of the Fibonacci series: 0,0 ! [Cf. Tab. A6 and the explanation in the Discussion.] A year later, I found that, with the inclusion of the Dedication, Njegoš also played Fibonacci's number 21, which certainly has to do with the six-bit binary tree. (Cf. Table D3.)

\{Additional Note 2 (30.03.2021): From the meeting that Prof. Koruga stated in this book, so until today, our cooperation has not stopped. He also initiated my participation in the Tucson Conference (MMR, 1994b) - he installed a poster, with all the illustrations found now in: (MMR, 1995), for which I am more than grateful. With these events, the line of my research of the structure of works of classics of literature (and the Bible) began, with the presentation of evidence that they (Homer, Dante, Shakespeare, Goethe, Pushkin, Njegoš, Tolstoy) consciously and intentionally conceived the structure and composition of their works be in correspondence with the Golden mean and the Fibonacci sequence, that is, with the universal code of Nature.

${ }^{47}$ Njegoš, at that time the Superior of Montenegro, and the high priest, sent the manuscript of Ray of microcosm to Belgrade, to the hands of his teacher Simo Milutinović, to put it in a wonderful press there. Seeing that the 28th stanza of the third poem has 9 verses instead of 10, Sima Milutinović invented the tenth verse and added it, with a footnote: "This verse does not exist, I added it, and who will better that has a wide field." 


\section{C - Atlas}

Table C1. Multiplication Table of decimal number system

\begin{tabular}{|c|c|c|c|c|c|c|c|c|c|}
\hline 0 & $\underline{0}$ & 0 & 0 & 0 & 0 & 0 & 0 & 0 & 0 \\
\hline$\underline{0}$ & 1 & $\underline{2}$ & 3 & 4 & 5 & 6 & 7 & 8 & 9 \\
\hline 0 & $\underline{2}$ & 4 & $\underline{6}$ & 8 & 10 & 12 & 14 & 16 & 18 \\
\hline 0 & 3 & $\underline{6}$ & 9 & $\underline{12}$ & 15 & 18 & 21 & 24 & 27 \\
\hline 0 & 4 & $\overline{8}$ & $\underline{12}$ & 16 & $\underline{20}$ & 24 & 28 & 32 & 36 \\
\hline 0 & 5 & 10 & 15 & $\underline{20}$ & 25 & 30 & 35 & 40 & 45 \\
\hline 0 & 6 & 12 & 18 & 24 & 30 & 36 & $\underline{42}$ & 48 & 54 \\
\hline 0 & 7 & 14 & 21 & 28 & 35 & 42 & $\overline{49}$ & $\underline{56}$ & 63 \\
\hline 0 & 8 & 16 & 24 & 32 & 40 & 48 & $\underline{56}$ & 64 & $\underline{72}$ \\
\hline 0 & 9 & 18 & 27 & 36 & 45 & 54 & 63 & 72 & 81 \\
\hline
\end{tabular}

Table C1.1. Multiplication Table of octal number system

\begin{tabular}{|cccccccc|}
\hline 0 & $\underline{\mathbf{0}}$ & 0 & 0 & 0 & 0 & 0 & 0 \\
$\underline{\mathbf{0}}$ & 1 & $\underline{\mathbf{2}}$ & 3 & 4 & 5 & 6 & 7 \\
0 & $\underline{\mathbf{2}}$ & $\mathbf{4}$ & $\underline{\mathbf{6}}$ & 10 & 12 & 14 & 16 \\
0 & $\mathbf{3}$ & $\underline{\mathbf{6}}$ & 11 & $\underline{\mathbf{1 4}}$ & 17 & 22 & 25 \\
0 & 4 & 10 & $\mathbf{1 4}$ & 20 & $\underline{\mathbf{2 4}}$ & 30 & 34 \\
0 & 5 & 12 & $\mathbf{1 7}$ & $\underline{\mathbf{2 4}}$ & $\mathbf{3 1}$ & $\underline{\mathbf{3 6}}$ & 43 \\
0 & 6 & 14 & 22 & $\mathbf{3 0}$ & $\underline{\mathbf{3 6}}$ & $\mathbf{4 4}$ & $\underline{\mathbf{5 2}}$ \\
0 & 7 & 16 & $\mathbf{2 5}$ & $\mathbf{3 4}$ & $\mathbf{4 3}$ & $\underline{\mathbf{5 2}}$ & 61 \\
\hline
\end{tabular}


Table C1.2. Multiplication Table of hexadecimal number system

\begin{tabular}{|cccccccccccccccc|}
\hline 0 & 0 & 0 & 0 & 0 & 0 & 0 & 0 & 0 & 0 & 0 & 0 & 0 & 0 & 0 & 0 \\
0 & 1 & 2 & 3 & 4 & 5 & 6 & 07 & 8 & 9 & $\mathrm{~A}$ & $\mathrm{~B}$ & $\mathrm{C}$ & $\mathrm{D}$ & $\mathrm{E}$ & $\mathrm{F}$ \\
0 & 2 & 4 & 6 & 8 & $\mathrm{~A}$ & $\mathrm{C}$ & $\mathrm{E}$ & 10 & 12 & 14 & 16 & 18 & $1 \mathrm{~A}$ & $1 \mathrm{C}$ & $1 \mathrm{E}$ \\
0 & 3 & 6 & 9 & $\mathrm{C}$ & $\mathrm{F}$ & 12 & 15 & 18 & $1 \mathrm{~B}$ & $1 \mathrm{E}$ & 21 & 24 & 27 & $2 \mathrm{~A}$ & $2 \mathrm{D}$ \\
0 & 4 & 8 & $\mathrm{C}$ & 10 & 14 & 18 & $1 \mathrm{C}$ & 20 & 24 & 28 & $2 \mathrm{C}$ & 30 & 34 & 38 & $3 \mathrm{C}$ \\
0 & 5 & $\mathrm{~A}$ & $\mathrm{~F}$ & 14 & 19 & $1 \mathrm{E}$ & 23 & 28 & $2 \mathrm{D}$ & 32 & 37 & $3 \mathrm{C}$ & 41 & 46 & $4 \mathrm{~B}$ \\
0 & 6 & $\mathrm{C}$ & 12 & 18 & $1 \mathrm{E}$ & 24 & $2 \mathrm{~A}$ & 30 & 36 & $3 \mathrm{C}$ & 42 & 48 & $4 \mathrm{E}$ & 54 & $5 \mathrm{~A}$ \\
0 & 7 & $\mathrm{E}$ & 15 & $1 \mathrm{C}$ & 23 & $2 \mathrm{~A}$ & 31 & 38 & $3 \mathrm{~F}$ & 46 & $4 \mathrm{D}$ & 54 & $5 \mathrm{~B}$ & 62 & 69 \\
0 & 8 & 10 & 18 & 20 & 28 & 30 & 38 & 40 & 48 & 50 & 58 & 60 & 68 & 70 & 78 \\
0 & 9 & 12 & $1 \mathrm{~B}$ & 24 & $2 \mathrm{D}$ & 36 & $3 \mathrm{~F}$ & 48 & 51 & $5 \mathrm{~A}$ & 63 & $6 \mathrm{C}$ & 75 & $7 \mathrm{E}$ & 87 \\
0 & $\mathrm{~A}$ & 14 & $1 \mathrm{E}$ & 28 & 32 & $3 \mathrm{C}$ & 46 & 50 & $5 \mathrm{~A}$ & 64 & $6 \mathrm{E}$ & 78 & 82 & $8 \mathrm{C}$ & 96 \\
0 & $\mathrm{~B}$ & 16 & 21 & $2 \mathrm{C}$ & 37 & 42 & $4 \mathrm{D}$ & 58 & 63 & $6 \mathrm{E}$ & 79 & 84 & $8 \mathrm{~F}$ & $9 \mathrm{~A}$ & $\mathrm{~A} 5$ \\
0 & $\mathrm{C}$ & 18 & 24 & 30 & $3 \mathrm{C}$ & 48 & 54 & 60 & $6 \mathrm{C}$ & 78 & 84 & 90 & $9 \mathrm{C}$ & $\mathrm{A} 8$ & $\mathrm{~B} 4$ \\
0 & $\mathrm{D}$ & $1 \mathrm{~A}$ & 27 & 34 & 41 & $4 \mathrm{E}$ & $5 \mathrm{~B}$ & 68 & 75 & 82 & $8 \mathrm{~F}$ & $9 \mathrm{C}$ & $\mathrm{A} 9$ & $\mathrm{~B} 6$ & $\mathrm{C} 3$ \\
0 & $\mathrm{E}$ & $1 \mathrm{C}$ & $2 \mathrm{~A}$ & 38 & 46 & 54 & 62 & 70 & $7 \mathrm{E}$ & $8 \mathrm{C}$ & $9 \mathrm{~A}$ & $\mathrm{~A} 8$ & $\mathrm{~B} 6$ & $\mathrm{C} 4$ & $\mathrm{D} 2$ \\
0 & $\mathrm{~F}$ & $1 \mathrm{E}$ & $2 \mathrm{D}$ & $3 \mathrm{C}$ & $4 \mathrm{~B}$ & $5 \mathrm{~A}$ & 69 & 78 & 87 & 96 & $\mathrm{~A} 5$ & $\mathrm{~B} 4$ & $\mathrm{C} 3$ & $\mathrm{D} 2$ & $\mathrm{E} 1$ \\
\hline
\end{tabular}


Table C1.3. Position of middle pair in Multiplication Table of number system with base "q"

\begin{tabular}{|c|lc|}
\hline $\mathrm{q}$ & \\
\hline 2 & $0 \times 1 \rightarrow\left[1^{\text {st }} \rightarrow(0-0) \leftarrow 1^{\text {st }}\right] \rightarrow(100)_{2}-4$ & \\
4 & $1 \times 2 \rightarrow\left[2^{\text {nd }} \rightarrow(2-2) \leftarrow 2^{\text {nd }}\right] \rightarrow(20)_{4}-6$ & 2 \\
6 & $2 \times 3 \rightarrow\left[3^{\text {rd }} \rightarrow(6-6) \leftarrow 3^{\text {rd }}\right] \rightarrow(20)_{6}-6$ & 0 \\
8 & $3 \times 4 \rightarrow\left[4^{\text {th }} \rightarrow(12-12) \leftarrow 4^{\text {th }}\right] \rightarrow(20)_{8}-4$ & 2 \\
$\mathbf{1 0}$ & $4 \times 5 \rightarrow\left[5^{\text {th }} \rightarrow(20-20) \leftarrow \mathbf{5}^{\text {th }}\right] \rightarrow(20)_{10} \pm \mathbf{0}$ & $\mathbf{4}$ \\
12 & $5 \times 6 \rightarrow\left[6^{\text {th }} \rightarrow(30-30) \leftarrow 6^{\text {th }}\right] \rightarrow(20)_{12}+6$ & $\mathbf{8}$ \\
14 & $6 \times 7 \rightarrow\left[7^{\text {th }} \rightarrow(42-42) \leftarrow 7^{\text {th }}\right] \rightarrow(20)_{14}+14$ & $\mathbf{1 0}$ \\
16 & $7 \times 8 \rightarrow\left[8^{\text {th }} \rightarrow(56-56) \leftarrow 8^{\text {th }}\right] \rightarrow(20)_{16}+24$ & \\
\hline$\ldots$ & & \\
\hline
\end{tabular}


Table C2. The first key point of difference between number systems in the Multiplication Table [as " 3 x $5=15$ " in decimal number system]

\begin{tabular}{|c|l|}
\hline$q$ & \multicolumn{1}{|c|}{ Display } \\
\hline 2 & $(1 \times 1),(2 \times 1),(3 \times 1)$ \\
4 & $(1 \times 2),(2 \times 2),(3 \times 2)$ \\
6 & $(1 \times 3),(2 \times 3),(3 \times 3)$ \\
8 & $\begin{array}{l}(1 \times 4),(2 \times 4),(3 \times 4),(4 \times 4) \\
04 \quad 08\end{array}$ \\
10 & $\begin{array}{l}(1 \times 5),(2 \times 5),(3 \times 5),(4 \times 5),(5 \times 5) \\
05 \\
12\end{array}$ \\
14 & $\left.\begin{array}{l}1 \times 6),(2 \times 6),(3 \times 6),(4 \times 6),(5 \times 6),(6 \times 6) \\
06\end{array}\right),(2 \times 7),(3 \times 7),(4 \times 7),(5 \times 7),(6 \times 7),(7 \times 7)$ \\
16 & $(1 \times 8),(2 \times 8),(3 \times 8),(4 \times 8),(5 \times 8),(6 \times 8),(7 \times 8),(8 \times 8)$ \\
$\ldots$ & \\
\hline
\end{tabular}

Multiplying by 5, in the Multiplication Table of the decimal number system, we find ourselves in the area of symmetry (because 5 is half of 10 , and 10 is exactly the whole of the decimal scale); by multiplying $1 \times 5$ we are at half the scale; with $2 \times 5$, at the end of the scale; only with $3 \times 5=$ 15 we "come down" from the scale. Hence the $3 \times 5$ is determinant of the Multiplication Table in the decimal number system. Analogously, $3 \times 4$ is a determinant of the Multiplication Table in the octal number system, $3 \times 8$ in the hexadecimal, and so on. The numbers in green, for $\mathrm{q}=10(05$, $10,20)$ correspond to the result in Survey 8. 
Table C3. The second key point of difference of the number systems in the Multiplication Table

\begin{tabular}{|c|c|c|}
\hline$q$ & & Display \\
\hline 2 & $(3 \times 1)$ & {$[3+2=(\mathbf{1} \times \mathbf{5})=1 \overline{+}-\overline{]}]$} \\
\hline 4 & $(3 \times 2)$ & {$[6+4=(2 \times 5)=4+6]$} \\
\hline 6 & $(3 \times 3)$ & {$[9+6=(3 \times 5)=9+6]$} \\
\hline 8 & $(3 \times 4)$ & {$[12+8=(4 \times 5)=16+4]$} \\
\hline 10 & $(3 \times 5)$ & {$[15+10=(5 \times 5)=25 \pm 0]$} \\
\hline 12 & $(3 \times 6)$ & {$[18+12=(6 \times 5)=36-6]$} \\
\hline 14 & $(3 \times 7)$ & {$[21+14=(7 \times 5)=49-14]$} \\
\hline 16 & $(3 \times 8)$ & {$[24+16=(8 \times 5)=64-24]$} \\
\hline 18 & $(3 \times 9)$ & {$[27+18=(9 \times 5)=81-36]$} \\
\hline 20 & $(3 \times 10)$ & {$[30+20=(10 \times \mathbf{5})=100-50]$} \\
\hline
\end{tabular}

Explanation for the decimal number system: take those $(3 \times 5=15)$ that occurred after descending from the scale; plus 10 from the scale, equals 25 . That is $(q / 2 \times q / 2) \pm 0$. For number systems with $\mathrm{q}>10$ (where $q$ is an even number) there is a change from the zeroth state, which occurs in the case of the decimal system, and for the result we have: $(q / 2 \times q / 2)-(q / 2 \times n)$, where $n=1,2,3$, and so on. In cases with $\mathrm{q}<10$, changes from $(q / 2 \times q / 2)$ are with positive values; such changes that, starting from the octal, and finished with the binary system, all four changes, taken together, give one specific "mirror image": 4 \& 6 vs $6 \& 4$. 
Table C4. Uniqueness of number 75 - quantity of nucleon number in the first protein amino acid, glycine

\begin{tabular}{|llllll|}
45 & $=52-07 \quad(52+07=59)(9+5=14)$ \\
55 & $=$ & $52+$ & 03 & $(52-03=49)(9+4=13)$ \\
65 & $=$ & $52+$ & 13 & $(52-13=39)(9+3=12)$ \\
75 & $=$ & $52+$ & 23 & $(52-23=29)(9+2=11)$ \\
85 & $=$ & $52+$ & 33 & $(52-33=19)(9+1=10)$ \\
95 & $=52+43 \quad(52-43=09)(9+0=09)$ \\
\hline
\end{tabular}

The key of the relationships is 75 as the number of atoms in glycine. The number 23 corresponds to the ratio $2: 3$ where $2 / 3$ is the harmonic mean of the whole and its half, and $3 / 2$ "represents the limit of the golden numbers" (Box 12, last paragraph); then 5/2 as the key for the mapping from the PSN (Fig. 2). In addition, there is a connection with Survey C2, where $45 / 54$ is given as the boundary in logical square 11-12-13-14, which also here results from the system-arrangement, with the starting number 11, just in the line of the quantity 75 . 
Table C5. Permutations of 100 and 101 (I)

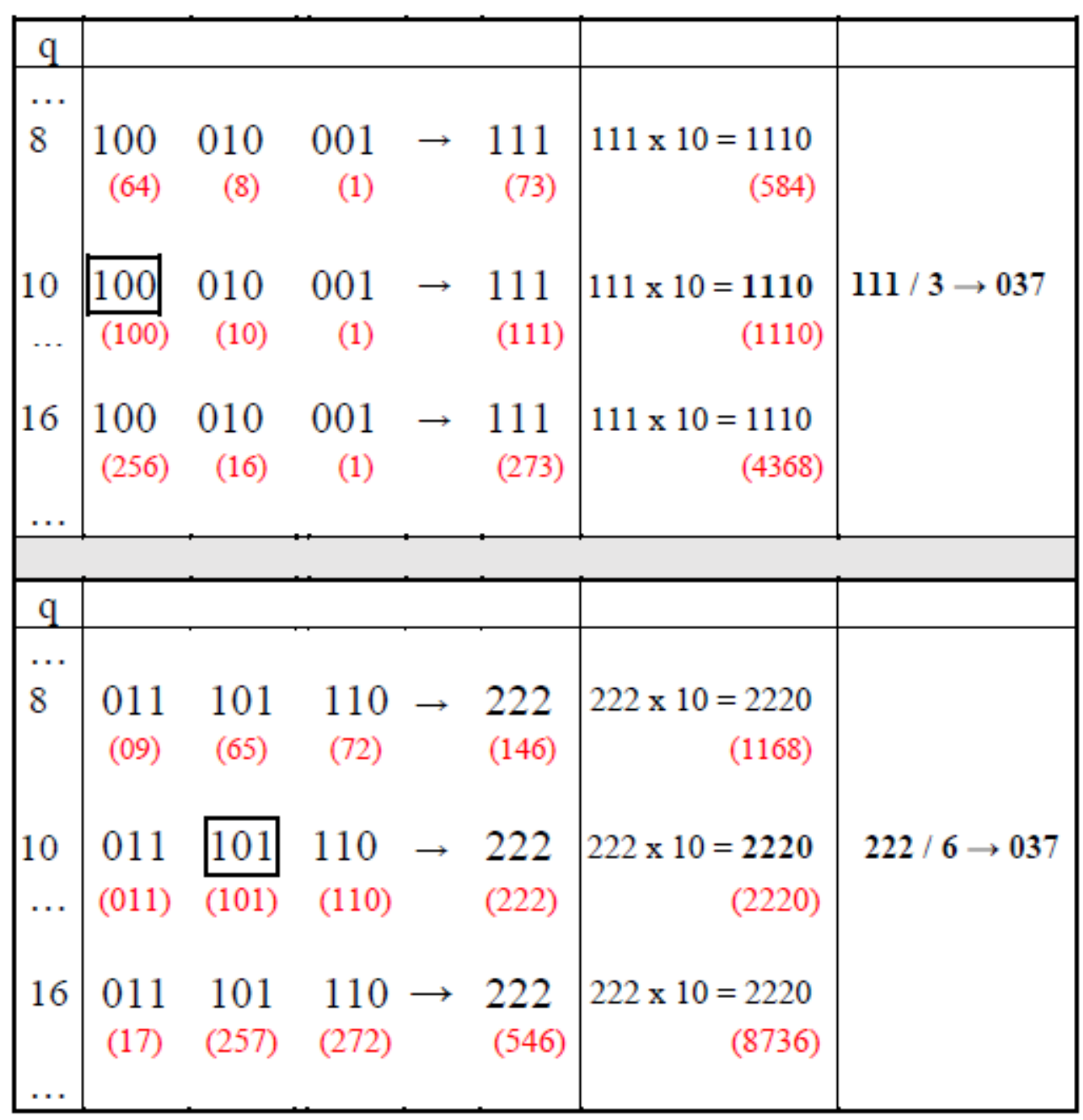

The correspondence with the appearance of the first pair of three-digit numbers, as shown in Figure 4.1. 
Table C5.1. Permutations of 100 and 101 (II)

\begin{tabular}{|c|c|}
\hline $\begin{array}{l}(101010)_{2} \rightarrow 52_{8}=42_{10} \\
(010101)_{2} \rightarrow 25_{8}=21_{10}\end{array}$ & Gen. code \\
\hline$\frac{(100101)_{2} \rightarrow 45_{8}=37_{10}}{(101100)_{2} \rightarrow 54_{8}=44_{10}}$ & $\begin{array}{l}\text { Key point in } \\
\text { Decimal system }\end{array}$ \\
\hline $\begin{array}{l}45_{8}+54_{8}=(77+22)(77-22=55) \\
37_{10}+44_{10}=[(9 \times 9)+00](99-22=77)\end{array}$ & $\begin{array}{l}\text { Key point in } \\
\text { Decimal system }\end{array}$ \\
\hline
\end{tabular}

Table C5.2. "The polar and non-polar amino acids" (MMR, 2004, Tab. 4, p. 225)

\begin{tabular}{|c|c|c|c|c|c|c|}
\hline D 07 & N 08 & A 04 & L 13 & $\rightarrow$ & $3 \overline{2}$ & \\
\hline$R_{17}$ & P 08 & $F_{14}$ & I 13 & $\rightarrow$ & 52 & \\
\hline $\mathrm{K}_{15}$ & $Y_{15}$ & $\mathrm{~T} 08$ & $M 11$ & $\rightarrow$ & $4 \overline{9}$ & \\
\hline H 11 & W 18 & S 05 & C 05 & $\rightarrow$ & 39 & 120 \\
\hline E 10 & $Q_{11}$ & G 01 & V 10 & $\rightarrow$ & 32 & \\
\hline$\downarrow$ & $\downarrow$ & $\downarrow$ & $\downarrow$ & & & \\
\hline 60 & 60 & 32 & 52 & & & \\
\hline \multicolumn{2}{|c|}{120} & \multicolumn{2}{|c|}{84} & & & \\
\hline
\end{tabular}

From MMR, 2004a, Tab. 4, p. 225: "The splitting into polar (light ton) and non-polar (bold, dark ton) AAs. The polarity as hydropathy, i.e. as hydropathy index. (After Table 2 in Kyte and Doolittle, 1982, p. 110). The number of atoms within AAs molecules (side chains) in first two rows as well as in second two columns is identical ( 84 atoms). The same is valid for second three rows in relation to first two columns (120 atoms)". [Example of a Molecular Self-Organized System (M-SOS), in relation to all system- arrangements in: MMR, 2004a.] 
Table C5.3. Table 9 The second variant of 4 x 5 AAs system: the splitting into two subsystems: inner and outer

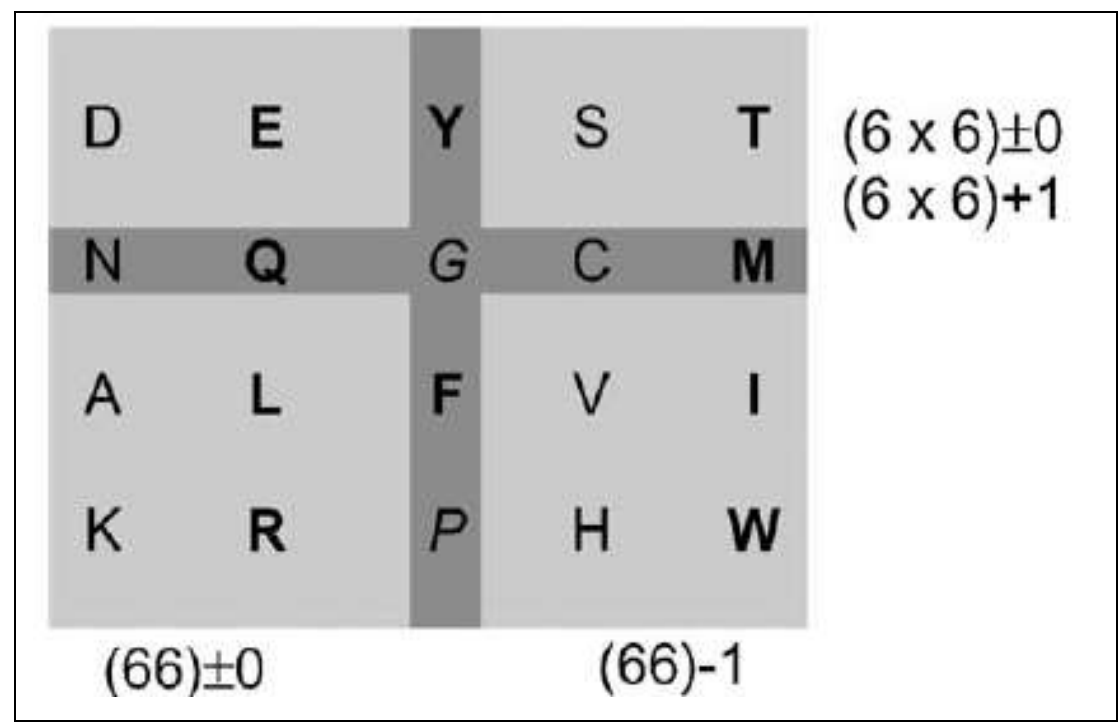

From MMR, 2004a, Tab. 4, p. 225: "This system follows from the system in Table 4 [here: Table C5.2]. First row (down): N-ended AAs. Second row: solely C-ended AAs. Last row (up): O-ended AAs. First to last row: remaining five AAs (one solely H-ended, two S-ended and two N-, O-ended, all five as a 'combination'. Within the cross there are only the exceptions: horizontally five the mentioned combining AAs; vertically: $\mathrm{Y}$ as aromatic within aliphatic AAs; $G$ without carbon; $F$ as aromatic within aliphatic AAs; and, finally, $\mathrm{P}$ as cyclic aliphatic amino acid. In the system there is a balanced proportionality as follows: within horizontal leg of the cross there are $(6 \times 6) 70$ of atoms, and within vertical leg (without glycine), there are $(6 \times 6)+1$. Without cross: on the left there are (66)70 and (66)-1 on the right. [cf. this "combination-cross" sub-system with 'four-codon-AAs-cross' sub-system in Codon path cube (Swanson, 1984; Rakočević, 1997a)]." [Example of a Molecular Self-Organized System (M-SOS), in relation to all system- arrangements in: MMR, 2004a.] 
Table C6. Specific arithmetic system-arrangement in relation to $\mathrm{GC}$

\begin{tabular}{|c|c|c|c|c|c|}
\hline e & $a_{1}$ & b & $a_{2}$ & C & d \\
\hline & 10 & 21 & 20 & $10+119=129$ & $06+123=129$ \\
\hline (44) & 21 & (44) & 31 & $21+108=129$ & $17+112=129$ \\
\hline & 32 & & 42 & $32+97=129$ & $\underline{\underline{28}}+101=129$ \\
\hline (44) & 43 & $\begin{array}{r}75 \\
\text { (44) }\end{array}$ & 53 & $43+86=129$ & $39+90=129$ \\
\hline 248 & $\begin{array}{l}54 \\
65\end{array}$ & 119 & $\begin{array}{l}64 \\
75\end{array}$ & $\begin{array}{l}54+75=129 \\
65+64=129\end{array}$ & $\begin{array}{l}50+79=129 \\
61+68=129\end{array}$ \\
\hline (44) & & (44) & & & \\
\hline 292 & 76 & 163 & 86 & $76+53=129$ & $72+57=129$ \\
\hline$(44)$ & 87 & (44) & 97 & $87+42=129$ & $83+46=129$ \\
\hline 336 & $\begin{array}{c}98 \\
109\end{array}$ & 207 & $\begin{array}{l}108 \\
119\end{array}$ & $\begin{array}{l}98+31=129 \\
109+20=129\end{array}$ & $\begin{array}{l}94+35=129 \\
105+24=129\end{array}$ \\
\hline & $\begin{array}{l}20 \\
16\end{array}$ & 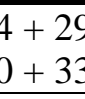 & & & x $248=496$ \\
\hline
\end{tabular}

From MMR, 2011b, Table A 4.1, p. 840: "The first two-digit number in 'moving' for 11 in all steps."

\{Additional Note (30.03.2021): Quantity 129 corresponds to quantity 109 which we presented as a determinant of "Number of groups" in PSE (MMR, 2020b, Table 2). Such a reference, however, only makes sense if the number 119 proves to be unique (Table C8). In such a case, the quantities 129 and 109 are indeed in the "quantum change relation" (119 \pm 10$)$ analogous to "quantum physics", as originally pointed out by V. Shcherbak (1994). The quantities found in GC are also marked in red (Fig. 5). The quantity 44 (columns "b" and "e") is related to the sum of 44 in the initial column in Figure A2.\} 
Table C7. The uniqueness of the number 120 in relation to the uniqueness of the sequence 117-118-119-120

\begin{tabular}{|c|c|}
\hline $1 \rightarrow 116=6786$ & $6786=[10 \times(660+066)]-(117+118+119+120)$ \\
\hline $1 \rightarrow 117=6903$ & $6903=[10 \times(660+066)]-(118+119+120)$ \\
\hline $1 \rightarrow 118=7021$ & $7021=[10 \times(660+066)]-(119+120)$ \\
\hline $1 \rightarrow 119=7140$ & $7140=[10 \times(660+066)]-120$ \\
\hline $1 \rightarrow 120=7260$ & $7260=[10 \times(660+066)] \pm 00$ \\
\hline $1 \rightarrow 121=7381$ & $7260=[10 \times(660+066)]+121$ \\
\hline $1 \rightarrow 122=7381$ & $7260=[10 \times(660+066)]+(121+122)$ \\
\hline $1 \rightarrow 123=7381$ & $7260=[10 \times(660+066)]+(121+122+123)$ \\
\hline $1 \rightarrow 124=7750$ & $7260=[10 \times(660+066)]+(121+122+123+124)$ \\
\hline \multicolumn{2}{|c|}{$[8658=(7770+0888)] 8658-6786=(4 \times 468)[468=496-28]$} \\
\hline \multirow[t]{2}{*}{$8658=6+28$} & [124 x $4=496]$ \\
\hline & $6786=6666+120$ \\
\hline
\end{tabular}


Table C8. The uniqueness of pairs $14 \& 20$ and $84 \& 119$

\begin{tabular}{|ll|}
\hline $1 \rightarrow 14=105 \times 1$ & $1 \rightarrow 6=015 \times 1$ \\
$1 \rightarrow 20=105 \times 2$ & $1 \rightarrow 34=119 \times 5$ \\
$1 \rightarrow 84=3570 \times 1$ & $1 \rightarrow 35=630 \times 1$ \\
$1 \rightarrow 119=3570 \times 2$ & $1 \rightarrow 203=357 \times 58$ \\
$3570 \times 2=7140 \times 1$ & $58=2 \times 29$ \\
$3570-630=1470 \times 2$ & $1 \rightarrow 38=741 / 147$ \\
Dante Alighieri: $4,7,10,13 \rightarrow 4,7,1,4 \rightarrow 1,4,7$ \\
$\quad(20-14=6)$ & $(20+14=34)$ \\
$(119-84=35)$ & $(119+84=203)$ \\
$1 \rightarrow 120=7260=6 \times 1210=11 \times 660$ \\
$660+066=726$
\end{tabular}


Table C9. The multiples of 6, 66, 666

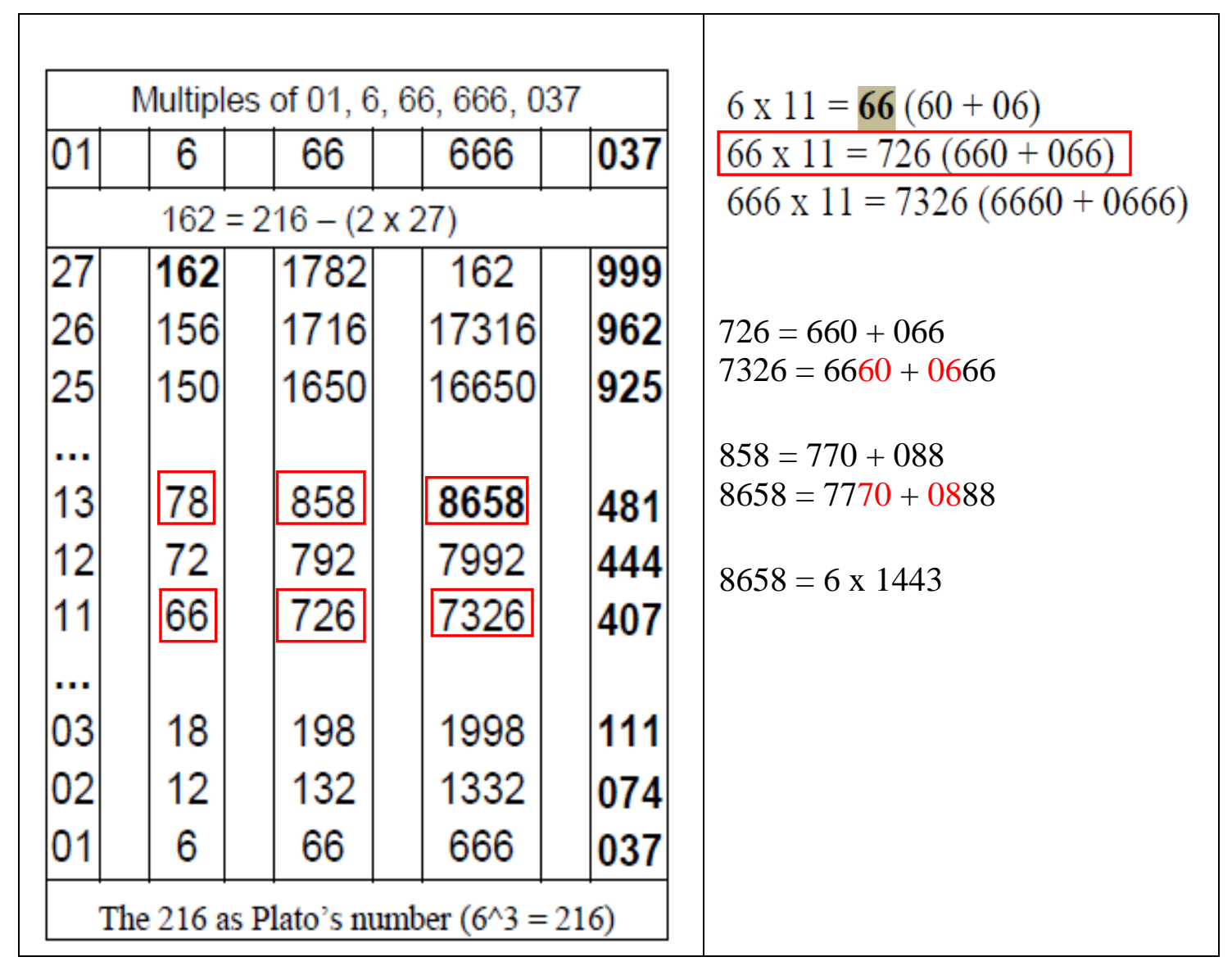

From MMR, 2017c, Tab. B1, p. 61: "The multiples of the numbers are presented in the first row. The $13^{\text {th }}$ case is the sum of the first four perfect numbers $(6+28+496+8128=8658) \ldots$ This first "mirror" corresponding case (66) and the first [Shcherbak's] integer case (037) ..."

\{Additional note (30.03.2021): The number 1443 as the number of nucleons in 23 AAs, in their side chains (Shcherbak, 1994). 
Table C10. The multiples of "Prime Quantum 037" and to it correspondent numbers.

\begin{tabular}{|lllllll|}
\hline 27 & 81 & 9 & 891 & 99 & 8991 & 999 \\
26 & 78 & $26 / 3$ & 858 & $286 / 3$ & 8658 & 962 \\
25 & 75 & $25 / 3$ & 825 & $275 / 3$ & 8325 & $\underline{925}$ \\
24 & 72 & $\mathbf{8}$ & 792 & $\mathbf{8 8}$ & 7992 & $\mathbf{8 8 8}$ \\
$\ldots$ & & & & & & \\
16 & 48 & $16 / 3$ & 528 & $176 / 3$ & 5328 & $\underline{592}$ \\
15 & 45 & 5 & 495 & 55 & 4995 & $\mathbf{5 5 5}$ \\
$\ldots$ & & & & & & \\
10 & 30 & $10 / 3$ & 330 & $110 / 3$ & 3330 & 370 \\
9 & 27 & 3 & 297 & 33 & 2997 & 333 \\
8 & 24 & $8 / 3$ & 264 & $88 / 3$ & 2664 & 296 \\
7 & 21 & $7 / 3$ & 231 & $77 / 3$ & 2331 & 259 \\
6 & 18 & 2 & 198 & $\mathbf{2 2}$ & 1998 & $\underline{\mathbf{2 2 2}}$ \\
5 & 15 & $5 / 3$ & 165 & $55 / 3$ & 1665 & 185 \\
4 & 12 & $4 / 3$ & 132 & $44 / 3$ & 1332 & 148 \\
3 & 9 & 01 & 99 & 11 & 999 & $\underline{111}$ \\
2 & 6 & $2 / 3$ & 66 & $22 / 3$ & 666 & 074 \\
1 & 3 & $1 / 3$ & 33 & $11 / 3$ & 333 & 037 \\
& & $1 / 3$ & & $11 / 3$ & & $111 / 3$ \\
"Steps" & $\rightarrow 1$ & 1 st & & $2^{\text {nd }}$ & & $3^{\text {rd }}$ \\
\hline
\end{tabular}

This Table is the same one given in (MMR, Surv. 2, p. 37), with the error corrected in the positions marked in green. These are the products of the number 66 and its half 33; as well as their correspondents. 
Survey C1. Relationships in Multiplication Table

\begin{tabular}{|c|c|}
\hline$x^{2}+x=z$ & $z$ \\
\hline$(0 \times 0)+0=00$ & $0 \times 1=00$ \\
\hline$(1 \times 1)+1=02$ & $1 \times 2=02$ \\
\hline$(2 \times 2)+2=06$ & $2 \times 3=06$ \\
\hline$(3 \times 3)+3=12$ & $3 \times 4=12$ \\
\hline$(4 \times 4)+4=20$ & $4 \times 5=20$ \\
\hline$(5 \times 5)+5=30$ & $5 \times 6=30$ \\
\hline$(6 \times 6)+6=42$ & $6 \times 7=42$ \\
\hline$(7 \times 7)+7=56$ & $7 \times 8=56$ \\
\hline$(8 \times 8)+8=72$ & $8 \times 9=72$ \\
\hline$(9 \times 9)+9=90$ & \\
\hline
\end{tabular}

From (MMR, 2011b, Tab. 1.2, p. 822): "The key of the harmonic Multiplication Table. This key is related to positive integers: $(0,1),(1,2),(2,3),(3,4),(4,5),(5,6)$ which appear as solutions ( $\mathrm{x} 1, \mathrm{x} 2)$, given by Equation (of Golden mean); as solutions for ... given $\mathrm{q}(\mathrm{q}=0,2$, $6,12,20,30, \ldots) . "$ 
Survey C2. The uniqueness of number 45 as the upper limit of the system-arrangement presented in Table C4.

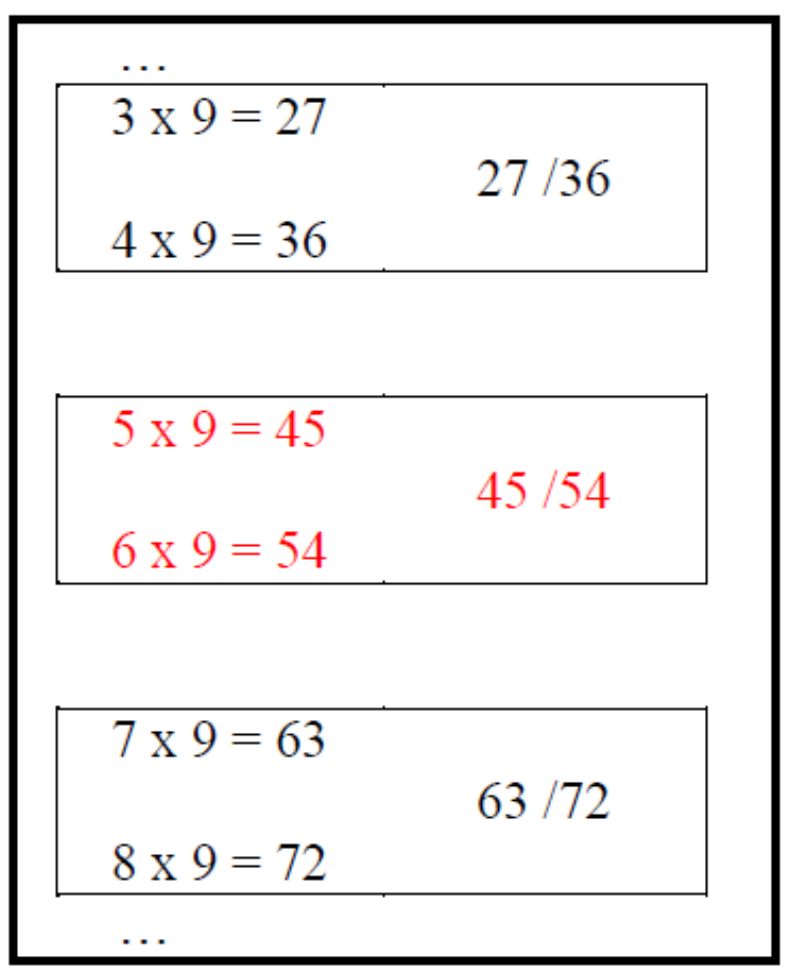

The 45/54 as the boundary in logical square 11-12-13-14 is exactly at 14 (Tab. C4).

Survey C3. The uniqueness of the ratio 3:2

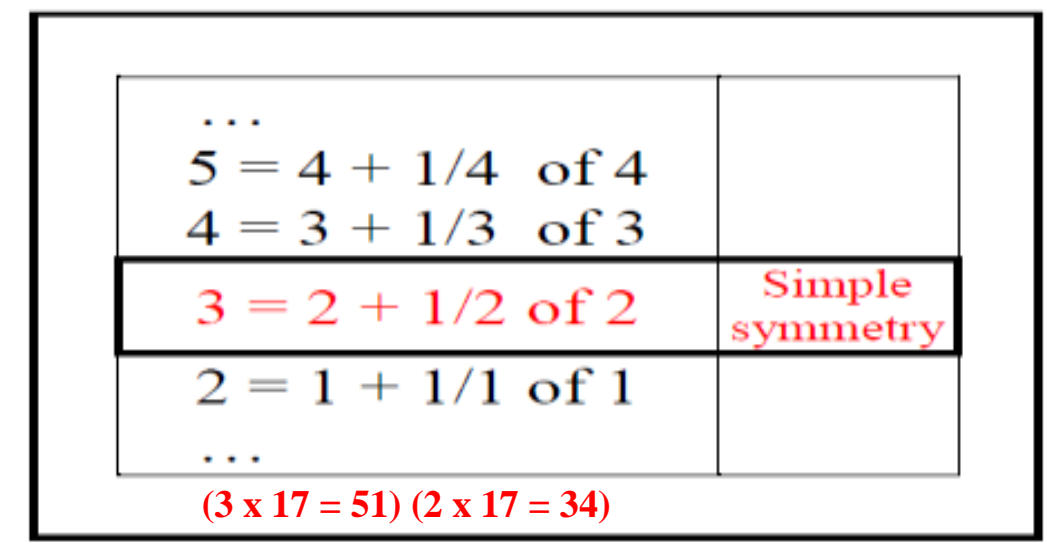

The unique relationship between numbers 2 and 3 in a series of natural numbers is shown, which corresponds to the common factor of the Gaussian and Dürer's numbers, with the number 17; because $2 \times 17=34$, and $3 \times 17=51$. (Details in the legend of Table C4.) 
Survey C4. The relations of two Plato's progressions with Pythagorean musical note scale (MMR, 2011b, Table A.2)

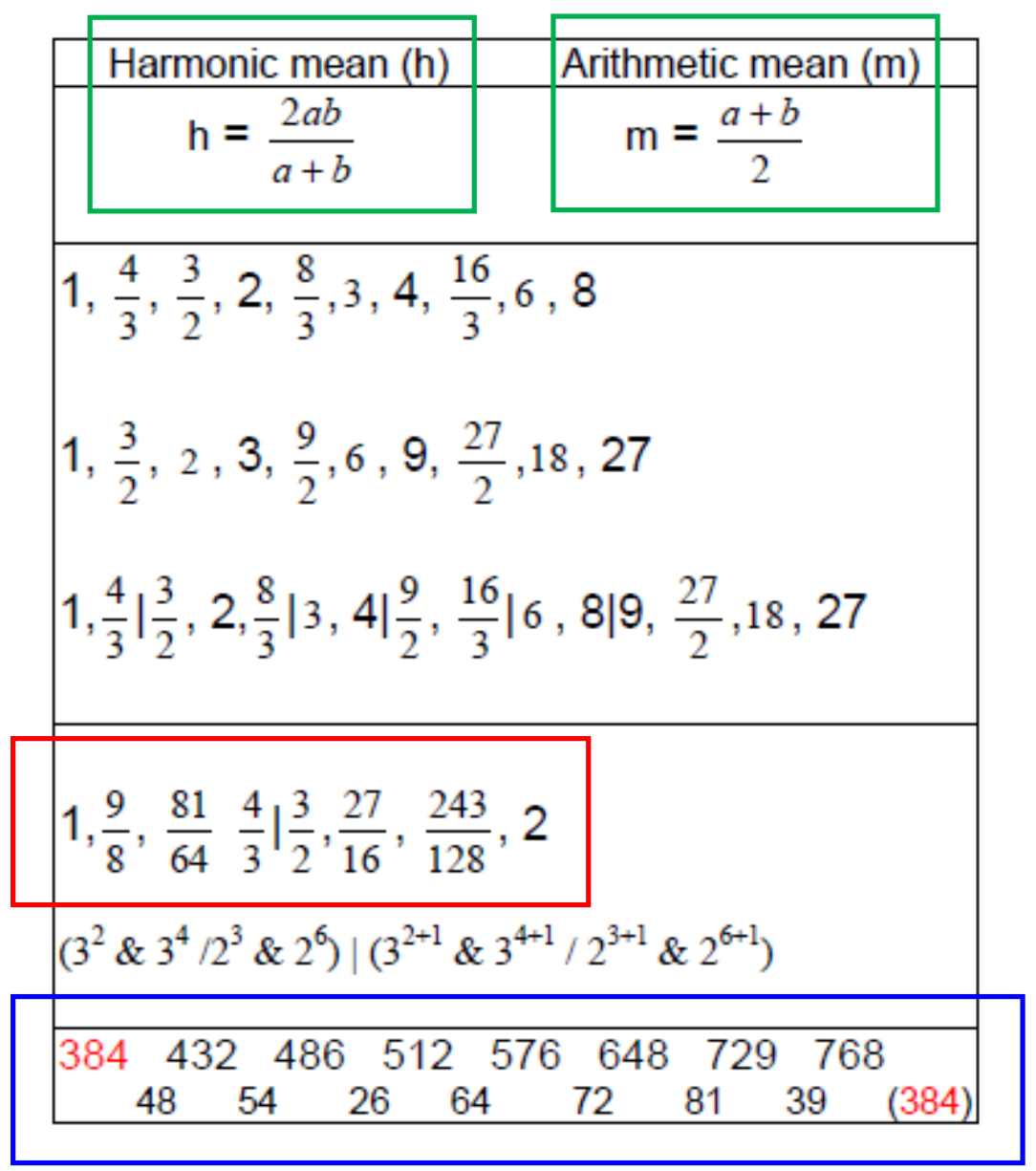

The final result is 384 , and there is just as many total number of atoms in 20 AAs ("head" plus "body"). 


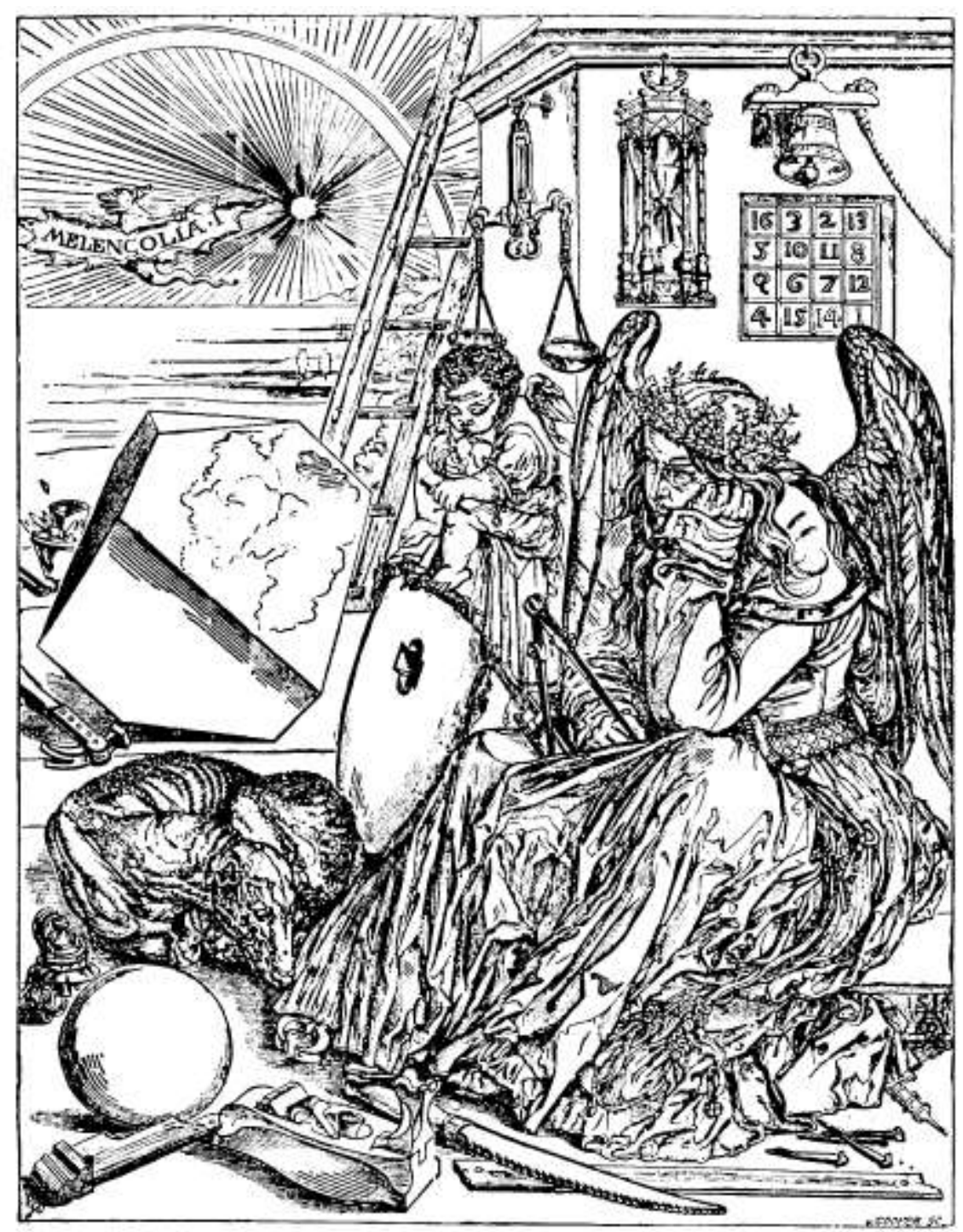

Figure C1. Dürer's copperplate engraving "Melancholy" [Melencolia I] (XVI century, 1514) 


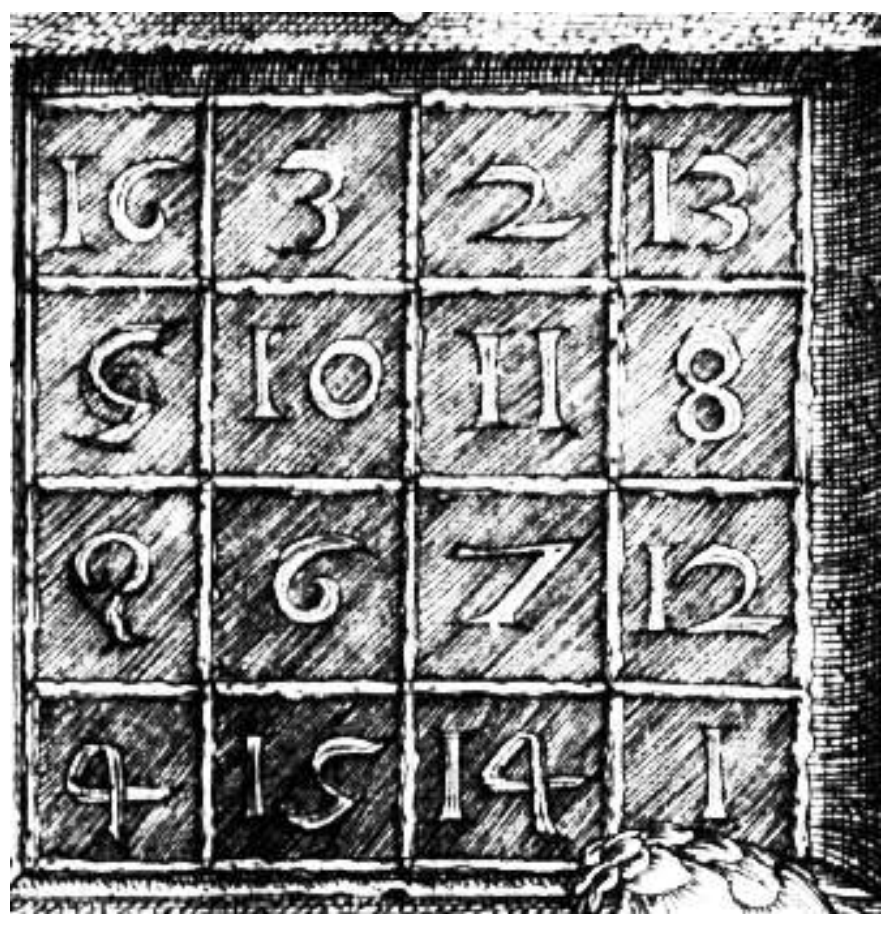

Figure C2. Dürer's magic square on the copperplate engraving "Melancholy" [Melencolia I] (XVI century, 1514) 


\begin{tabular}{|c|c|c|c|c|c|c|c|c|c|}
\hline \multirow{2}{*}{$\begin{array}{l}\text { lst } \\
\text { lett. }\end{array}$} & \multicolumn{8}{|c|}{ 2nd letter } & \multirow{2}{*}{$\begin{array}{l}\text { 3rd } \\
\text { lett. }\end{array}$} \\
\hline & \multicolumn{2}{|l|}{$\mathrm{U}$} & \multicolumn{2}{|l|}{ C } & \multicolumn{2}{|l|}{$\mathrm{A}$} & \multicolumn{2}{|l|}{$\mathrm{G}$} & \\
\hline \multirow{4}{*}{$\mathrm{U}$} & $00 . \mathrm{UUU}$ & & 08. UCU & \multirow{4}{*}{ S } & 32. UAU & \multirow{3}{*}{$\mathbf{Y}$} & 40. UGU & C & $U$ \\
\hline & 01. UUC & F & 09. UCC & & 33. UAC & & 41. UGC & & C \\
\hline & 02. UUA & & 10. UCA & & 34. UAA & & 42. UGA & CT & $A$ \\
\hline & 03. UUG & L & 11. UCG & & 35. UAG & CT & 43. UGG & W & G \\
\hline \multirow{4}{*}{$\mathrm{C}$} & 04. CUU & \multirow{4}{*}{ L } & 12. CCU & \multirow{4}{*}{$\mathbf{P}$} & 36. CAU & \multirow{3}{*}{ H } & 44. CGU & \multirow{4}{*}{ R } & $U$ \\
\hline & 05. CUC & & 13. $\mathrm{CCC}$ & & 37. CAC & & 45. CGC & & C \\
\hline & 06. CUA & & 14. CCA & & 38. CAA & & 46. CGA & & A \\
\hline & 07. CUG & & 15. CCG & & 39. CAG & Q & 47. CGG & & G \\
\hline \multirow{4}{*}{ A } & 16. AUU & \multirow{2}{*}{ I } & $24 . \mathrm{ACU}$ & \multirow{4}{*}{$\mathrm{T}$} & 48. AAU & \multirow{3}{*}{ N } & 56. AGU & \multirow[b]{2}{*}{ S } & $U$ \\
\hline & 17. AUC & & 25. ACC & & 49. AAC & & 57. AGC & & C \\
\hline & 18. AUA & \multirow{2}{*}{ M } & 26. $\mathrm{ACA}$ & & 50. AAA & & 58. AGA & & A \\
\hline & 19. $\mathrm{AUG}$ & & 27. $\mathrm{ACG}$ & & 51. $A A G$ & $\mathbf{K}$ & 59. $A G G$ & R & G \\
\hline \multirow{4}{*}{ G } & 20. GUU & \multirow{4}{*}{ V } & 28. GCU & \multirow{4}{*}{$A$} & 52. GAU & \multirow[b]{2}{*}{ D } & 60. GGU & \multirow{4}{*}{ G } & $U$ \\
\hline & 21. GUC & & 29. GOC & & 53. GAC & & 61. GGC & & C \\
\hline & 22. GUA & & 30. GCA & & 54. GAA & $F$ & 62. GGA & & $A$ \\
\hline & 23. GUG & & 31. GCG & & 55. $\mathrm{GAG}$ & $\mathrm{E}$ & 63. GGG & & G \\
\hline
\end{tabular}

Figure C3. The GCT corresponds with 6-bit binary-code tree (Rakočević, 1998, Biosystems, 46, pp. 283-291). In such a case, the key distinctions (Py/Pu) are determined with the first four perfect numbers. So, the first distinction is with the natural numbers 0-3 whose sum is 6 (first perfect number); the second one 0-7 with the sum 28 (second perfect number); and the third distinction with the sequence 0-31 which numbers give the sum of 496 (third perfect number); finally, the cycling sequence 0-63-0 (from the beginning to the end and vice versa) [0-63-127] gives a sum of 8128 (fourth perfect number). [From (MMR, 2007b, Tab. 11, p. 96) and from (MMR, 2017a, Chapter VII, Fig. 1.1, p. 2/43.] 


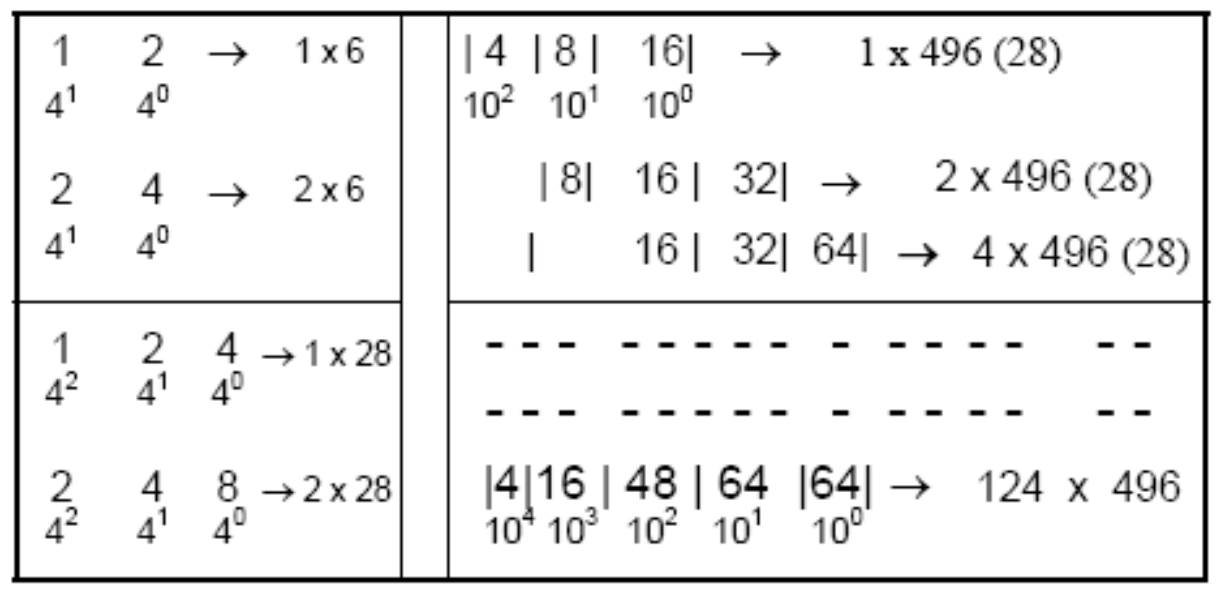

Figure C4. The relations of perfect numbers (I)

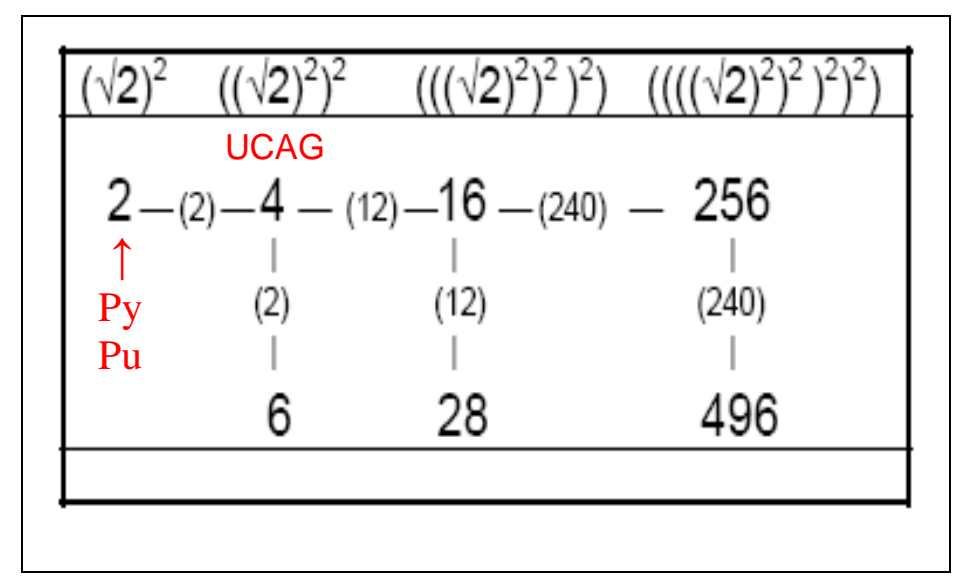

Figure C5. The relations of perfect numbers (II) 


\begin{tabular}{|c|c|c|c|c|}
\hline (1) & & 1 & & \\
\hline (2) & $\underline{3}^{3}$ & 27 & 28 & $0-3 \rightarrow 2^{2}$ \\
\hline (3) & $5^{3}$ & 125 & & \\
\hline (4) & $7^{3}$ & 343 & 496 & $\begin{array}{c}0-7 \rightarrow 2^{3} \\
(1+2 \ldots+6+7=28\end{array}$ \\
\hline (5) & $9^{3}$ & 729 & & $1 \rightarrow 3=6$ \\
\hline (6) & $11^{3}$ & 1331 & & $\begin{aligned} 1 \rightarrow 7 & =28 \\
1 \rightarrow 31 & =496\end{aligned}$ \\
\hline (7) & $13^{3}$ & 2197 & & $1 \rightarrow 127=8128$ \\
\hline (8) & $\underline{15}^{3}$ & 3375 & 8128 & $0-15 \rightarrow 2^{4}$ \\
\hline
\end{tabular}

Figure C6. The relations of perfect numbers (III) 


\section{D - Atlas}

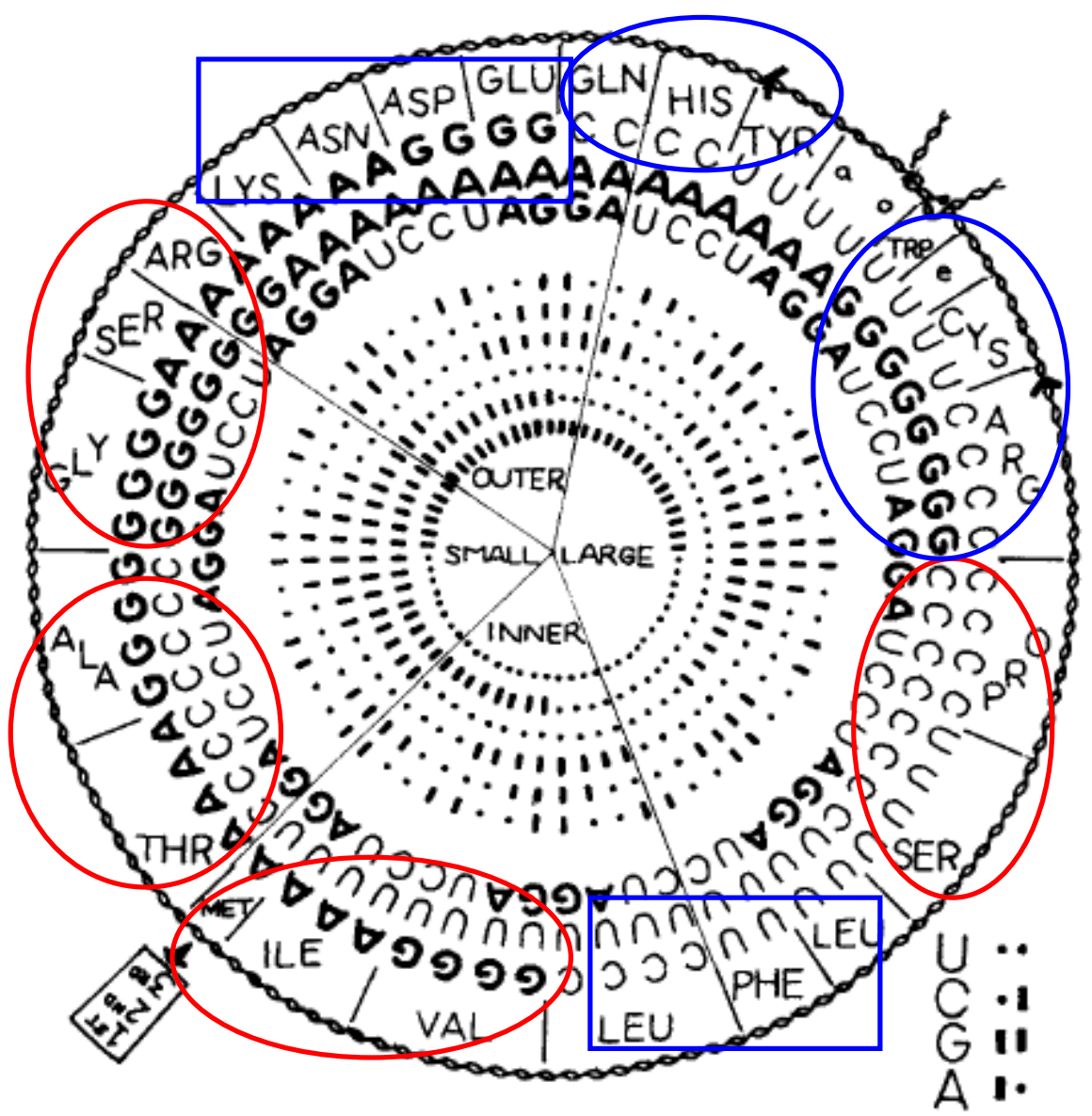

Figure D1. Rosemarie Swanson's Codon ring (Swanson, 1984, Fig. 3, p. 191): "The central part of the figure is an example of minimum change binary code. Note that the inner two rings are split into a dotted half and a dashed half. Successive rings split into quarters, eighths, sixteenths, etc. The two split inner circles correspond to identical splitting of the middle and first base rings of the nucleotide circles into pyrimidine and purine halves. The codons are arranged so that the middle base changes most slowly, the first base more often and the third base most frequently. The following rules connect the codons and their Gray code representation. The most important characteristic of a codon is whether it has a purine (most significant bit 1) or a pyrimidine (most significant bit 0 ) at the middle base position. Next in importance is whether there is a purine (second bit 1 ) or a pyrimidine (second bit 0 ) in the first-base position. The third most significant characteristic of a codon is which purine $(\mathrm{G}$ is $1, \mathrm{~A}$ is 0$)$ or pyrimidine $(\mathrm{C}$ is $1, \mathrm{U}$ is 0$)$ occurs in the middle. Fourth in significance is which purine or pyrimidine occurs in the first position. Of fifth importance is whether the wobble base is a purine or a pyrimidine, and of least significance is which purine or which pyrimidine the wobble base is. Note the interleaving of the four Gray code bits representing the first and second bases of a codon."

\{Additional Note (30.03.2021): I marked Boolean Space-3 (red) and Space-4 (blue), corresponding to the markings on the binary tree (Fig. D2). 


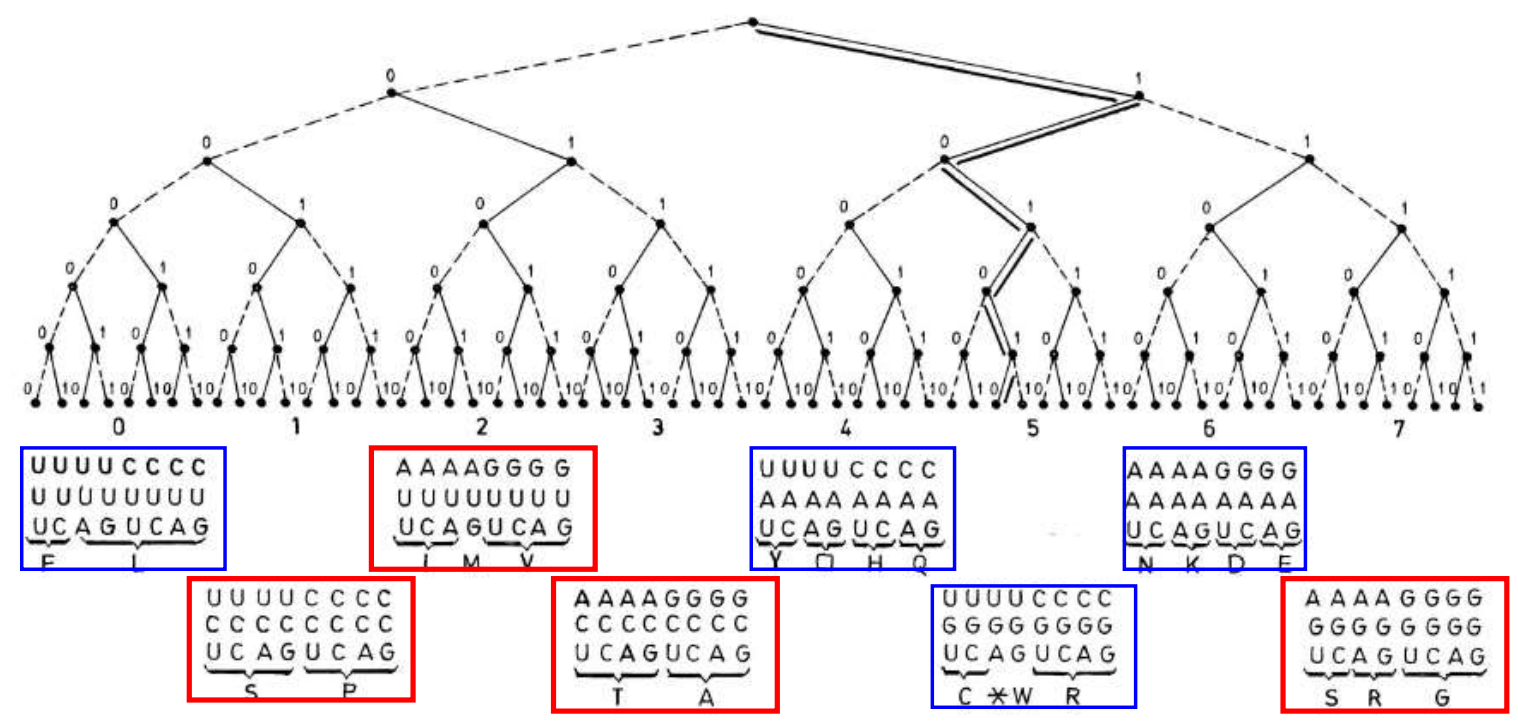

Figure D2. From (MMR, 1998a Fig. 1, p. 284): "Genetic code as a binary-code tree. The full lines: the routes of the greater (faster) changes from pyrimidine to purine or from two to three hydrogen bonds and vice versa. The dotted lines: the routes of the less (slower) changes. The double full line: the route of the maximum possible (fastest) changes; the route corresponding to the 'Golden mean route' on the Farey tree [Fig. 2 in (MMR, 1998a)]. Asterisks: 'stop' codon UGA. Quadrangles: 'stop' codons UAA and UAG.” 


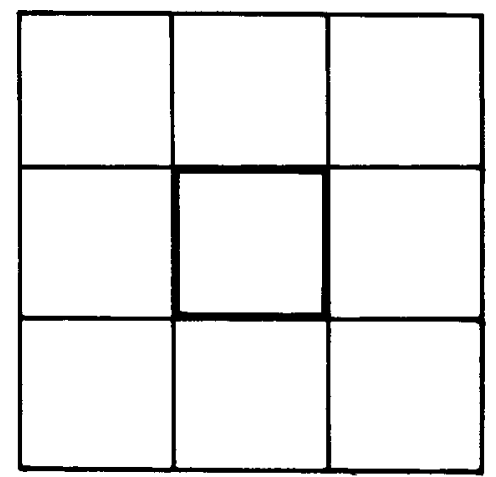

Figure D2.1. From (MMR, 1997b, Fig. 9, p. 94): "Construction of the middle ninth Cantor set. The next step within the Boolean spaces, $\mathrm{B}^{\mathrm{n}}$, after initial vector, $\mathrm{B}^{1}$, is a Boolean square $\left(\mathrm{B}^{2}\right)$ with maximum possible still 8 squares as neighbors ... Model in Figure is an adequate model for the genetic code..."

\{Additional Note (30.03.2021): The model fits both: the genetic code as the Gray code, and as the binary tree, presented in the two previous illustrations. (Cf. also Surv. B5).\} 


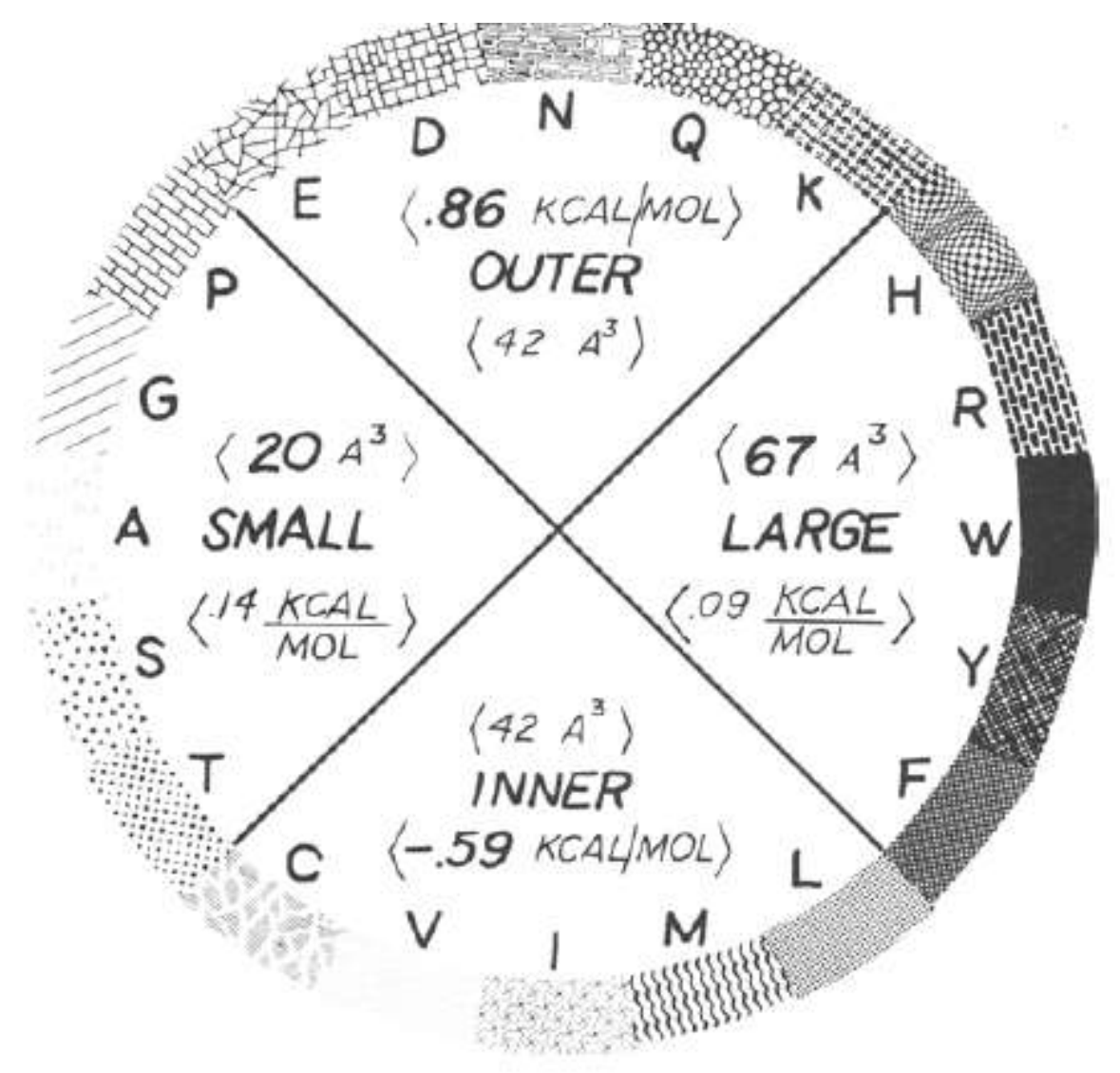

Figure D3. Rosemarie Swanson's Mutation ring (Swanson, 1984, Fig. 3, p. 191): "Mutation ring. As the codon ring expresses the minimum change relation among codons, so the mutation ring expresses the minimum change relation among the amino acids. The mutation ring shows the broader relationships among the amino acids, as well as the detailed ordering. For this the ring is quartered into the four groups, and for each group the average values of energy and volume are entered. The amino acids are marked by their one-letter codes and textured patterns. The patterns represent progressions in the physical properties of the amino acids. Dark tones are for large residues, light for small. Coarse, checkered or blotchy textures signify external residues, and smooth, delicate or even-textured patterns designate internal." 


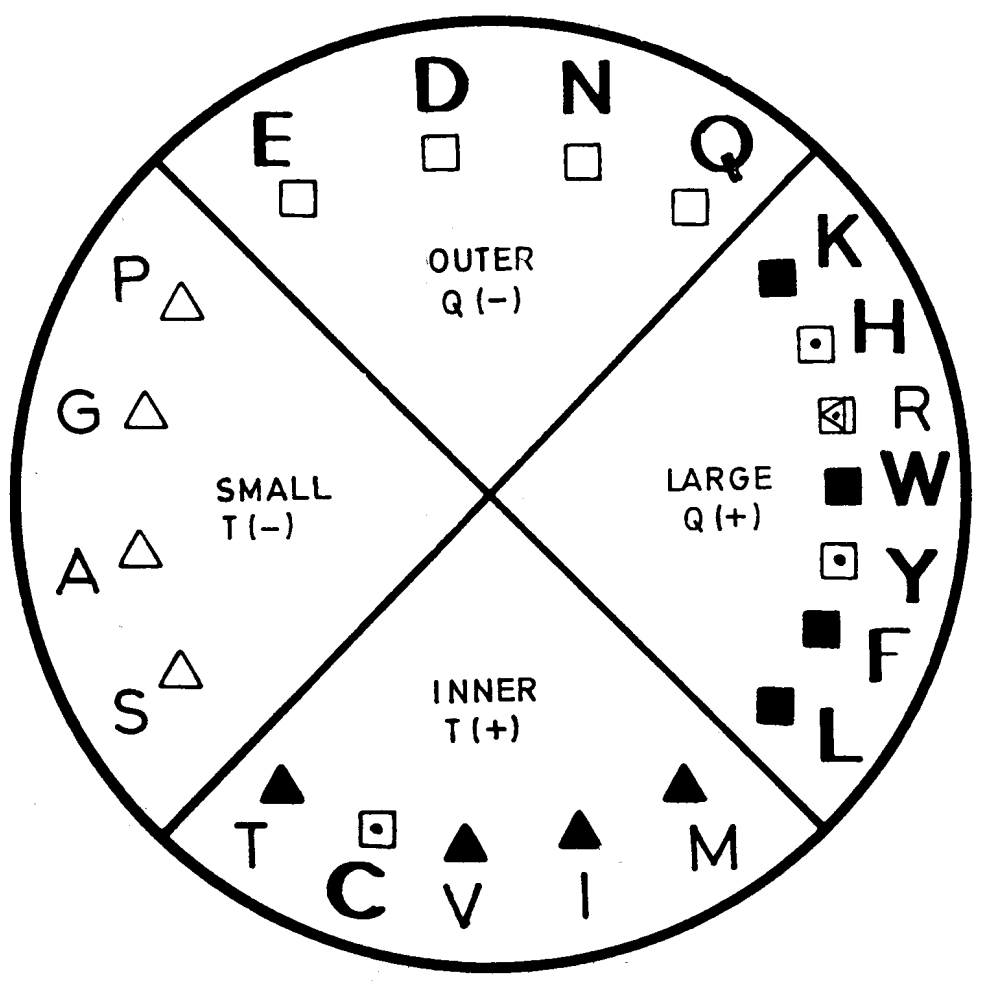

Figure D4. From (MMR, 1994, Fig. 6.7, p. 85; and MMR, 1997b, Fig. 6, p. 28): "Mutation ring II. This Ring could be regarded the Mutation ring II provided that R. Swanson's Mutation Ring (Swanson, 1984, Fig. 3) is regarded the Mutation Ring I; Everything is the same as on Mutation Ring I, only the ST-QK line is shifted by one step on both ends in relation to Mutation Ring I; and PE-ML line is shifted only on one (the other) end. The squares designate the amino acids from Space-4 and triangles designate the amino acids from Space-3 [Boolean space]. The empty squares and empty triangles designate the nonessential amino acids, otherwise they designate the essential amino acids; the dots designate the semi-essential amino acids. The lines strictly separate non-essential from yes-essential amino acids; then the lines strictly separate the Space-3 amino acids from Space-4 amino acids. There are the two exceptions: $\mathrm{C}$ is full-strayed; $\mathrm{R}$ is semistrayed. One should note that the complementarity principle is applied as follows: outer-inner: non-essential amino acids from Space-4 are complementary with the essential amino acids from Space-3, etc." 


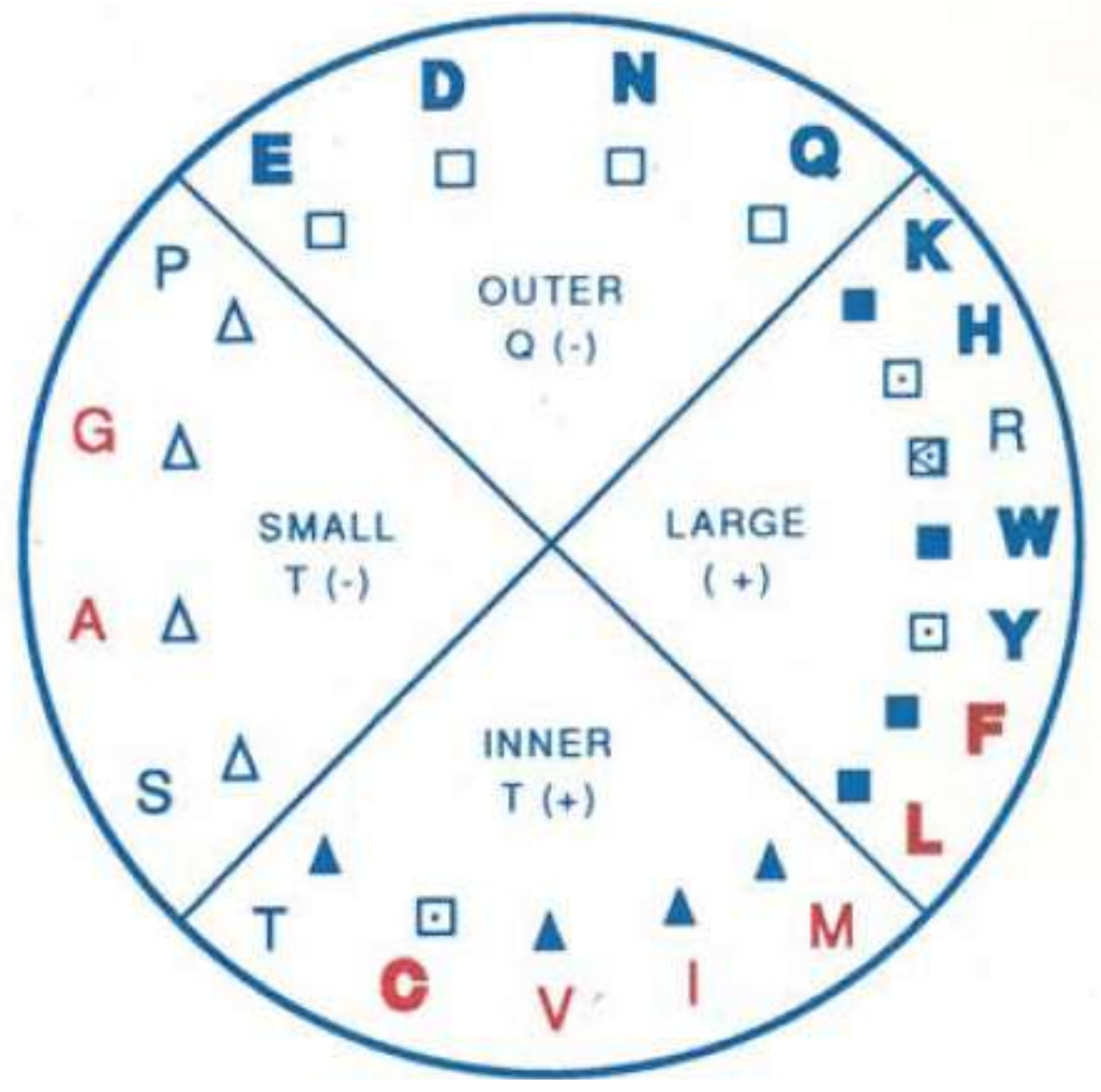

Figure D5. "Mutation ring II". All is the same as in Figure D4, except that here the polarity of the molecules is indicated (blue as polar and red as non-polar). Polarity according to the index of hydropathy (Kyte and Doolittle, 1982), except for glycine, whose polarity is determined according to the index of Cloister energy (Swanson, 1984). The data for polarity are given here in the legend to Table 3. 


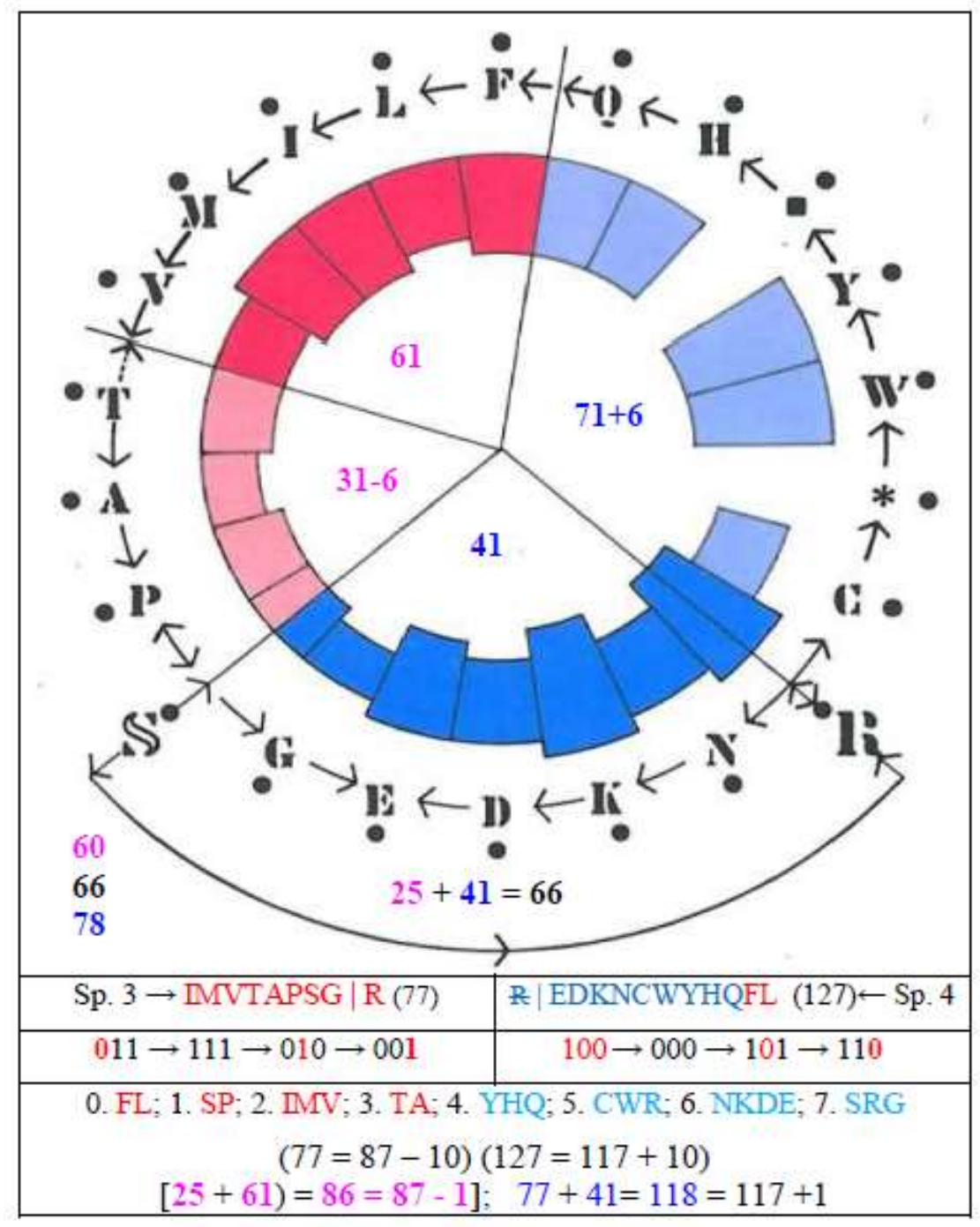

Figure D6. From (MMR, 1988b, Fig. 30, p. 117 (black), and Fig. 34, p. 129 (in color): "The starting position in the first group is occupied by phenylalanine (F), and in the second by threonine (T). Further path of changes is indicated by arrows. Amino acids... (S, R) in the ring occupy boundary positions. [The S-R bond should be imagined in the third dimension]. Otherwise, for the whole system, in addition to several smaller 'clasps' (the path of change in both directions), one main clasp is also characteristic..., SPONCE clasp, which comes from: S-P, Over Neighbors, C-E. The neighbors in this case are R and G.... Large clasp S-P / C-E designates the return of the flow of changes in the opposite direction. Here, too, it should be imagined that contact can be made in space, i.e. connection with the first group of amino acids $(\mathrm{F}-\mathrm{V})$..."

\{Additional Note 1 (30.03.2021): Sp.3 as "Space 3" and Sp. 4 as "Space 4", where the numbers 3 and 4 do not mean the dimensions but the vertices in the Boolean cube, $\mathrm{B}^{3}$.\}

\{Additional Note 2 (30.03.2021): By comparison with Fig. 3.1 we find the same quantities as here [61, 41 / (31-6), 71+6)] although these quantities do not make all the same AAs, some are different. It should also be noted that there are analogies through the influence of the principle of self-similarity: 117 as the number of hydrogen atoms within 20 amino acid side chains and 87 as the number of nonhydrogen atoms. We also find correspondence with the quantities $60,66,78$, which we also found in CIPS (Figs 3 and 4) [60 near 61; 78 near 77, and 66 as the sum of the quantities 25 and 41]; [CWR = 40 and $\mathrm{NKDE}=40$; both with $\mathrm{YHQ}=37$ give 70 , that is $71+6$ in relation to Gauss' algorithm]. $\}$ 
Table D1. Classification of amino acids into essential, semi-essential and non-essential

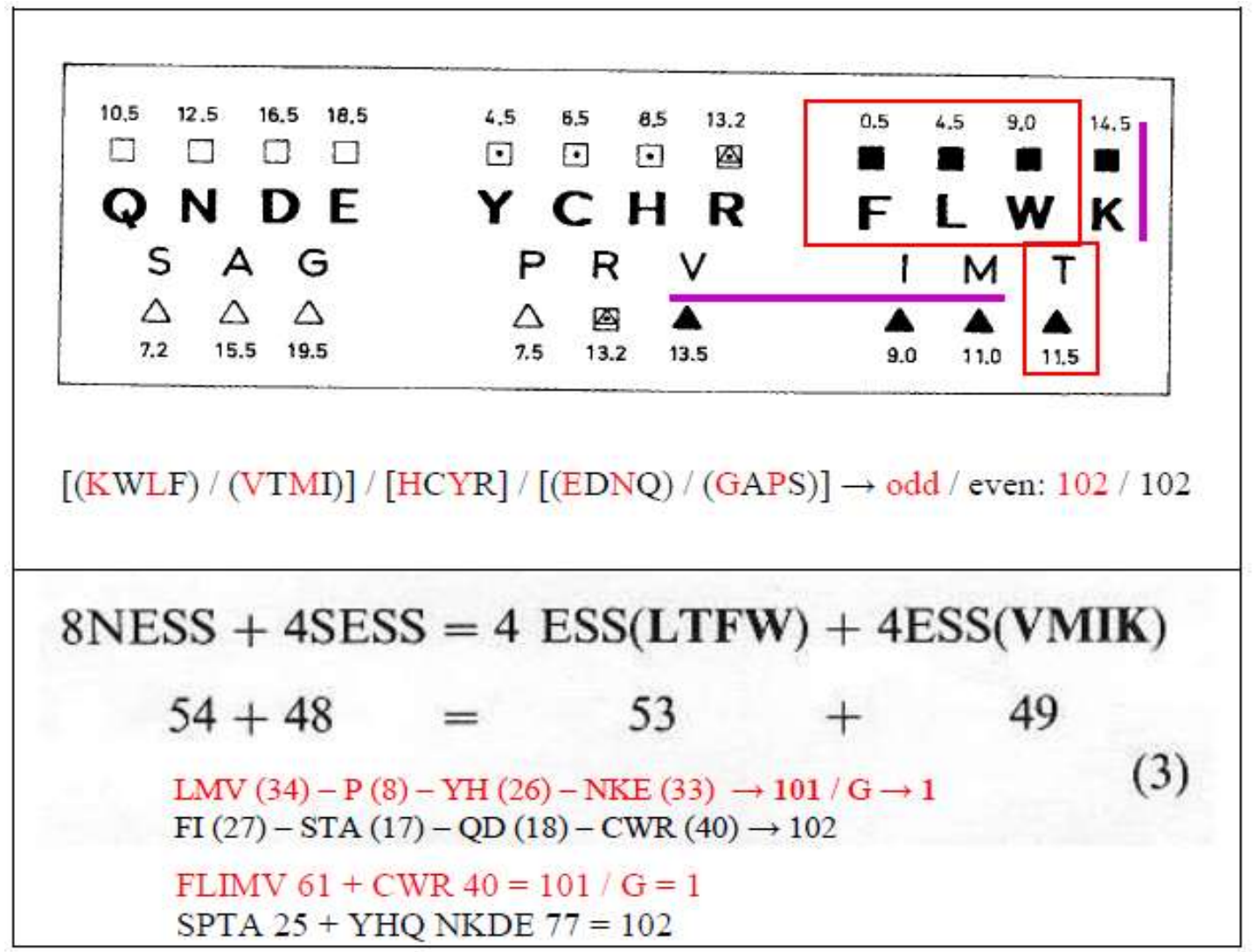

From (MMR, 1994a, Fig. 6.4, p. 81); or in (MMR, 1997b, Fig. 5, p. 27). In the upper part: Nonessential, semi-essential and essential protein amino acids, respectively. (Classification of AAs by Van Nostrand Scientific Encyclopedia, 1983, Tab. 2, p 119.) The order through the binary values calculated by models presented in Figures D2 and D3. In the lower part is the scanning of equation 3 from (Rakočević and Jokić, 1996), and everything else is now added. [From MMR, 1994a, Fig. 6.4, P. 81: "Here are given the amino acids from quaternity line (triangles) depending on the binary value (strict order per rising values in each group) and depending on the best possible harmony. It becomes evident that there exists the classification of the amino acids under request for the best possible harmony: $(3 \times 3)+(3 \times 4)$. The binary values are given in (Tables D2 and D3, here). Note that the sequences $(\mathrm{Q}, \mathrm{N}, \mathrm{D}, \mathrm{E})$ and $(\mathrm{S}, \mathrm{A}, \mathrm{G}, \mathrm{P})$ are the same as in Mutation ring. "] 
Table D2. Calculation of codon binary values (expressed in decimal system) (I)

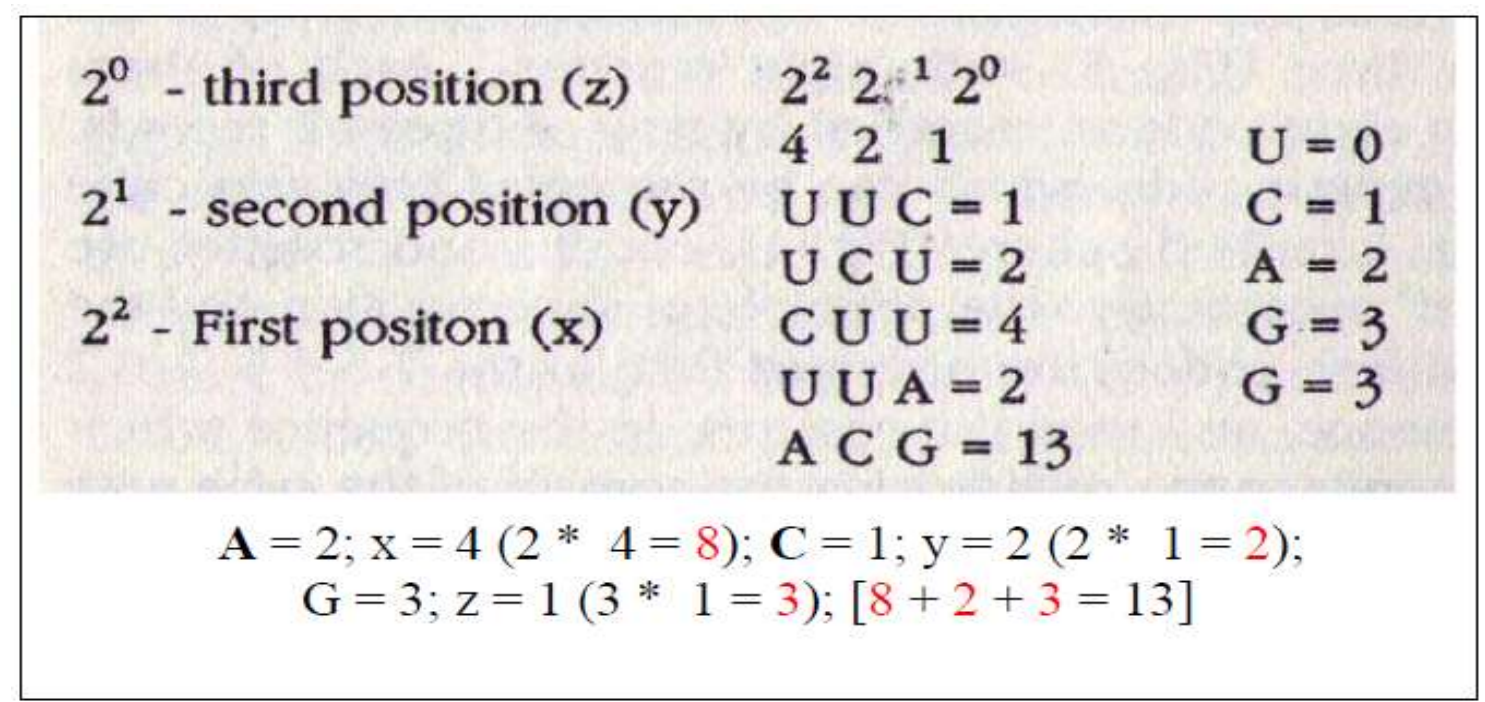

The method of calculating the binary values of the codons (Rakočević, 1994a, p. 72). For example: $(13)_{10}=(1101)_{2}$. 
Table D3. Calculation of codon binary values (expressed in decimal system) (II)

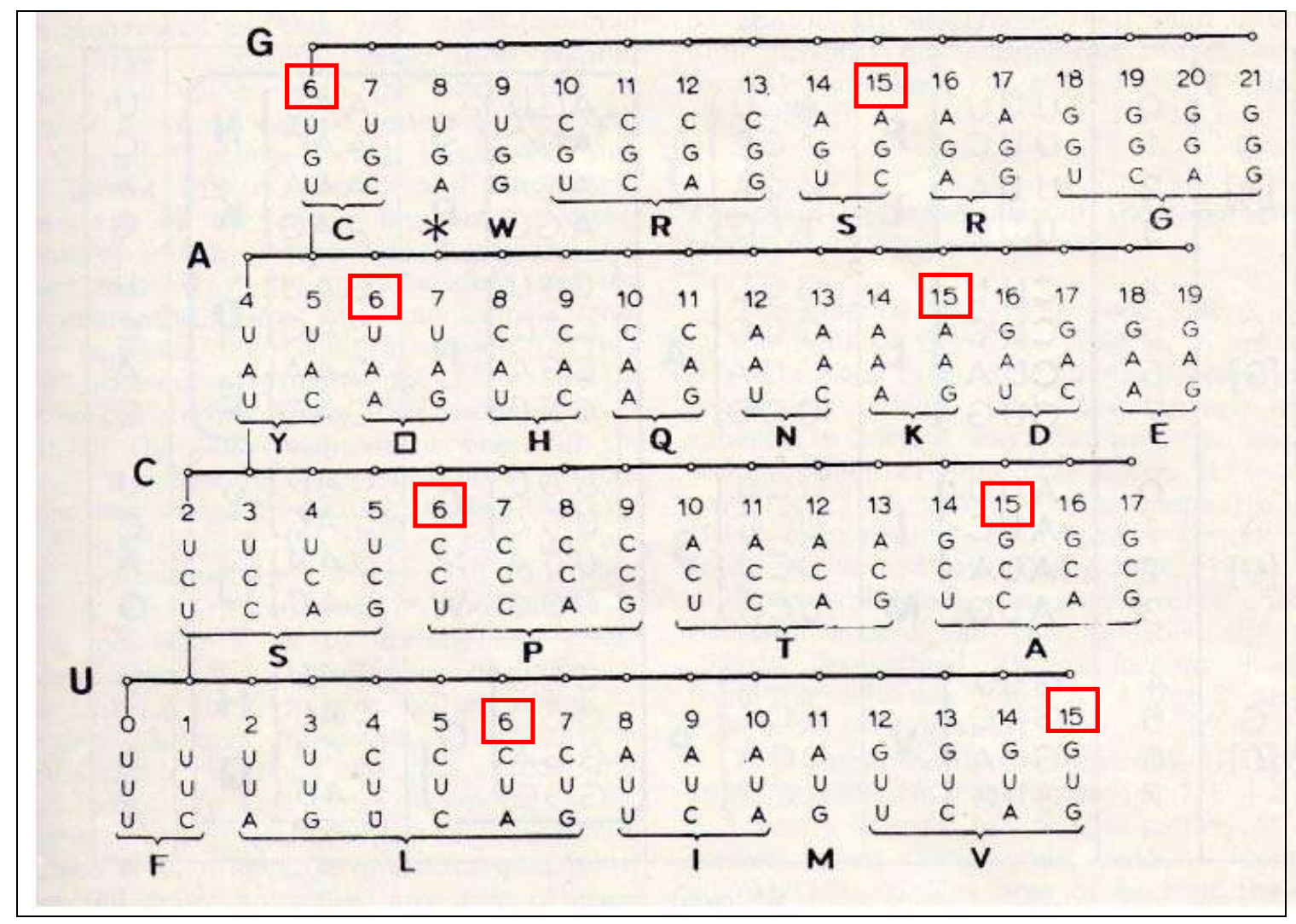

The calculated binary values of the codons (Rakočević, 1988a).

Calculation: For example, for Q: $10+11=21 ; 21: 2=10.5$. 
Table D4. Official mutation matrix in the PIR system (according to M. Dayhoff, 1972-1979) [MMR, 1988b, Tab. 52, p. 196] www.rakocevcode.rs http://slobodni-univerzitet-srbije.org/files/geni-molekuli-jezik-rakocevic.pdf

\begin{tabular}{|c|c|c|c|c|c|c|c|c|c|c|c|c|c|c|c|c|c|c|c|c|c|}
\hline Auta & ation & Dat & & Matr & ix & $(25)$ & O PAH & is) & & & & & & & & & & & & & \\
\hline & R & & D & C & Q & $\dot{E}$ & G H & I & $\mathrm{L}$ & $K$ & M & $\mathrm{F}$ & P & $\mathbf{S}$ & & W & $Y$ & V & B & & \\
\hline & -2 & & & -2 & 0 & 0 & $1-1$ & -1 & -2 & -1 & -1 & -4 & 1 & 1 & & -6 & -3 & 0 & 0 & 0 & \\
\hline & & & $-1-$ & -4 & $1-$ & $1-$ & -32 & -2 & -3 & 3 & 0 & -4 & 0 & 0. & -1 & 2. & -4 & $-2-$ & -1 & 0 & 0 \\
\hline & & & & -4 & 1 & 1 & 2 & -2 & -3 & & -2 & -4 & -1 & 1 & & -4 & -2 & -2 & 2 & & \\
\hline & -1 & & & -5 & 2 & 3 & 1 & -2 & -4 & & -3 & -6 & -1 & 0 & 0 & -7 & -4 & -2 & 3 & 3 & \\
\hline-2 & $2-4$ & $-4-$ & $\begin{array}{ll}-51 \\
\text {. }\end{array}$ & $12-$ & $-5-$ & $5-$ & $-3-3$ & -2 & -6 & & -5 & -4 & -3 & & -2 & -8 & 0. & -2 & -4 & -5 & \\
\hline & 1 & 1 & $2-$ & -5 & 4 & & 3 & -2 & -2 & & -1 & -5 & & -1 & -1 & -5 & & -2 & 1 & & \\
\hline & -1 & & & -5 & 2 & 4 & 1 & -2 & -3 & 0 & -2 & -5 & -1 & 0 & 0 & -7 & -4 & -2 & 2 & & \\
\hline & $1-3$ & 0 & & $-3-$ & -1 & 0 & $5-2$ & -3 & -4 & -2 & -3 & -5 & -1 & 1 & 0 & -7 & -5 & -1 & 0. & -1 & \\
\hline & & & & -3 & 3 & & -2 & -2 & -2 & 0 & -2 & -2 & 0 . & -1 & -1 & -3 & 0 & -2 & 1 & & \\
\hline & -2 & $-2-$ & $-2-$ & $-2-$ & $-2-$ & 2 & $-3-2$ & 5 & 2 & -2 & 2 & & -2 & -1 & 0 & -5 & -1 & 4 & -2 & -2 & \\
\hline & $2-3$ & $-3-$ & $-4-$ & $-6-2$ & -2 & 3 & $-4-2$ & 2 & 6 & -3 & 4 & 2. & -3 & -3 & -2 & -2 & -1 & 2 & -3 & -3 & \\
\hline & 3 & 1 & $0-$ & -53 & 1 & & & -2 & -3 & 5 & & -5 & & 0 & 0 & -3 & & -2 & 1 & & \\
\hline & & $-2-$ & $-3-$ & -5 & 1 & & $3-2$ & 2 & 4 & 0 & 6 & 0 & -2 & -2 & -1 & -4 & -2 & 2 & -2 & -2 & \\
\hline & -4 & $-4-$ & $-6-$ & -4 & -5 & -5 & -2 & 1 & 2 & -5 & 0 & 9 & -5 & -3 & -3 & 0 & & -1 & -5 & & \\
\hline & 0 & $-1-$ & $-1-$ & -3 & 0 - & -1 & -1 & -2 & -3 & -1 & -2 & -5 & 6 & 1 & 0 & -6 & -5 & -1 & -1 & 0 & \\
\hline 1 & 10 & 1 & 0 & $\begin{array}{lll}0 & -1\end{array}$ & -1 & 0 & $1-1$ & -1 & -3 & 0 & -2 & -3 & 1 & 2 & 1 & -2 & -3 & -1 & 0 & & \\
\hline & -1 & 0 & $0-$ & -2 & 1 & 0 & $0-1$ & 0 & -2 & 0 & -1 & -3 & 0 & 1 & & -5 & -3 & 0 & 0 & & \\
\hline & & $-4-$ & -7 & 8 & $-5-$ & -7 & 3 & -5 & -2 & -3 & -4 & 0 & -6 & -2 & -5 & 17 & 0 & -6. & -5 & -6 & \\
\hline-3 & $3-4$ & -2 & -4 & $0-2$ & -4 & -4 & 50 & -1 & -1 & -4 & -2 & 7 & -5 & -3 & -3 & & 10 & -2 & -3 & -4 & \\
\hline & -2 & -2 & $-2-$ & $-2-2$ & -2. & -2 & $-1-2$ & 4 & 2 & -2 & 2 & -1 & -1 & -1 & 0 & -6 & -2 & 4. & -2 & -2 & \\
\hline & -1 & 2 & $3-$ & -4 & & 2 & & -2 & -3 & 1 & -2 & -5 & -1 & 0 & & -5 & -3 & -2 & 2 & & \\
\hline 0 & 0 & 1 & $3-$ & -5 & 3 & & 2 & -2 & -3 & 0 & -2 & -5 & 0 & & -1 & -6 & -4 & -2 & 2 & 3 & \\
\hline 0 & 0 & & 0 & & & & & 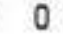 & 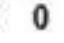 & 0 & 0 & 0 & 0 & & & 0 & 0 & 0 & 0 & 0 & \\
\hline
\end{tabular}

PIR - Protein Identification Resource National Biomedical Research Foundation Georgetown University Medical Center 3900 Reservoir Road, NW, Washington, D.C. 2007 USA. 
Table D5. Official mutation matrix in the PIR system (according to M. Dayhoff, 1972-1979), arranged according to the amino acid ring in Figure D6 [MMR, 1988b, Tab. 54, p. 198]

\begin{tabular}{|c|c|c|c|c|c|c|c|c|c|c|c|c|c|c|c|c|c|c|c|c|c|c|c|}
\hline & 0 & & 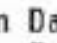 & & & 1 & & & & & & & & & & & & & & & & & \\
\hline & $F$ & L & $I$ & $M$ & V & $\mathrm{T}$ & A & P & $\$$ & G & $\mathrm{N}$ & K & D & E & $R$ & C & W & $\gamma$ & H & $Q$ & B & $z$ & \\
\hline $\mathrm{F}$ & 9 & 2 & 1 & 0 & -1 & -3 & -4 & -5 & -3 & -5 & -4 & -5 & -6 & -5 & -4 & -4 & 0 & 7 & -2 & -5 & -5 & -5 & \\
\hline L & 2 & 6 & 2 & 4 & 2 & -2 & -2 & -3 & -3 & -4 & -3 & -3 & -4 & -3 & -3 & -6 & -2 & -1 & -2 & -2 & -3 & -3 & \\
\hline I & 1 & 2 & 5 & 2 & 4 & 0 & -1 & -2 & -1 & -3 & -2 & -2 & -2 & -2 & -2 & -2 & -5 & -1 & -2 & -2 & -2 & -2 & \\
\hline 1 & 0 & 4 & 2 & 6 & 2 & -1 & -1 & -2 & -2 & -3 & -2 & 0 & -3 & -2 & 0 & -5 & -4 & -2 & -2 & -1 & -2 & -2 & \\
\hline & 1 & 2 & A & 2 & 4 & 0 & 0 & -1 & -1 & -1 & -2 & -2 & -2 & -2 & -2 & -2 & -6 & -2 & -2 & -2 & -2 & -2 & \\
\hline 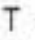 & -3 & -2 & 0 & -1 & 0 & 3 & 1 & 0 & 1 & 0 & 0 & 0 & 0 & 0 & -1 & -2 & -5 & -3 & -1 & -1 & 0 & -1 & \\
\hline A & -4 & -2 & -1 & -1 & 0 & 1 & 2 & 1 & 1 & 1 & 0 & -1 & 0 & 0 & -2 & -2 & -6 & -3 & -1 & 0 & 0 & 0 & \\
\hline & -5 & -3 & -2 & -2 & -1 & 0 & 1 & 6 & 1 & -1 & -1 & -1 & -1 & -1 & 0 & -3 & -6 & -5 & 0 & 0 & -1 & & \\
\hline 5 & -3 & -3 & -1 & -2 & -1 & 1 & 1 & 1 & 2 & 1 & 1 & 0 & 0 & 0 & 0 & 0 & -2 & -3 & -1 & -1 & 0 & 0 & \\
\hline 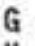 & -5 & -4 & -3 & -3 & -4 & 0 & 1 & -1 & 1 & 5 & 0 & -2 & 1 & 0 & -3 & -3 & $-\overline{7}$ & -5 & -2 & -1 & 0 & -1 & \\
\hline & -4 & -3 & -2 & -2 & -2 & 0 & 0 & -1 & 1 & 0 & 2 & 1 & 2 & 1 & 0 & -4 & -4 & -2 & 2 & 1 & 2 & 1 & \\
\hline & -5 & -3 & -2 & 0 & -2 & 0 & -1 & -1 & 0 & -2 & 1 & 5 & 0 & 0 & 3 & -5 & -3 & -4 & 0 & 1 & 1 & 0 & \\
\hline & -6 & -4 & -2 & -3 & -2 & 0 & 0 & -1 & 0 & 1 & 2 & 0 & 4 & 3 & -1 & -5 & -7 & -4 & 1 & 2 & 3 & 3 & \\
\hline E & -5 & -3 & -2 & -2 & -2 & 0 & 0 & -1 & 0 & 0 & 1 & 0 & 3 & 4 & J-1 & -5 & -7 & -4 & 1 & 2 & 2 & 3 & \\
\hline 2 & -4 & -3 & -2 & 0 & -2 & -1 & -2 & 0 & 0 & -3 & 0 & 3 & -1 & -1 & 6 & -4 & 2 & -4 & 2 & 1 & -1 & & \\
\hline 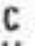 & -4 & -6 & -2 & -5 & -2 & -2 & -2 & -3 & 0 & -3 & -4 & -5 & -5 & -5 & -4 & 12 & -8 & 0 & -3 & -5 & -4 & -5 & \\
\hline & 0 & -2 & -5 & -4 & -6 & -5 & -6 & -6 & -2 & -7 & -4 & -3 & -7 & -7 & 2 & -8 & 17 & 0 & -3 & -5 & -5 & -6 & \\
\hline & 7 & -1 & -1 & -2 & -2 & -3 & -3 & -5 & -3 & -5 & -2 & -4 & -4 & -4 & -4 & 0 & 0 & 10 & & -4 & -3 & & \\
\hline 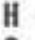 & -2 & -2 & -2 & -2 & -2 & -1 & -1 & 0 & -1 & -2 & 2 & 0 & 1 & 1 & 2 & -3 & -3 & 0 & 6 & 3 & 1 & & \\
\hline & -5 & -2 & -2 & -1 & -2 & -1 & 0 & 0 & -1 & -1 & 1 & 1 & 2 & 2 & 1 & -5 & -5 & -4 & 3 & 4 & 1 & & \\
\hline & -5 & -3 & -2 & -2 & -2 & 0 & 0 & -1 & 0 & 0 & 2 & 1 & 3 & 2 & -1 & -4 & -5 & -3 & 1 & 1 & 2 & & \\
\hline & -5 & -3 & -2 & -2 & -2 & -1 & 0 & 0 & 0 & -1 & 1 & 0 & 3 & 3 & 0 & -5 & -6 & -4 & 2 & 3 & 2 & & \\
\hline & 0 & 0 & 0 & 0 & 0 & 0 & 0 & 0 & 0 & 0 & 0 & 0 & 0 & 0 & 0 & 0 & 0 & & 0 & 0 & 0 & & \\
\hline
\end{tabular}




\section{E - Atlas}

Table E1. "A new Table of genetic Code"

\begin{tabular}{|c|c|c|c|c|}
\hline & $\mathrm{F}$ & $\mathrm{C}$ & & \\
\hline 气ิ & L & $40 \quad 40 \quad \mathrm{~W}$ & E & Isotope (nuclide) number: \\
\hline & I & $\mathrm{S}$ & & $\begin{array}{l}\mathrm{F}_{28}+\mathrm{L}_{26}+\mathrm{L}_{26}+\mathrm{I}_{26}+\mathrm{I}_{26}+\mathrm{M}_{24}+\mathrm{V}_{20}+ \\
\mathrm{A}_{08}+\mathrm{T}_{17}+\mathrm{P}_{16}+\mathrm{S}_{11}+\mathrm{Y}_{31}=259\end{array}$ \\
\hline$\stackrel{\circ}{\circ}$ & $\begin{array}{l}\mathrm{I} \\
\mathrm{M}\end{array}$ & $\begin{array}{l}R \\
G\end{array}$ & 2 & $\begin{array}{l}\mathrm{H}_{22}+\mathrm{Q}_{23}+\mathrm{N}_{17}+\mathrm{K}_{30}+\mathrm{D}_{16}+\mathrm{E}_{22}+\mathrm{G}_{02}+\mathrm{R}_{34} \\
+\mathrm{S}_{11}+\mathrm{R}_{34}+\mathrm{W}_{36}+\mathrm{C}_{12}=259\end{array}$ \\
\hline 8 & V & $\begin{array}{l}E \\
D\end{array}$ & $\overline{8}$ & Conformation number: \\
\hline & $\mathrm{T}$ & $\mathrm{K}$ & & $\begin{array}{l}\left(\mathrm{F}_{12} \mathrm{~L}_{22} \mathrm{~L}_{22}\right)_{56}+\left(\mathrm{S}_{09} \mathrm{R}_{66} \mathrm{G}_{04}\right)_{79}+\left(\mathrm{E}_{20}\right. \\
\left.\mathrm{D}_{10} \mathrm{~K}_{66}\right)_{96}+\left(\mathrm{P}_{02} \mathrm{~S}_{09} \mathrm{Y}_{12}\right)_{23}=261-7=254\end{array}$ \\
\hline 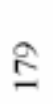 & $\mathrm{s}$ & 28 & $\overline{\text { ง }}$ & $\begin{array}{l}\left(\mathrm{C}_{21} \mathrm{~W}_{24} \mathrm{R}_{66}\right)+\left(\mathrm{I}_{20} \mathrm{I}_{20} \mathrm{M}_{20}\right)_{60}+\left(\mathrm{V}_{08} \mathrm{~A}_{03} \mathrm{~T}_{08}\right) \\
+\left(\mathrm{N}_{16} \mathrm{Q}_{38} \mathrm{H}_{24}\right)_{78}=261+7=268\end{array}$ \\
\hline & $\mathrm{Y}$ & $\mathrm{H}$ & & \\
\hline 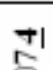 & & $\begin{array}{ll}126+1 & 126-1\end{array}$ & Fi & $268-254-14$ \\
\hline की & & $\begin{array}{l}-126-11(750-99=\underline{6 j} 1) \\
-126+11(750+99=849\end{array}$ & 点 & $259=260-1$ \\
\hline & & & & \\
\hline
\end{tabular}

From (MMR, 2007a, Tab 7): "A new Table of genetic Code". The distribution of the canonical AAs in standard Genetic Code Table, in correspondence with special case at Isoleucine: AUY for "I" and AUR for two different AAs: codon AUA for "I" ones more, and codon AUG for "M". [Y for pyrimidine; $\mathrm{R}$ for purine.] 
Table E2. The amino acid system- arrangement that follows from "Spiral model of genetic code" (Damjanović, 1998; MMR, 2004a) (I)

\begin{tabular}{|c|c|c|c|c|c|c|}
\hline$T$ & II & III & IV & V & & \\
\hline IV $03 \otimes$ & $04 \mathrm{~T}$ & 11 C,W $\otimes$ & $12 \mid, M, I$ & $19 Y$ & 83 518) & $126+10$ \\
\hline ||| $02 \mathrm{E}$ & $05 \mathrm{P}$ & $10 \mathrm{G}$ & $13 \mathrm{~L}$ & $18 \mathrm{D}$ & 39 (231) & $(750-1)$ \\
\hline$\| 01 Q$ & $06 \mathrm{~A}$ & $09 R$ & $14 \mathrm{~V}$ & $17 \mathrm{H}$ & \begin{tabular}{|l|l|}
53 & 3111 \\
\end{tabular} & $126-10$ \\
\hline I $00 \mathrm{~K}$ & $07 \mathrm{~S}$ & $08 \mathrm{~S}, \mathrm{R}$ & $15 \mathrm{~F}, \mathrm{~L}$ & $16 \mathrm{~N}$ & $77\lceil(440)$ & $(750+1)$ \\
\hline \multirow[t]{2}{*}{ (36) } & 25 & (63) & 87 & 41 & & \\
\hline & & (88) & (87) & & & \\
\hline
\end{tabular}

From (Damjanović and Rakočević, 2006, App. 1, Survey 1): "Amino acid order read from GCT (I). The splitting (classification and/or grouping) of canonical amino acids in accordance to their ordinal number, given by first variant of spiral model of genetic code ... The ordinal numbers are reading from codons and/or their digrams (doublets) in the quaternary numbering system. A strict balance in atom number and nucleon number is self-evident. The three AAs groups (77-78-88), read from columns, stay in correspondence with Golden mean balance (60-66-78) as it is shown in [CIPS, Figure 4]. The reading from the rows gives an atom number balance: $83+53=126+10$ and $39+77=126-10$; then, a nucleon number balance: $518+231=750-1$ and $311+440=750+1 \ldots$. [Correspondence: "Spiral model of genetic code" in (Damjanović and Rakočević, 2005, Fig. 1, p. 518).] 
Table E3. The amino acid system- arrangement that follows from "Spiral model of genetic code" (Damjanović, 1998; MMR, 2004a) (II)

\begin{tabular}{|c|c|c|c|c|c|c|c|}
\hline & I & II & III & IV & \multicolumn{3}{|l|}{ V } \\
\hline IV & $03 \otimes$ & $04 \mathrm{~T}, \underline{\mathbf{W}}$ & $11 \mathrm{C}$ & $12 I$ & $19 Y$ & 59 (386) & \multirow{2}{*}{$\frac{102-1}{(628+10)}$} \\
\hline III & $02 \mathrm{E}$ & $05 \mathrm{P}, \mathrm{M}$ & $10 \mathrm{G}$ & $13 \mathbf{L}$ & $18 \mathrm{D}$ & $50(306)$ & \\
\hline II & $01 Q$ & $06 \mathrm{~A}$ & $09 \mathbf{R}$ & $14 \mathrm{~V}$ & $17 \mathrm{H}$ & 53 (311) & \multirow{2}{*}{$\begin{array}{c}102+1 \\
(627-10)\end{array}$} \\
\hline I & $00 \mathbf{K}$ & $07 \mathrm{~S}$ & $08 \varnothing$ & $15 \mathrm{~F}$ & $16 \mathbf{N}$ & 42 (252) & \\
\hline \multirow{2}{*}{\multicolumn{2}{|c|}{36}} & 54 & 23 & 50 & \multirow[t]{2}{*}{41} & & \\
\hline & & & & (50) & & & \\
\hline
\end{tabular}

From (Damjanović and Rakočević, 2006, App. 1, Survey 2): "Amino acid order read from GCT (II). All as in previous Survey except the amino acids are given as onemeaning. A strict balance in atom number and nucleon number is also self-evident. The three AAs groups (77-77-50), read from columns, stay in correspondence with Golden mean balance (60-66-78) as it is shown in [Figure 4]. The reading from the rows gives an atom number balance: $59+42=102-1$ and $50+53=102+1$; then, a nucleon number balance: $386+252=628+10$ and $306+311=627-10$. "

Table E4. Relation of the number of atoms in Surv. 2 and Surv. 3

\begin{tabular}{|c|c|c|c|c|}
\hline 60 & 66 & 78 & 87 & 87 \\
- & + & - & - & - \\
10 & 11 & 01 & 10 & 01 \\
50 & 77 & 77 & 77 & 88 \\
\hline
\end{tabular}

From (Damjanović and Rakočević, 2006, App. 1, Survey 3): "Arithmetical regularities as determinants of Genetic code ... The connection of arithmetical regularities presented in two previous Surveys." 
Table E5. Relations with "Spiral model of genetic code" (I)

\begin{tabular}{|c|c|}
\hline $\mathrm{R}-\mathrm{K}$ & $(8.5-0.0=8.5)$ \\
\hline $\mathrm{L}-\mathrm{A}$ & $(14.0-6.0=8.0)$ \\
\hline $\mathrm{M}-\mathrm{T}$ & $(12.0-4.0=8.0)$ \\
\hline I - P & $(12.0-5.0=7.0)$ \\
\hline $\mathrm{H}-\mathrm{W}$ & $(17.0-11.0=6.0)$ \\
\hline$Y-F$ & $(19.0-15.0=4.0)$ \\
\hline V-G & $(14.0-10.0=4.0)$ \\
\hline $\mathrm{C}-\mathrm{S}$ & $(11.0-7.5=3.5)$ \\
\hline $\mathrm{D}-\mathrm{N}$ & $(18.0-16.0=2.0)$ \\
\hline$E-Q$ & $(2.0-1.0=1.0)$ \\
\hline
\end{tabular}

From (MMR, 2000a, Table 5, p. 288; in arXiv: Table 5, p. 11): "Five amino acid quadruplets. In the middle are four aromatic amino acids. Above: four aliphatic, A-L as source aliphatic amino acids and K-R as amine derivatives. Below: carboxylic amino acids with their amide derivatives (altogether: four). Within the first concentric cycle (G, V, I, P): four AAs of non-alanine stereochemical types. Within second concentric cycle (S, C, M, T): four chalcogen amino acids. The order as well as the numbers (within Order, on the right) follow from the First Damjanović's system (Damjanović, 1998; Damjanović and Rakočević, 206). [Table E2 in this paper.] Notice that in relation to aromatic amino acids, four pairs are above and four below ( $4 \pm 0$ in relation to the arithmetic mean)." [Cf. with CIPS, in Fig. 4 in this paper.] 
Table E6. Relations with "Spiral model of genetic code" (II)

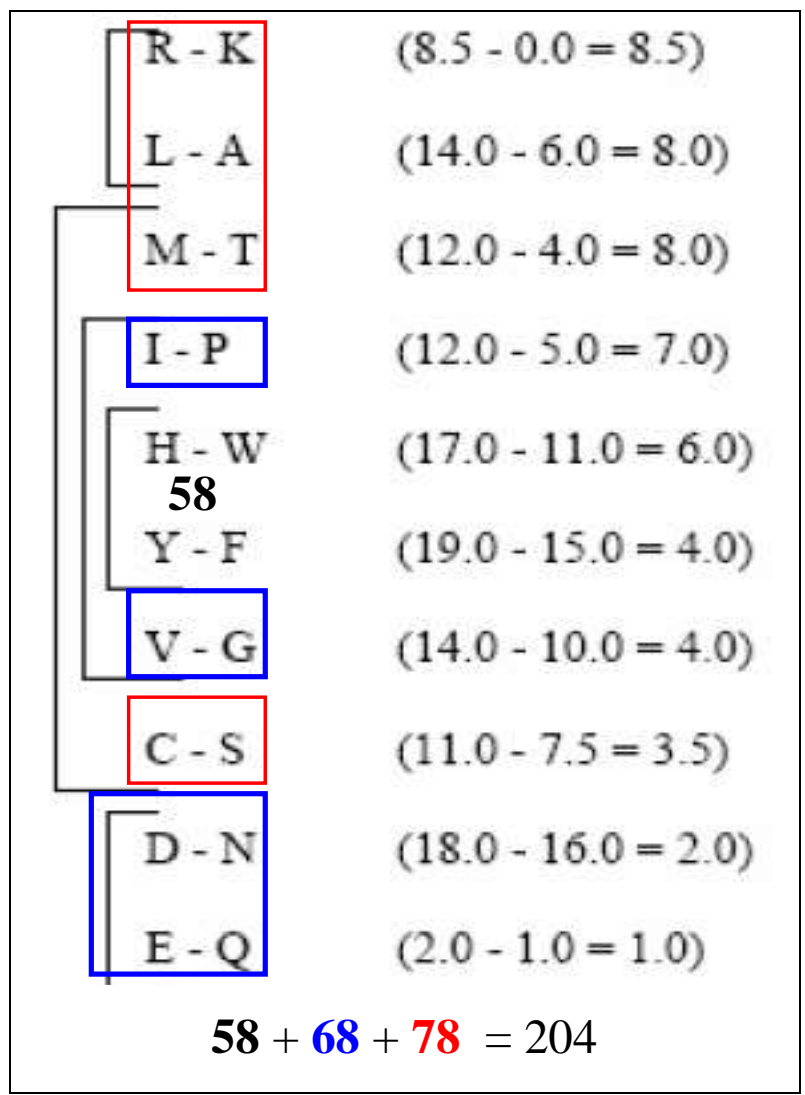

Everything is the same as in the previous Figure, except for the addition of frames showing the classes of AAs in CIPS, as given in Figure 4. At the bottom is the number of atoms (within the side chains of AAs) in the indicated classes. 


\section{F - Atlas}

Table F1. The distribution of amino acids within the Codon path cube

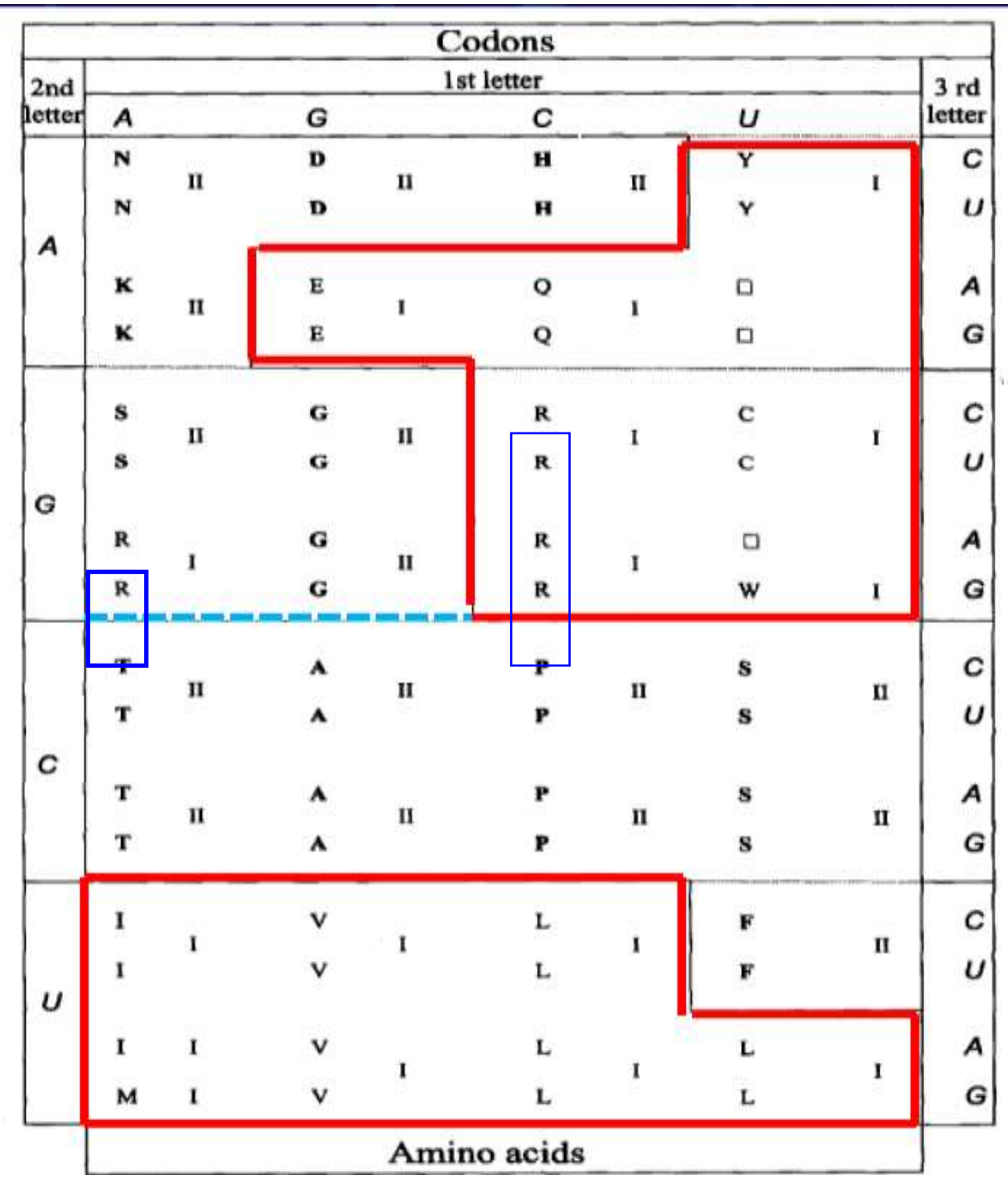

From (MMR, 1997a, Fig. 1, p. 646): "The distribution of amino acids within the 'Codon path cube' (Swanson, 1984) is followed with a strict distinction into the two and two spaces for two classes (I and II) of the enzymes amino-acyl-tRNA synthetases; a strict distinction, with only one exception, valid for arginine $(\mathrm{R})$ in positions: A-G-A and A-G-G. Bearing this in mind, by the calculation of atom number, the ammo acid R must be included: four times in space I ( 4 X $17=68$; row 1' in Table 1$)$ and two times $(2 \times$ $17=34$; row 2 ' in Table 1) in space II."

\{Additional Note (30.03.2021): Analogous to the cyclic system in Table 1.1, this system is also cyclic, in the sense that the upper and lower red blocks touch. A connection is established between tyrosine and leucine as it is between phenylalanine and glycine (MMR, 2018a). The sub-blocks in the class II have the connection through glycine and alanine. 
Table F2. Official

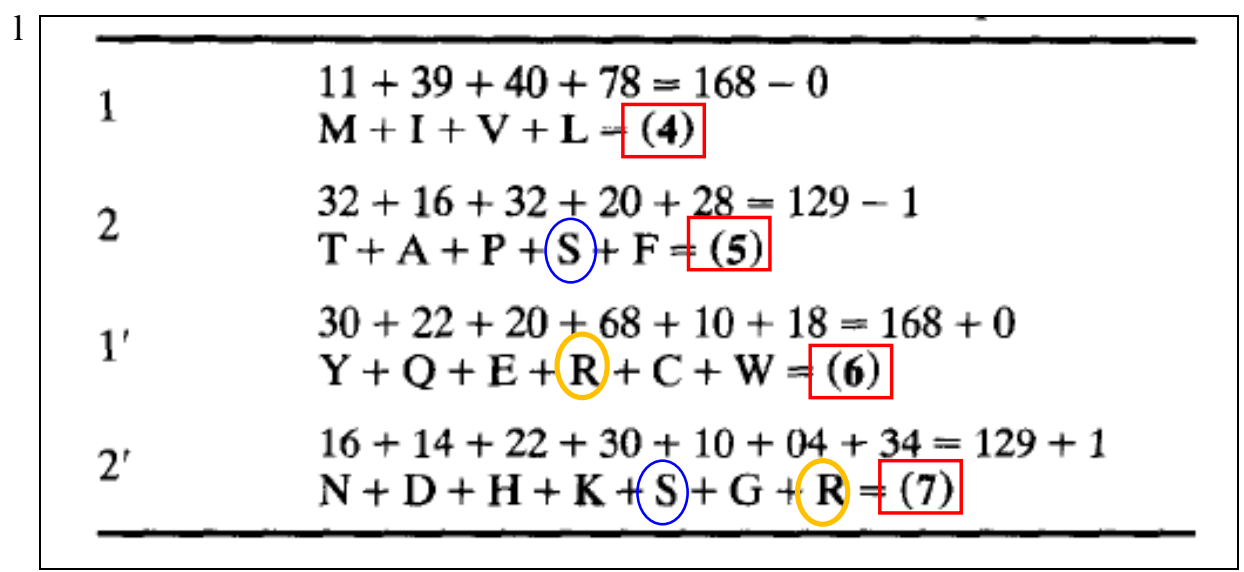

From (MMR, 1997a, Tab. 1, p. 647): “The two (1 and 1') and two (2 and 2') rows correspond to two and two sub-blocks within [Table F1]. By calculation of total atom number within side chains of amino acid molecules, each molecule must be included so much times how much codons code it." 
Table F3. "A new Table of genetic Code"

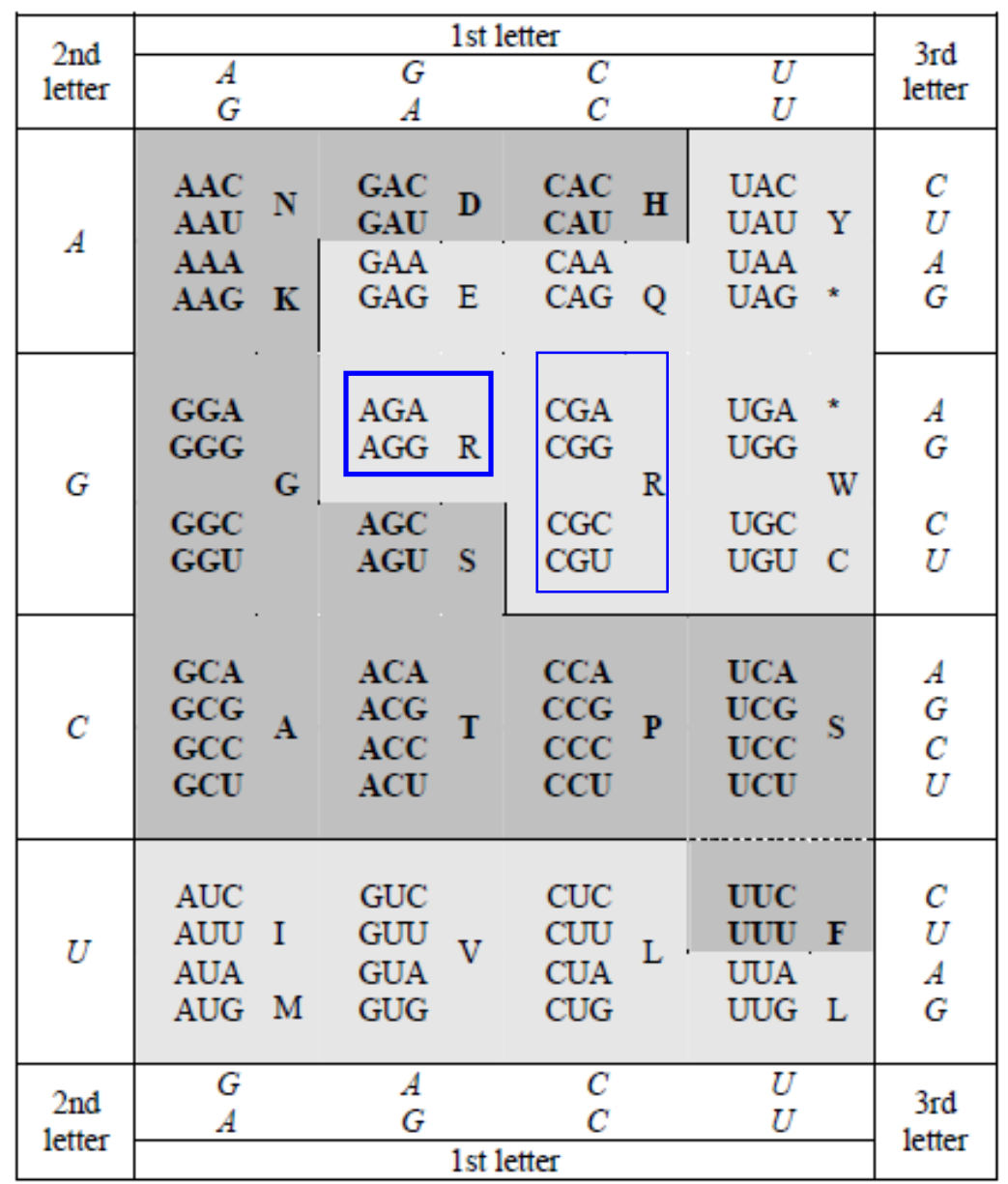

From (MMR, 2007a, Tab 2). "A new Table of genetic Code as a Combined Table, realized in a specific combination of Watson-Crick Table and Codon Path Cube (Swanson, 1984), through the first three permutations from the first octet in Table 1. Bold positions (dark tones): the codons coding for AAs handled by class II of aaRS; non-bold positions: the codons coding for AAs handled by class I aaRS plus three 'stop' codons, denoted with *." 
Table F4. The system of 24 permutations of GC alphabet

\begin{tabular}{|c|c|c|c|}
\hline 01. UCAG & 07. CUAG & 13. AUCG & 19. GUCA \\
\hline 02. UCGA & 08. CUGA & 14. AUGC & 20. GUAC \\
\hline 03. UACG & 09. CAUG & 15. ACUG & 21. GCUA \\
\hline 04. UAGC & 10. CAGU & 16. ACGU & 22. GCAU \\
\hline 05. UGCA & 11. CGUA & 17. AGUC & 23. GAUC \\
\hline 66. UGAC & 12. CGAU & 18. AGCU & 24. GACU \\
\hline 01. UCAG & 07. CUAG & 13. AUCG & 19. GUCA \\
\hline 02. UCGA & 08. CUGA & 14. AUGC & 20. GUAC \\
\hline 03. UACG & 09. CAUG & 15. ACUG & 21. GCUA \\
\hline 04. UAGC & 10. CAGU & 16. ACGU & 22. GCAU \\
\hline 05. UGCA & 11. CGUA & 17. AGUC & 23. GAUC \\
\hline 06. UGAC & 12. CGAU & 18. $A G C U$ & 24. $G A C U$ \\
\hline \multicolumn{2}{|c|}{ 01. $\underline{\mathrm{UCAG}}$ / 24. GACU (I) } & \multicolumn{2}{|c|}{ 07. $\underline{\mathrm{CU} A G}$ / 23. GAUC (VII) } \\
\hline \multicolumn{2}{|c|}{ 02. UCGA / 18. AGCU (II) } & \multicolumn{2}{|c|}{ 08. CUGA / 17. AGUC (VIII) } \\
\hline \multicolumn{2}{|c|}{ 03. UACG / 22. GCAU (III) } & \multicolumn{2}{|c|}{ 09. $\underline{\mathrm{CAUG}}$ / 20. GUAC (IX) } \\
\hline \multicolumn{2}{|c|}{ 04. UAGC / 12. CGAU (IV) } & \multicolumn{2}{|c|}{ 11. CGUA / 14. AUGC (X) } \\
\hline \multicolumn{2}{|c|}{ 05. UGCA / 16. $\underline{\mathrm{ACGU}}(\mathrm{V})$} & \multicolumn{2}{|c|}{ 13. AUCG / 21. GCUA (XI) } \\
\hline \multicolumn{2}{|c|}{ 06. $\underline{U G} A C /$ 10. $C A G U(\mathrm{VI})$} & \multicolumn{2}{|c|}{ 15. ACUG / 19. GUCA (XII) } \\
\hline
\end{tabular}


Table F5. "The new Table of genetic Code"

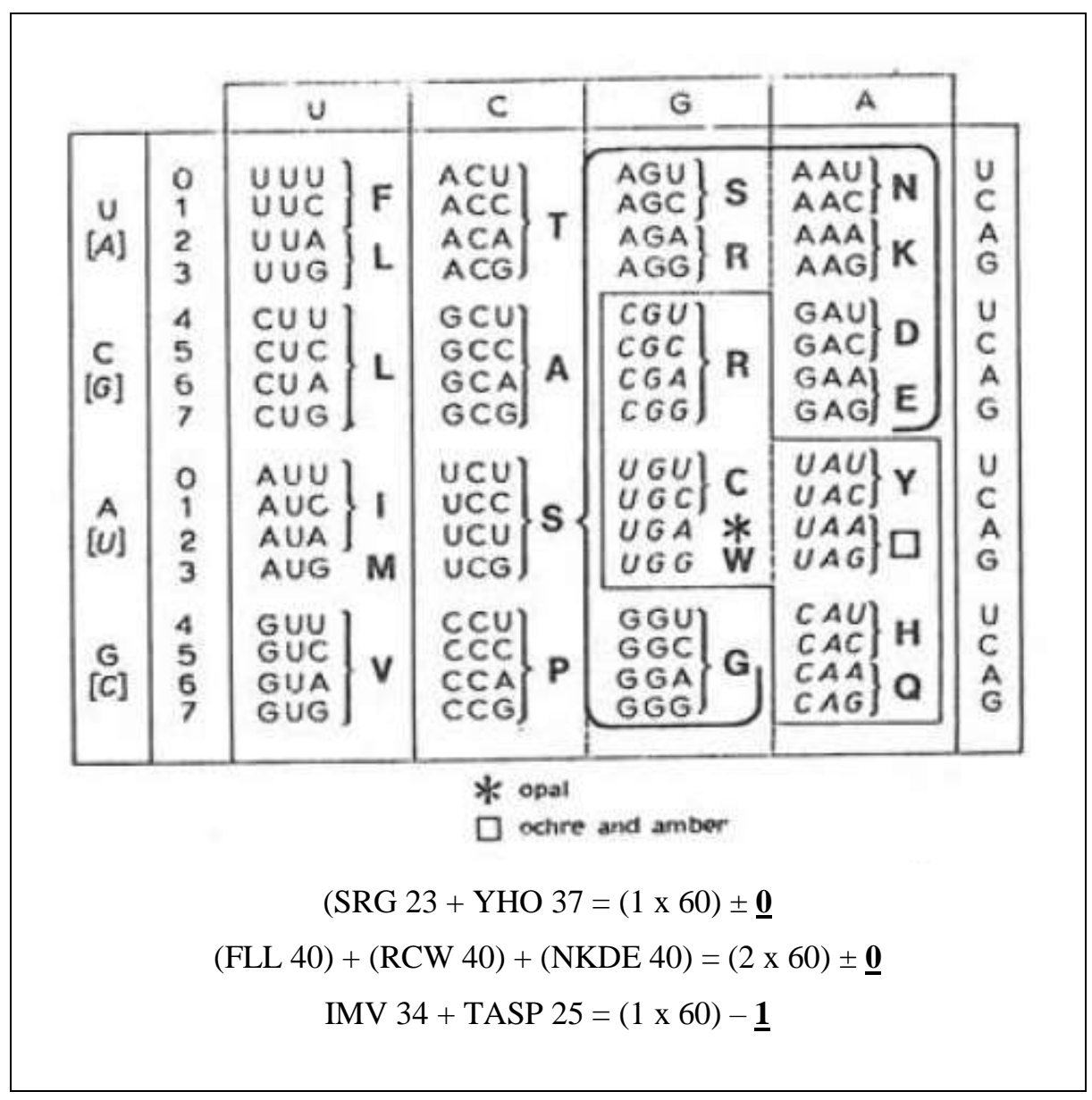

From (MMR, 1988b, Tab. 30, p. 124); and from (MMR, 1994a, Tab. 2.4, p. 45): "The New Table of Genetic Code: the neighborhood of codons in 3-dimensional space. Note the next situation: when neighborhood ordering is more ... determinated from the aspect of two dimensions (Table 2.3), then it is more indefinite from the aspect three dimensions (Table 2.4) and vice versa". \{Additional Note (30.03.2021): From this Table follows amino acid ring in Fig. D6. Otherwise, this rearranged Table of GC solves the neighborhood issue, as well as having 20 AAs. The quantities as follows: $\mathrm{NKFE}=40 ; \mathrm{RCW}=40 ; \mathrm{G}=1$; YHQ $=37$; FLIMV $=61$; TASP $=25 ; 61+25=62$. (Cf. Fig. 3.1 and Fig. D6.) www.rakocevcode.rs 
Table F6. Decimal and quaternary number systems in correspondence with the logical square and the logical segment, respectively

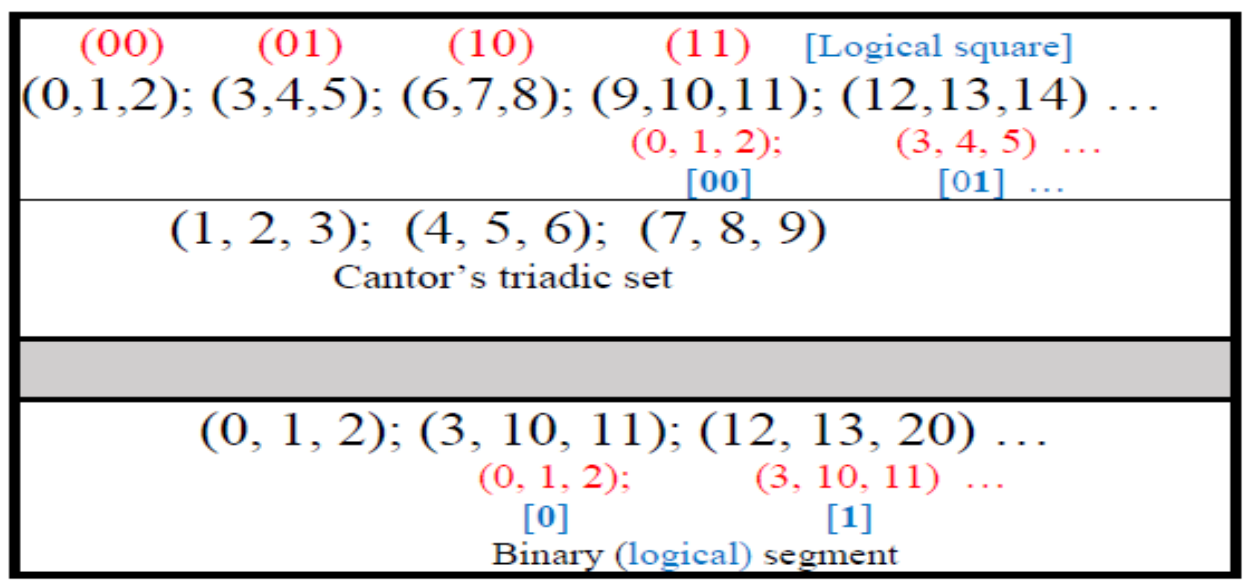

